\title{
Chapitre VI - Une économie générale du décor ecclésial
}

Jérôme Baschet, Jean-Claude Bonne et Pierre-Olivier Dittmar

\section{(2) OpenEdition}

\section{Journals}

Édition électronique

URL : http://journals.openedition.org/imagesrevues/1789

DOI : 10.4000/imagesrevues. 1789

ISSN : 1778-3801

Éditeur :

Centre d'Histoire et Théorie des Arts, Groupe d'Anthropologie Historique de l'Occident Médiéval, Laboratoire d'Anthropologie Sociale, UMR 8210 Anthropologie et Histoire des Mondes Antiques

\section{Référence électronique}

Jérôme Baschet, Jean-Claude Bonne et Pierre-Olivier Dittmar, « Chapitre VI - Une économie générale du décor ecclésial », Images Re-vues [En ligne], Hors-série 3 | 2012, mis en ligne le 21 novembre 2012, consulté le 30 janvier 2021. URL : http://journals.openedition.org/imagesrevues/1789 ; DOI : https:// doi.org/10.4000/imagesrevues.1789

Ce document a été généré automatiquement le 30 janvier 2021.

\section{(c) (i) \&}

Images Re-vues est mise à disposition selon les termes de la Licence Creative Commons Attribution -

Pas d'Utilisation Commerciale 4.0 International. 


\title{
Chapitre VI - Une économie générale du décor ecclésial
}

\author{
Jérôme Baschet, Jean-Claude Bonne et Pierre-Olivier Dittmar
}

Après avoir analysé en détail le décor sculpté de plusieurs édifices, nous souhaitons maintenant adopter une perspective à la fois transversale et comparative. Approfondir la réflexion sur le décor sculpté du lieu rituel impose d'en prendre en compte toutes les dimensions avec un égal degré de sérieux et d'attention. Si une telle démarche est nécessaire, c'est d'abord parce que les

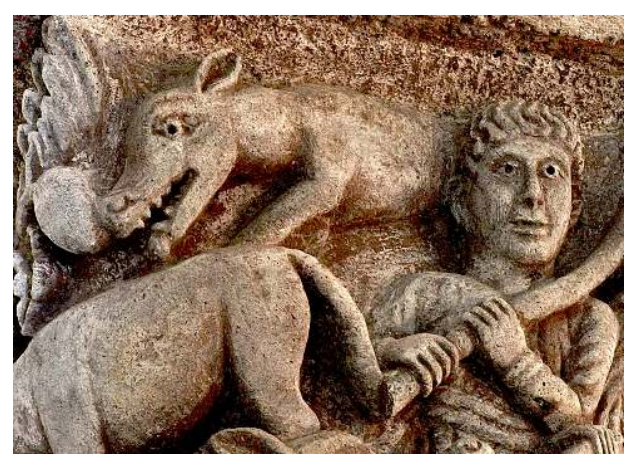
approches longtemps dominantes ont usé de catégories empêchant de considérer le décor sculpté de l'église comme un ensemble, appelant comme tel l'analyse. Ainsi, la disjonction (entièrement à récuser de notre point de vue) entre ce qui relèverait d'un côté de l'iconographique et de l'autre du décoratif a conduit à focaliser l'attention sur les chapiteaux historiés et à négliger les motifs animaliers, rebelles aux lectures iconographiques classiques, et plus encore les chapiteaux végétaux, purement et simplement écartés ou du moins enfermés dans le domaine spécifique d'une approche dite stylistique. Il est donc indispensable de réunifier le seul corpus sur lequel il soit pertinent de faire porter l'analyse, à savoir la totalité des chapiteaux d'un édifice donné (sans oublier leur articulation avec l'architecture elle-même, certainement trop peu prise en compte dans nos études, ou encore les interactions avec d'autres composantes de décor, comme les peintures murales, malheureusement presque entièrement perdues, dans le cas des édifices retenus ici). C'est sous le nom d'économie générale du décor ecclésial que l'on engage cette démarche, en usant d'une expression qui entend souligner le caractère de saisie aussi exhaustive que possible du corpus des chapiteaux (l'adjectif « général » indiquant ce souci de considérer tous les éléments d'un ensemble donné). En même temps, il ne saurait s'agir d'une exhaustivité purement accumulative, ce pourquoi le terme 
d'économie entend suggérer les rapports internes constitutifs et, plus largement, la distribution des éléments au sein de chaque ensemble, ce qui renvoie à la notion d'agencement, telle que nous l'avons proposée.

Il s'agira, en tout premier lieu, de faire honneur aux déploiements de la végétalité et à la diversité des figures de l'animalité, trop rarement réfléchies. Que viennent faire en effet dans le lieu rituel, au côté de l'humain, des créatures spirituelles et du divin, une si abondante efflorescence végétale et de si diverses figures de l'animalité ? Aborder cette question suppose en outre de les associer, dans leurs différences constitutives comme dans leurs croisements, afin de tenter de comprendre ce qu'ils font ensemble et comment ils contribuent, à la fois conjointement et spécifiquement, à la constitution du décor sculpté. Il faudra aussi en passer par une recherche des catégories qui confèrent leur sens médiéval aux domaines du végétal et de l'animal, ainsi qu'à celles qui nous permettent d'analyser leur présence comme ornatus du bâtiment ecclésial. Il n'est pas indifférent d'observer qu'il n'existe pas au Moyen Age de notion de « l'animal » au sens où nous l'entendons aujourd'hui (ni non plus de catégorie unifiée du "végétal »). Ce n'est donc exactement ni du végétal, ni de l'animal, au sens qu'un lecteur du XXI ${ }^{\mathrm{e}}$ siècle donne spontanément à ces termes, qu'il sera question ici, ce qui impose un travail de décentrement des catégories.

3 Traiter de la végétalité et de l'animalité, autant que de l'humain, renvoie à la question très générale du statut qui est alors conféré au monde créé. On ne saurait trop insister sur le caractère fondamental de l'opposition Créateur/création, qui structure les conceptions médiévales du monde. C'est la raison pour laquelle, malgré la position dominante que la Genèse attribue à l'homme vis-à-vis des animaux et, dans une moindre mesure, des végétaux (et malgré le fait que ce texte fondateur a pu jouer un rôle décisif pour préparer l'émergence de la conception prométhéenne de l'homme occidental), cette supériorité de l'homme sur les autres créatures demeure subordonnée à la dualité Créateur/création. Et c'est aussi la raison pour laquelle la notion de Nature, telle qu'elle émerge au Moyen Age, ne saurait avoir le sens qui lui est donné de nos jours (de ce fait, nous éviterons de recourir au terme " nature ", qu'il est fort difficile de ne pas associer aux présupposés modernes qui fondent cette notion) ${ }^{1}$. Par ailleurs, on insistera sur l'ambivalence constitutive du monde créé dans le mythe chrétien, et tout particulièrement dans les conceptions des siècles centraux du Moyen Age, qui s'éloignent d'un dualisme vouant au mépris un univers matériel entièrement livré au mal : si la Chute a de lourdes conséquences pour l'ensemble de la création, celle-ci n'en continue pas moins de porter la marque de la perfection que le Créateur a voulu imprimer à son œuvre. Enfin, il faudra faire place à une tension, dont nos images semblent tout particulièrement imprégnées, entre, d'une part, des conceptions qui séparent et hiérarchisent l'humain, l'animal et le végétal et, d'autre part, les marques innombrables de leur association, au sein d'une continuitas qui les traverse. C'est notamment pourquoi nous prêterons une attention particulière aux différentes formes $\mathrm{d}$ 'hybridations que nos chapiteaux permettent d'observer, notamment entre l'animal et le végétal (mais aussi entre ceux-ci et le minéral architecturé), ainsi qu'aux figures qui donnent forme aux forces vitales qui animent la création dans son entier.

4 Approfondir l'analyse des registres du monde créé devrait permettre d'enrichir la compréhension du fonctionnement du décor sculpté et notamment de son agencement au sein du lieu rituel. Il sera alors possible de revenir à l'analyse de la distribution des chapiteaux, ce que nous ferons en comparant les diverses options mises en œuvre dans 
les édifices traités ici, notamment en ce qui concerne les manières d'activer l'iter qui traverse l'église. Mais il nous faut tout d'abord - c'est ce à quoi on consacrera le premier moment de notre périple -, revenir à la constitution même de l'église comme lieu rituel. Dans la mesure où nous traitons des conceptions médiévales qui tendent à faire de la sacralisation de l'église, opérée par le rituel de dédicace, une sorte de spiritualisation, entendue comme articulation du matériel et du spirituel, nous accorderons, dans les pages qui suivent, une place importante au couple notionnel matériel/spirituel. Il n'y a là nul effet d'une quelconque inclination de notre part, mais simplement l'expression du fait que ces catégories jouent un rôle majeur dans les représentations propres au système ecclésial médiéval.

Il s'agit en somme d'articuler les conceptions du monde créé et les conceptions du lieu rituel, afin de mieux saisir pour quelles raisons (et comment) on s'est efforcé de convoquer l'ensemble des registres de la création pour constituer le décor efficace de l'église, capable tout à la fois de rendre sensible la constitution d'un locus sacré/ spiritualisé et d'activer l'iter qui s'efforce de faire accéder, depuis le monde créé, au Créateur.

\section{Le lieu rituel, à l'articulation du matériel et du spirituel}

6 Il est courant de faire des siècles qui encadrent l'an mil l'époque d'un dualisme exacerbé qui ne verrait de salut que dans la fuite du monde et l'absolu mépris de la chair. Certes, la distinction de l'âme et du corps et la ferme hiérarchisation établie entre eux sont plus qu'insistantes. Pourtant, les conceptions chrétiennes de la personne, quoique clairement duelles, ne sont pas pour autant dualistes ${ }^{2}$. Le dualisme suppose en effet une incompatibilité totale entre le charnel et le spirituel, ainsi qu'une dévalorisation complète du matériel ; il n'accorde de valeur qu'à un spirituel entièrement pur et séparé du matériel. Or, le christianisme s'est toujours démarqué du véritable dualisme, tel qu'il s'est manifesté par exemple dans le manichéisme, puis dans diverses dissidences médiévales. Déjà, Augustin, tout en affirmant avec force la dualité du charnel et du spirituel, avait engagé ce dépassement du dualisme, notamment en récusant la définition du corps comme prison de l'âme, en accordant une valeur positive au mariage ou encore en assumant, à la différence des Pères grecs, une interprétation résolument matérielle du «corps spirituel » des élus ressuscités. Même si une pesanteur dualiste, qui accable le corps, se fait bien souvent sentir, il convient d'accorder une attention non moins soutenue à une puissante dynamique anti-dualiste, qui ne cesse de s'amplifier.

7 Dans L'image à l'époque romane, Jean Wirth interprète la réforme grégorienne, qu'il place au centre de ses analyses, comme l'expression d'un dualisme radical ${ }^{3}$. Ce mouvement, qui acquiert toute sa vigueur dans la seconde moitié $\mathrm{du} \mathrm{XI}^{\mathrm{e}}$ siècle, serait animé par l'idéologie monastique du mépris du monde et de la haine du corps : la chair et le monde ayant été entièrement corrompus par les effets de la Chute, il ne saurait y avoir place pour une image apaisée ou un tant soit peu positive de la création. Au cœur des conceptions des cercles réformateurs, on trouverait, selon lui, un ascétisme exacerbé dont Pierre Damien apparait comme le représentant par excellence ${ }^{4}$. Mais la réforme grégorienne est-elle aussi unilatéralement dualiste que le suggère Jean Wirth ? S'agissant de Pierre Damien, il conviendrait d'évaluer avec plus d'attention les implications d'une version extrême du mépris du monde, qui atteint certes des 
sommets avec les exploits d'auto-flagellation rapportés dans la Vie de Dominique l'Encuirassé, mais qui se conjugue aussi avec la promotion d'autres figures saintes associant de manière plus complexe érémitisme pénitentiel et souci du monde ${ }^{5}$. Surtout, la rhétorique hyper-dualiste maniée par les grégoriens les plus enflammés ne saurait être analysée de manière isolée. Elle peut certes constituer une arme de combat fort efficace : lorsqu'on prétend réformer la société et défendre la "libertas Ecclesiae » pour mieux proscrire les interventions des laïcs dans les affaires du clergé, il est judicieux d'instaurer une démarcation aussi tranchée que possible entre spirituel et matériel, c'est-à-dire aussi entre clercs et laïcs. Mais ce radicalisme ne saurait définir, à lui seul, la nature de la refondation de l'institution ecclésiale que l'on dénomme « réforme grégorienne ». Impliquant une suréminence nouvelle du clergé sous l'égide du pouvoir centralisateur de la papauté, celle-ci n'est nullement une entreprise monastique, même si elle s'appuie largement, dans un premier temps au moins, sur des alliances nouées au sein du clergé régulier. L'Église grégorienne ne vise pas la fuite du monde, mais l'organisation du monde social. Or, une institution qui revendique de régenter entièrement la société ne saurait se fonder sur un strict dualisme.

De fait, ce qui est au cœur de la réforme grégorienne, ce n'est pas la séparation du corporel et du spirituel (aussi nécessaire que soit le rappel de leur dualité), mais bien davantage leur articulation positive (laquelle ne saurait entraîner le corporel dans une dynamique positive que si la prééminence du spirituel est respectée). Du reste, l'Église tout entière est une institution éminemment incarnée (dans l'immensité de ses possessions), mais elle ne saurait avoir de légitimité qu'en se réclamant du principe spirituel qui la guide. Exemplaire de cette logique est l'affirmation du moine Placide de Nonantola qui, dans son Liber de honore Ecclesiae, rédigé en 1111, justifie la possession des biens matériels de l'Église par une homologie avec la relation de l'âme et du corps : " De même que le corps est animé (vivificatur) et gouverné par l'âme, de même les biens matériels, dans l'Église, sont sanctifiés par les dons du Saint-Esprit... De même que l'âme dans cette vie n'existe pas sans le corps, de même la sainte Église, dans le temps présent, ne peut, sans les dons matériels, faire usage des choses spirituelles ${ }^{6}$. » Il s'agit tout à la fois d'affirmer la nécessaire incarnation du principe spirituel (le corps est indispensable à l'âme tout comme les biens matériels le sont à l'Église) et de faire valoir la capacité du principe spirituel à conférer ses qualités propres aux choses matérielles (l'âme vivifie le corps comme l'Esprit sanctifie les possessions). Nous avons là une expression remarquable de la logique d'articulation positive du corporel et du spirituel, qui souligne non seulement le caractère nécessaire du matériel mais aussi sa capacité à être transformé par une telle conjonction. De telles conceptions, qui visent à légitimer l'institution ecclésiale en conciliant son engagement dans le monde matériel (et en premier lieu les nombreuses donations qu'elle reçoit) avec le primat du principe spirituel qui la fonde, étaient déjà au cœur de l'action des premiers cercles grégoriens et avaient notamment été exprimées par le cardinal Humbert de Moyenmoutier, l'un de ses membres les plus éminents ${ }^{7}$.

9 Si la légitimation des possessions matérielles de l'Église et la valorisation des lieux reposent sur une logique d'articulation non dualiste du matériel et du spirituel, il en va de même des images qui ornent ces derniers. On peut même faire l'hypothèse que l'expansivité des images, à partir du $\mathrm{IX}^{\mathrm{e}}$ siècle et plus nettement encore du $\mathrm{XI}^{\mathrm{e}}$ siècle, est portée par l'intensification du schème d'articulation positive du spirituel et du matériel. De fait, l'image ne vaut que pour autant que sa matérialité permet de se projeter au-delà d'elle-même. Dès qu'on lui dénie cette capacité à articuler le matériel 
et le spirituel (ou, de manière homologue, le visible et l'invisible), elle est vouée à être condamnée comme idole, ou du moins comme une pure matérialité ne s'adressant qu'aux sens et entravant le cheminement vers le divin. A l'inverse, les usages assumés de l'image reposent sur la possibilité de conjoindre le matériel et le spirituel, et notamment d'opérer un passage vers le spirituel à partir de l'objet matériel ${ }^{8}$. Mais il convient de relever que, dans cette conception anagogique de l'image, il ne s'agit pas seulement de traverser le visible pour s'en affranchir et s'élever ainsi vers l'invisible. $C^{\prime}$ est d'abord une manière d'assumer la matérialité des lieux de culte et de leur décor, une matérialité par laquelle et dans laquelle s'opère l'accès au spirituel ${ }^{9}$.

La dynamique anti-dualiste qui caractérise la période grégorienne peut se manifester à la fois par la valorisation des inscriptions matérielles du spirituel et par la célébration visible du monde créé. De ce fait, au lieu de postuler que les images de l'époque romane ne sauraient montrer le monde créé autrement qu'écrasé par les conséquences du Péché, il s'avère nécessaire de faire place à une lecture beaucoup plus ambivalente de celles-ci. La dénonciation grimaçante des vices et de la chair coupable peut certes y tenir une place de choix. Mais la dynamique anti-dualiste - inhérente au rôle croissant conféré au décor du lieu rituel, ainsi qu'à la valeur spirituelle de l'édifice matériel qu'il orne - s'exprime également avec force dans des représentations de la vitalité du monde créé et dans la figuration d'une corporéité potentiellement réévaluée. Il est vrai que le monde, et l'humain en particulier, ont été profondément affectés par la Chute : la perfection de l'ordre voulu par le Créateur a alors été rompue. Mais cet ordre même n'a pas été entièrement aboli, pas plus que la relation d'image entre l'homme et Dieu, certes désormais voilée, ne s'est totalement perdue. Surtout, l'Incarnation est venue effacer en partie les effets du Péché et rouvrir la voie d'un accès à Dieu. Le monde créé doit dès lors être perçu dans la tension entre une constitution initiale parfaite, la perte de celle-ci lors de la Faute, et la possibilité, soutenue par l'œuvre rédemptrice, de recouvrer l'harmonie des premiers jours.

11 Cette perception littéralement ambivalente du monde créé ne peut que s'accentuer à mesure que s'approfondit une dynamique incarnationnelle soucieuse de valoriser les implications de la réconciliation apportée par le Christ. C'est tout particulièrement le cas à partir de la fin du $\mathrm{XI}^{\mathrm{e}}$ siècle, comme en témoigne le Cur Deus Homo d'Anselme de Cantorbery ${ }^{10}$. Comme chez les auteurs du haut Moyen Age mais avec plus d'intensité encore, il s'agit alors de rechercher, dans le monde créé, la marque de l'harmonie musicale voulue par Dieu, dans ses hiérarchies et ses consonances constitutives. Et lorsque Honorius Augustodunensis amplifie cette conception de l'ordre musical du cosmos en affirmant que Dieu " a créé l'univers comme une grande cithare », il est clair qu'il parle non de la perfection initiale de la création mais du temps présent, dans son ambivalence même, puisque son explication suggère, à la suite de Boèce, que les sons opposés, rendus par le corps et l'âme, les anges et les diables, le ciel et l'enfer, ont leur place sur l'instrument divin ${ }^{11}$. L'ambivalence qui caractérise les conceptions romanes du monde créé est celle d'un monde tiraillé entre le poids du péché et la promesse du salut. Mais elle tient aussi à l'inscription dans les choses de l'univers d'une positivité propre, pensée comme harmonie musicale et qui, pour une large part, n'est pas affectée par les fluctuations de la guerre du Bien et du Mal.

$12 \mathrm{Au}$ total, le processus de refondation institutionnelle que l'on dénomme réforme grégorienne se caractérise d'une part par une accentuation de la dualité âme/corps et une insistance vigoureuse sur la supériorité du principe spirituel (ce qui permet 
d'assimiler à une souillure toute intromission des laïcs dans les affaires de l'Église) et de l'autre, par l'affirmation d'une logique anti-dualiste d'articulation du corporel et du spirituel, qui s'avère d'autant plus nécessaire que leur dissociation est forte. L'équilibre entre ces deux aspects peut varier selon les périodes, ou encore selon le contexte et le type d'effets que l'on cherche à produire; mais ils sont l'un et l'autre nécessaires, dans leur conjonction même. L'articulation positive du corporel et du spirituel peut être considérée comme un schème fondamental, qui tout à la fois exprime et permet de faire valoir la puissance dominante de l'institution ecclésiale. C'est cette articulation qui lui permet d'accepter des dons matériels considérables tout en affirmant ne rien perdre de sa pureté spirituelle, bref de s'assumer comme institution incarnée et engagée dans le monde, mais prétendant néanmoins être fondée rigoureusement sur des valeurs spirituelles ${ }^{12}$.

Lorsqu'elle est assez poussée, l'articulation du corporel et du spirituel ne consiste pas seulement en un passage de l'un à l'autre ou en une simple conjonction des deux. Leur mise en rapport les modifie l'un comme l'autre, et le sens de cette opération dépend de la dynamique qui préside à leur association. Dans les conceptions de l'Occident médiéval, le "corps spirituel» des élus ressuscités offre un cas extrême de cette conjonction transformatrice : sans rien perdre de la pleine matérialité de sa chair, le corps glorieux acquiert, du fait de son union parfaite avec l'âme, des qualités nouvelles, qui sont normalement celles de l'âme elle-même ${ }^{13}$. Certes, la gloire des élus ressuscités relève de l'horizon eschatologique, mais son importance ne saurait être sous-estimée : le paradis est pensé comme un modèle idéal offert à la société chrétienne et en fonction duquel l'Église justifie ses efforts pour ordonner l'ici-bas.

On propose donc d'appeler spiritualisation du matériel les différentes modalités du processus paradoxal par lequel le matériel, sans cesser d'être matériel, acquiert des qualités propres au spirituel. Ce n'est pas là une question de substance, mais de relations. Et il ne s'agit pas de remplacer le matériel par du spirituel, mais bien d'opérer une conjonction que l'on pourrait qualifier d'oxymore, au même titre que l'Incarnation du divin. De même que Dieu ne cesse d'être Dieu en devenant homme, le matériel ne cesse d'être matériel en devenant spirituel. La spiritualisation doit donc être entendue comme un devenir spirituel, non comme un devenir esprit ${ }^{14}$. Et ce devenir spirituel comporte différents degrés, dont le corps glorieux des élus est certainement le plus achevé. Mais peut aussi être dit spirituel, ce qui, quelle que soit sa nature (âme ou corps), est guidé voire conformé par le principe spirituel et en acquiert par conséquent certaines des caractéristiques éminentes. A la limite, le spirituel peut n'être qu'une qualification normative, ainsi lorsque les clercs sont appelés « hommes spirituels », ou lorsqu'on englobe dans la définition des spiritualia le bâtiment-église, ainsi que «toutes les choses par lesquelles s'accomplissent les sacrements spirituels ", et même les charges et redevances dues au clergé ${ }^{15}$. Encore s'agit-il alors, le plus souvent, d'un effet des sacrements, qui opèrent une sanctification faisant passer dans l'ordre du spirituel.

15 Mais revenons plus précisément à l'édifice ecclésial. Comme on l'a dit au chapitre I, une nouvelle doctrine du lieu sacré est élaborée par les clercs grégoriens (en même temps que s'impose la doctrine de la Présence réelle). Alors que le christianisme des premiers siècles se caractérisait par une relative indifférence à la localisation du sacré et à la matérialité du lieu de culte, on aboutit alors à une ecclésiologie qui, non seulement assume son inscription architecturale, mais fait du bâtiment-église le cadre 
indispensable à l'action sacramentelle et, par conséquent, à la (re)production du corps social ${ }^{16}$. Conférer à l'édifice de pierre une telle efficacité sociale suppose un rituel, dont l'amplification progressive, à partir du IX $\mathrm{I}^{\mathrm{e}}$ siècle, est à la mesure de la suréminence qui lui est peu à peu accordée. Orchestrant une ample combinaison de gestes, de paroles, de manipulations d'objets et de matériaux divers (eau, sel, cendres, mortier, etc.), de déplacements et de marquages spatiaux, la consécration est l'acte qui constitue le lieu sacré, le rend apte à l'effectuation des sacrements et le charge de sa capacité à constituer un référent spatio-social majeur. Assimilée à un baptême de l'édifice, la consécration revêt une importance si considérable qu'on en prolonge la mémoire par des signes visibles (comme les croix de consécration), par des récits (dont le De consecratione de Suger est un exemple remarquable) et surtout, par une célébration annuelle qui, pour chaque église, compte parmi les fêtes liturgiques les plus importantes ${ }^{17}$.

Le rituel de consécration peut être considéré comme une véritable "activation du bâtiment ecclésial $»^{18}$. Or, afin qu'il devienne le cadre des diverses transformations sacramentelles, à commencer par celles qu'implique l'Eucharistie, il faut opérer d'abord une transformation de la nature du lieu lui-même. C'est ce qu'exprime avec une force singulière (et exemplaire de la nouvelle doctrine du lieu sacré), l'évêque Bonizon de Sutri, à la fin du $\mathrm{XI}^{e}$ siècle. Grégorien convaincu et auteur de l'une des premières Sommes sur les sacrements, il établit un parallèle saisissant entre l'opération qui s'accomplit lors de la consécration et celle qui concerne les espèces eucharistiques : de même que le prêtre change le pain et le vin en corps et sang du Christ, les mains de l'évêque "transforment ces pierres insensibles en une autre nature, lorsque par consécration elles font de la maison faite de main d'homme la demeure de la Trinité et des anges $»^{19}$. L'intensité de la mutation opérée par la consécration ne saurait être affirmée avec plus de force, dès lors qu'on lui prête la même portée qu'au changement d'essence que les théologiens, un demi-siècle après Bonizon, commenceront à qualifier de transsubstantiation. De fait, l'édifice de pierres est transformé «en une autre nature » (in aliam naturam) : il acquiert une nouvelle essence. Bonizon n'explicite pas quelle est la nature de l'édifice au terme de sa transmutation rituelle et il affirme seulement que le bâtiment de pierre devient la demeure de la Trinité et des anges. Pourtant, il faut bien supposer, non seulement que cette capacité à accueillir la présence divine et angélique implique une qualité nouvelle du lieu, mais aussi que cette " autre nature ", qui est désormais la sienne, excède les limites de la matérialité inerte des pierres. Il faut donc comprendre que cette nouvelle nature du bâtiment ne vise pas à en occulter la dimension matérielle, mais vient s'ajouter à elle : sans cesser d'être un édifice fait de pierres assemblées par la main de l'homme, l'église consacrée, habitée par les puissances célestes, est désormais animée d'un souffle de vie qui lui confère des propriétés nouvelles. La transmutation rituelle lui a conféré une nature nouvelle, inscrite dans l'ordre du spirituel.

Une telle conception de la consécration comme transmutation spirituelle de l'édifice de pierre n'a pu qu'intensifier, notamment dans les commentaires des liturgistes ou dans les formules associées à la consécration, les usages des métaphores néotestamentaires évoquant le Christ comme pierre angulaire (Ac, 4, 11; I Pierre 2, 7; Eph. 2, 20-22), l'investiture de Pierre (Mt 16,18) ou encore les fidèles comme pierres vivantes ( $\mathrm{Rm} 8$, 9-11; I Pierre 2, 5) ${ }^{20}$. De même, les liturgistes s'emploient à conférer à chacune des parties de l'église un sens spirituel, qui est avant tout la marque d'une cléricalisation de l'édifice architectural, comme de l'édifice social dont il est l'image. De manière 
générale, ils rappellent que l'église (matérielle) ne vaut que par la relation qui la lie à l'Église (spirituelle), c'est-à-dire à la communauté des fidèles et à l'institution qui la guide $^{21}$. Il pourrait ne s'agir là que du déploiement d'une logique allégorique qui joue d'un rapport d'image entre l'ordre du matériel (ici, minéral) et l'ordre du spirituel (l'Église vivante). Mais la nouvelle conception du lieu rituel pousse certainement à passer d'une simple correspondance à un rapport participatif. C'est le cas par exemple lorsque, décrivant la cathédrale de Saint-Jacques de Compostelle, faite de pierres dures comme du marbre, peinte à l'intérieur et protégée à l'extérieur par des tuiles et du plomb, le Liber sancti Jacobi qualifie ces pierres de «vivantes" (" ex fortissimis lapidibus vivis »)22. Alors, les pierres vivantes ne sont plus seulement les fidèles assemblés dont l'édifice seraient l'image : la qualité d'animation propre à la communauté spirituelle imprègne désormais le bâtiment rituel lui-même. Fortement souligné par le texte (qui enchâsse le mot vivis au milieu de ceux qui soulignent la dureté minérale des pierres), ce glissement est l'indice d'un renversement majeur : c'est désormais moins l'édifice qui doit sa justification à la communauté que celle-ci qui doit son existence (en tant que communauté chrétienne) à l'édifice.

18 Au total, on peut considérer que la multiplication de bâtiments ecclésiaux de plus en plus valorisés et richement ornés repose sur un principe d'articulation positive du matériel et du spirituel. A l'inverse de toute accentuation dualiste, ce principe peut être tenu pour l'une des lignes directrices de la refondation ecclésiale que l'on dénomme réforme grégorienne. La nouvelle doctrine du lieu sacré qui s'impose alors autorise à penser la consécration comme une forme de transmutation de l'édifice : sans nullement nier la matérialité du lieu (qu'il souligne au contraire en convoquant objets et matériaux multiples), le rituel lui confère un statut nouveau qui s'exprime en des termes liés aux registres de la sacralité, de la présence du divin, de l'animation vitale ou du devenir spirituel. Le bâtiment rituel n'est donc pas seulement voué à conjoindre des ordres de réalité différents (la terre et le ciel, l'humain et le divin); il est aussi le lieu par excellence d'une transformation des essences (de l'édifice lui-même, des espèces eucharistiques ou encore des chrétiens engagés dans la conversion propre à l'iter ecclésial).

19 On peut dès lors énoncer, en forme d'interrogation, l'hypothèse qui guidera la suite de ce chapitre : le décor, dont l'amplification même est un aspect de la dynamique antidualiste d'articulation positive du matériel et du spirituel, ne vient-il pas activer cette qualité du lieu qui, tout matériel qu'il est, n'en acquiert pas moins un caractère si spirituel que Dieu et les anges peuvent l'habiter ? Les chapiteaux qui ponctuent l'ensemble du lieu ecclésial ne contribuent-il pas à rendre sensible cette transmutation des pierres insensibles qui leur confère une nouvelle nature, animée d'un « souffle de vie », selon la formule par laquelle un lion de bronze accueille les entrants à la porte de l'église Saint-Julien de Brioude ${ }^{23}$ ?

\section{Végétalité}


Fig. 1

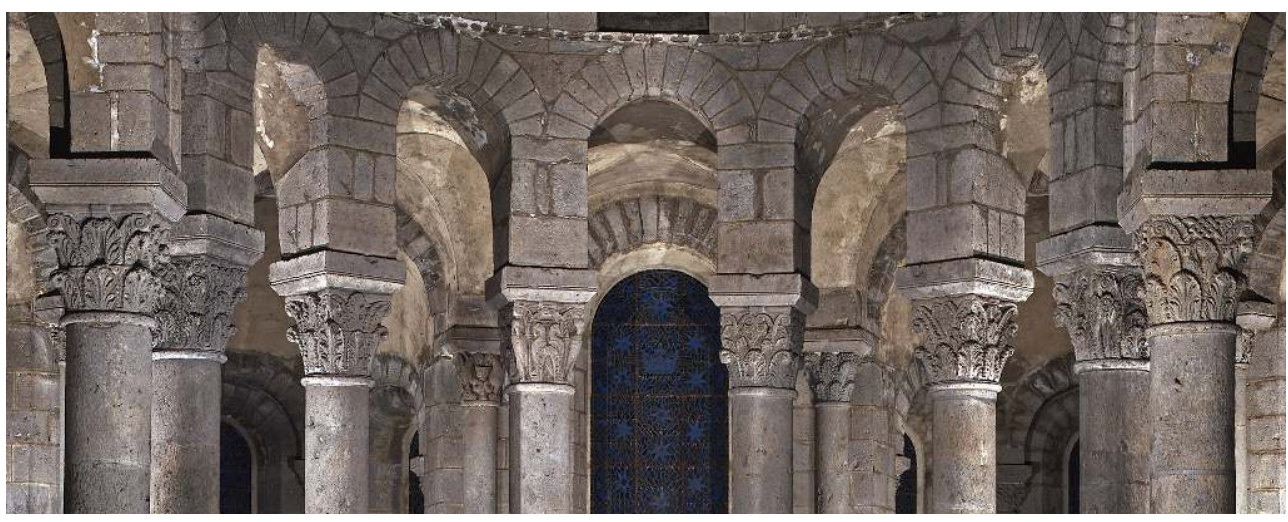

Pourquoi une telle abondance du végétal sur les huit chapiteaux de l'hémicycle de Notre-Dame d'Orcival?

(Ph. Inv. Choplain-Maston, 95.63.0375VA, recadrée, copyright Région Auvergne - Inventaire général, AGAGP)

20 À quel(s) titre(s) le végétal, qui couvre la majorité des chapiteaux des églises romanes d'Auvergne et s'impose même dans certains chapiteaux à figures, contribue-t-il à la transmutation de l'église - édifice matériel - en un lieu spirituel ${ }^{24}$ ? Cette transmutation spirituelle dont la dédicace, comme on l'a indiqué plus haut, est le premier et véritable opérateur n'est pas un devenir immatériel, mais - postulat fondamental du christianisme médiéval - un devenir sensiblement présent du spirituel dans le matériel.

\section{De l'ornement et de son efficience}

21 On qualifie traditionnellement ces chapiteaux, comme d'une manière générale les décors de type végétal, d'ornementaux ${ }^{25}$. Et il est vrai que, vers 1125 , le moine Théophile - commentant la parole du psalmiste : «Seigneur, j'ai aimé la beauté de ta maison " (Domine dilexi decorem domus tuœ) - voit dans la végétation (fleurs, feuilles, branches, rinceaux...) répandue sur les parois ou sur le mobilier liturgique des églises «l'ornement » par excellence de la «maison matérielle de Dieu en tant qu'elle est le lieu de la prière » (ornatum materialis domus Dei qua locus est orationis) ${ }^{26}$. Le végétal, en effet, "rend visible d'une certaine manière aux spectateurs l'aspect du paradis ("paradysi Dei speciem floribus variis... quodammodo aspicientibus ostendendi $[t]) »{ }^{27}$. Ce faisant, dans l'esprit des clercs au moins, la végétalisation de l'église est censée, sous certaines conditions liées à la nature et à la fonction spécifiques de ce locus orationis, transformer réellement, et non pas seulement d'une manière métaphorique, « la maison matérielle de Dieu » en une manière d'Eden provisoire qui est la promesse et l'anticipation du paradis à venir où devrait se réaliser une nouvelle et parfaite conjonction de l'âme et du corps, du matériel et du spirituel. Suger ne dit pas autre chose, dans son traité sur la consécration de Saint-Denis (1144), quand il voit dans le faste liturgique lié à la célébration de l'eucharistie (à l'occasion, précisément, de la consécration de la basilique) une façon admirable (et donc visible) d'«unir harmonieusement les choses matérielles aux immatérielles, les corporelles aux spirituelles...»; puis, s'adressant à Dieu, il déclare en prière d'action de grâce : « tu transformes merveilleusement l'église présente en royaume céleste (ecclesiam presentem in regnum celeste mirabiliter transformas). ${ }^{28}$ Le mirabiliter ne doit pas s'entendre d'une 
opération à proprement parler miraculeuse mais plutôt extraordinaire, suscitant une modalité intensive et admirative du regard (selon l'étymologie du mot). Sous condition d'être associée au lieu où s'effectue la transmutation sacramentelle du pain et du vin dans le corps du Christ, l'ornementation merveilleuse de l'église est appelée - «avec toutes les bénédictions [liturgiques] visibles (benedictionibus visibilibus)» - à rendre effectivement présent ici-bas et sous un aspect sensible (species) ${ }^{29}$ à ceux qui regardent (aspicientibus, comme dit Théophile), une anticipation du royaume céleste à venir. «L'ornement » est supposé opérer, et pas seulement suggérer d'une façon imagée, une conjonction harmonieuse entre l'église comme lieu matériel et l'église comme lieu spirituel voué à la célébration liturgique ${ }^{30}$.

Cela est pensable au Moyen Age, parce que, en latin médiéval, les termes ornatus, ornamentum, ornare, decor, decus, decorare... ont un champ sémantique foncièrement positif qui ne recoupe que partiellement le français moderne «ornement, ornementation, décor, décoration, décorer... », mais qui peut prendre une connotation péjorative dans les discours polémiques. Le Moyen Age désigne du terme d'ornementa des choses dotées de qualités particulières que nous ne qualifierions pas d'ornements tels la voile du navire, l'âme de l'homme, le trésor d'une église, ses possessions immobilières et foncières, mais aussi les instruments liturgiques (qui sont nécessaires au culte et, pour cette raison, décorés). En portant la fonction d'une chose à sa perfection, les ornamenta la rendent digne d'être célébrée et donc - par glissement métonymique - de recevoir une «ornementation » qu'on peut qualifier d'esthétique en ce sens qu'elle fait valoir d'une façon particulièrement sensible sa dignité propre. La fonction de la liturgie étant précisément de célébrer le Créateur, elle ne saurait se passer, aux yeux de Suger, de la plus somptueuse ornementation. Celle-ci est donc (en droit, du moins ${ }^{31}$ ) une beauté qui revient à la chose en tant qu'elle mérite d'être honorée. C'est ce qu'implique le mot latin decor qui signifie la beauté en tant qu'elle doit célébrer ce qui convient de l'être et comme il le convient (decet). C'est, par exemple, ce que demande Gérard II de Cambrai pour les chapiteaux, puisqu'ils sont la "tête » de la colonne (capitula columnarum... decenter coronare ») ${ }^{32}$. Et decus désigne la dignité intrinsèque d'une chose rendue manifeste par la beauté qui l'honore en l'ornant et qui en vient à se superposer, sinon même à coïncider dans une certaine mesure, avec son être ${ }^{33}$. Et ceci d'autant plus que la destination ultime des créatures humaines éminemment accomplie par ses serviteurs ecclésiastiques et, à leur manière, par ceux des ornementa des églises qu'on qualifiera d'ornementaux - est de rendre gloire au Créateur dans la création ${ }^{34}$. Le " paradis » à venir de Théophile et le "royaume céleste " de Suger sont précisément conçus comme des lieux où l'on rendra éternellement gloire à Dieu face à face. Faire apparaître la gloire ou la rendre sensible dès ici-bas, c'est la faire exister sur un mode sensible - celui d'une apparition réelle et non d'une simple apparence. Celui qui, «porté par l'amour de la beauté de la maison de Dieu (ex dilectione decoris domus Dei)», fait l'expérience de la beauté (speciositas) de ses ornements, aura, comme Suger, le sentiment qu'il "se trouve dans une région extérieure à la sphère terrestre, qui ne serait pas tout entière dans sa fange ni dans toute la pureté du ciel $»^{35}$. C'est de cette façon que l'ornementation doit être considérée comme opérante (et transportante) et non pas comme un decorum flatteur appliqué de l'extérieur sur les choses et les gens. Cette opérativité, Théophile la dit en termes de performativité (supposée) quand, s'adressant à un discipline censé avoir réalisé le décor végétal paradisiaque qu'il vient de décrire, il déclare : «tu as fait [fecisti] que les spectateurs louent le Dieu Créateur dans les créatures et le proclament admirable [mirabilem - c'est 
le terme de Suger] dans ses œuvres $»^{36}$. Ce passage du Prologue au troisième et dernier Livre du De diversis artibus se conclut par la déclaration que toutes les choses dont son traité va définir les techniques de fabrication et de décoration - à savoir « les calices, les chandeliers, les encensoirs, les ampoules, les burettes, les châsses des saints, les croix, les missels" - sont d'une absolue "utilité pour l'accomplissement du rituel ecclésiastique [in usum ecclesiastici ordinis]. ${ }^{37}$ L'ornementation ne peut donc être comprise en termes étroitement stylistiques ou formalistes: elle relève d'une pragmatique de l'esthétique ${ }^{38}$, inhérente à l'usage rituel (des lieux) du pouvoir (dominium) divin/clérical, mais aussi laïque. Elle a pris au Moyen Age des formes végétales qui s'inscrivent dans une longue tradition, mais les églises romanes d'Auvergne leur ont donné un accent propre.

\section{En quel sens les chapiteaux végétaux peuvent être dits « sacrés »}

23 Si les chapiteaux végétaux sont légitimement considérés comme efficients, c'est que, selon la nouvelle conception grégorienne qui exalte l'église en tant que maison de Dieu, la consécration qui la sacralise fait, en même temps, que tous les ornamenta qui s'y rattachent, et donc les chapiteaux, deviennent "sacrés ». En principe, ici-bas (à la différence de l'au-delà), rien ne possède de sacralité par nature ${ }^{39}$. Est sacré, avant tout, ce qui a été consacré par un rite ecclésiastique qui le met à part, en sorte que cela ne relève plus du droit humain - et donc d'un dominium laïque - mais du droit divin et donc des clercs consacrés à Dieu pour le servir et (se) consacrer à leur tour ${ }^{40}$. La réforme grégorienne est caractérisée par un renforcement de l'exigence de pureté des consécrateurs et d'inviolabilité des personnes et des biens qui ont été consacrés. En conséquence, le sacré se concentre dans des hommes, des lieux et des temps qui sont hiérarchisés, car il y a divers degrés et catégories de sacré et divers temps et formes de son activation ou de son actualisation sensible. Et les ornamenta ornementaux comme les chapiteaux, qui ne sont pas à proprement parler consacrés mais font partie de l'église qui l'est, « sont cependant sacrés [tamen sacra] - selon Hugues de Saint-Victor - en ce qu'ils appartiennent aux choses saintes [ad sancta pertinent] et sont étroitement liées (ou adhèrent) à celles qui possèdent la sainteté (illis cohorent quœe et sanctitatem habent) et qui confèrent la sanctification. $»^{41} \mathrm{Il}$ s'agit donc bien d'une sacralité réelle mais seulement participative (par métonymie ontologique, si l'on peut dire), qui n'est effective que par adhérence ou par appartenance à ce qui, étant saint - à savoir ici le corps ecclésiastique -, confère la sanctification par son ministère sacramentel. Être sacré pour les ornements matériels, c'est être censément imprégné d'une certaine qualité spirituelle par la présence du divin qui, à la suite de la consécration, habite (inhabitat) dans «l'église matérielle » en tant que «lieu de prière » (qua locus est orationis).

Le végétal n'est pas absent de la liturgie de la consécration, car celle-ci fait appel à une plante - l'hysope - dont l'évêque utilise une branche pour faire les aspersions sur les murs extérieurs et intérieurs de l'église, ainsi que sur l'autel ${ }^{42}$. Cette même liturgie est aussi amenée à recourir explicitement à la métaphore végétale. C'est ainsi que, dans un sermon pour la dédicace de l'église, Pierre Damien compare l'église à un champ resplendissant de fleurs odorantes ${ }^{43}$. Un autre texte pour la dédicace de l'abbatiale du Mont-Cassin conclut une évocation du décor coloré des peintures, des mosaïques et des pierres du pavement de l'église en disant que le sol donne l'impression de reverdir en se couvrant de fleurs ${ }^{44}$. 
Fig. 2

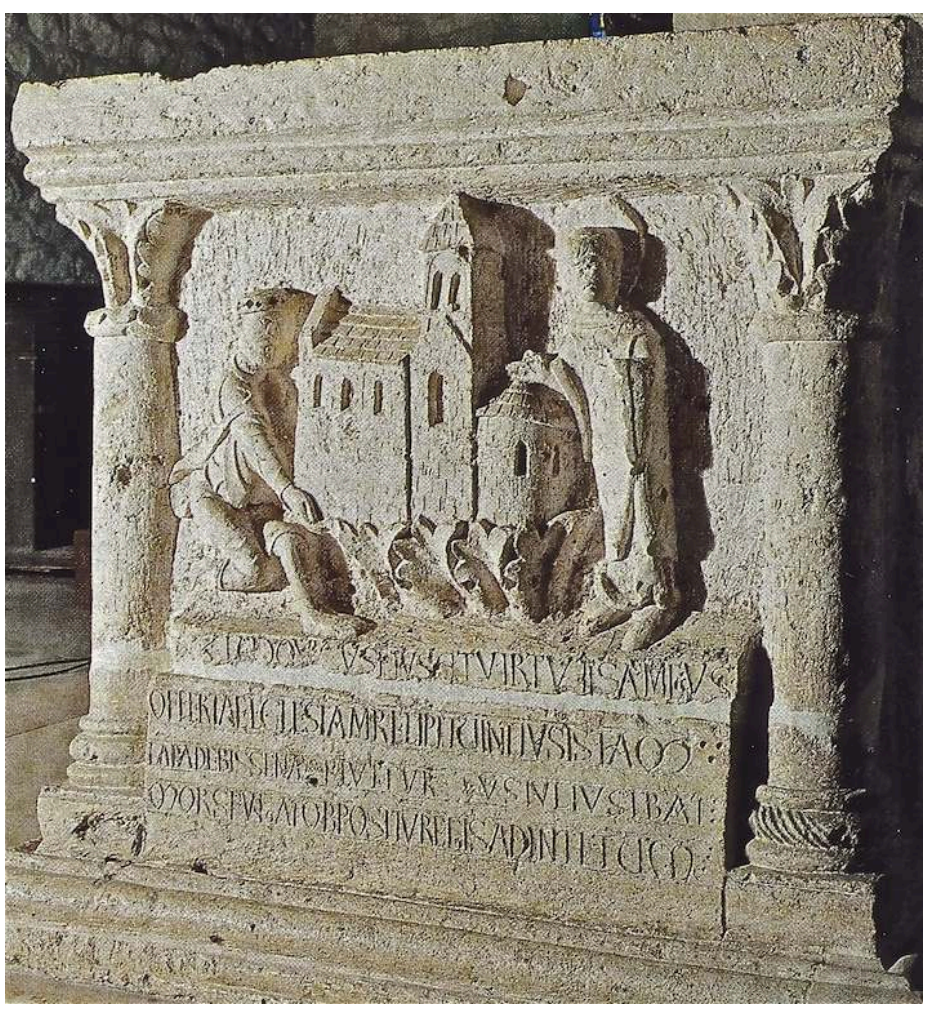

Fondement végétal de l'église (côté de l'autel de l'église d'Avenas)

Une scène de donation évoque, d'une manière exceptionnelle, la signification sacrée du végétal dans la conception romane de l'église (fig. 2). Elle se trouve sur une face latérale de l'autel sculpté d'Avenas (diocèse de Mâcon, vers 1120 ; les autres faces présentent le Christ en majesté entre les apôtres et quatre scènes de la Vie de la Vierge $)^{45}$. Le végétal $\mathrm{y}$ figure deux fois. Une première fois comme soubassement - et donc en manière de fondement - de l'église qui est présentée et offerte par un donateur royal, un genou au sol, à saint Vincent debout qui, d'un geste de la main, l'accepte. Le végétal y revêt la forme d'une rangée de feuilles polylobées, soudées entre elles et semblant émerger du sol. L'église, au bel appareil de pierres régulier et à l'architecture romane, est inscrite dans cette sorte de grand calice végétal comme dans une matrice dont elle sort telle une fleur gigantesque, ou mieux tel le fruit de la donation. L'ornatus des feuilles qui enveloppent la base de l'église la met en honneur, tout en délimitant et en marquant comme sacré le lieu où est elle implantée. Les feuilles sont légèrement inclinées vers le donateur, comme si elles ployaient sous le poids de ce qu'elles portent. Le dispositif signifie clairement que le végétal enracine l'église dans un sol vivant dont la virtus sous-jacente la fait pousser au-dessus de terre ${ }^{46}$ (où sont situés le donateur et le donataire) et la soutient jusqu'à ce que sa tour, purement architecturale, atteigne au sommet (que touche aussi l'auréole du saint). Le sol végétal trouve lui-même une assise dans l'inscription écrite sur le socle de la scène. Elle fait référence à un roi Louis dont elle célèbre la virtus et elle situe la donation vers le milieu d'un mois de juillet (mois de la floraison ou de la fructification). Quasiment le même végétal apparaît une seconde fois sur les chapiteaux qui couronnent les colonnes portant symboliquement la table d'autel et qui sont aussi une image des colonnes à chapiteaux végétaux intérieurs à 
l'église. On ne peut guère imaginer plus belle image de la participation de l'ornatus végétal à tout ce processus de sublimation spirituelle de l'église matérielle et, donc, à son fondement.

Fig. 3

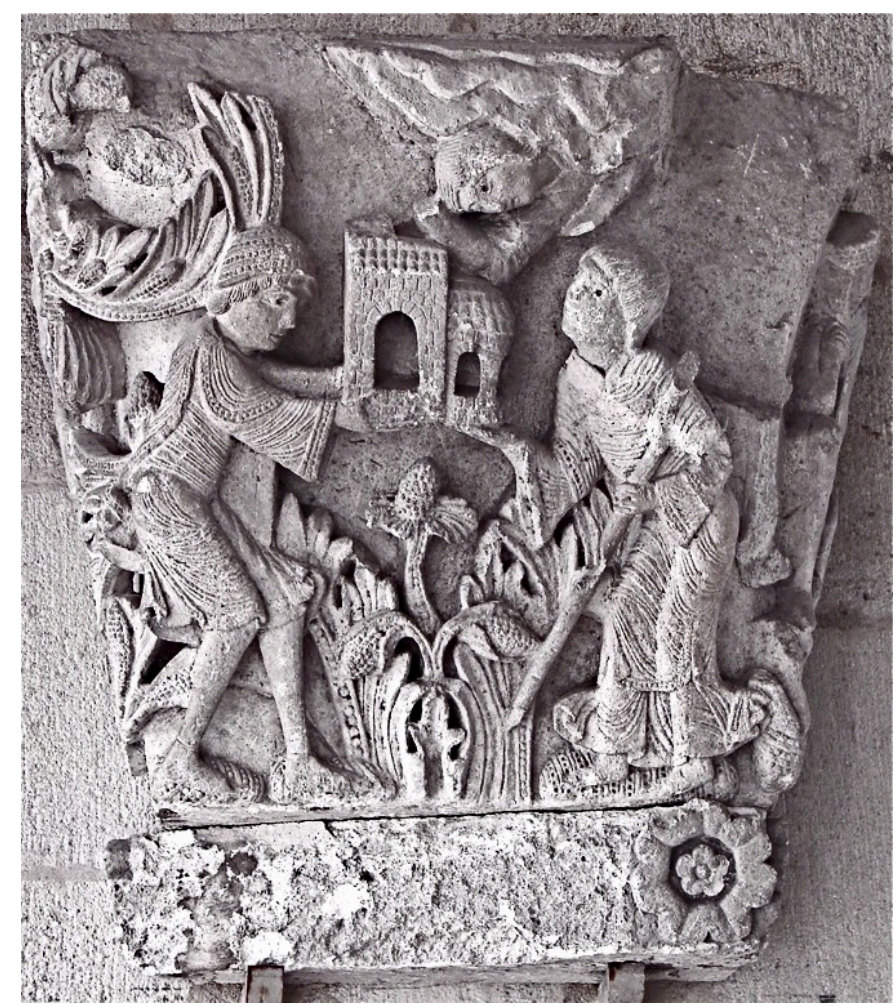

Donation de l'église par un laïc à un évêque (chapiteau de Saint-Lazare d'Autun, vers 1120)

Un chapiteau de Saint-Lazare d'Autun montre une variation remarquable sur le même thème (fig. 3). Ici l'église ne repose pas directement sur le végétal mais un riche et large déploiement de feuilles et de fruits «soutient » et honore comme il convient le geste de donation ${ }^{47}$. Le donateur a la tête inclinée devant ce qu'il offre tandis que le donataire, qui reçoit le don d'une main, lève la tête vers la figure sainte émergeant d'un nuage pour accueillir et sanctifier le don d'un geste du bras ou de la main (qui touche les deux éléments de l'édifice). Les trois personnes sont engagées dans la transaction en raison de leur statut: l'évêque, crosse en main, est à la fois le récepteur du don matériel, symbolisé par une abside accolée au massif du transept, et le médiateur institutionnel de la spiritualisation qui vient du ciel. Le végétal, dont les trois fruits désignent et célèbrent les trois instances de cette opération, en marque aussi l'épanouissement.

\section{Transversalité du végétal}

27 L'exemple de l'autel d'Avenas suggère que la virtus du végétal sous-tend, accompagne et anime, de la base au sommet, un processus ascensionnel conduisant au sacrifice rédempteur opéré sur l'autel lui-même, et ultime fondement de la sacralité. Si on revient de cette image à une église romane réelle, on peut caractériser cette transversalité du végétal par rapport aux trois catégories fonctionnelles - locus, iter, transitus - qui nous servent à articuler dynamiquement l'organisation du lieu ecclésial. 

extérieure de nos églises d'Auvergne comporte presqu'exclusivement de petits chapiteaux végétaux qui sont d'une très grande varietas, même quand ils sont simples ${ }^{48}$. Ils couronnent les colonnettes des baies principales, des arcades aveugles ou des arcades d'encadrement des fenêtres des murs latéraux, de la partie haute du chevet, du massif barlong, des étages de la tour ${ }^{49}$. À l'intérieur, le végétal a une présence plus prégnante, qui n'est pas seulement liée à la taille, à la visibilité, à l'abondance et à la diversité des chapiteaux dont il fait le décor, mais aussi aux diverses modalités de son association avec des figures. Les chapiteaux purement végétaux s'enchaînent en une pure succession qui ne connaît pas, en elle-même, d'arrêts, même si des chapiteaux historiés viennent s'insérer entre eux. La continuité du végétal est aussi maintenue lorsqu'il est habité par diverses figures (têtes humaines ou non), ou même quand il sert de cadre à une scène (comme celle du singe cordé dont les deux protagonistes sont assis sur une couronne d'acanthes). Le végétal s'hybride aussi avec certaines figures, ce qui constitue encore une autre façon de créer de la continuité (cf. infra). Enfin, il peut être appelé par le sujet d'un chapiteau (Péché originel et arbre de la personnification des forces vitales de la création à Notre-Dame-du-Port, par exemple), mais il prend alors des aspects liés aux besoins de l'iconographie, sans perdre tout caractère ornemental. Par-delà ses espacements et ses variations formelles d'un chapiteau à l'autre, et ses divers modes et degrés d'association avec des figures, le végétal forme un milieu continu et transversal qui exalte et unifie le lieu ecclésial, car il est le principal vecteur de l'ornatus qui le traverse. Il inscrit et rassemble tout sous le signe de l'ordre spirituel qu'il incarne, célèbre et dissémine. L'ornatus végétal ainsi entendu comme milieu est toutefois visuellement suspendu, mais pas objectivement aboli, sur les chapiteaux qui constituent des lieux particuliers pour les scènes historiées et allégoriques où cet ordre apparait, pour ainsi dire, en personne ou pour lui-même, comme dans la Tentation du Christ. Ce sont des sortes de stations, sur le fond de sa continuité, consacrées à un épisode dont les conditions temporelles et spatiales sont liées à ce qui est figuré, même si elles restent indéterminées ou suprahistoriques. À Saint-Nectaire, dans la scène d'affrontement où le dragon est écrasé par un ange, il n'y a aucun signe végétal. En particulier, il n'est pas indifférent de relever que le dragon n'y a pas de queue végétalisée, alors qu'à Mozat les deux couples de dragons, qui figurent seuls sur leurs chapiteaux, sont, eux, pourvus de queues à extrémités végétales. Sans elles, ces dragons auraient pu être pris pour des forces soustraites à l'ordre qui règne partout ailleurs, ce qui aurait donné à ce thème diabolique un accent dualiste (au sens d'une autonomie du Mal par rapport à l'ordre du Bien). L'ornementalité végétale intervient ainsi jusque dans des chapiteaux qui semblent exclure sa «noblesse » et sa "dignité » - figures diaboliques, mais aussi figures anthropomorphes ou zoomorphes énigmatiques, inquiétantes ou ambivalentes - comme pour canaliser leur négativité potentielle ou spiritualiser leur vitalité. À Notre-Dame-du-Port, la scène du dragon terrassé par un ange manifeste une solution intermédiaire ou de compromis quelque peu différente de celle de Saint-Nectaire, puisque la queue du dragon vaincu est pourvue d'une terminaison végétale (qui semble d'ailleurs l'enserrer ou l'encadrer?), mais courte et sans commune mesure avec celle, largement épanouie, des centaures.

L'ornementalité végétale contribue donc d'une manière essentielle à la sacralisation globale du locus, mais il est évident que ni les fidèles ni le clergé ne sont en mesure de l'appréhender dans toute sa varietas (objective), en se déplaçant. Les chapiteaux ornementaux se voient en passant: c'est par excellence un art de la peregrinatio 
intérieure à l'église. Dans les conditions ordinaires de cette peregrinatio, l'œil n'aperçoit que certains de ces chapiteaux, au hasard du déplacement du regard. Dans ces conditions, plus un chapiteau a une riche ornementation, plus sa perception ne saurait être que très globale, avec quelques saillances au milieu de détails qui restent subliminaux. L'important n'est pas de tout voir, mais de sentir une sorte d'omniprésence foisonnante, fonctionnant à la manière d'une basse continue, qui affleure plus ou moins, avec des changements de rythme ou de composition. On peut même dire que ces chapiteaux ne sont pas fait pour être regardés pour eux-mêmes mais plutôt pour qu'on entrevoit dans leur composition et a fortiori dans leur succession un excès du visible sur l'effectivement vu. Cette opacité leur confère une sorte de substantialité objective qui participe aussi à l'effet sensible de sacralité. Dans le cas où les chapiteaux végétaux présentent la simplicité de ceux des colonnes de la nef de Saint-Nectaire, c'est, au contraire, la clarté et la monumentalité de l'ordre, dont on ne détaille pas non plus habituellement les subtiles variations, qui constitue l'un des principes de leur vision.

Pour ce qui est d'iter, l'ornementalité végétale n'entretient pas avec lui de relations aussi fines ni aussi continues qu'avec locus, mais elle permet aussi d'articuler ces deux fonctions. C'est ainsi que les chapiteaux extérieurs développent un ornatus dont la varietas, si elle n'implique généralement pas de progression ou de hiérarchie entre les lieux qu'elle jalonne, fonctionne globalement en mineur par rapport à ceux de l'intérieur ${ }^{50}$. On observe une hiérarchie globale du même ordre entre les chapiteaux végétaux des tribunes, des arcs-diaphragmes, ou des absidioles et les chapiteaux de la nef et de l'hémicycle. Mais les chapiteaux purement ornementaux de l'intérieur n'indiquent guère une progression continue en dignité dans l'organisation et la succession des lieux - narthex, nef, portes, chœur liturgique, déambulatoire jusqu'au sanctuaire. Il n'y a guère qu'à Notre-Dame-du-Port où l'on a pu suivre une certaine transformation marquée par la réduction d'une grande diversitas au profit d'un ordo dont la varietas est à la fois plus unifiée et plus élaborée dans l'hémicycle. À SaintNectaire, c'est, au contraire, le contraste entre l'abondance des chapiteaux végétaux dans la nef et leur absence dans l'hémicycle qui marque le changement qualitatif entre les lieux. On notera aussi que, par sa continuité, l'ornementalité végétale contribue à l'intégration des forces ambiguës ou négatives, lorsqu'elles se sont manifestées par des tensions ou des désordres locaux, dans le processus général de soumission à l'ordre sacré qui culmine dans le sanctuaire et dans le moment de la messe.

Quant à la fonction de la végétalité dans le transitus - ce qu'on pourrait appeler une ascensio architecturale et symbolique par le végétal -, elle a été évoquée d'une manière générale à propos des textes cités de Théophile et de Suger (sous le nom d'anagogie) ${ }^{51}$. $\mathrm{Au}$ terme de l'iter qui aboutit au sanctuaire, lieu même du transitus, le végétal peut s'effacer devant les scènes christologiques ou hagiographiques, comme à SaintNectaire, ou garder au contraire une place importante, comme à Mozat et Notre-Damedu-Port: il soutient alors jusqu'à son terme l'exaltation de la spiritualisation de l'édifice, même s'il n'entretient pas de rapport aussi prégnant avec le principe du transitus que la Résurrection du Christ ou l'Assomption de la Vierge. 
Fig. 4
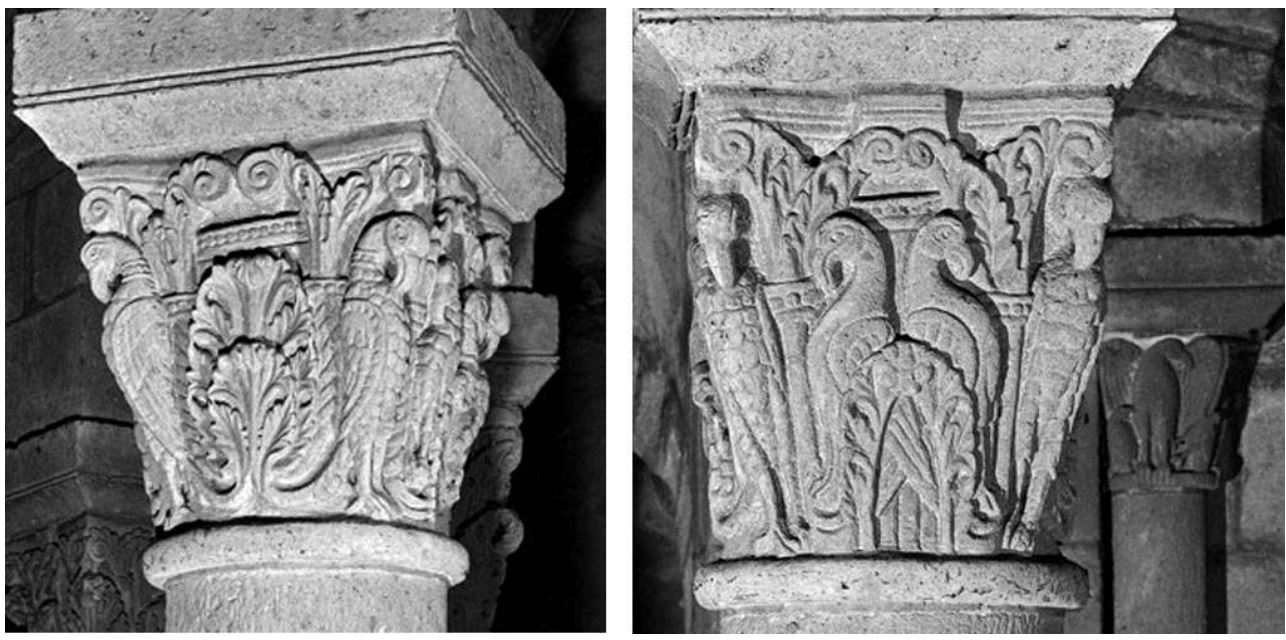

Deux faces du chapiteau de l'hémicycle de Notre-Dame d'Orcival associant l'architectural, la végétalité ornementale et l'animalité céleste (les aigles et les oiseaux) dans le transitus

Ph. Inv. Choplain-Maston, 94.63.1873X et 94.63.1875X, copyright Région Auvergne - Inventaire général, AGAGP

La capacité du végétal à s'associer au sacré, voire même à le signifier, connaît une apothéose dans le sanctuaire de Notre-Dame d'Orcival (fig. 1). Là, ce sont les huit colonnes du rond-point qui se voient couronnées de grands chapiteaux végétaux richement décorés dans un esprit corinthisant mais très libre. Le végétal y participe beaucoup plus directement qu'ailleurs à l'expression du transitus car, sur l'un de ces chapiteaux, il est couplé avec deux quaternités d'oiseaux (fig. 4). Quatre grands aigles, placés par couple dos à dos, en occupent les arêtes et leurs queues se joignent et s'hybrident en une sorte de double panache de feuilles d'acanthes qu'encadrent deux caulicoles à gaine torsadée et feuillage s'épanouissant en hélices et volutes ${ }^{52}$ conjonction, rehaussée de bandeaux perlés, de l'oiseau et du végétal sous leur forme la plus noble. Sur les deux autres faces - dont l'une est tournée vers le sanctuaire -, deux couples d'oiseaux plus petits et étroitement adossés ont leurs ailes couvertes par une feuille d'acanthe échancrée qui laisse voir le croisement de leur pointe et, à la base, un motif évoquant un pilastre plat et cannelé. Cet élément renvoie donc à l'architecture spiritualisée par la végétalité ornementale, elle-même associée au transitus par la médiation des oiseaux qui en sont les vecteurs symboliques ${ }^{53}$. C'est le chapiteau auvergnat qui offre l'association la plus achevée de l'architectonique, du végétal et de l'animalité céleste ${ }^{54}$.

33 En somme, le végétal est susceptible d'affecter toute l'église - figures comprises - de l'ornatus dont il est à la fois le signe éminent et le vecteur inépuisable. La multiplicité de ses registres plastiques, rythmiques et symboliques (du terrestre au paradisiaque) contribue ainsi à activer les divers modes de fonctionnement du lieu rituel (locus, iter, transitus).

\section{Types de végétation}

La végétalité des chapiteaux ornementaux romans n'est pas une végétation naturelle, même si elle recourt abondamment au motif de l'acanthe. Elle s'inspire sur ce point de la tradition antique de l'ordre corinthien qui était lui-même une idéalisation, à des fins 
décoratives politico-rituelles, d'une composition végétale épousant bien la forme des chapiteaux, tout en conservant, malgré leur artificialité, le sens d'une croissance organique dont l'art roman se montrera peu soucieux. On ne reviendra pas ici sur l'acanthe $e^{55}$. On soulignera plutôt que la végétalité ornementale, fondée ou non sur l'acanthe et ses dérivés formels, ne doit pas être considérée isolément, car elle joue dans nos églises par différence fonctionnelle avec plusieurs autres types de végétation qui lui sont hétérogènes.

Fig. 5
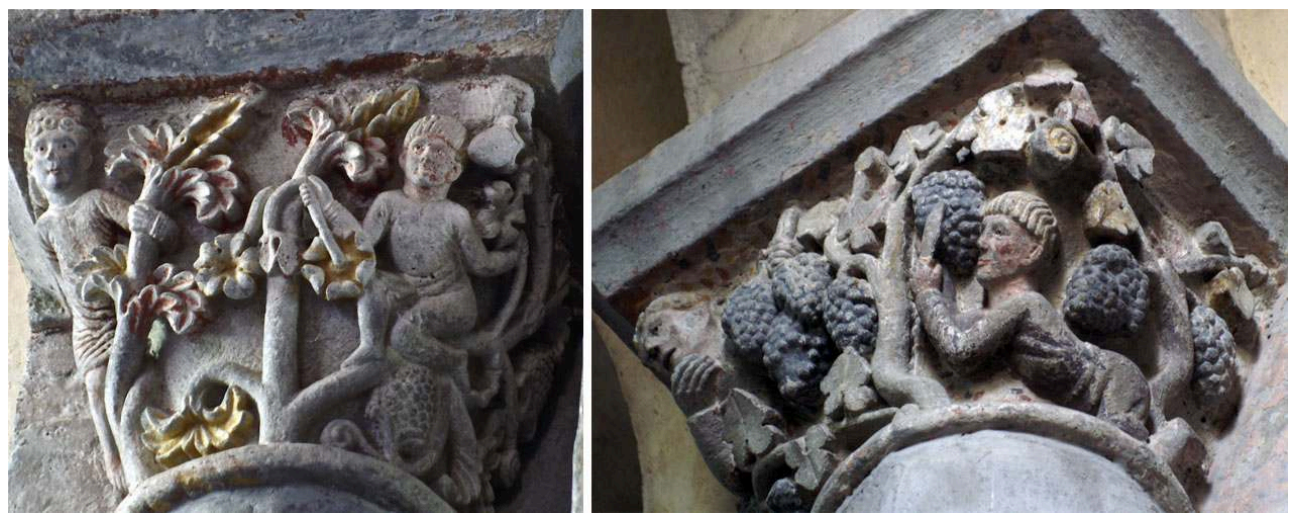

Végétalité terrestre : a) deux hommes perchés dans des arbres féconds (Mozat) ; b) vigne et vendange (Mozat)

Il s'agit d'abord d'une végétation que nous qualifions simplement de "terrestre », car elle ne vise pas à «faire naturel»; mais à signifier qu'elle se situe ici-bas. Quand l'iconographie recourt à une végétation de ce type, en général dans une figuration historiée ou allégorique, c'est, conformément aux pratiques romanes, sous des formes schématiques, fort peu naturalistes, qui suffisent à marquer qu'on a affaire à un arbre, des fleurs, des plantes ou à du végétal en général. Quand on identifie une espèce, comme la vigne à Mozat (fig. 5b), elle est peu singularisée et quand on singularise un arbre symbolique, comme celui de la personnification des forces vitales de la création à Notre-Dame-du-Port, la question de son identification avec une espèce particulière n'a aucun sens. La végétation terrestre d'une image à sujet figuratif a le plus souvent aussi quelque caractère ornemental qui la fait participer, à son degré, à l'ornatus général de l'édifice. A Mozat, par exemple (fig. 5a), les deux arbres terrestres dans lesquels deux jeunes gens sont perchés et dont l'un porte des fleurs (leur identification n'importe pas) sont disposés en une symétrie intentionnellement très libre, comparativement à la symétrie rigoureuse d'autres chapiteaux, mais pourtant réelle. 
Fig. 6
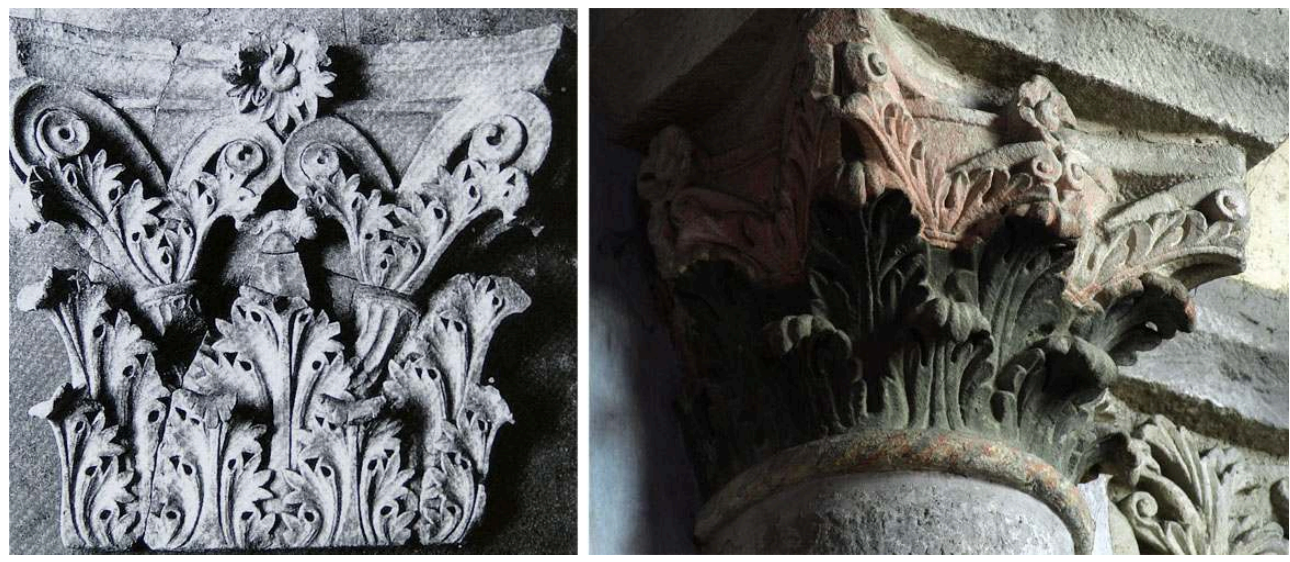

a) chapiteau corinthien antique (temple d'Apollo in Circo, Rome, 28 avant J-C ; b) chapiteau corinthien semblable à l'antique dans le schéma de construction et les motifs (Mozat)

36 A une autre extrémité du spectre ornemental, les chapiteaux les plus corinthiens de Mozat $^{56}$ - à double couronne d'acanthes, caulicoles à collerette, hélices et volutes d'angle, calathos convexe, abaque concave et rosace à l'emplacement du dé (fig. 6) sont une manière d'honneur que l'église fait à la romanité dont, réciproquement, elle s'approprie le pouvoir valorisant mais en le revitalisant spirituellement. Cette végétalité ornementale antiquisante se distingue nettement de la vigne terrestre bien identifiable des vendangeurs, dans laquelle la symétrie est la moins sensible, sans être tout à fait absente, et qui a un aspect décoratif par son caractère couvrant ou des détails comme une vrille formant volute sous un angle (fig. $5 b$ ).

Fig. 7
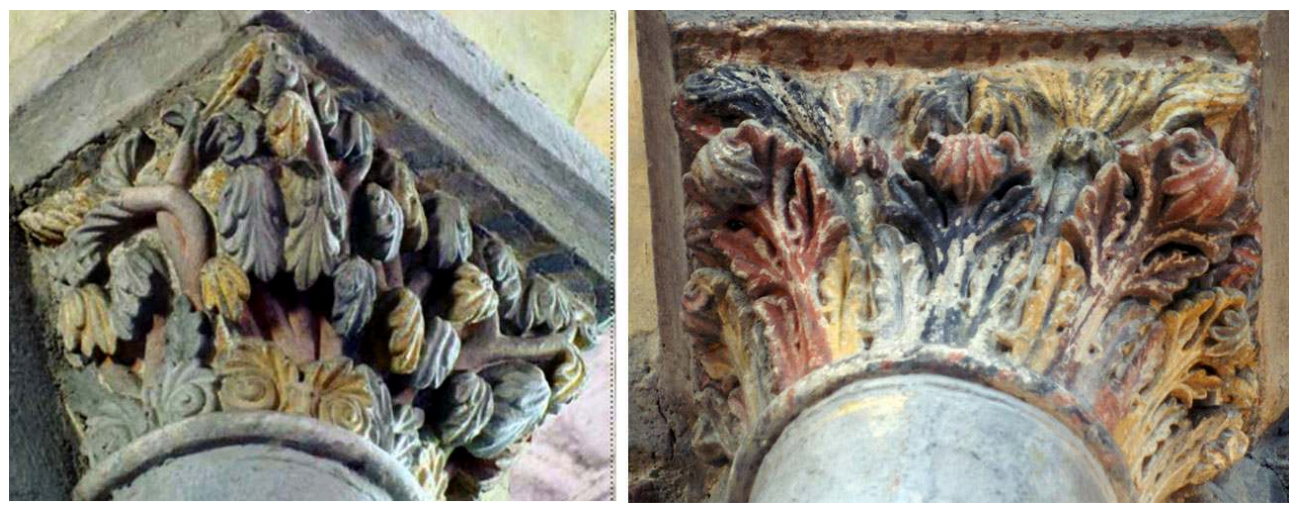

Mozat : a) chapiteau à tronc d'arbre terrestre et feuilles pendantes évoquant la retombée de feuilles d'acanthe; b) chapiteau corinthisant simplifié

37 À Mozat encore, ce processus est poussé une étape plus loin. On y observe, en effet une opposition coordonnée entre, d'une part (fig. 7a), les feuilles pendantes qui poussent de branches évoquant clairement, jusque dans leur croisement, les arbres des deux jeunes gens perchés ou des vendangeurs (fig. 5) et, d'autre part, les acanthes dressées haut et les caulicoles à feuillage largement déployé du chapiteau antiquisant voisin (fig. 7b). Sa revitalisation spiritualisante permet ici au corinthien antique de devenir le signe d'une revitalisation des forces végétales-vitales de la création. 
Fig. 8
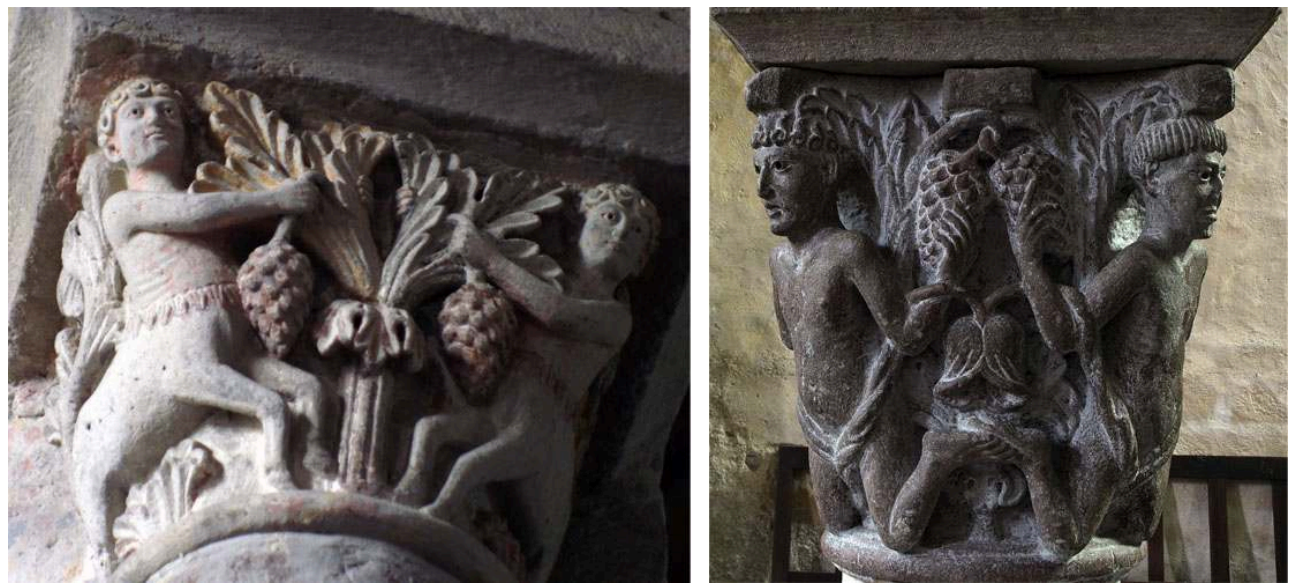

Mozat : de l'arbre-caulicole à feuilles d'acanthes et fruit tenus ou embrassés par des centaures (à gauche) à la longue acanthe-palmette portant fruits et cosse ouverte tenus ou enlacés par une quaternité d'hommes à signification cosmologique (à droite)

Toujours dans cette série de Mozat, des acanthes (bien identifiables) dont l'organisation est reconfigurée autour d'un axe de symétrie - un tronc-caulicole - sont associées à d'autres éléments qui en poussent, comme le "gros fruit", et se prêtent à l'intervention de figures comme des hommes ou des centaures qui les tiennent embrassés. Et dans le rond-point de cette église, les longues feuilles associées sur toute leur hauteur à la quaternité d'hommes nus n'ont plus de rapport clair avec des acanthes (ce sont plutôt des sortes de palmettes distendues); par contre, on y retrouve les "gros fruits" auxquels s'ajoutent de grandes cosses ouvertes - une composition très originale qui signe la relève chrétienne ou plutôt le dépassement, dans une quaternitas où l'homme et le végétal se voient conjointement cosmologisés, de l'ornementation antiquisante.

Fig. 9
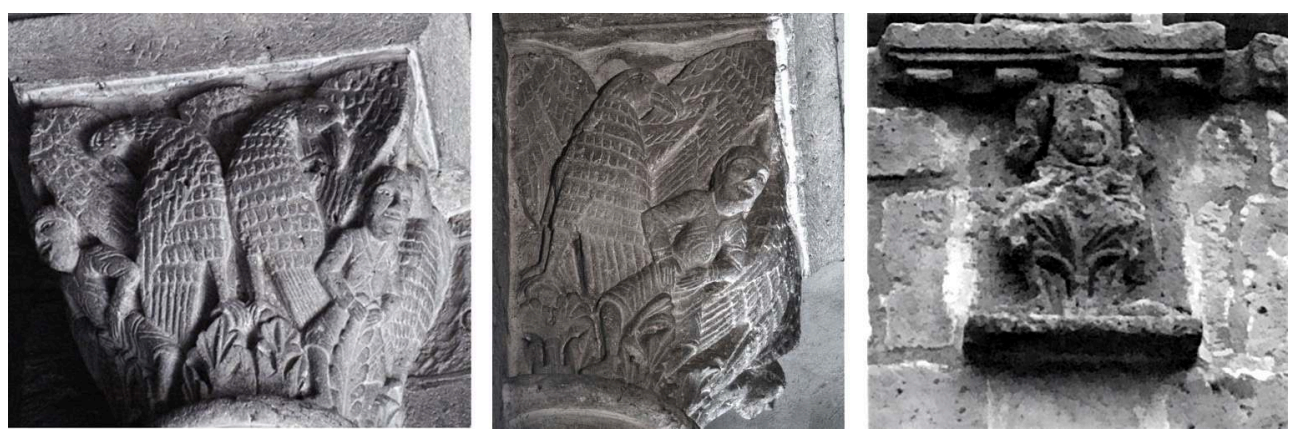

A gauche et au centre : quaternité d'aigles et deux hommes avec une grande feuille entre les jambes. A droite : homme (Christ?) assis sur du végétal (fragment de relief inséré dans le pignon du transept sud d'Orcival).

L'église d'Orcival offre une autre formule d'association originale de l'homme avec du végétal (fig. 9). Sur un chapiteau qui fait face à celui qui entre par la porte sud et regarde vers l'est figurent deux hommes en tunique courte debout et ayant une grande feuille dressée entre leurs jambes ; ils sont encadrés chacun par une paire d'aigles aux ailes déployées et juchés sur une couronne basse d'acanthes (ces oiseaux forment donc une quaternité). La feuille associée à chacun des deux hommes est simple et sans 
continuité apparente avec la couronne d'acanthes des aigles: on a ainsi établi une distinction de dignité entre les deux types de feuillage. Tandis que l'homme de droite, l'air serein, saisit des deux mains l'extrémité de la feuille bien régulière placée devant lui, l'autre, les mains sur le ventre - lieu probable de son péché - tire la langue et ne tient pas la plante qui fléchit comme s'il l'avait laissé échapper. Le contraste des attitudes se comprend comme une allégorie de la condition de l'homme pris entre le péché et la possibilité du salut. La feuille régulière a la silhouette d'une acanthe en puissance qui serait pleinement actualisée par le développement de ses digitations : elle fonctionne symboliquement comme un végétal de vie (assumant une connotation sexuelle) dont l'entrant est, pour ainsi dire, invité à " se saisir ». Elle est ainsi une manière de viatique destiné à protéger et accompagner le fidèle, sous la vigilance des quaternités d'oiseaux célestes, jusqu'au transitus rituel auquel la communauté est invitée à s'associer dans l'hémicycle dont les chapiteaux d'acanthes sont hypervégétalisés. Ce chapiteau appelle la comparaison avec une statue romane (dont la tête est brisée) qui a été insérée, à une date indéterminée, au sommet (remanié) du mur pignon du transept sud (fig. 9). Des plis semblent dessiner une spirale sur la poitrine de la figure assise frontalement et une plante s'épanouit entre ses jambes: pourrait-il s'agir d'un Christ ayant élu du végétal pour trône? On ne peut que poser la question.

A Notre-Dame-du-Port, à côté des différents types de chapiteaux végétaux ornementaux, il y a un type bien distinct de feuille associé au Péché originel et à des figures négatives du déambulatoire, mais ce feuillage revient à côté de "gros fruits " dans l'arbre que chevauche la personnification des forces de la création (nous y reviendrons plus loin). C'est à partir de l'époque gothique que la figuration de la végétation va se naturaliser et se diversifier, sous des formes et dans des compositions idéalisées mais qui rendront ses espèces désormais identifiables ${ }^{57}$.

41 Quand un clerc de l'époque romane, comme Honorius Augustodunensis, évoque la végétation "naturelle », les catégories qu'il utilise instruisent sur la façon quelque peu distanciée et foncièrement optimiste (ou idéaliste) dont il la voit et que, d'une certaine façon, on peut mettre en regard de l'appréhension "artistique ». Dans l'Elucidarium, Honorius voit en effet dans la végétation l'occasion d'une delectatio de la création : «À celui qui la considère dans sa totalité, la création de Dieu offre un grand agrément (delectatio), puisqu'il y a dans certains êtres de la beauté (decor), comme dans les fleurs, dans d'autres, des remèdes (medicina), comme dans les herbes, dans certains, de la nourriture (pascus), comme dans les produits de la terre, dans d'autres, de la signification (significatio), comme dans les vers et les oiseaux. $»^{58}$ Les deux catégories plus spéculatives - decor et significatio - qui, dans cette formule, encadrent les catégories relatives aux usages que le corps peut faire du végétal - medicina et pascus -, dénotent deux modes de vision d'un clerc fondamentalement pénétré de l'idée que la création n'est pas seulement bénéfique à la vie de l'homme ici-bas, mais aussi qu'elle est belle et qu'elle a du sens. Si le terme decor qu'il emploie convient éminemment à la végétation ornementale des chapiteaux romans, la question de sa significatio, au-delà de son symbolisme paradisiaque général qui n'éclaire ni la construction des chapiteaux ni leur succession, est très problématique. (On notera, mais c'est probablement une simple coïncidence car il n'est pas question ici d'ornementation végétale, qu'Honorius n'a pas donné d'exemple végétal pour illustrer sa quatrième notion - significatio-, lui préférant sans doute une opposition allégorique forte entre les bêtes qui rampent sur terre et les animaux qui volent dans le ciel.) Le « sens » de l'ornemenal se pose, dans les 
divers lieux de l'église, plutôt en termes pragmatiques ou fonctionnels qu'en termes proprement sémantiques ou discursifs, et à l'échelle des ensembles sériels plutôt qu'au niveau de chaque chapiteau. Comment faut-il donc comprendre l'ornementalité si elle ne relève que très partiellement d'une sémiotique de la signification?

Fig. 10
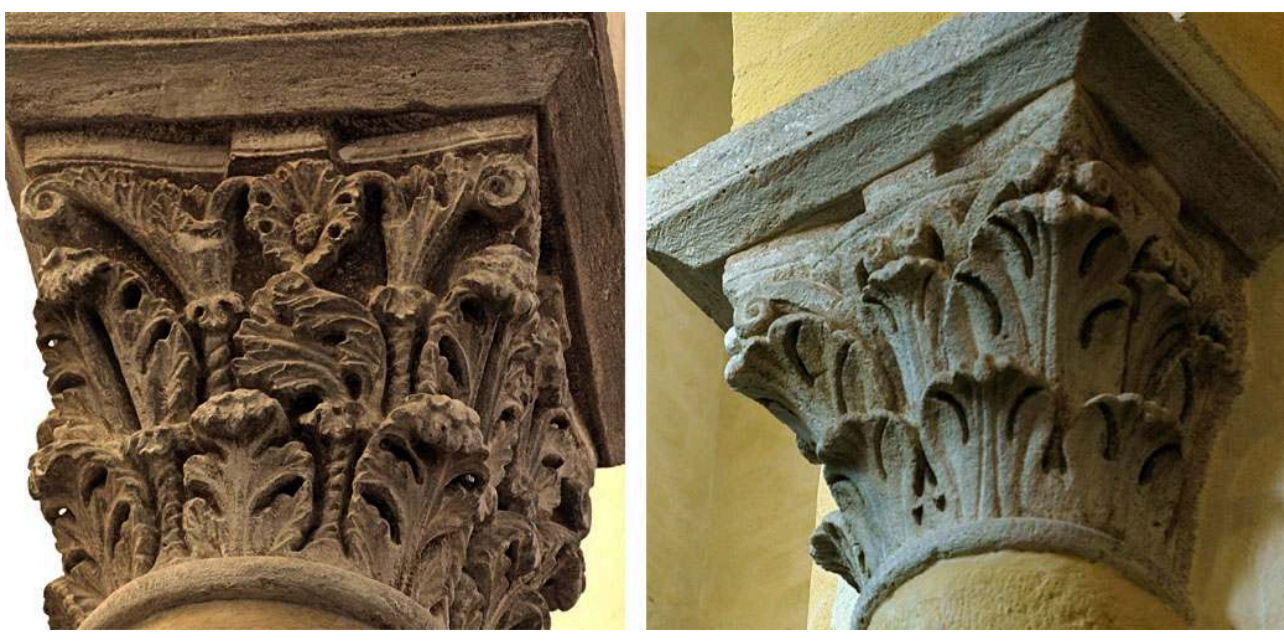

A gauche : corinthisant (variation riche) ; à droite : corinthisant (très simplifié). Chapiteaux de NotreDame-du-Port

Fig. 11
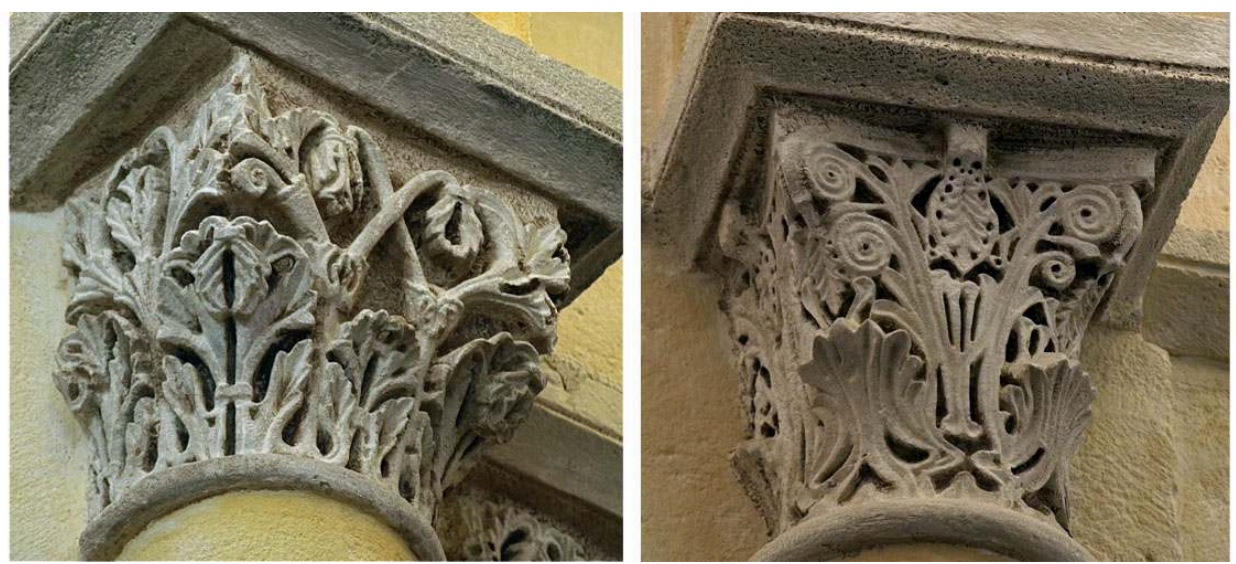

A gauche : corinthisant très libre ; à droite : invention romane (Notre-Dame-du-Port)

La question se pose d'autant plus que l'ornementalité végétale se caractérise par une très grande artificialité. Celle-ci est visible aussi bien dans la morphologie et le caractère hétéroclite de ses éléments que dans leur mode de liaison. Bien que cette végétation ornementale ne soit pas totalement inédite mais s'étaye très largement sur une tradition corinthienne, elle manifeste tout particulièrement son artificialité dans la façon dont ses formules l'utilisent, la remanient et l'intègrent (quelque puisse avoir été son prestige) dans un contexte sériel qui est complètement étranger à cet héritage, par sa variété et son hétérogénéité, et par rapport auquel pourtant elle prend sens (fig. 10). Qu'il s'agisse d'une inspiration manifeste, d'une refonte plus ou moins radicale ou d'une innovation (autant qu'on puisse en juger dans l'ignorance où nous sommes des 
vestiges dont les hommes du $\mathrm{XI}^{\mathrm{e}}$ siècle avaient connaissance), le résultat se caractérise par une vitalité profondément inorganique (fig. 11).

Fig. 12
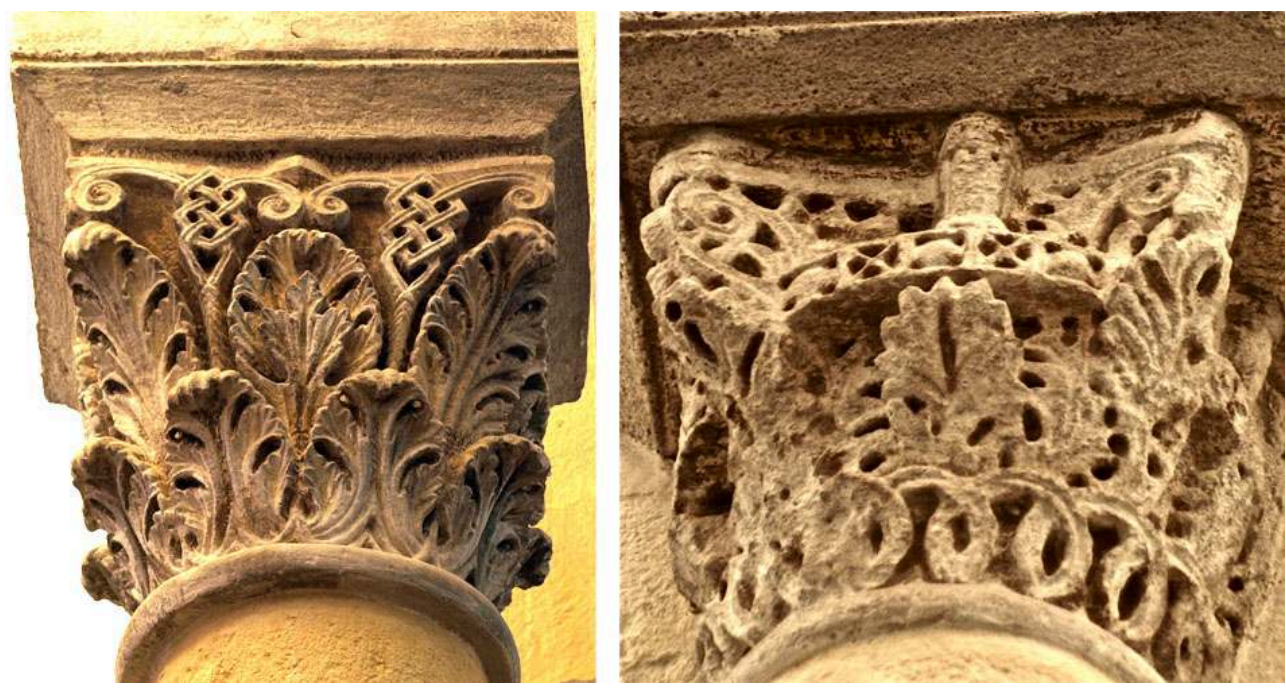

a) couplage du végétal avec de l'entrelacs ; b) couplage du végétal avec un bandeau orfévré (NotreDame-du-Port) branchement, de pousse vers le haut ou d'épanouissement sur les côtés manifestant, dans le retombement des feuilles, leur lutte contre la pesanteur, et pouvant aboutir à une floraison ou à une fructification. Mais l'articulation des parties n'est pas soumise à un principe d'arborescence organique continue et multipliée par différenciation et subordination fonctionnelle et intégrante des parties dans le tout, même si on observe localement des organes d'une plante (racine, tiges, branches, feuilles, fruits). L'agencement des éléments est à ce point artificiel que le dit végétal peut devenir quasi abstrait ou s'hybrider avec divers éléments non végétaux (géométriques, orfévrés, architecturaux, animaux, humains...; fig. 12).

Mais artificialité ne veut pas dire désordre. Selon Théophile, l'ornatus doit posséder trois propriétés : ordo, varietas, mensura. De l'ordo, il existe de multiples espèces, car il doit, en principe et idéalement, pénétrer toutes choses. Sur nos chapiteaux, l'ordo se manifeste de multiples façons : l'étagement des registres, l'articulation systématique et quelquefois hiérarchique des éléments (pas d'élément laissé en déshérence), la symétrie de la composition qui fait de chaque chapiteau une entité centrée ou rapportée à elle-même, le rythme, la sérialité, notamment sous la forme de correspondances entre des compositions différentes d'éléments eux-mêmes distincts. 
Fig. 13
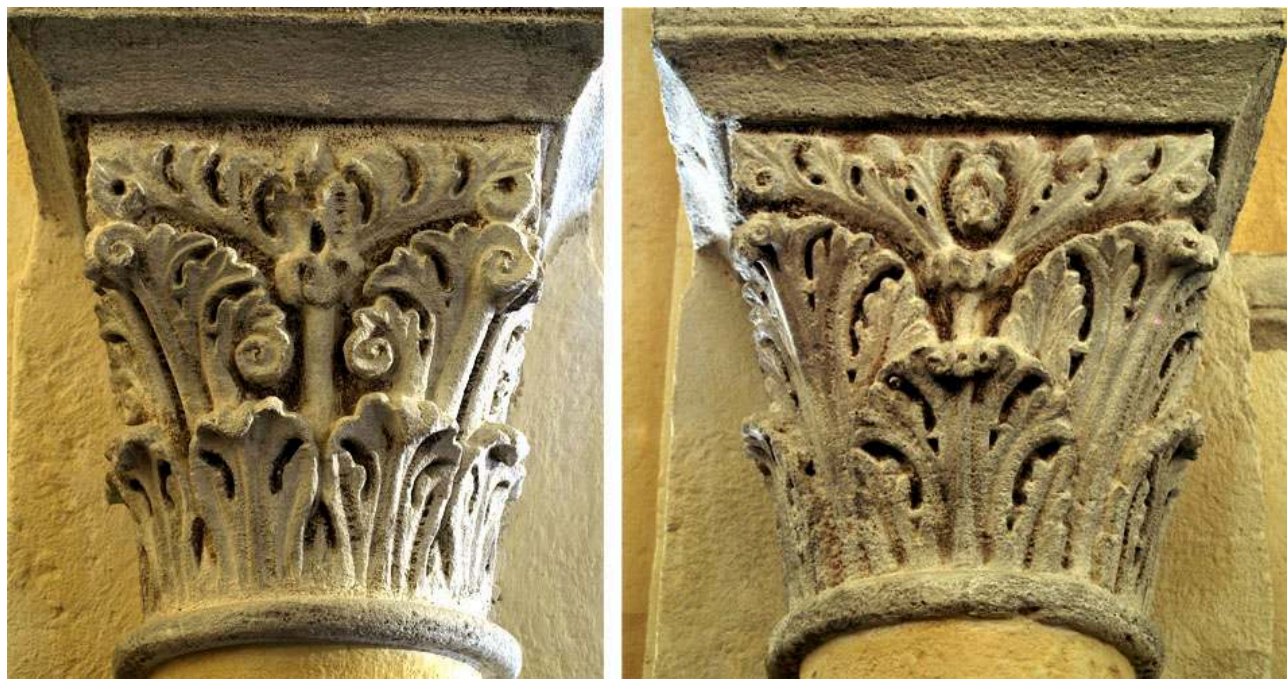

Varietas comme variante. Elle est particulièrement facile à observer dans le cas de chapiteaux formant une paire ou une quasi paire (chapiteaux proches de Notre-Dame-du-Port)

Fig. 14
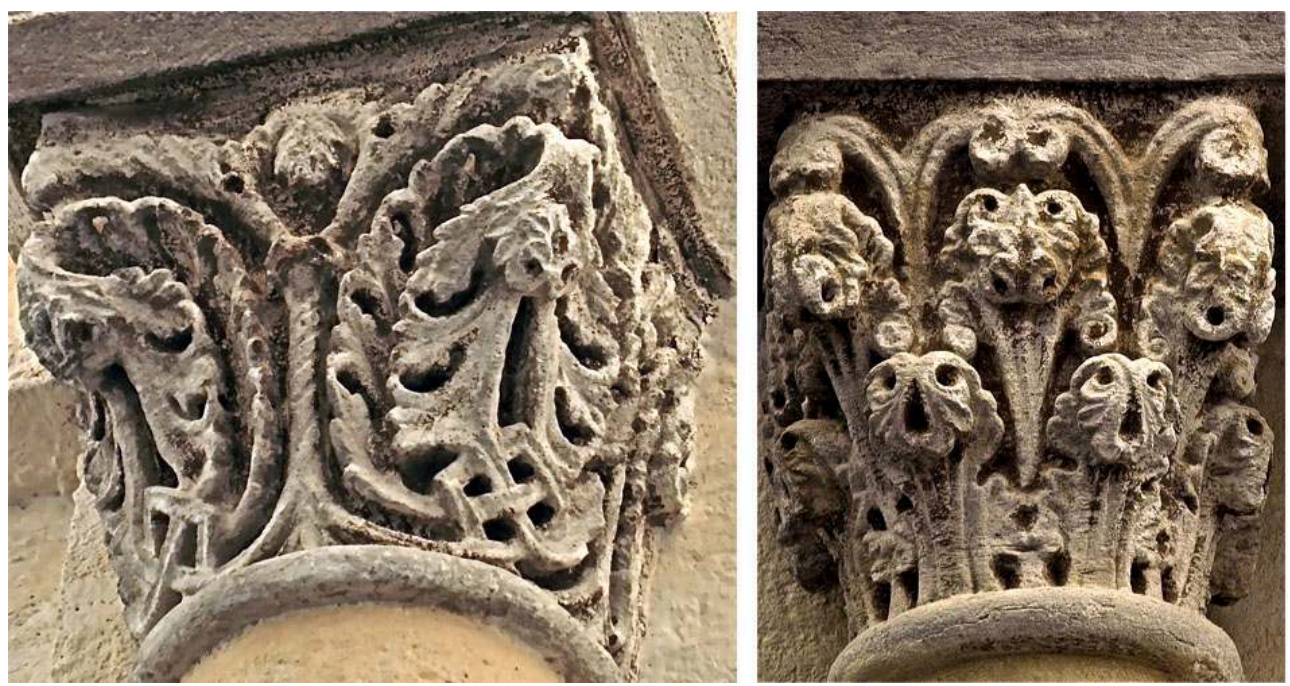

Varietas comme variété (Notre-Dame-du-Port)

La multiplication et la complication de l'ordre conduisent à l'idée de varietas qu'on a proposé d'entendre de trois façons différentes : les variantes, les variations et les variétés. Une variante se distingue par des différences formelles mineures qui n'altèrent pas un dessin commun, comme la substitution d'un élément à un autre, par exemple d'un fleuron à un fruit à grains (fig. 13). Une variation suppose une différence dans les principes de construction, mais telle que soit maintenue la possibilité de penser en termes de transformations le passage d'une composition à une autre. La variation procède souvent par actualisation d'une virtualité latente ou développement d'une possibilité non exploitée: ajout d'une nouvelle excroissance ou démultiplication, inversion de sens, rebroussement, jonction ou disjonction, ou reconfiguration des mêmes éléments comme la feuille et ses découpes...). La variété implique au contraire une discontinuité entre des organisations hétérogènes, comme entre une végétalité 
corinthisante et une végétalité admettant un géométrisme abstrait (fig. 14). La varietas, particulièrement caractéristique de l'époque romane au sein d'une même série (comme l'ensemble des chapiteaux d'un édifice), par rapport à d'autres périodes qui, sans récuser l'originalité recourent plus volontiers à la répétitivité, est donc travaillée par une tension entre le développement de l'ordre et la richesse d'une variété dont il lui est difficile d'assumer l'unité. Quant à mensura, il ne faut pas l'entendre en termes étroitement numériques mais comme une quantité qualitative au service de l'ordo. C'est par exemple une mesure rythmique qui commande ou plutôt s'applique au nombre, à la taille et aux proportions réciproques des feuilles et de leurs éléments, ou bien une manière d'ajuster les symétries ou d'établir des correspondances. Comme le voit à de multiples petites différences et inflexions, la mesure qui définit la position des feuilles de deux couronnes superposées mais décalées d'une demi-feuille n'astreint pas à une exactitude rigoureuse) ${ }^{59}$. On soulignera enfin qu'en définissant l'ornatus par ces trois propriétés (ordo, varietas, mensura), Théophile ne le réduit pas à une question de motifs formels, ce qui permet de le comprendre en terme de processus (ou modus operandi).

\section{Le végétal comme modèle du vital}

Fig. 15

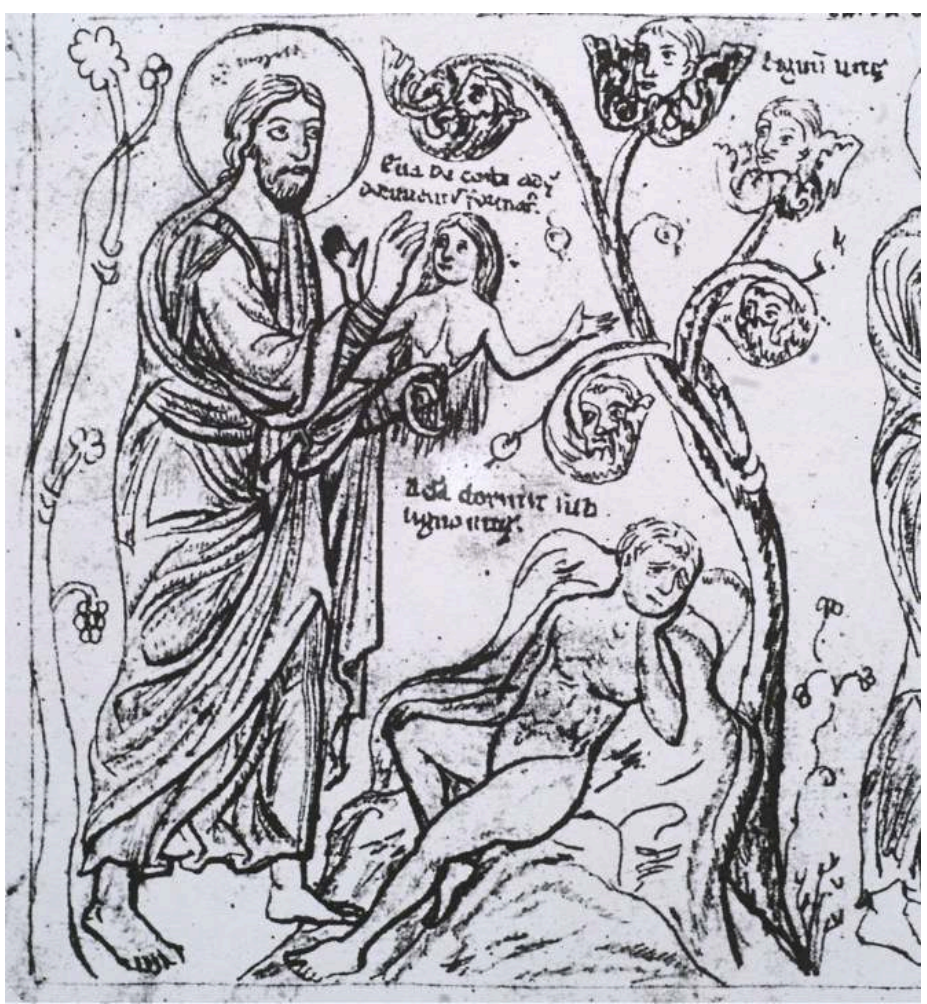

Dieu créant Ėve devant l'Arbre de vie (lignum vitæ), Herrade de Landsberg, Hortus deliciarum (entre 1160 et 1175)

Le végétal, qui a la propriété de pousser directement de la terre dans laquelle il s'enracine, en est venu très tôt à incarner une forme première et privilégiée de la vie. Dans la Genèse, les rapports emblématiques du végétal avec la vie de l'homme sont signifiés de plusieurs façons. Selon le premier récit de la Création, les plantes réparties en deux catégories: les «herbes » et les «arbres» - naissent du sol, le 
troisième jour (au commandement de Dieu: «terra germinet »), elles deviennent florissantes, portent des fruits et se reproduisent en portant semence. Après la création des animaux et de l'homme, Dieu leur donne en nourriture les plantes dont aucune n'est nuisible: « Dieu dit : "Je vous donne toutes les herbes portant semence, qui sont sur la surface de la terre, et tous les arbres qui ont des fruits portant semence : ce sera votre nourriture. A toutes les bêtes sauvages, à tous les oiseaux du ciel, à tout ce qui rampe et qui est animé de vie, je donne pour nourriture toute la verdure des plantes" et il en fut ainsi.»(Gn 1, 29-30). Les plantes, d'après ce récit, ont donc quatre caractéristiques : le fait de naître de la terre, l'épanouissement (herbam virentem), la reproduction par semence et l'alimentation exclusive des êtres vivants. Le second récit de la Création fait jouer aux plantes un rôle beaucoup plus important. Après avoir créé Adam, Dieu lui «planta un jardin en Eden » où «il fit pousser du sol toute espèce d'arbres séduisants à voir et bons à manger (omne lignum pulchrum visu, et ad vescendum suave) ». L'arbre a ici une image plus positive que l'herbe qui est présente dans ce paradis mais n'est pas nommée. Dans ce récit, deux arbres ont des particularités remarquables: "l'arbre de vie planté au milieu du paradis [lignum vitce in medio paradisi] », dont les fruits rendent immortels ${ }^{60}$, et « l'arbre de la connaissance du bien et du mal ", dont Dieu interdit à Adam et Ève de manger les fruits sous peine de mourir (Gn 2, 8-9 et 16-17). Les plantes - ou plus spécifiquement les arbres - font du paradis, par leur beauté et leurs fruits, un lieu de plaisir (paradisum voluptatis), à charge pour l'homme de s'en occuper et de le garder (ut operaretur et custodiret illum). Après la Chute, provoquée par la consommation du fruit de l'arbre de la connaissance, Adam et Ève n'ont plus accès à l'arbre d'immortalité et une malédiction s'étend sur les plantes pour punir les premiers parents : "Maudit soit le sol à cause de toi ! - déclare Dieu à Adam - À force de peines, tu en tireras subsistance tous les jours de ta vie. Il produira pour toi épines et chardons et tu mangeras l'herbe des champs» (Gn 3, 17-18). Manger l'herbe qui pousse au sol semble ici un signe d'humiliation par rapport à la simple cueillette des fruits des arbres, plantes par excellence du paradis. L'arbre et, plus généralement, les plantes garderont une fonction et un sens fondamentalement vitaux, mais liés, désormais, à la condition devenue mortelle de l'homme, à sa rédemption par le bois de la Croix (avatar par excellence de l'Arbre de vie et de son pouvoir cosmique) et à la promesse d'un accès à un nouveau paradis plus riche encore en arbres. Dans la Jérusalem céleste, en effet, ce ne sera plus un arbre mais « de part et d'autre du fleuve, des arbres de vie qui fructifient douze fois, une fois par mois; et leurs feuilles peuvent guérir les nations $\gg(\mathrm{Ap} \mathrm{22,2})^{61}$.

Dans l'espace et le temps de l'église, lieu matériel du rituel, c'est un végétal abstrait et idéalisé par l'ornatus qui accompagne et soutient aussi l'homme dans la voie - l'iter de la spiritualisation revitalisante, mais il est probable aussi que la végétalisation du chapiteau (et quelquefois de toute la colonne elle-même, comme on en connaît des exemples hors de l'Auvergne) ait aussi soutenu le sentiment que l'église était désormais caractérisée par l'enracinement ou l'implantation dans un lieu (voir l'autel d'Avenas, fig. 2).

Si l'on regarde du côté du vocabulaire, il faut rappeler ici qu'en latin médiéval vegetatio ne désigne pas d'abord ce que nous appelons "végétation ", mais l'activité du principe - âme (anima) ou esprit (spiritus) - qui fait que les créatures végétales, animales et humaines se nourrissent, croissent et se reproduisent; et le verbe correspondant à cette propriété est vegetare. Ainsi Hugues de Saint-Victor pose-t-il qu'un esprit (spiritus) 
constitue « une force occulte de la nature [qui] nourrit et vivifie l'univers (occultam naturce vim... quae universa nutrit et vegetat) $\aleph^{62}$. Et une formule d'Honorius atteste que l'idée d'une anima dotée d'une vertu vitale première que l'homme a en partage avec les végétaux et les animaux est largement répandue : «à un premier degré, sa présence [de l'âme] vivifie le corps (corpus vivificat), elle le conserve par la croissance et la génération, et l'homme a cela en commun avec les arbres et les herbes (homini commune cum arbustis et herbis) ${ }^{63}$. Guillaume de Conches, qui fait de vegetatio une des propriétés essentielles de la «naturalis vigor [qui] est spiritus sanctus » (et qui est inhérente pour lui à une anima mundi créée par Dieu), avance l'expression d'anima vegetabilis au sens (vital) latin ${ }^{64}$. Et comme la végétation, au sens courant, ne possède que cette seule propriété de l'anima, elle est pour lui le modèle par excellence d'un vegetare vital. Ainsi écrit-il : «anima est [...] vegetabilis in herbis et in arboribus, sensibilis in brutis animalibus, rationabilis in homine ${ }^{65}$.

Fig. 16

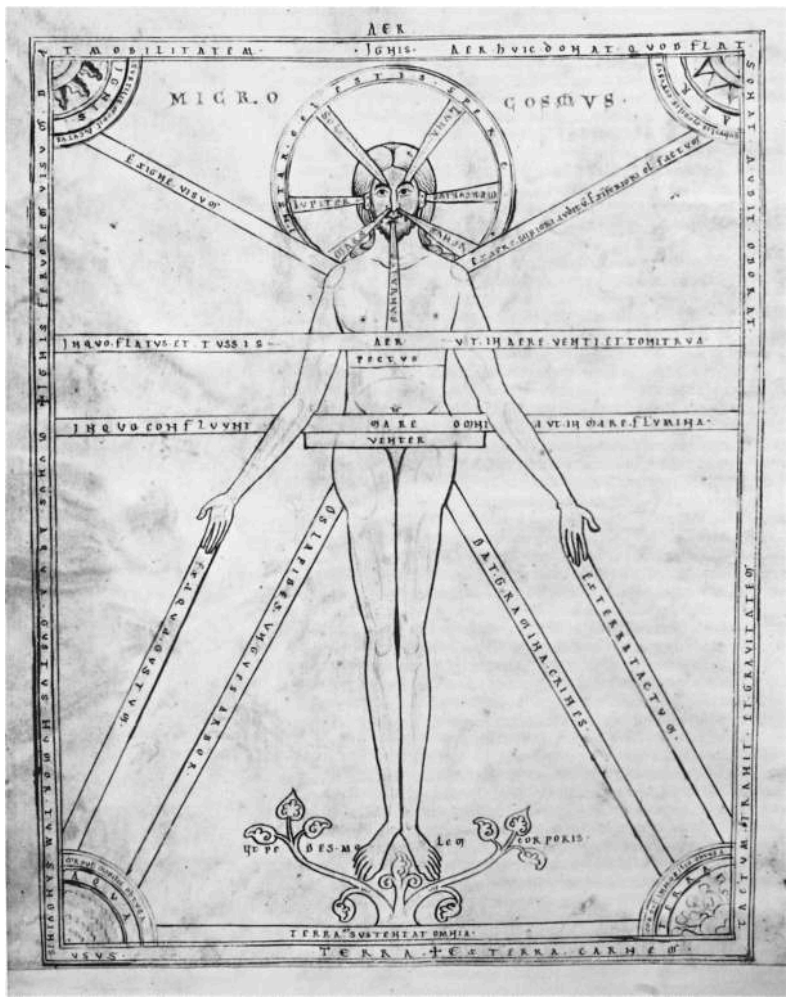

L'homme-microcosme (Munich, Bayerische Staatsbibliothek, Clm 13002, fol. 7 v.; vers 1165)

Mais le modèle végétal est interprétable de deux façons différentes. Il peut servir de simple métaphore pour établir une analogie très schématique entre certaines parties du corps et du végétal, dans la perspective d'une mise en correspondance de l'homme avec le cosmos. Un bon exemple en est donné par un dessin à la plume de l'homme microcosmus dans un manuscrit provenant du monastère de Prüfening, près de Ratisbonne $^{66}$ (fig. 16). On y voit un homme nu dont les ouvertures de la tête sont reliées par sept bandeaux au cercle des planètes, tandis que deux bandeaux transversaux croisent la poitrine et le ventre et que six autres joignent les épaules, les mains et les cuisses aux schémas des quatre éléments situés dans les angles de l'image. Tous ces bandeaux, comme celui qui forme la bordure, portent des inscriptions évoquant les 
éléments, leurs propriétés, leur rapport avec les cinq sens. Les pieds de l'homme reposent sur les branches d'un arbre sommaire associé à l'inscription: "la terre soutient [et/ou nourrit] tout (terra sustentat omnia), comme les pieds, le poids du corps ». Les inscriptions des deux bandes reliant les cuisses aux schémas (placés dans les deux angles inférieurs) de la terre (figurée par des plantes auxquelles son image est traditionnellement associée) et de l'eau mettent plus particulièrement le végétal en rapport avec l'homme: les ongles avec les arbres (ungues arbor) et les cheveux avec les herbes (gramina crines). Ces métaphores sont reprises de l'Elucidarium, qui précise : « Le corps [humain] participe [participium... habet] de la dureté de la pierre par ses os [même idée dans une inscription du dessin], de la vigueur des arbres [vigorem arborum] par ses ongles, de la beauté des herbes [decorem granium] par ses cheveux, et des animaux par ses sens. $\|^{67}$

On distiguera cet analogisme cosmologique de la conception plus substantialiste d'Hildegarde de Bingen qui pose, par-delà l'apparence verdoyante de la végétation, une essence végétale du vegetare ${ }^{68}$. Bien que sa conception savante de la viriditas - dont la notion évoque la verdeur et la vigueur de la végétation - n'ait pas de répondant direct dans l'art roman qui l'a précédé, on l'évoquera en quelques mots, parce qu'elle est très symptomatique d'un sentiment d'affinité fondamentale du végétal avec la vie, dont la médecine de l'époque est un des meilleurs témoins ${ }^{69}$, et parce que son idée d'une viriditas spirituelle, qui pour elle n'est pas purement métaphorique, pourra être transposée au fonctionnement des chapiteaux végétaux qui nous occupent. Certains Pères de l'Église voyaient dans ce qu'ils qualifiaient déjà de viriditas une qualité des plantes, voire même un suc de fécondité (succum feconditatis) ${ }^{70}$, mais ils en avaient surtout fait « une métaphore pour signifier la fécondité des vertus $»^{71}$. Sans ignorer ces références patristiques, ainsi que la signification morale et spirituelle qu'elle donne à cette notion, Hildegarde l'a d'abord reprise d'une ancienne physiologie botanique (qu'on peut reconstituer sur la base de textes qui lui sont postérieurs) ${ }^{72}$, mais, et c'est là son originalité, elle a en précisé et développé la conception en l'étendant à tous les êtres vivants, notamment au corps humain ${ }^{73}$. Elle s'appuyait pour cela sur sa très grande expérience horticole des plantes et de leurs vertus médicinales, elles-mêmes pensées selon les catégories physiques de l'époque. La viriditas apparaît ainsi comme une véritable substance que ses qualités dotent d'un pouvoir vivifiant : c'est une humeur (humor) essentiellement aqueuse mais aussi ignée, tendant à une combinaison, idéalement équilibrée et équilibrante, des qualités (chaud, froid, humide, sec) des quatre éléments. Liée au cycle astronomique et météorologique des saisons (et donc à tout le mécanisme du cosmos), elle remonte de la terre où elle a, pour ainsi dire, fermentée et, sous l'action de l'eau, des vents et du soleil, elle diffuse dans les plantes et les herbes sa vigueur (vis) et sa vertu (virtus). Elle les en nourrit et les fait verdir (virere), fleurir et fructifier, en sorte que le corps humain en est lui-même vivifié et soigné. La pensée d'Hildegarde recoupe ainsi la conception prémoderne de l'univers dont «les concepts de base - les éléments, les qualités, les humeurs - pouvaient être transférés avec succès des plantes à l'homme $\aleph^{74}$. La viriditas d'Hildegarde suppose, à la différence des métaphores d'Honorius, une identité substantielle entre le corps humain et les plantes. Victoria Sweet en déduit que la notion implique "une continuité et une similarité entre la terre, les plantes [qui en poussent], les animaux et les hommes $»^{75}$. On en retiendra plutôt que tous les êtres (sensibles et insensibles) sont faits des mêmes éléments - ce qui assure en effet une continuité entre eux -, mais les combinaisons de ces éléments dans des proportions infiniment variables font les différences de nature 
entre ces êtres - on ne peut donc parler de similarité proprement dite entre eux. Le système a même pour fonction de rendre compte aussi subtilement qu'il lui est possible de leurs différences. Si pour Grégoire le Grand, viriditas était le nom de la vie végétale ${ }^{76}$, elle devient, pour Hildegarde, le nom végétal de la vie. Elle résulte, certes, de l'action conjuguée de l'élément igné et de l'élément aqueux concentrés dans les cercles supérieur et intermédiaire de la sphère céleste, d'où son humeur aqueuse "irrigue tous les autres cercles $\aleph^{77}$. Toutefois, cette sphère, Dieu l'a créée conformément à sa nature, laquelle est comparable à un cercle parfait et à un feu mystérieux ${ }^{78}$. De la sphère céleste, elle se répand sur la terre où "chaleur du soleil et humeur aqueuse se conjuguent et se mêlent dans les nuages pour régler et affermir la fructification ». L'âme (anima) elle-même est dans l'homme le souffle de vie (spiraculum vitce) humide (et chaud) que Dieu a infusé dans tout le corps pour que la partie rationnelle ignée (igneam rationalitatem animce) lui commande ${ }^{79}$. Aussi n'est-il pas étonnant que l'anima de l'homme soit qualifiée de viriditas corporis. La viriditas a donc une nature ambiguë chez Hildegarde, non par défaut de pensée mais, au contraire, en raison de la nature de ce qu'elle cherche à penser. Le spiramentum qu'elle accorde à l'âme répond à une tentative pour penser le rapport - dans l'impossible identité de nature entre le Créateur et la créature, comme entre l'âme et le corps - entre souffle de vie (humidum) et souffle de l'Esprit (ignis occultus). La notion de viriditas se situe donc chez Hildegarde aux limites de l'orthodoxie chrétienne, qui maintient une césure entre le corps et l'âme : il ne faut donc pas la prendre comme représentative de la pensée de cette époque mais plutôt comme symptomatique de l'effort du $\mathrm{XII}^{\mathrm{e}}$ siècle pour penser, sur un mode végétal à la fois empirique, botanique, médicinal, physico-cosmologique et théologique, une spiritualisation vitale du corporel.

\section{Ornementalité végétale et vitalité de l'ordre divin}

51 C'est une opération et une pensée de ce genre qui est à l'œuvre, mais transposée, dans le décor des chapiteaux végétaux. Leur viriditas n'est pas celle d'une végétation terrestre; elle est celle d'une végétalité produite pour rendre sensible et honorer par son decor et son decus une vitalité spirituelle qui habite l'église matérielle et qu'elle diffuse à travers elle comme la transversalité d'un principe (re)vitalisant - articulant une vitalité sensible ( $d$ 'après la Chute) et une vitalité spirituelle d'après l'Incarnation rédemptrice. 
Fig. 17

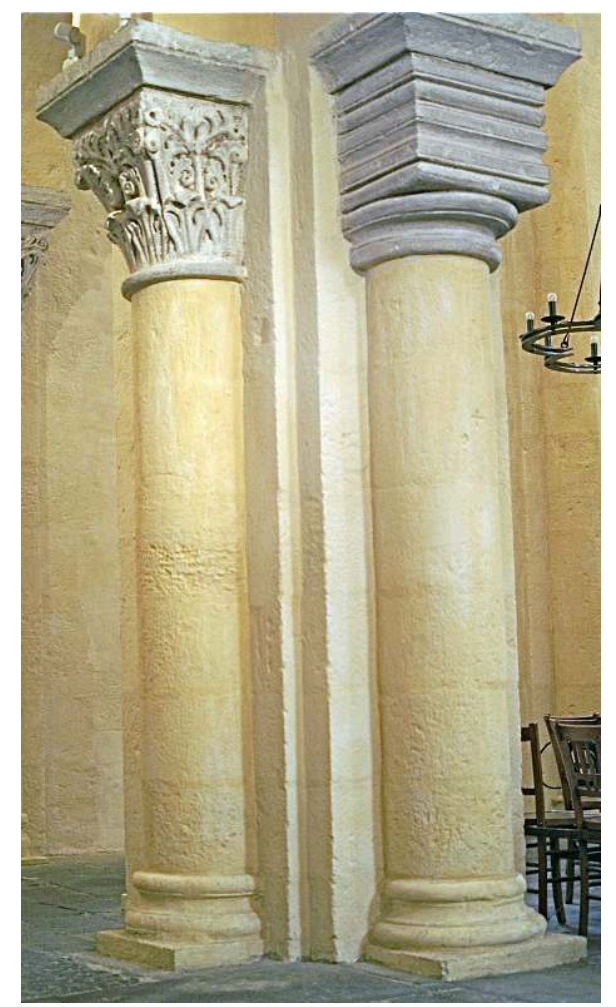

De la base à l'antique de la colonne à son « chapiteau-base » et de celui-ci au chapiteau végétal (SaintNectaire)

La végétalité ornementale prend, en réalité, le relais d'un processus engagé sous forme initialement minérale dans le narthex de trois des églises de notre corpus, sous les espèces de ce qu'on a appelé des chapiteaux-bases ${ }^{80}$. Ces chapiteaux marquent en effet la sublimation de la base (antique) ${ }^{81}$ de la colonne (plus exactement de la demi-colonne engagée d'une pile), par élévation au sommet de celle-ci, par retournement et esthétisation fondée sur l'amplification du jeu de la modénature. Ce dispositif, luimême placé à un point d'articulation fondamental de l'architecture, vaut déjà célébration du principe de mutation du lieu matériel en un lieu plus éminent, plus noble qu'un simple bâtiment matériel, parce que sacré (au sens qu'on a dit). Le processus de spiritualisation de l'église commence donc, dans ces chapiteaux, sous la forme d'un ornatus propre à la puissance de la pierre en tant qu'architecturée. La nudité et la sévérité purement architectoniques de la base et du chapiteau-base confèrent par contraste une force particulière au déploiement de la végétalité dans le reste de l'édifice. De même, la stricte horizontalité de la modénature de ces chapiteaux donne toute sa force au dispositif du caulicole, avec sa tige raide couronnée d'une collerette, qui se donne à la fois comme un prolongement, une réplique et une animation végétale de la colonne et de son chapiteau dans le chapiteau.

La végétalisation des chapiteaux n'est pas une décoration autonome, surimposée à l'architecture et qui lui resterait extrinsèque. Elle ne relève pas de l'art appliqué et son fonctionnement n'est ni local ni individuel. Elle est à la fois l'expression d'un changement d'ordre de réalité du bâtiment de pierre, qui est élevé à un degré de réalité supérieure et plus noble; et elle rend sensible cette nouvelle réalité comme un principe de vie animant l'architecture. Le végétal n'existe qu'en tant que vecteur 
métaphoriquement sensible et anagogiquement spirituel de cette vitalité qu'il diffuse à travers tout l'édifice. Il n'a donc aucune substantialité formelle ni identité propre : ce n'est pas une végétation. La végétalité est l'expression de surface de la force plastique de la continuitas $\mathrm{du}$ principe vital sous-jacent en une varietas perpétuellement différenciante qu'il anime pour qu'elle anime l'architecture. C'est pourquoi l'artificialité, l'inorganicité, la labilité des formes, l'hétérogénéité même de la végétalité ornementale par rapport à la végétation naturelle, que l'on a soulignées, loin d'être un obstacle à cette vitalisation spirituelle des églises et de ceux qui viennent y prier, en est à la fois un puissant vecteur sensible et une condition substantielle, donc efficiente.

Fig. 18
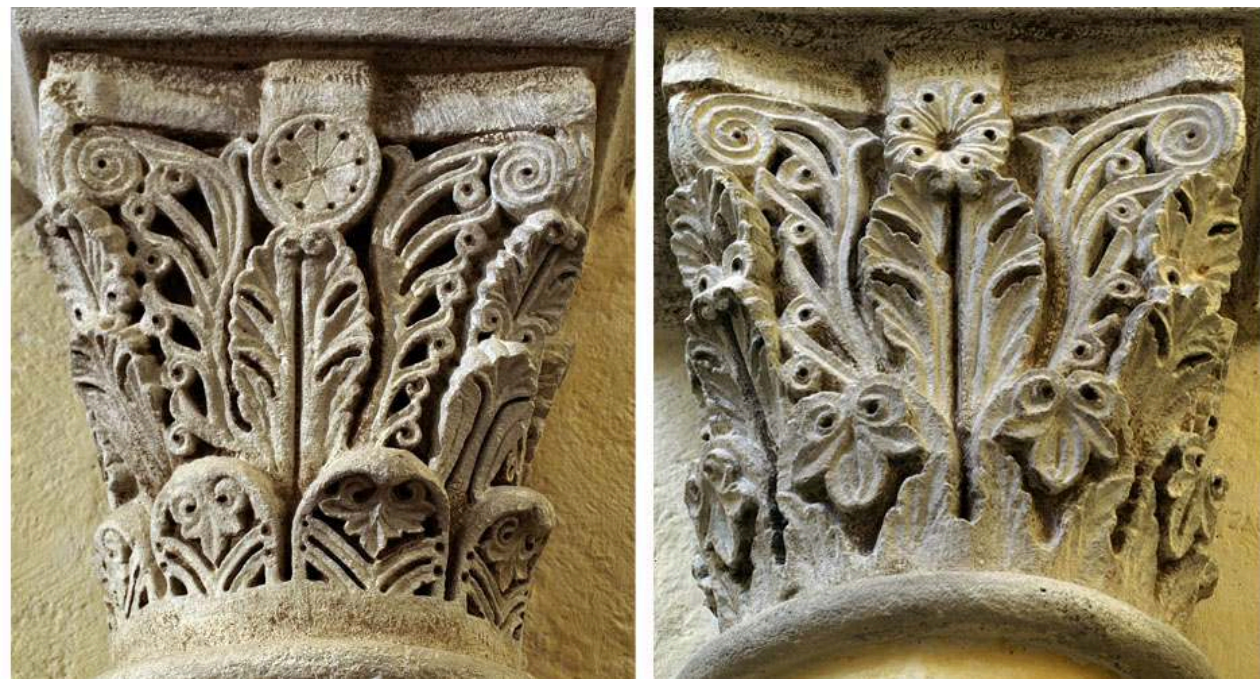

L'itération comme variation différenciante (chapiteaux de Notre-Dame-du-Port)

Fig. 19
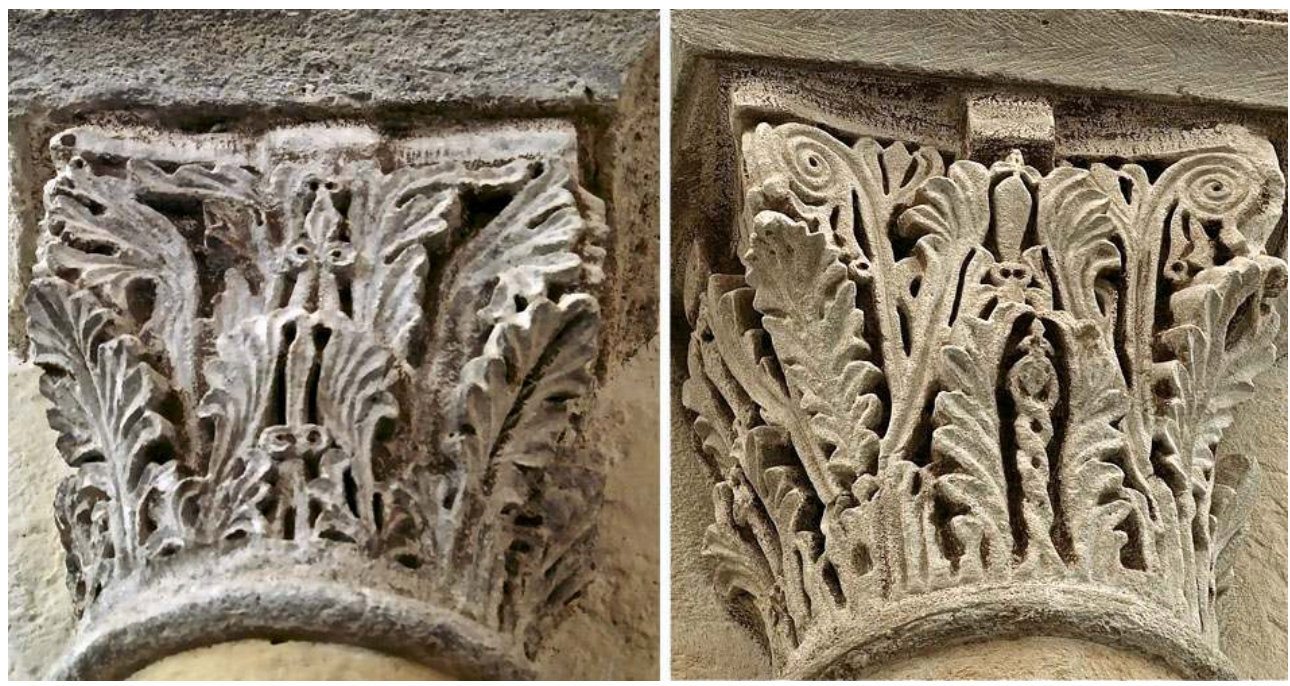

L'emprunt d'un fragment de signe pour raboutage avec un élément différent (Notre-Dame-du-Port)

A la différence d'un chapiteau thématique, un chapiteau végétal n'a par lui-même aucune signification, ni symbolisme (sauf naturellement par association avec une figure). Leur succession ne répond pas à un plan ou à un programme de bout en bout 
unitaire. Elle se fait d'une façon ouverte, semi-aléatoire mais pas quelconque. Elle est soumise à un ordre qui n'est empiriquement ni continu ni déterminé. C'est un mixte d'itération et d'émission de singularité - un devenir qui n'écrit pas une histoire mais qui scande le locus et stimule l'iter. Il y a alternance entre des couplages partiels ou complets (les paires) et un chaînage entre des chapiteaux hétérogènes mais qui s'empruntent des morceaux de code (comme des morceaux de caulicole, des types de digitation ou des façons de volutes), tout en les remodelant et en les combinant autrement avec de nouveaux éléments qui susciteront de nouvelles greffes partielles sur d'autres bifurcations. Le système est en perpétuelle transformation: l'ordo de chaque chapiteau se voit débordé par le jeu de la variété, mais il y a ré-enchaînement sous l'effet et l'énergie du flux transversal - une continuitas invisible - qui passe pardessus les coupures et saute les discontinuités attestant la fécondité du principe et son inépuisabilité ou sa variabilité (le développement peut être donc compliqué à souhait comme à Notre-Dame-du-Port ou simplifié comme à Saint-Nectaire). C'est seulement au niveau des grands ensembles, à l'échelle de l'église, que la distribution des chapiteaux végétaux prend un sens différencié et différenciant.

La fonction par excellence de chaînage et d'unification de la végétalité s'exprime d'une façon remarquable quand elle se met en abyme dans un chapiteau en couplant du végétal avec des entrelacs qui n'ont rien de végétal (nombreux et importants exemples à Notre-Dame-du-Port). Il n'y a pas de "monde» végétal (pas de figuration d'une végétation spécifique) dans les chapiteaux végétaux, la végétalité est l'entre-dumonde : à la fois milieu qualifiant pour ce qui se déploie dans l'église et flux transversal où se joue, dans sa vitalité, l'entre-deux du matériel et du spirituel.

Nous avons considéré jusqu'ici l'ornementalité végétale dans sa plus grande généralité, en relevant seulement au passage qu'elle s'hybride avec d'autres êtres vivants (animaux et même humains) pour leur transmettre à la fois son ornatus et sa vitalité. Il lui arrive aussi de s'hybrider, sous des formes qui ne sont plus seulement celles d'une vitalisation spiritualisante, avec des figures anthropomorphes, pour incarner les forces vitales de la création. Ces questions qui concernent aussi d'une façon essentielle la végétalité seront traitées plus loin, mais il nous faut d'abord analyser les figures de l'animalité.

\section{Animalités}

L'animal joue un rôle de premier plan dans la sculpture romane : la présence massive des bêtes sur les chapiteaux, jusque dans les parties les plus honorées des églises, est l'une des caractéristiques fortes de ce moment historique. Cette profusion contribue sans doute au sentiment d'étrangeté et à l'aura attachés à ces édifices, et elle est effectivement surprenante dans la mesure où le christianisme s'est largement distingué des religions juives et romaines par l'exclusion presque totale de l'animal du champ religieux, et spécialement des rituels. En écartant les interdits alimentaires et la pratique du sacrifice sanglant, la religion du Christ semblait abandonner l'animal au monde profane et ne lui accorder qu'une importance très secondaire ${ }^{82}$. Cependant, et la chose ne cesse d'interroger les chercheurs, en dépit de ce désintérêt théorique et cultuel pour les bêtes, leur représentation connaît une diffusion remarquable dans les lieux de culte. Comment comprendre ce paradoxe?

Une première façon de répondre est de faire appel au symbolisme: les animaux présents sur les chapiteaux seraient des symboles, des idées morales diffusées par un 
ouvrage à l'autorité prestigieuse : le Bestiaire. Cette hypothèse, reprise indéfiniment dans les (mauvais) ouvrages de vulgarisation, doit aujourd'hui être abandonnée. Il y a un siècle déjà, Émile Mâle montrait avec pertinence que les représentations des bestiaires et celles des églises ne correspondaient absolument pas ${ }^{83}$. D'une part, les bestiaires regorgent d'animaux exotiques (comme la leucrote) ou quotidiens (la fourmi) qu'on ne rencontre jamais dans la sculpture; de l'autre, de nombreuses figures présentes sur les chapiteaux ne sont pas clairement identifiables en tant qu'espèces et ne correspondent à rien dans le Bestiaire. Plutôt que de chercher dans ce texte la raison des images, Émile Mâle conseillait de se tourner vers l'Elucidarium, texte extrêmement diffusé de vulgarisation du message chrétien ${ }^{84}$. Il ne saurait être question de remplacer un texte par un autre pour trouver une explication globale à toutes ces images, mais l'intuition n'est pas mauvaise: c'est bien dans ce genre d'écrits, qui précisent didactiquement le rôle des différents êtres au sein de la création, que l'on trouvera les meilleurs pistes pour comprendre les images animales.

\section{L'animal dans la création}

Les formes de vie animale possèdent une singularité: elles occupent une place prépondérante dans l'évocation de la vie paradisiaque d'avant la Chute, ce qui offre de précieux renseignements sur les critères de l'animalité idéale dans le mythe chrétien. Dans le premier récit de la Création (Gn 1), les plantes sont créées le troisième jour, les oiseaux et les poissons le cinquième (ils sont littéralement qualifiés "d'âmes vivantes ", animam viventem), les animaux terrestres ainsi que l'homme étant créés le sixième jour. Cette première classification témoigne d'emblée de la proximité des animaux terrestres avec l'homme et du caractère intermédiaire des oiseaux (et des poissons), qui se trouvent situés entre le végétal et les autres créatures. A la fin de ce récit, Dieu révèle à l'homme le rôle qu'il doit tenir et qui concerne largement le monde animal : «Soyez féconds, multipliez, remplissez la terre, et soumettez-la ; et dominez sur les poissons de la mer, sur les oiseaux du ciel, et sur tout animal qui se meut sur la terre. $»^{85} \mathrm{Si} \mathrm{l'on} \mathrm{ne}$ devait retenir qu'une phrase pour qualifier le mythe chrétien du rapport homme/ animal, c'est à n'en pas douter celle-ci qui serait la plus représentative. On verra à partir de nos exemples auvergnats à quel point la question de la domination est centrale pour la compréhension des chapiteaux animaliers. Le second récit de la Création est plus prolixe (Gn 2, 1-20) sur le rôle idéal que l'animal doit jouer au sein de l'univers créé. Contrastant avec la violence hiérarchique du premier récit, il confère aux créatures un rôle de soutien affectif pour l'homme. Dans ce monde parfait où les humains ne travaillent pas, vivent nus et suivent un régime végétarien ${ }^{86}$, l'animal ne fournit aucune assistance matérielle. De fait, c'est littéralement pour pallier la solitude d'Adam que les animaux sont créés ${ }^{87}$. Dans ce récit, l'animal est créé - au même titre que la femme - après l'homme et pour lui : sa présence ne se pense qu'en fonction et à partir de l'homme.

La relation idéale entre l'homme et l'animal se manifeste ensuite dans une scène clé, celle de la nomination. En donnant un nom à chacun des animaux (et non aux végétaux), Adam s'engage dans une action à la fois classificatrice et hiérarchisante. Le fait que toutes les créatures qui le pouvaient répondent à son appel montre que le règne du premier homme sur la faune est total, et que sa domination s'étend jusqu'aux espèces ensuite réputées les plus violentes et sauvages ${ }^{88}$. Cette animalité paradisiaque des premiers versets de la Bible offre une ressource de poids pour l'exégèse qui 
l'institua comme un puissant modèle de la domination, susceptible d'être utilisé pour naturaliser les hiérarchies les plus ordinaires entre humains (entre les groupes sociaux, entre l'homme et la femme, etc.) ${ }^{89}$. Elle fournit aussi un modèle de vie pour l'hagiographie, et l'on ne compte pas le nombre de saints qui, à l'instar de Jérôme et de son lion, entretiennent des rapports de sympathie avec les bêtes les plus agressives.

61 L'écart entre ce passé mythique et la violence des relations homme/animal dans un quotidien où l'on exploite sans retenue les bêtes pour l'alimentation, la traction ou la fabrication d'objets est unanimement interprété comme une conséquence du Péché et de la Chute. A la suite de cette dernière, l'homme se voit en effet contraint de tuer les animaux pour manger et se vêtir (usage dont l'épisode du don des tuniques de peau par Dieu est l'expression).

Plus important pour nos images, les animaux eux-mêmes sont modifiés par la Chute et se divisent désormais en deux catégories. A la suite d'Augustin, Isidore propose une répartition largement reprise au cours du Moyen Âge. Le premier groupe, qualifié de pecus, regroupe les animaux domestiques, exploités par l'homme, ou qui par leur soutien et leur soumission sont restés fidèles au modèle adamique ${ }^{90}$. L'autre groupe est constitué par les bestiae et rassemble les créatures sauvages, agressives envers l'homme, qui contestent son autorité et constituent une menace qui ne saurait être seulement physique ${ }^{91}$. L'usage de ces deux catégories, pecus et bestia, traverse tout le champ social, les discours moraux, mais aussi les pratiques (les bestiae sont réputées incomestibles). Dans le champ des représentations, elles composent une opposition paradigmatique dans laquelle le pecus tient le pôle positif de l'animal soumis à l'homme, parfaitement incarné par la figure de l'agneau. A celui-ci, s'oppose la bête, l'animal carnassier, qui s'impose jusque dans l'Apocalypse comme une incarnation du Mal (le terme de bête sera dans notre texte toujours utilisé dans ce sens fort). De manière générale, les différentes catégories utilisées dans la Bible et l'exégèse (oiseau, poisson, pecus, bestia, vermines) sont plus pertinentes pour la période qui nous concerne que le terme animal. Celui-ci est alors un vocable technique qui désigne la faculté d'animation d'une créature, et englobe presque toujours l'humain. De fait, l'animal au sens moderne (c'est-à-dire tous les êtres animés sauf l'homme) n'existe pratiquement pas avant le XIII ${ }^{\mathrm{e}}$ siècle ${ }^{92}$.

\section{Entre morale et ornement}

Comment la présence des bêtes nuisibles sur terre était-elle perçue autour des années 1100 ? Sans prétendre épuiser cette délicate question, il convient tout d'abord de rappeler la sentence augustinienne, constamment reprise, qui veut que « les animaux nuisibles s'attaquent aux hommes vivants pour les punir, les poursuivent pour leur salut, les éprouvent pour leur bien, les instruisent à leur insu. $»^{93}$ Pour sévère qu'il paraisse, ce rôle moral des nuisibles ne peut pourtant se penser en dehors du cadre d'une création heureuse. Bien qu'ils soient parfois des acteurs du châtiment autant que les diables, les animaux n'atteignent cependant jamais un tel degré de négativité et ils continuent de participer de la beauté de la création. Dans l'Elucidarium, si cher à E. Mâle, et précisément dans le passage déjà cité à propos de la végétalité, le maître rassure le novice et cherche à le convaincre que tous les animaux (jusqu'aux mouches et aux moustiques) concourent à la louange et à la gloire de Dieu. Pour qui sait percevoir le rôle qu'ils jouent, c'est une délectation, puisque dans l'ensemble des êtres de la création, «il y a de la beauté (decor), comme dans les fleurs, dans d'autres, des 
remèdes (medicina), comme dans les herbes, dans certains, de la nourriture (pascus), comme dans les produits de la terre, dans d'autres, de la signification (significatio), comme dans les vers et les oiseaux ${ }^{94}$. De fait, l'animal s'inscrit toujours dans cette tension entre sa fonction morale, indissociable de la Chute, et sa fonction d'ornement de la création qu'il continue à partager avec le reste de celle-ci. Tel est probablement l'enjeu figuratif auquel essaient de répondre les chapiteaux animaliers des églises d'Auvergne.

Pratiquement, le discours moral suit des règles bien précises qu'il convient de définir, ce qui implique de se déprendre de l'influence du Bestiaire. Trop longtemps, les historiens ont persévéré dans l'infructueuse quête de comportements types qualifiant telle ou telle espèce animale. De fait, la stricte logique symbolique des bestiaires suit une séquence que l'on peut synthétiser ainsi : image = un oiseau se déchire le ventre $\rightarrow$ identification $=$ le pélican donne sa chair à ses petits $\rightarrow$ moralisation $=$ la charité. $\mathrm{Ce}$ type de séquence, qui suppose des représentations standardisées afin que le code symbolique soit reconnu, ne se rencontre pour ainsi dire jamais dans nos chapiteaux. Bien au contraire, les images d'animaux présentent une variété de comportements et d'associations tout à fait remarquable. L'historien se trouve alors confronté à une inventivité formelle qu'il est indispensable de prendre en compte, sans chercher à la rabattre sur de lointains modèles standardisés. D'ailleurs, l'identification même des espèces animales est généralement impossible, pour peu que l'on fasse preuve de rigueur. Il est alors plus prudent et plus juste de prendre acte de l'indétermination de ces figures dont, le plus souvent, rien ne nous permet d'affirmer qu'elles représentent, par exemple, un chien ou un loup. Dans la plupart des cas, la notion d'espèce s'avère aussi peu pertinente pour l'analyse de l'animalité qu'elle l'est pour la compréhension du monde végétal. En somme, même lorsqu'elles sont identifiables, ce ne sont pas les espèces qui sont signifiantes, mais plutôt les grandes catégories génériques (oiseaux, pecus, bestia...). Plus encore, ce n'est pas tant la nature de l'animal en lui-même qui est signifiante, mais bien plutôt le rapport dans lequel il est engagé. Dès lors, de nombreuses scènes dont l'identification reste douteuse tant que l'on raisonne en termes d'espèces peuvent, sur une autre base, faire l'objet d'une analyse féconde : peu importe, par exemple, de savoir si tel chapiteau de Chanteuges représente un homme tenant par le cou des loups, des ours ou des lions (fig. 23). En effet, ces trois possibilités renvoient à une même catégorie générique, à partir de laquelle il est possible de mettre en évidence un rapport - « un homme contrôle des bêtes » - qui constitue l'enjeu même de l'image : cet homme, en recouvrant la domination de l'homme sur le monde sauvage, restaure une part de la dignité que l'humanité avait perdue lors de la Chute.

\section{L'animalité ornementale des oiseaux et des « merveilles »}

65 Avant d'entamer l'analyse générale des interactions homme/animal, il est nécessaire de mentionner certaines espèces particulières, justement parce qu'elles ne rentrent pas totalement dans la conception générique des animalités décrite précédemment. C'est tout d'abord le cas des oiseaux, qui sont globalement l'objet d'une qualification très positive dans la société médiévale. Parce qu'ils évoluent entre le monde terrestre et le monde céleste, ces créatures s'imposent comme des médiateurs entre le matériel et le spirituel ${ }^{95}$. L'une des sentences bibliques les plus citées à leur endroit est : « regardez les oiseaux du ciel, qui ne sèment point, qui ne moissonnent point, qui n'amassent point dans les greniers, et votre Père céleste les nourrit » (Mt 6, 26). Le mode de vie 
idéal de ces créatures, sans travail et sans souffrance, leur confère - plus encore qu'au pecus - le statut de traces de la vie irénique d'avant la Chute. Surtout, les oiseaux incarnent, mieux encore que les autres animaux, la fonction d'ornement du monde que leur attribue la Genèse, comme en témoigne l'abondante production littéraire qui met en scène des poètes cherchant à s'inspirer et à reproduire le chant des oiseaux dans les jardins élégiaques de la reverdie ${ }^{96}$. Les liens très fort qui les associent à l'ornatus et au monde céleste expliquent la sympathie de l'institution ecclésiale à leur égard, laquelle ira jusqu'à autoriser la fauconnerie pour les jeunes moines, et tolérera dans les chapelles de ses églises la présence de cages à oiseaux dont l'entretien est assuré par les novices ${ }^{97}$. La présence réglementée au sein de l'église d'un animal vivant est suffisamment rare pour marquer le statut d'exception de ces créatures. Pour toutes ces raisons, et parce que les images d'oiseaux se donnent à voir comme de pures présences, souvent non agissantes, cet animal nous semble devoir être traité sur un plan très proche de celui du végétal, avec lequel il est extrêmement lié et même très souvent hybridé. C'est sur le mode d'une présence ornementale (au sens fort), au sein de l'édifice, que doivent se penser les images de ces créatures.

Parmi les oiseaux, une espèce doit faire l'objet d'un traitement particulier. Il s'agit de l'aigle, dont les apparitions sont tout à fait singulières. Cet animal, présent à plusieurs reprises à Mozat et Brioude et surtout à Orcival (où on le rencontre à 22 reprises), est l'un des plus fréquemment représenté dans les églises d'Auvergne : parce qu'il est le plus prestigieux des oiseaux ${ }^{98}$, et peut-être parce qu'il évoque les figures romaines de l'aigle impérial, sa représentation possède une positivité intrinsèque - une positivité qui n'est pas morale, mais relève plutôt de l'évocation d'un passé glorieux, de l'appropriation d'une image prestigieuse issue d'une Antiquité dont les restes foisonnaient dans la région.

67 Il est indispensable d'associer le griffon à ce groupe d'animaux singuliers. Constitué d'éléments de deux animaux particulièrement honorables - le lion et l'aigle -, son aura est indéniable, et peut d'ailleurs être rapprochée de celle de l'aigle : le griffon bénéficie lui aussi du prestige d'une tradition pluri-séculaire dont les sarcophages gallo-romains, autant que les précieux textiles venus d'Orient, perpétuent la mémoire. De fait, l'image des deux griffons affrontés existe comme un motif à part entière dans un large cadre eurasien et fonctionne très fréquemment sur un mode ornemental. Dans le contexte roman et auvergnat, ce motif est re-sémantisé par la présence d'un calice qui l'associe à l'eucharistie ${ }^{99}$.

Dans nos chapiteaux, les oiseaux autant que les griffons n'interagissent pratiquement jamais avec l'humain ${ }^{100}$ et leur mode de représentation se singularise par un niveau de standardisation très élevé ${ }^{101}$. Il convient en fait d'admettre que ces images possèdent une dynamique propre et ne peuvent s'appréhender à partir des règles qui régissent par ailleurs la représentation animale. Enfin, relevons que cet usage ornemental de l'animalité qui, on va le voir, passe souvent par une végétalisation, concerne également les autres créatures « merveilleuses » que sont les « centaures » et les « sirènes » ${ }^{102}$.

\section{Interactions I. De la coopération à la domination}

L'inventaire exhaustif des animaux présents dans notre corpus révèle une animalité assez limitée en nombre et en variété103. D'un point de vue strictement numérique, on est loin, par exemple, de la faune proliférante des églises de Saintonge. Mais c'est 
surtout la faible diversité de ce bestiaire qui doit être relevé : sur les centaines de chapiteaux de notre corpus, seule une petite vingtaine de créatures animales différentes est repérable ${ }^{104}$, ce qui est très peu, tant par comparaison avec la littérature savante de cette époque, qu'avec les espèces présentes dans l'horizon visuel quotidien $\mathrm{du} \mathrm{XI}^{\mathrm{e}}$ siècle. Cette faible diversité est la première conséquence de l'usage massif des catégories génériques que nous avons relevé précédemment. On notera d'ailleurs que les rares espèces que l'on parvient à identifier sont loin de rappeler l'expérience ordinaire que l'on pouvait avoir de l'animal : ainsi, les créatures les plus consommées (comme le cochon et le bœuf) n'apparaissent pratiquement jamais dans les églises d'Auvergne. Tout en refusant une logique strictement symbolique, le traitement de l'animalité dans ces chapiteaux est aussi éloigné que possible d'une préoccupation réaliste. Comment dès lors qualifier la présence des animaux dans ces édifices ? Le caractère récurrent des figures représentées contraste avec la richesse et la variété des situations dans lesquelles elles sont engagées. C'est par l'analyse de ces situations que se révèlent le mieux les enjeux et les partis-pris que ces images assument dans les églises considérées.

Fig. 20

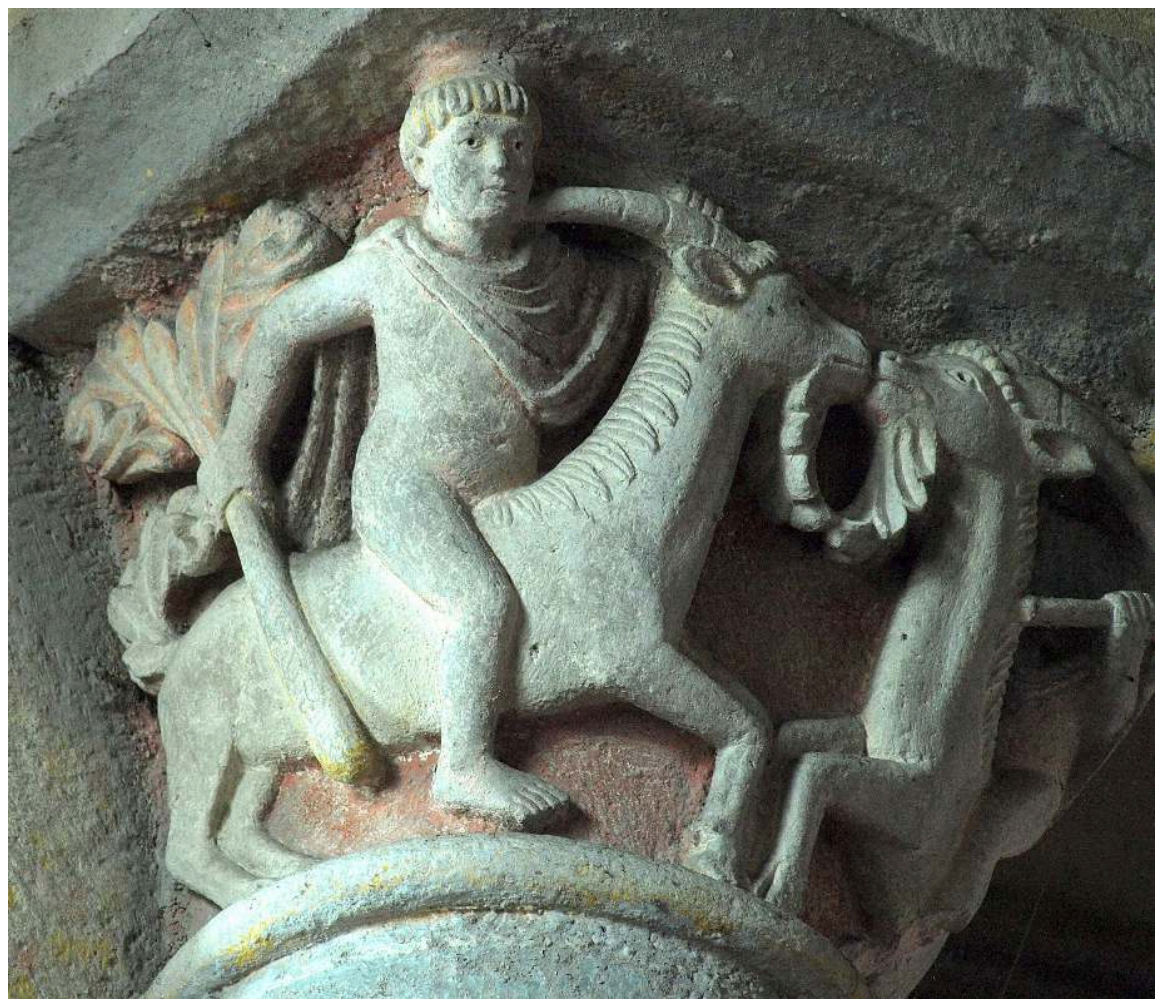

Hommes chevauchant des boucs (Mozat)

Une première série d'images met en scène des rapports de collaboration ou d'entraide entre l'homme et les animaux. Il s'agit d'images comportant des animaux faisant l'objet d'usages ordinaires (même si les situations, en l'occurrence ne le sont pas) : cheval du cavalier de l'Apocalypse ou poissons de la Multiplication des pains. Ces créatures sont entièrement réifiées et ne jouent pas de rôle véritablement spécifique. Bien plus troublantes sont les sculptures qui manifestent une intimité entre les êtres vivants. Elles sont particulièrement présentes à Mozat, où la création est traitée sous un jour 
très positif. Ici, des hommes quasi-nus montent à cru, se passant du moindre équipement pour utiliser leurs montures (fig. 20) ${ }^{105}$.

Fig. 21

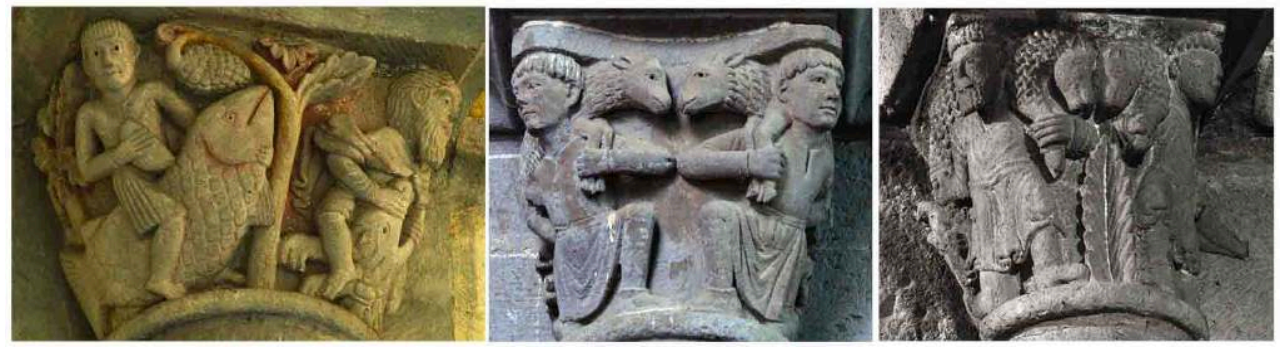

Coopération entre homme et animaux (Mozat, Chanteuges, Orcival)

71 Ailleurs, c'est l'animal qui vient spontanément au secours et au service de l'homme, comme en témoigne l'image possible du dauphin sauvant Arion de la noyade (fig. 21). A ces figures de la complicité entre les espèces, on ajoutera celles des porteurs de moutons de Chanteuges et Orcival (fig. 21), où la référence au «bon pasteur ", évoque un des versets les plus soucieux de l'animal dans un corpus évangélique qui l'est globalement très peu: "Je suis le bon berger. Je connais mes brebis, et elles me connaissent, comme le Père me connaît et comme je connais le Père ; et je donne ma vie pour mes brebis. " L'image de ces bergers portant sur leurs épaules leurs chères brebis est à rapprocher de celle des hommes nus sur les boucs (fig. 20) : toutes deux évoquent une coopération heureuse avec l'animal qui s'exprime par un contact physique direct. Si l'interprétation chrétienne de ces images est parfaitement possible (dans le cadre des relations de domination entre l'homme et le pecus), force est de constater que ce type d'interaction fait souvent appel à un répertoire où les modèles tardo-antiques sont nombreux. La figure de Mercure, dont le culte avait été important dans la région, était positivement associé au bouc et à l'agneau (sous la forme de Mercure enfant chevauchant l'animal ou du dieu adulte le portant sur ses épaules : c'est la tradition de l'Hermès cryophore $)^{106}$. De fait, certaines de ces images de collaboration sont présentes dans les deux édifices dont les liens avec le répertoire antique sont les plus forts, Mozat et Chanteuges. 
Fig. 22

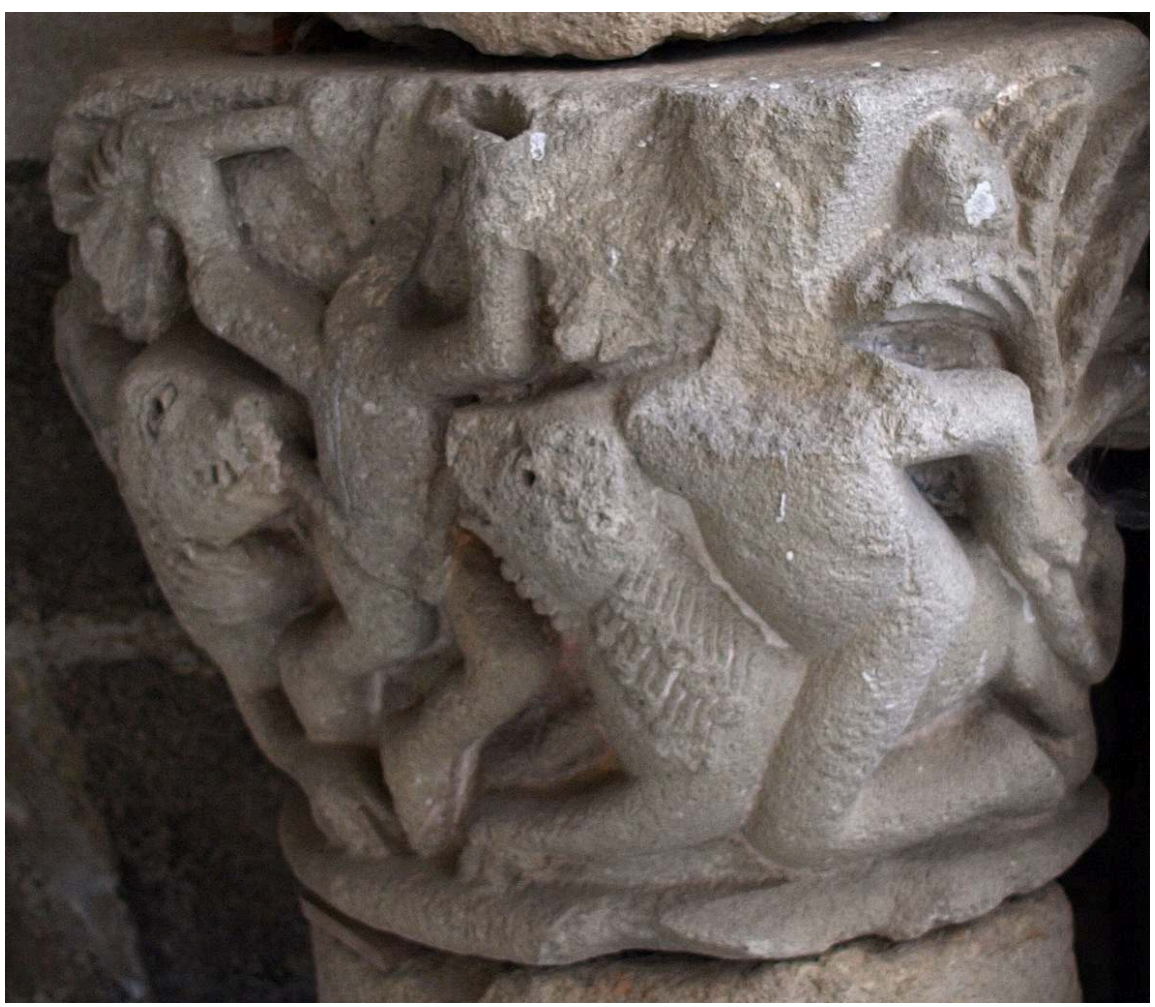

Hommes nus chevauchant des fauves, avec une figure centrale (Mozat)

72 Si cette intimité de l'homme avec les animaux domestiques est parfois troublante, les images le mettant en relation positive avec des animaux normalement sauvages le sont encore plus. Nous sommes ici confrontés à toute une gamme de relations allant de la coopération à la domination. C'est ainsi qu'à Mozat, des hommes nus chevauchent des bêtes (fig. 22). Cette image curieuse, qui n'échappe pas à une certaine ambiguïté, peut être vue de manière positive: de par sa construction symétrique, son absence de narration et de référents textuels, de par aussi le lien très fort qu'elle entretient avec le végétal (les lions « crachent » des rinceaux), son mode de figuration est très proche des hybridations végétales qui viennent ornementaliser le monde créé (on y reviendra plus loin). La relation entre l'homme et la bête que suppose ce chapiteau est quasiparadisiaque dans la mesure où une telle domination sur les fauves était l'une des prérogatives d'Adam avant la Chute. Nulle violence ici, mais une intimité rendue possible par une hiérarchie ferme: l'homme, qui tient la bête sous le cou et par la queue, manifeste qu'il la maîtrise totalement. 
Fig. 23

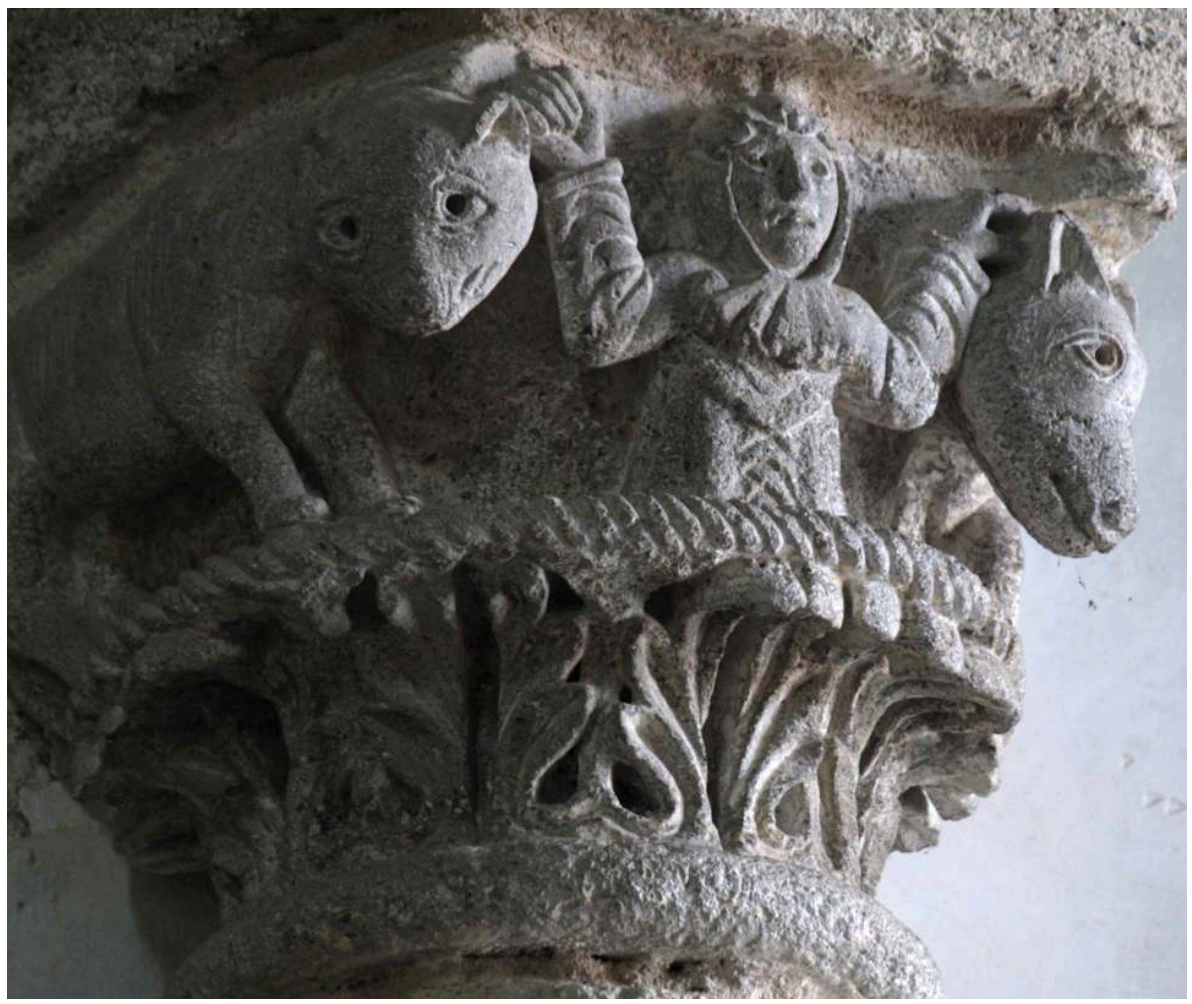

Homme dominant des bêtes (Chanteuges)

73 La domination sur l'animalité sauvage se rencontre également à Chanteuges, mais traitée sur un mode plus actualisé, mettant en scène des personnages non plus nus, mais vêtus des habits du siècle. C'est le cas d'un chapiteau très étrange mettant en scène un homme tenant deux bêtes sauvages par l'encolure (fig. 23). L'échine basse des bêtes laisse peu de doute sur leur soumission à l'homme, qui semble ici moins optimiste qu'à Mozat (où les forces animales étaient exprimées avec vigueur). Dans le proche voisinage de cette image, se rencontre un saint, qui est peut-être Marcellin, protégeant son navire des attaques de deux griffons. Ici, la domination ne peut plus être confondue avec une coopération, et doit se comprendre comme le résultat d'un rapport de force et d'une opposition diamétrale entre les puissances propres au saint et celles qui sont propres aux bêtes. C'est alors l'exceptionnalité de l'humain - sa sainteté - qui permet de contrôler le désordre instauré à la suite du Péché. 
Fig. 24

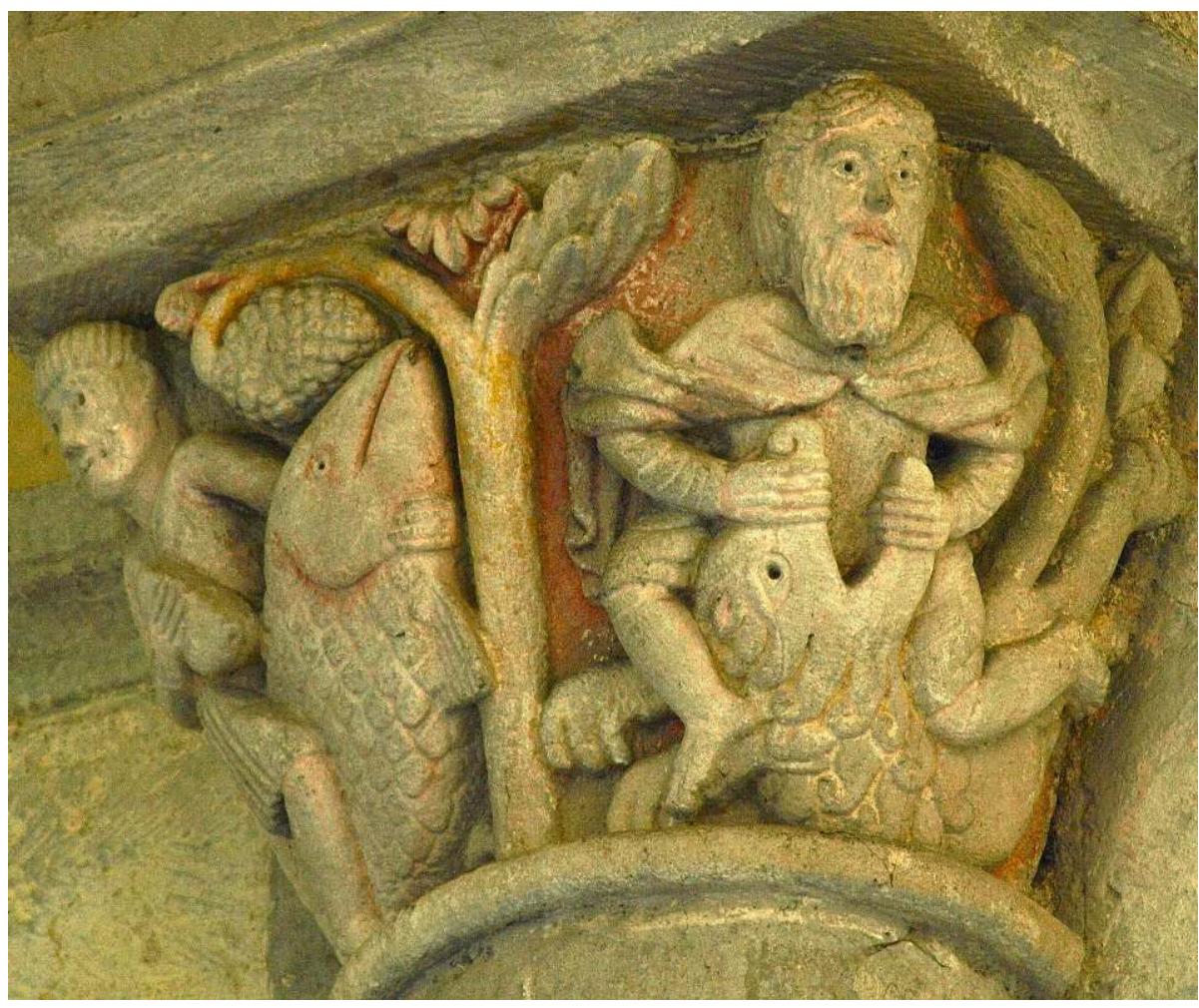

Homme porté par un poisson; homme (David ? Samson ? Hercule ?) dominant un lion (Mozat)

74 Les deux formes de hiérarchie entre l'homme et l'animal sont réunies sur un important chapiteau de Mozat (fig. 24), qui met en parallèle et confronte à la fois l'assistance, représentée ici par le poisson venant sauver l'homme de la noyade, et la domination violente que manifeste un homme en train de casser la mâchoire d'un lion. On ne saurait mieux et plus synthétiquement exposer la différence entre pecus et bestia. Ce chapiteau offre d'ailleurs un bon exemple de la pertinence d'une lecture en termes génériques : si l'animal est clairement identifiable, il est impossible de déterminer si l'homme est David, Samson ou Hercule! Peu nous importe dans ce cas (d'autant que l'image joue très probablement de cette ambivalence), car il s'agit de manifester la possibilité pour un personnage vénérable, dont la barbe marque peut-être la dignité, de recouvrer par la violence la domination sur les créatures rebelles.

L'implication dans des rapports intenses avec l'animal n'est jamais sans risque. La littérature médiévale regorge d'exemples où la domination qu'il exerce finit par mener l'homme à sa perte. Dans le corps à corps avec la bête, dans les actes de poursuite, l'homme court toujours le risque de s'animaliser, ce qui explique largement l'acrimonie particulière de l'Église envers les chasses "à force», les plus physiques. Cette ambiguïté de la domination sur l'animal n'a pas échappé aux artisans d'Auvergne, et la plupart des figures que nous venons de voir sous un jour positif, ont connu des reprises plus tardives mettant en scène la potentialité négative qu'implique tout rapport à l'animal, fût-il de domination. 
Fig. 25

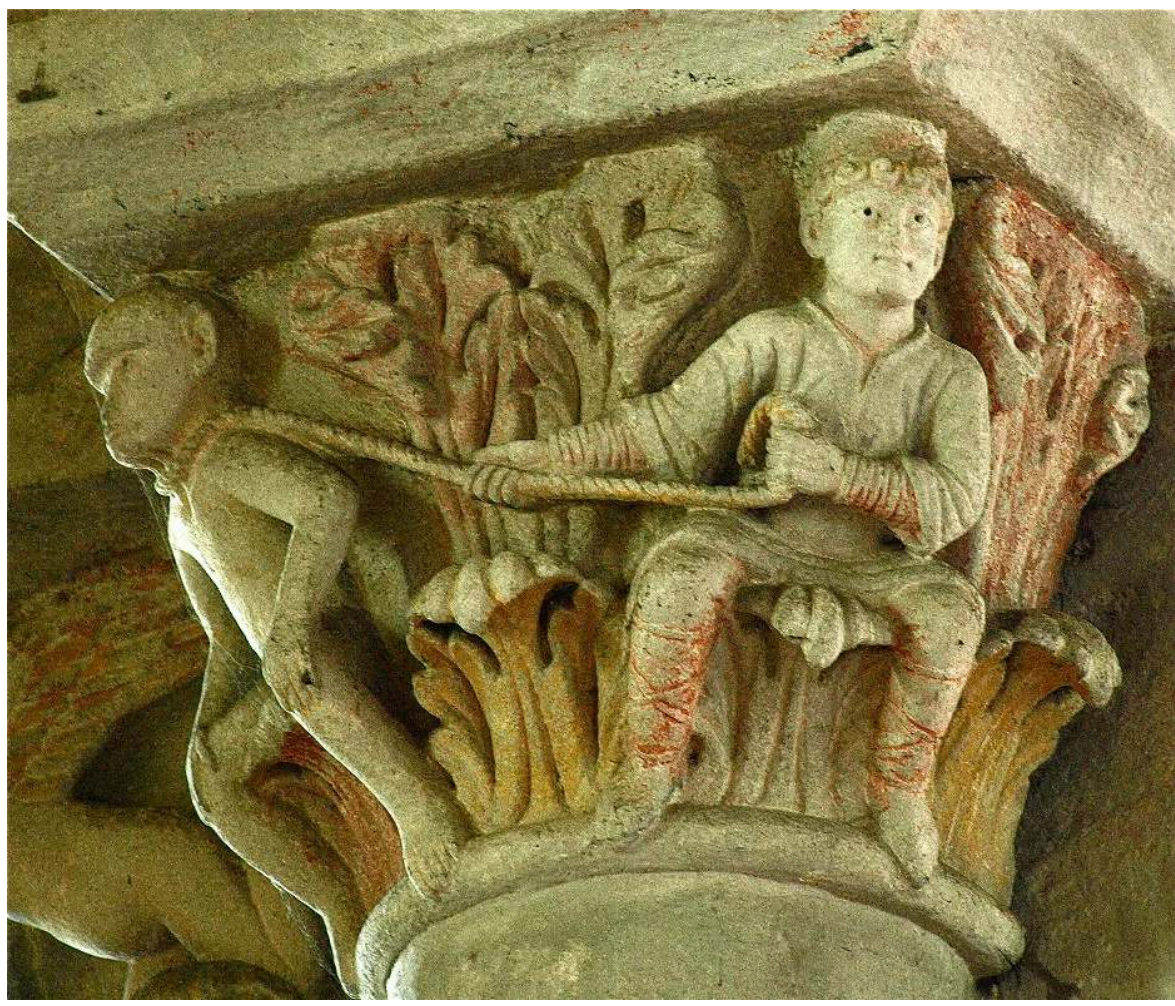

Homme et singe cordé (Mozat)

Une des scènes les plus emblématique de ce rapport est celle, si souvent reprise dans le domaine auvergnat, du singe cordé (fig. 25). La lecture que nous en avons proposé en fait une image morale : l'homme tient le singe en laisse et le domine, comme l'homme doit dominer le monde animal et les passions animales qui l'agitent intérieurement. L'image fonctionne sur un registre dualisant qui oppose assez clairement le Bien et le $\mathrm{Mal}^{107}$, mais sur un mode qui diffère de celui en vigueur dans les représentations de Michel dominant le dragon, ou de l'homme dominant le lion. Il est important de relever la singularité de cette image qui présente généralement un homme et un animal de la même taille, disposés sur un même plan, dans un rapport d'homologie-opposition, sur chaque angle du chapiteau. Le singe a beau être capturé, il n'en possède pas moins une posture assurée, similaire à celle de l'homme, les jambes largement ouvertes sur une feuille tout à fait phallique. Seule la présence de la corde témoigne ici de la souveraineté de l'homme, qui semble en l'occurrence bien fragile, au point que l'on est invité à se demander si l'homme n'est pas aussi quelque peu entraîné par le singe (ou du moins lié à lui). 
Fig. 26

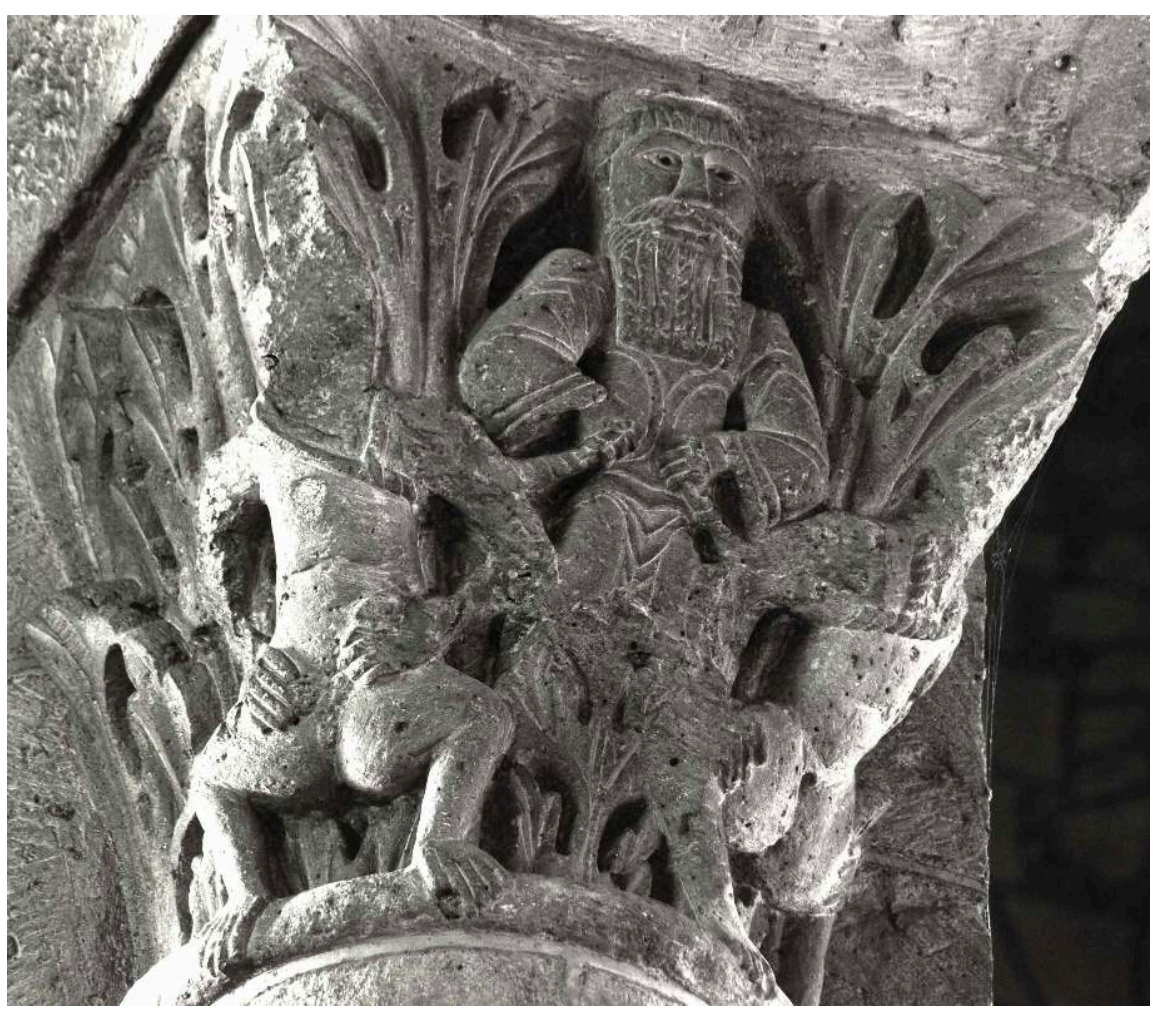

Homme et deux singes cordés mutilés (Orcival)

77 Un indice de l'ambiguïté de ce motif se rencontre peut-être à Orcival, où le singe cordé est présent à deux reprises. Le premier chapiteau possède une construction originale, très différente de celle des autres exemples (fig. 26). L'homme, ici gratifié d'une barbe vénérable, tient en laisse deux singes. Le rapport de hiérarchie est d'ailleurs renforcé, puisque l'homme est au centre, en position surélevée par rapport aux animaux. A une période ultérieure, ceux-ci ont fait l'objet d'une destruction volontaire des têtes et des $\operatorname{sexes}^{108}$. Ce type de mutilation n'est pas surprenant en soi, car il n'est pas rare que les images du Mal fassent l'objet d'atteintes violentes au cours du Moyen Âge ${ }^{109}$. 
Fig. 27
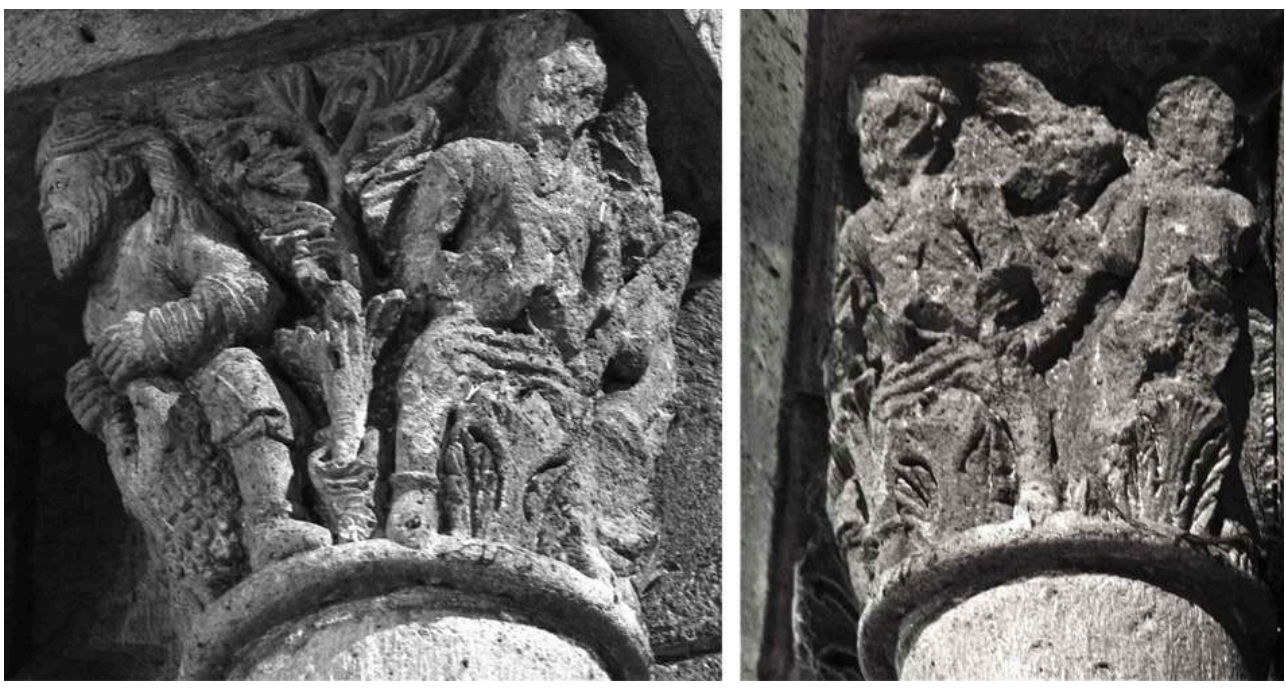

Homme dominant un lion et homme tenant un singe cordé (?) (Orcival)

78 On doit en revanche s'attarder sur la seconde représentation de l'homme au singe, plus fortement détruite encore (fig. 27). L'intervention est ici plus étrange : non seulement le singe, mais aussi l'homme ont été bûchés, au point que la scène est très difficilement identifiable ${ }^{110}$. Pourquoi l'homme a-t-il été détruit? Il n'est pas impossible que ce soit en raison de sa proximité trop forte avec l'animal démoniaque : la nature positive de l'homme, à un moment donné, n'a sans doute plus semblé évidente. A cette image ambiguë, les censeurs ont préféré celle de l'homme dominant le lion : ils laissèrent indemne cette image positive et plus hiérarchique, présente sur l'autre moitié du même chapiteau.

Fig. 28
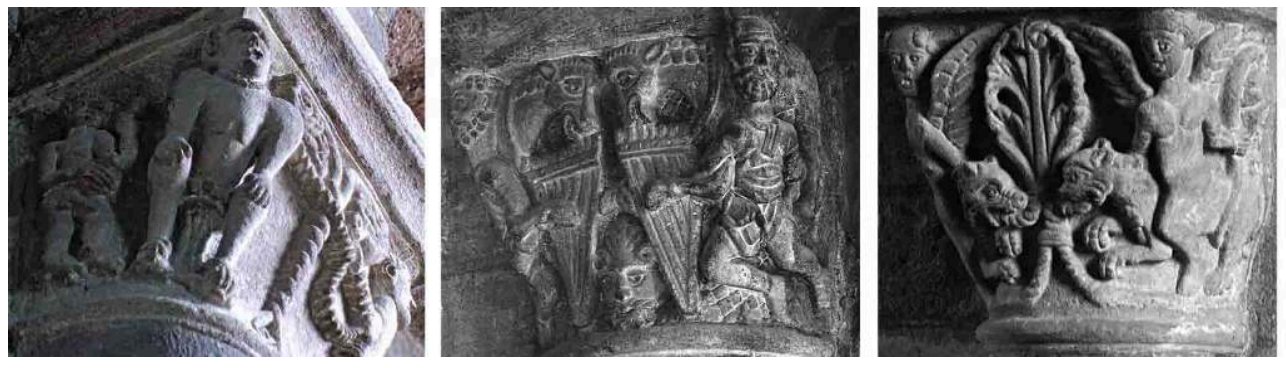

Moralisation des figures animales à Brioude : singe cordé; homme portant des ânes à la lyre (?); esprits maléfiques chevauchant des bêtes

Les singes cordés de l'église d'Orcival sont en tous points exceptionnels, et leur interprétation est sans doute périlleuse, mais ils ont le mérite d'attirer notre attention sur le caractère potentiellement problématique de ces images. Un peu plus tard, à Saint-Julien de Brioude, ce même motif a fait l'objet d'une clarification morale, le singe étant secondé d'un petit homme au sexe proéminent (fig. 28). Ce cas n'est pas isolé, et nous sommes plutôt confrontés à un phénomène massif, qui traverse notre période : toutes les images de coopération ou d'assistance entre l'homme et l'animal que l'on rencontre à Mozat et Chanteuges ont fait ultérieurement l'objet de reprises plus négatives et moralisantes. Ce processus, qui n'est pas encore systématisé à Saint- 
Nectaire et Notre-Dame-du-Port, est particulièrement frappant dans les dernières campagnes de construction de Saint-Julien de Brioude. C'est ainsi que, entre les porteurs de moutons, on voit d'abord apparaître une petite tête bestiale à Orcival, suggérant une menace subtile derrière les bergers. Plus tard, à Issoire et plus encore à Brioude, ce motif pastoral tend progressivement vers le négatif avec des bergers déséquilibrés, tirant la langue ou portant non plus des moutons mais des ânes musiciens ! (fig. 28). Il en va de même des hommes sur les boucs. Ce motif est déjà associé sur un mode critique à l'animal musicien à Saint-Nectaire; puis, à Orcival, le bouc est chevauché par un diable nu qui, sur l'autre face du chapiteau, tire des hommes par les cheveux. Enfin, les hommes chevauchant les bêtes sauvages sont interprétés par le sculpteur de Brioude comme des esprits maléfiques, dotés d'ailes et d'une langue tirée (fig. 28). Le processus de moralisation à l'œuvre sur l'ensemble de ces motifs déborde de beaucoup la question de l'animal, et nous reviendrons sur les conséquences d'un tel changement un peu plus loin à propos de l'hybridation.

\section{Interaction 2. Menaces et châtiments}

Fig. 29

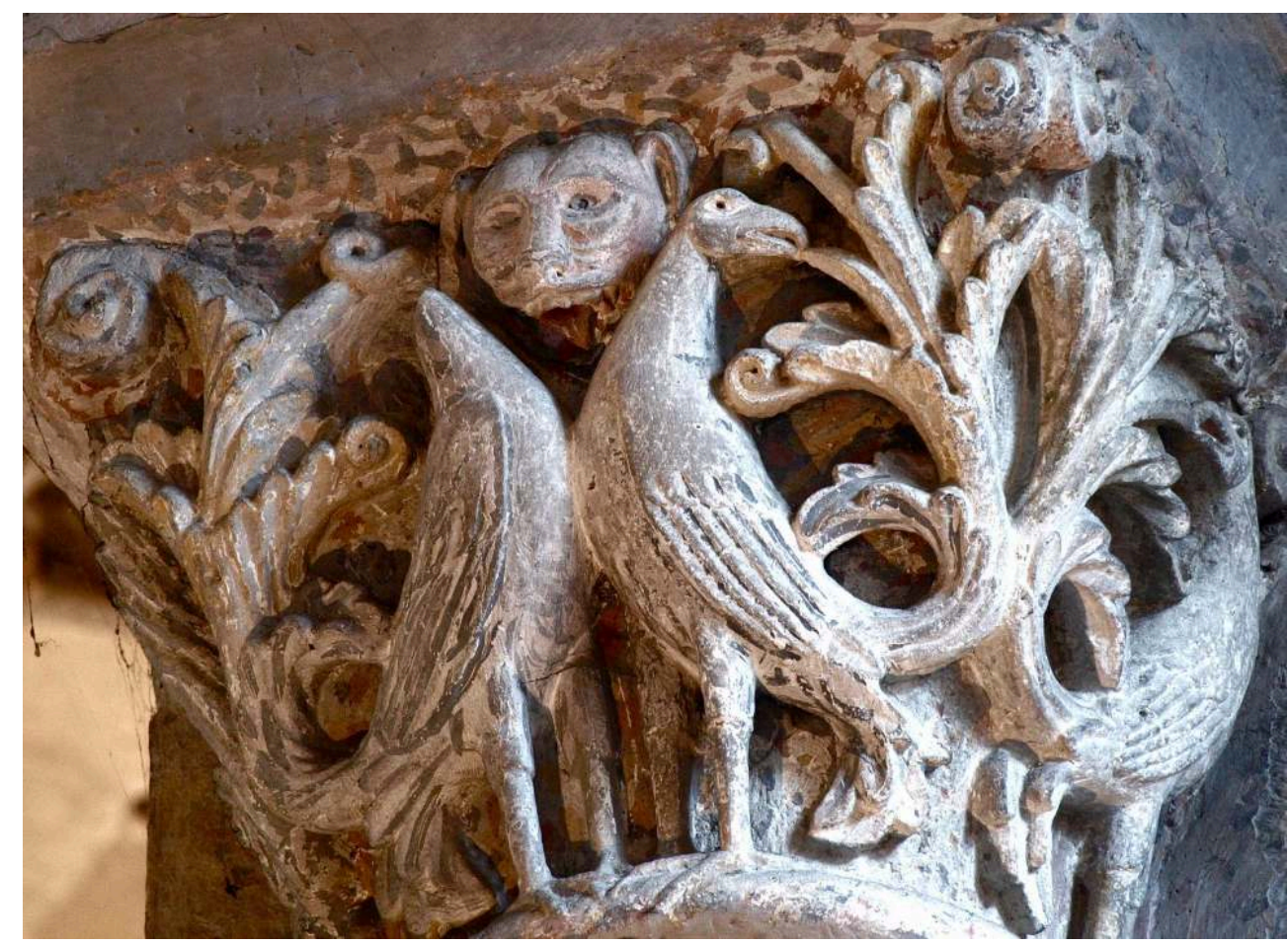

Tête de bête entre des oiseaux aux queues végétalisées (Mozat)

Tous les hommes ne sont pas des saints, l'homme ne domine pas toujours les bêtes sauvages, et la vie des animaux est loin de fournir un modèle naturel de coopération idyllique. La violence au sein du monde animal, sur laquelle nous reviendrons, n'est pas occultée dans ces édifices. Des têtes de bête, parfois à la dentition bien visible, apparaissent derrière les quaternités d'oiseaux ornementalisés à Mozat, à un emplacement particulièrement stratégique de l'église, à la lisière du transept (fig. 29). Ce type de menace, qui vient troubler les plus positives des images animales, se rencontre également à Notre-Dame-du-Port, Saint-Nectaire et Orcival. A côté de 
l'évocation de cette violence interne au monde animal, quelques chapiteaux, rares mais très importants, donnent à voir une série de menaces ou d'agressions de la faune contre les humains. L'exégèse accorde une place de choix à la mission d'édification des bêtes, qui doivent enseigner l'humilité à l'homme, en lui montrant sa faiblesse, et le châtier dans ses errements. L'image n'accorde pas la même importance à ce discours, qui est relativement rare dans les édifices auvergnats. Situés à des emplacements stratégiques, ces chapiteaux n'en sont que plus significatifs. Le fait qu'une bête menace un homme est d'ailleurs un marqueur temporel crucial qui renseigne sur le statut général de ces images : ces chapiteaux témoignent d'un monde où la souveraineté de l'homme sur la création ne va plus de soi, et où l'homme subit les conséquences du Péché originel. Ce faisant, ils tempèrent la propension du végétal et des oiseaux à faire de l'église un milieu paradisiaque, car il est impossible de s'affranchir complètement des réalités ambivalentes du monde terrestre.

Fig. 30

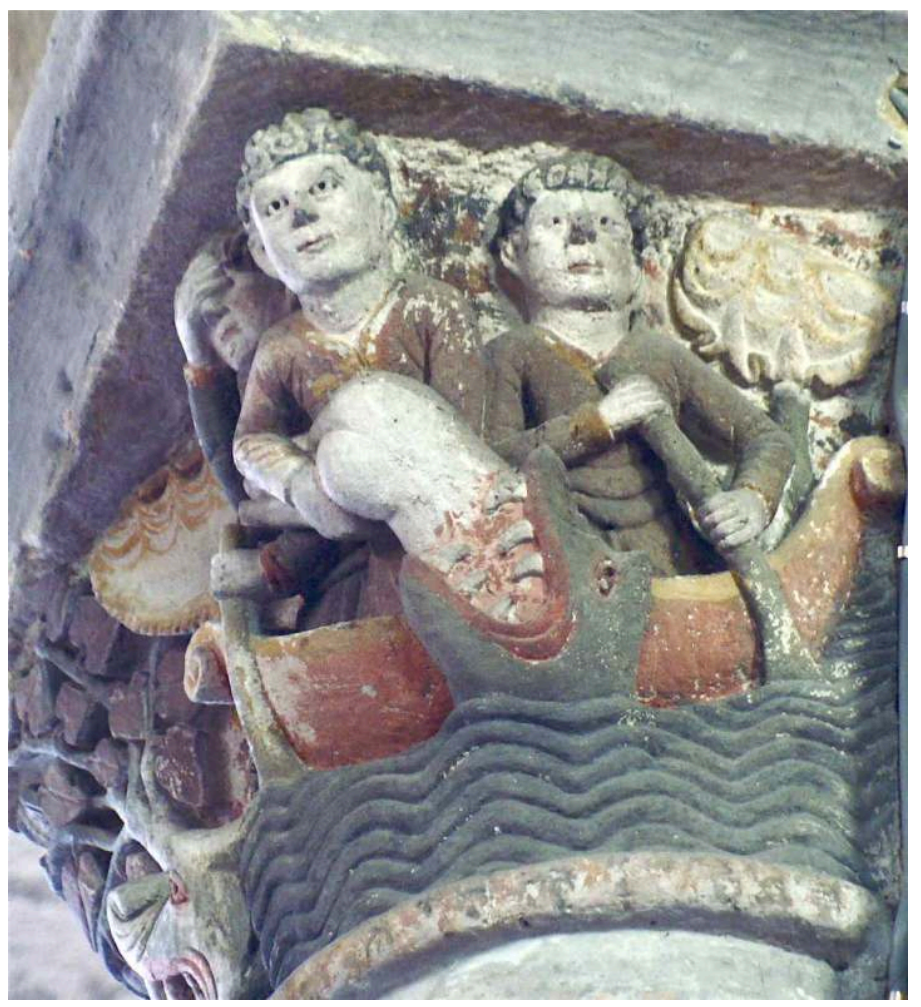

La baleine avale Jonas (Mozat) 
Fig. 31

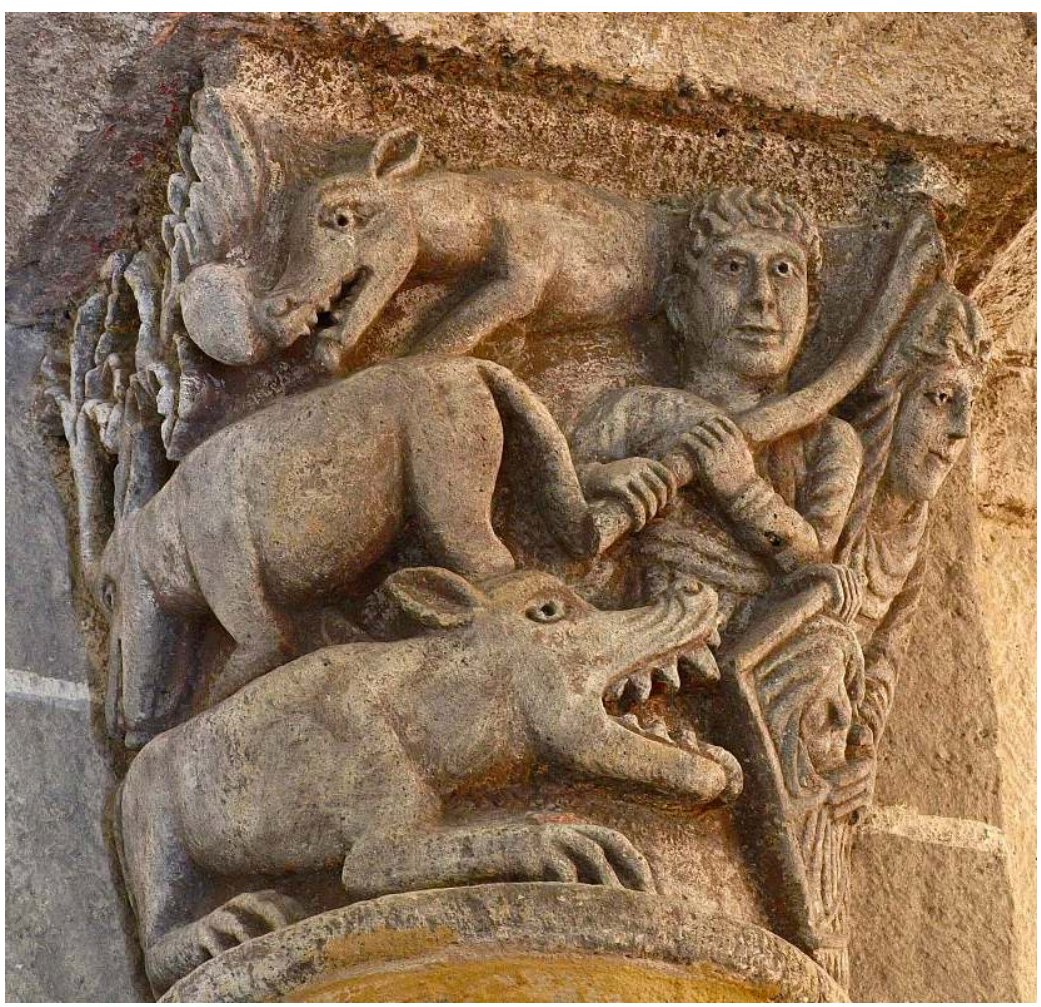

Bêtes attaquant des humains (Saint-Nectaire)

81 Dans la maison de Dieu, la cruauté animale n'est ni gratuite, ni définitive. A Mozat, qui offre la vision la plus positive de la Création, la seule attaque animale repérable dans les chapiteaux conservés est la dévoration de Jonas par la baleine ${ }^{111}$. L'animal est ici représenté sous une forme particulièrement agressive, avec une dentition proéminente (fig. 30). Mais cette image de prédation est d'emblée contredite par la délivrance de l'homme dans la scène suivante, qui est une préfiguration de la résurrection. Un tel couple prédation/sauvegarde est traité de façon totalement différente à Saint-Nectaire, dans l'étrange chapiteau où l'on a peut-être trop hâtivement identifié Moïse sauvé des eaux (fig. 31). Plus qu'ailleurs, le recours aux catégories génériques est ici nécessaire. La moitié gauche du chapiteau est occupée par trois bêtes dont les instruments de prédation, les dents et les griffes, sont mis en relief. A cette animalité agressive, fait face, dans la partie droite, le monde des humains où un homme armé d'un bâton ainsi qu'une femme protègent l'enfant, particulièrement menacé par les dents de l'une des bêtes. Peu de chapiteaux mettent aussi explicitement en scène la tension entre les hommes et les «bêtes ». La présence de celles-ci est pensée sous la forme d'un danger dont il est cependant possible de se prémunir : un thème qui peut aussi se comprendre de façon métaphorique, les fauves étant une image traditionnelle des passions les moins contrôlées de l'âme. Dans les deux cas, dans ce chapiteau comme dans celui de Jonas, la présence d'une menace animale n'aboutit pas à une issue fatale, mais va de pair avec la possibilité d'une sauvegarde, voire d'une délivrance, par ailleurs récurrente dans ces édifices. 
Fig. 32
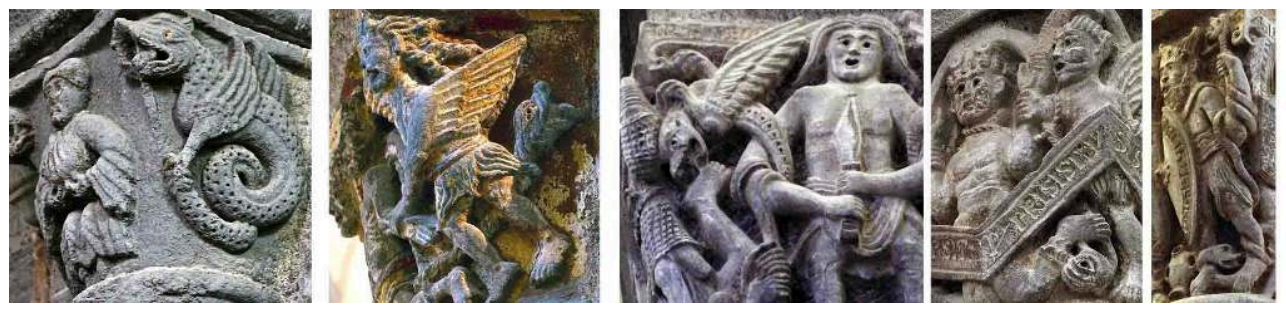

Le serpent comme attribut du mal (Chanteuges, Saint-Nectaire et, pour les trois vues de droite, NotreDame-du-Port)

Enfin, il existe un dernier régime d'apparition de l'animal, plus violent que celui des bêtes sauvages ordinaires. Il s'agit des images de châtiment, où des animaux, sergents de la justice divine, punissent ou du moins désignent les pécheurs. Ces motifs sont bien connus, et l'art roman est communément associé aux images de dévoration d'hommes par des fauves ou des monstres ${ }^{112}$. A ce titre, l'art auvergnat se singularise plutôt par la faible place accordée à ce thème et par la forme particulière qu'il lui confère. Il faut tout d'abord constater que cette mission cruelle n'est ici confiée qu'aux seuls "serpents» (au sens médiéval), c'est-à-dire des reptiles de diverses natures et des dragons. Ces animaux, qui apparaissent pour châtier ou désigner des pécheurs (Chanteuges, Notre-Dame-du-Port, Saint-Nectaire, Orcival), existent uniquement sous une forme négative. Plus encore, leur seule présence à proximité d'un corps humain suffit à le qualifier comme mauvais, le serpent fonctionnant comme attribut du mal. C'est notamment le cas à Notre-Dame-du-Port où les serpents sont étroitement associés aux personnifications des Vices dans le sanctuaire (fig. 32). Les corps serpentins possèdent une plasticité formelle considérable, de par leur capacité à s'étirer indéfiniment ; ce faisant, ils se jouent de la répartition des scènes sur différentes faces des chapiteaux: sans se cantonner au cadre de l'historia, ces animaux créent un lien négatif entre les figures et les thèmes et constituent l'envers maléfique de la continuitas végétale. Lorsqu'ils interviennent dans le châtiment des damnés, les serpents se confondent d'ailleurs avec les cordes enlaçant les pécheurs, au point qu'il est possible $d$ 'y voir un très rare exemple d'hybridation négative, associant un objet et un animal (fig. 32). En somme, pour peu que l'on adopte un point de vue structural du type "positif vs négatif", les reptiles s'opposent parfaitement aux oiseaux. Face à l'ornementalisation de ces créatures évoluant aux frontières du monde céleste, à leur ordonnancement symétrique en paires ou en quaternités, à leur hybridation végétale, les serpents, par leur reptation montrent leur attachement à la terre, à la chair, et par leurs formes sinusoïdales s'insinuent dans la composition des chapiteaux, dont ils constituent l'élément le plus diabolique.

Néanmoins, ces images de châtiment animal, au demeurant fort rares dans les édifices pris en compte ici, traitent la peine sous un mode relativement euphémisé. Nulle dévoration dans ces sculptures, où les animaux démoniaques encadrent et enlacent les humains plus qu'ils ne les dévorent. Une fois n'est pas coutume, dans le cas des serpents, ce n'est pas l'acte, mais leur simple présence qui est signifiante ${ }^{113}$, puisque le seul élément à être véritablement dévoré est le fruit du Péché originel. Dans les autres cas, c'est par une simple morsure que les serpents marquent la damnation de telle ou telle figure. 


\section{L'animation des lieux}

84 les chapiteaux végétaux traduisent artificiellement la vitalité du principe créatif et dotent ainsi l'édifice d'un ornatus performatif, les différentes formes animales jouent le rôle d'interface entre l'humain et les autres formes créées. Parce que les animaux ont été indirectement affectés par la Chute de l'homme, ils indexent le monde créé sur l'histoire humaine et permettent de lier des considérations morales aux forces amorales de la création. C'est particulièrement le cas des représentations de quadrupèdes qui, tout en contribuant à l'éloge de la création, de ses forces et de sa varietas, ne peuvent se penser sans l'humain. Parce qu'ils sont forcement répartis entre pecus et bestia, parce qu'ils appartiennent soit aux animaux restés fidèles à la domination paradisiaque, soit à ceux qui contestent l'empire de l'homme, ces animaux témoignent par leur seule présence du devenir de l'humanité et, plus largement, de la création toute entière.

Ce qui est vrai pour le monde animal en lui-même, l'est plus encore lorsqu'il entretient une relation avec l'humain. De fait, les animaux constituent un moyen d'amorcer la question morale au sein de l'édifice, en évoquant les rapports que l'homme entretient avec les autres créatures. C'est ainsi qu'à Mozat, les seules oppositions frontales entre le Bien et le Mal s'expriment dans deux chapiteaux mettant en scène l'homme et l'animal (l'homme et le singe; l'homme et le lion) ${ }^{114}$. Dans la chaîne des êtres, le moment animal marque ainsi l'arrivée de la question morale. Ce n'est sans doute pas un hasard si ces représentations se rencontrent essentiellement dans la nef, souvent en relation avec la porte latérale. Dans bien des cas, il est d'ailleurs possible de repérer des analogies entre ces luttes interspécifiques et les oppositions Bien/Mal dans le cadre de l'histoire christologique ou hagiographique. C'est ainsi qu'à Notre-Dame-du-Port, l'homme dominant le singe est placé en symétrie axiale avec le Christ repoussant la tentation satanique, tandis qu'à Saint-Nectaire c'est l'agression du nouveau-né par les bêtes qui fait écho à la même scène. Enfin, à Chanteuges, l'image de l'avare menacé par les dragons, qui accueille les laïcs, s'oppose à celle de saint Marcellin tenant à distance les griffons, face à la porte des clercs. Que ce soit à Orcival, Saint-Nectaire ou NotreDame-du-Port, l'animalité est rarement neutre dans la nef, mais relève bien d'une relation agonistique.

A ces conflits qui résonnent dans les nefs, les chapiteaux du sanctuaire semblent offrir une solution en évacuant presque totalement la question animale. Dans l'espace le plus sacré, l'historia proprement humaine se développe dans des proportions inégalées et coexiste souvent avec une ornementation végétale grandiose ${ }^{115}$. La faune, quand à elle, n'y apparaît qu'au titre de l'anecdote ou de l'attribut et ne structure plus la composition des chapiteaux. Dans cet espace, toute l'ambivalence de l'animalité a été levée et ne demeurent que les espèces représentant les deux pôles extrêmes, avec du côté positif les aigles et les griffons au calice ${ }^{116}$, et pour la part négative, les différents serpents incarnant le $\mathrm{Mal}^{117}$. Dans la partie la plus sainte de l'édifice, l'animalité apparaît ainsi parfaitement classifiée, comme pour mieux s'effacer devant les affaires humaines et divines. Enfin, entre le conflit et sa résolution, le troisième terme, celui de l'ambivalent et $\mathrm{du}$ "Neutre $»^{118}$, se rencontre de façon privilégiée dans les déambulatoires, notamment à la faveur de la reprise des thèmes de Mozat. Mais ici, 
cette animalité particulière ne peut se comprendre sans le lien très fort qu'elle entretient avec l'hybridation végétale.

Cette distribution des thèmes animaliers dans l'espace (la dimension agonistique/ morale dans la nef, sa résolution dans le sanctuaire, l'ambivalence dans le déambulatoire) témoigne peut-être d'une tendance générale, mais elle souffre de trop nombreuses exceptions pour constituer une formulation totalement satisfaisante. Ces dernières nous invitent à ralentir une dernière fois le regard que nous posons sur ces images, pour les considérer dans leur ensemble.

On se rappelle que le concept d'animal, au sens moderne, n'existe pratiquement pas aux $\mathrm{XI}^{e}$ et $\mathrm{XII}^{e}$ siècles, et que les images des différentes créatures non-humaines tirent essentiellement leur signification des catégories génériques (pecus, bestia, oiseaux, reptiles) qui les englobent. Une fois cela admis, il faut cependant constater que ces créatures partagent des caractéristiques communes qui forment le propre de l'animalité. On notera en premier lieu que si le végétal exprime une idée de force vitale en lien avec la notion de croissance, la représentation des animaux, avec toute la diversité des valeurs qu'ils supportent, suggère un mouvement, une animation qui par essence est refusée aux végétaux ${ }^{119}$. Autre différence importante avec le végétal, l'existence animale pose toujours (au moins de façon indirecte) la question des pratiques alimentaires : de par son essence et son régime spécifique, chaque animal est soit le prédateur, soit la proie d'un autre animal, ce qui confère à l'animalité une nature à la fois plus extensive et plus relationnelle que celle de la végétalité. De fait, les forces vitales qui étaient comme données per se par les chapiteaux végétaux, ne peuvent ici se penser qu'en termes de rapports. On dira en définitive que si le végétal exprime la force et la croissance, l'animal met en jeu plus spécifiquement les rapports de force; plus extensive, cette vitalité est aussi plus ambivalente. 
Fig. 33

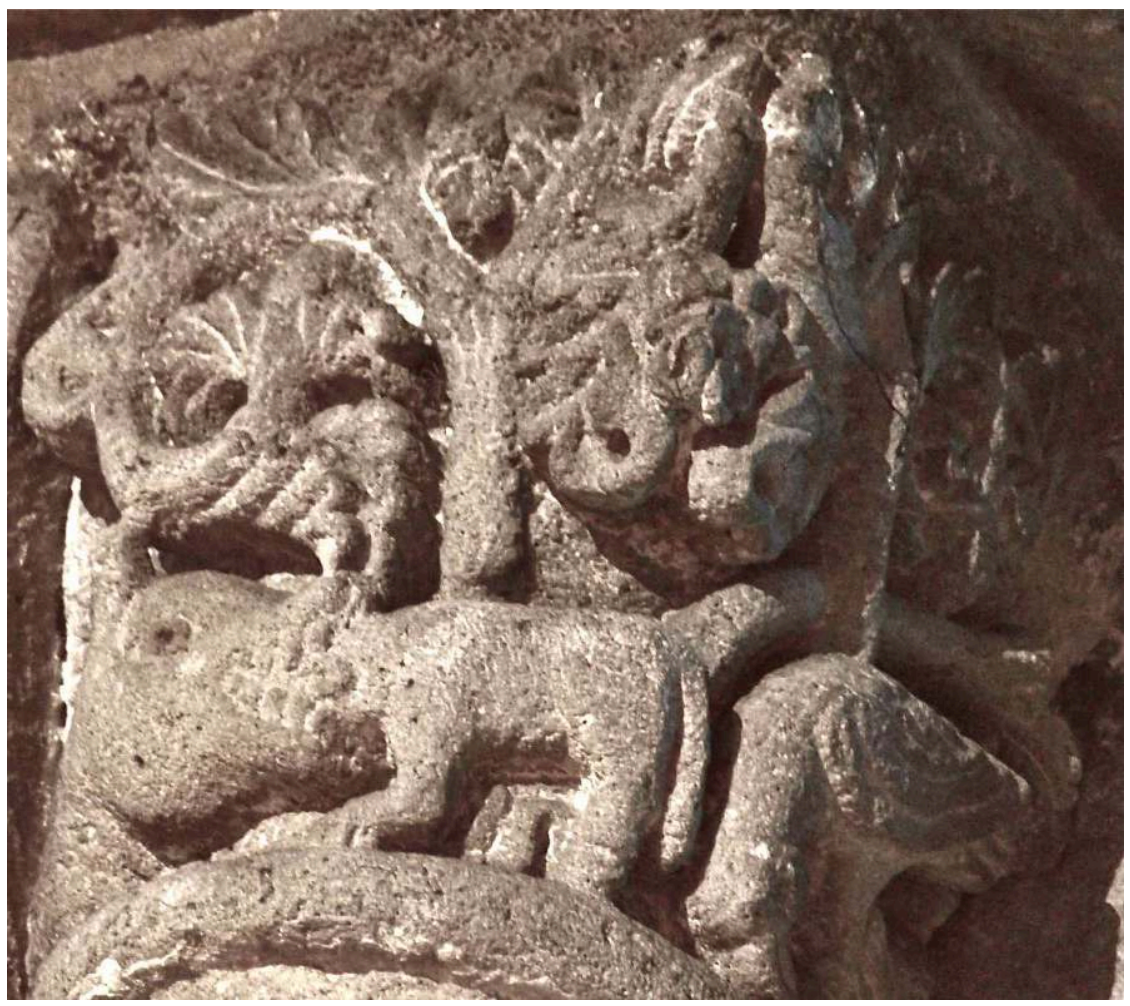

Bête dévorant un animal (Orcival)

89 Qui mange qui ? Qui mord, qui poursuit, qui domine qui ? Ces rapports violents, très présents entre les créatures, ne peuvent pas toujours se traduire en termes moraux. C'est tout particulièrement le cas des chapiteaux où la violence oppose des animaux entre eux et ne fait pas intervenir l'humain. Que signifie par exemple ce chapiteau d'Orcival où une bête en dévore une autre au pied d'un arbre aux ramures particulièrement épanouies? (fig. 33) Nous aurons l'occasion d'y revenir : de telles images, comme celles, inquiétantes, de bêtes fauves ou de dragons aux dents proéminentes, contribuent à l'ornatus de l'édifice, par-delà le sens moral qu'elles peuvent porter $^{120}$. La violence des animaux sauvages n'est pas contradictoire avec leur vocation d'ornement; elle participe à sa manière du prestige et du mode d'intervention de ces images, qui tirent une part de leur efficace de leur force potentiellement incontrôlée.

Ces chapiteaux particuliers reconduisent dans le domaine de l'image les liens particulièrement complexes qui associent les bêtes à l'ornement dans la tradition chrétienne. Car, si la beauté des oiseaux est pour ainsi dire sans risque, celle de la violence animale est plus troublante; la gêne qu'éprouve Augustin dans les Confessions est assez symptomatique de l'ambivalence de cette situation. L'évêque d'Hippone avoue à plusieurs reprises sa fascination pour les forces animales, pour la poursuite d'un lièvre par un chien ou la capture soudaine d'une mouche par un lézard et son agonie entre les pattes de l'araignée ${ }^{121}$. Face à ce plaisir contemplatif, les positions de l'auteur varient. Tantôt il considère que ces actes participent de la beauté de la création et sont louables en tant que tels, tantôt que leur contemplation est vaine et relève d'une inutile curiosité. Mais c'est dans sa Genèse au sens littéral qu'Augustin affronte le plus directement cette question : 
«On objectera: pourquoi donc les bêtes se font-elles du mal les unes aux autres, puisqu'il n'y a en elles nul péché à punir, nulle vertu à parfaire par l'exercice ? C'est tout simplement que les unes sont la nourriture des autres. Et nous aurions tort de dire : il ne devrait pas y en avoir qui soit la nourriture des autres. Tous les êtres en effet, aussi longtemps qu'ils existent, ont leur mesure, leur nombre, leur ordre : toutes choses qui, pour peu qu'on y soit attentif, méritent louanges et les transformations, même quand il s'agit d'un passage d'un être à un autre, sont réglées par les lois d'un devenir qui, à sa manière, n'est pas sans secrète beauté. Si ces lois échappent aux ignorants, elles apparaissent dans un demi-jour aux progressants, et dans leur pleine clarté aux parfaits $»^{122}$.

91 C'est ainsi que jusque dans la dévoration, jusque dans les changements d'états qu'impose l'ingestion alimentaire d'un animal par un autre, il est possible de trouver un ordo digne de louange. Cette beauté, qui est qualifiée de «temporelle » par Augustin, n'est cependant pleinement accessible qu'aux plus avancés des croyants.

Cette position très nuancée aide sans doute à comprendre le statut des images animales violentes dans les églises d'Auvergne. La force dont elles sont chargées possède différents niveaux d'efficacité et d'intelligibilité. A un niveau très général, comme l'a montré Meyer Schapiro, la présence d'images évoquant la force sous une forme animale, participe de conceptions culturelles qui dépassent le cadre ecclésial. Ces représentations de lutte, de dévoration, de bêtes sauvages, avec éventuellement leurs occurrences bibliques comme Samson et le lion, sont omniprésentes dans l'ornementation de cette époque, aussi bien dans les lettrines que sur la vaisselle, les selles de chevaux ou les murs des demeures aristocratiques. A ce titre, la «beauté temporelle » de la force animale trouve clairement un écho dans l'usage séculier des images animales. Celles-ci doivent alors être interprétées à un niveau très générique, comme étant des ornements (au sens fort), conférant à leur support une partie de la force et de la beauté que leurs référents expriment ${ }^{123}$. A un autre niveau, et parce qu'elles sont intégrées dans l'église, dotée d'un statut propre, parce qu'elles s'inscrivent dans un iter qui possède sa dynamique singulière, ces images peuvent servir de support à des discours moraux ou à des développements sur l'harmonie (mais aussi la dysharmonie) de la création, dans la lignée d'Augustin par exemple.

La diversité des images animales et la difficulté de leur interprétation tiennent à leur capacité à jouer d'une multiplicité de niveaux de lecture. C'est pour cette raison que les animalités dont nous avons parlé ici ne peuvent se comprendre qu'au pluriel. Tel n'est pas le cas de la végétalité, puisque les infinies variations de l'ornementation végétale concourent toutes à exprimer la puissance de la création, par le truchement de la vitalité articificialisée d'un milieu paradisiaque. Une telle unicité n'est pas envisageable pour le monde animal qui, bien qu'il soit unifié d'un certain point de vue (en sa qualité d'ornatus de la création) est clairement marqué par sa division en catégories génériques et par la diversité des rapports dans lesquels il s'inscrit (soumission/rébellion, coopération/menace...). Autant de relations qui se trouvent potentiellement moralisables dans les termes de la dualité Bien/Mal, sans pour autant relever d'un symbolisme systématique. Loin d'être un handicap, c'est précisément cette plasticité, entre ornementation et morale, qui confère toute leur force à ces images et les gratifie d'un rôle articulatoire entre la vitalité spiritualisante du végétal et la pleine vitalité qui est celle de la Vie céleste avec Dieu. 


\section{Hybridations}

Fig. 34
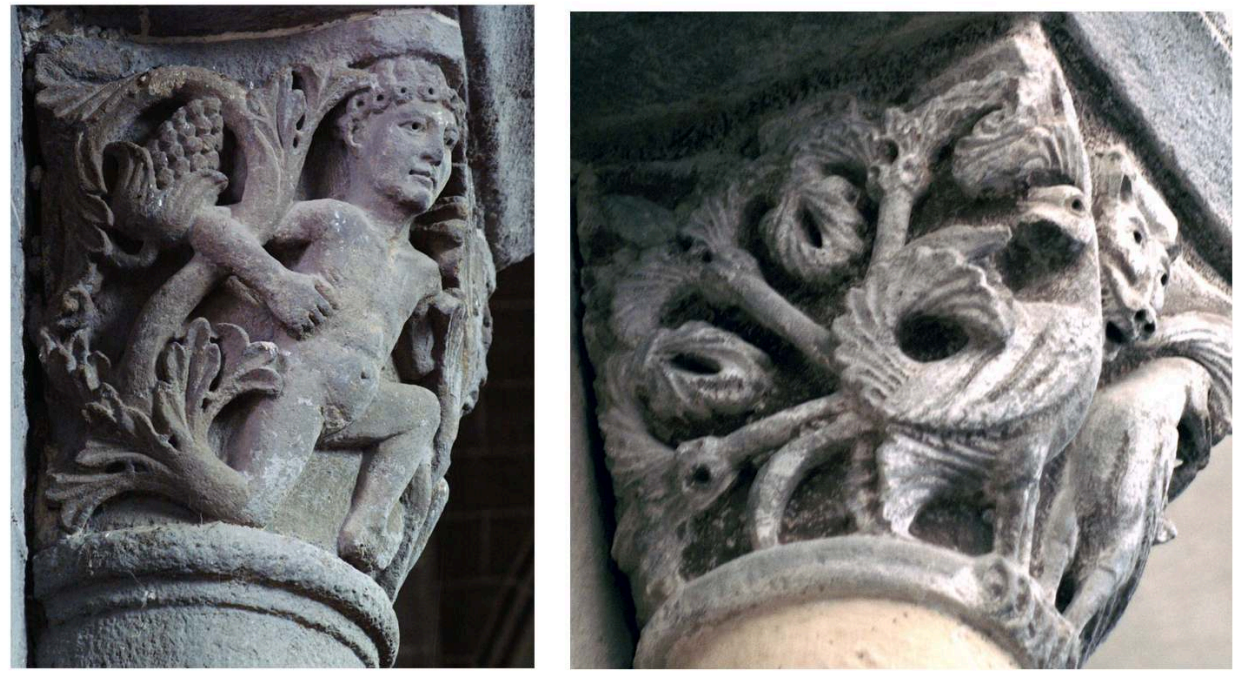

Hybrides (Chanteuges et Notre-Dame du Port)

\section{Misères de l'hybridation animale}

La volonté d'analyser l'ensemble des images présentes sur les chapiteaux d'un édifice se heurte à un obstacle de taille : l'absence quasi totale de documentation historique pour la plupart de ces représentations. Une lacune particulièrement sensible dans le cas d'images qui comptent parmi les plus étonnantes de l'art roman, celles des créatures hybrides, qui à l'instar des hommes-végétaux de Chanteuges ou des oiseaux à queues hyper-végétalisées de Notre-Dame-du-Port (fig. 34), mélangent de façon originale des natures les plus diverses. Ces chapiteaux sont pourtant loin d'être anecdotiques : on les rencontre en nombre dans les églises d'Auvergne, où ils sont particulièrement mis en valeur. Trop vite classées comme des fantaisies d'artistes, quand elles ne sont pas simplement négligées par les historiens, ces figures paradoxales méritent la même attention que les autres. A leur endroit, deux textes - forts célèbres - s'imposent d'emblée à l'esprit. Le premier est la fameuse condamnation de la décoration des cloîtres par saint Bernard, contenue dans l'Apologie à Guillaume de Saint-Thierry (1144) :

«Mais que signifient dans vos cloîtres, là où les religieux font leurs lectures, ces monstres ridicules [ridicula monstruositas], ces horribles beautés et ces belles horreurs? A quoi bon, dans ces endroits, ces singes immondes, ces lions féroces, ces centaures monstrueux, ces monstres demi-hommes [semi-homines], ces tigres bariolés, ces soldats qui combattent et ces chasseurs qui sonnent du cor? Ici, on voit une seule tête pour plusieurs corps ou un seul corps pour plusieurs têtes : là, c'est un quadrupède ayant une queue de serpent et, plus loin, c'est un poisson avec une tête de quadrupède. Tantôt on voit une bête qui est cheval par devant et chèvre par derrière, ou qui a la tête d'un animal à cornes et le derrière d'un cheval. Enfin, le nombre de ces représentations est si grand et la diversité si charmante et si variée qu'on préfère regarder ces marbres que lire dans des manuscrits, et passer le jour à les admirer qu'à méditer la loi de Dieu. Grand Dieu! si on n'a pas de honte de pareilles frivolités, on devrait au moins regretter ce qu'elles coûtent. $»^{124}$ 
A ce texte, il convient d'adjoindre la critique plus tardive mais très proche thématiquement, contenue dans le Pictor in carmine (vers 1200) :

« En effet, pour résumer beaucoup de choses en peu de mots, est-il plus décent, estil plus fructueux de chercher du regard autour de l'autel de Dieu des aigles à deux têtes, quatre lions possédant une seule tête, des sagittaires, des acéphales qui grognent, la chimère logique telle qu'on l'imagine [chimeram ut fingunt logicam], le renard de la fable et des combats de coqs, des singes flûtistes et l'âne à la lyre de Boèce, ou de contempler l'histoire des patriarches [...] Le contenu de l'Ancien et du Nouveau Testament est-il vraiment si pauvre qu'il faille, comme on dit, plaisanter avec son argent, en le dépensant pour des inventions honteuses [ad inventionum turpitudine], en négligeant l'honnête et l'utile? Mais ces fantaisies illusoires [fantasmatum ludibria] ont été progressivement introduites par la néfaste présomption des peintres que le sérieux ecclésiastique n'aurait jamais dû accepter

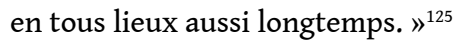

Notons d'emblée que les textes qui se soucient de mentionner les images d'hybridation développent un regard négatif à leur égard. Inversement, et malgré la présence massive de ces images dans l'art roman, on ne connait pas de texte qui prenne la défense d'un tel décor: tout se passe comme si l'acceptation de ces figurations se passait de justifications explicites. En tout état de cause, la rareté de la documentation relative à ces images, la qualité formelle du texte de saint Bernard et le prestige de son auteur ont conduit à projeter ces prises de position sur l'ensemble de la production romane. Dès lors, les images d'hybrides ont été considérées comme étant soit clairement négatives, soit purement décoratives. Au-delà des importants débats qu'ont suscités ces deux textes, plusieurs précisions doivent être apportées.

1. Ces deux diatribes sont particulièrement virulentes envers les images d'hybrides, mais il convient de noter que l'argumentation vise avant tout à contester l'abondante décoration des lieux propres au clergé. Cette critique participe d'une prise de position spécifique aux cisterciens au sein du " champ » ecclésial : elle vise, par une surenchère dans le spirituel, à afficher une supériorité sur d'autres ordres monastiques, dont la posture était ainsi dévaluée, car jugée trop compromise avec la matérialité du siècle. Par l'accentuation de la dualité matériel/spirituel qu'il exprime ici, Bernard ne condamne pas seulement les hybrides, mais aussi et plus généralement la violence animale et humaine, soit tout ce qui renvoie au désordre charnel du monde. Pour lui, rien de tout cela ne peut avoir place dans un lieu qui doit être voué au spirituel (pur). Mais, pour frappantes qu'elles soient, rien ne dit que ces critiques soient représentatives d'une perception commune au XII ${ }^{e}$ siècle. En tout cas, elles n'ont guère été suivies d'effet dans la production d'images. Le contexte rhétorique précis de ces condamnations ne doit par ailleurs pas être évacué, car il pointe - par la négative - une association dont on verra qu'elle est fondamentale, entre l'hybridité et l'ornementalité : être contre l'ornement va de pair avec un refus de l'hybridation. Par ailleurs, on n'oubliera pas que, selon la chronologie adoptée ici pour les édifices auvergnats, le texte de saint Bernard est nettement plus tardif que les œuvres que nous étudions, l'écart entre nos images et la critique du cistercien pouvant aussi témoigner d'une évolution historique des sensibilités vis-à-vis de certains thèmes iconographiques, dans certains milieux spécifiques.

98 2. Parmi les créatures décrites, certaines sont nommées (comme les centaures) et possèdent une longue tradition de moralisation. Mais nos auteurs font mine d'en ignorer la lecture chrétienne, pour mieux les opposer au « sérieux ecclésiastique ». Si 
l'association de ces figures, dont certaines (le centaure, les semi-homines) se retrouvent dans nos chapiteaux, fait sens au sein de cette rhétorique, force est de constater qu'il n'existe pas de vocable médiéval pour regrouper ces figures très hétérogènes, comme nous le permet le terme « hybride».

3. On notera enfin et surtout que ces textes n'évoquent que des mélanges entre hommes et animaux ou entre espèces animales. Ils n'évoquent aucune hybridation impliquant du végétal, telle qu'on la rencontre dans nos deux exemples, et dans l'immense majorité des cas auvergnats.

On le voit par ces textes : il existe tout un champ iconographique de la monstruosité et de l'hybridation - particulièrement problématique pour les contempteurs de l'ornementation -, mais qui n'est pas associé à un concept indigène propre. Cette absence de nom et de concept fournit en elle-même une indication sur ces figures et prend un sens tout à fait particulier dans le contexte médiéval, où le rapport à la faune est très largement informé par l'épisode d'Adam nommant les animaux. On se rappelle (voir plus haut) que le «nom » et l'« espèce animale » sont associés par des liens très forts dans le contexte chrétien. Le récit de la Genèse est ici incontournable : le seul acte d'Adam avant la Chute consiste dans une nomination des animaux, un acte qui établit à la fois une hiérarchie et une classification dans le monde créé. Donner un nom, c'est créer une catégorie, c'est "ordonner» et se donner les moyens d'appeler à soi la créature ainsi classée. La distinction des espèces animales est évoquée à plusieurs reprises dans le premier livre de la Bible, où l'expression «selon son espèce » revient sept fois. L'idéal édénique est ainsi construit sur une séparation des différentes espèces animales, un ordre qui se trouve par la suite confirmé au sein de l'arche de Noé126. Cette classification/séparation des espèces ne concerne pas seulement le Paradis; elle est ensuite répétée et traduite de façon concrète dans les interdits alimentaires du Lévitique et, bien que le christianisme les ait abolis, l'anthropologue Mary Douglas a montré qu'ils innervaient largement les différentes sociétés chrétiennes ${ }^{127}$.

101 A ce niveau de généralité, on comprend aisément que dans une société analogique basée sur la discontinuité entre les différents existants ${ }^{128}$, et compte tenu de la vocation proprement classificatoire du monde animal, l'image de créatures hybrides semble ne pouvoir revêtir qu'un caractère négatif et renvoyer au statut dégradé du monde après la Chute. Mais cette lecture, qui a le mérite de s'accorder aux propos de saint Bernard, ne s'applique guère à notre corpus qui appelle une autre conception - plus positive de l'hybridation.

\section{Qu'entendre par « hybride »?}

Pour évoquer ces figures auxquelles le Moyen Age n'a pas donné de nom, nous choisissons le terme d'hybride. Ce vocable était alors utilisé, mais dans un sens beaucoup plus restreint, puisqu'il désignait spécifiquement, dans la langue savante, le résultat d'un accouplement fertile entre deux espèces physiologiquement proches, en général un cochon et un sanglier ${ }^{129}$. Nous l'adoptons dans un sens large, en préférant le terme d'« hybride», qui présente l'avantage de désigner un croisement de vivants, à celui de "composite", qui semble renvoyer davantage au domaine des artéfacts qu’à celui des êtres animés. 
Fig. 35

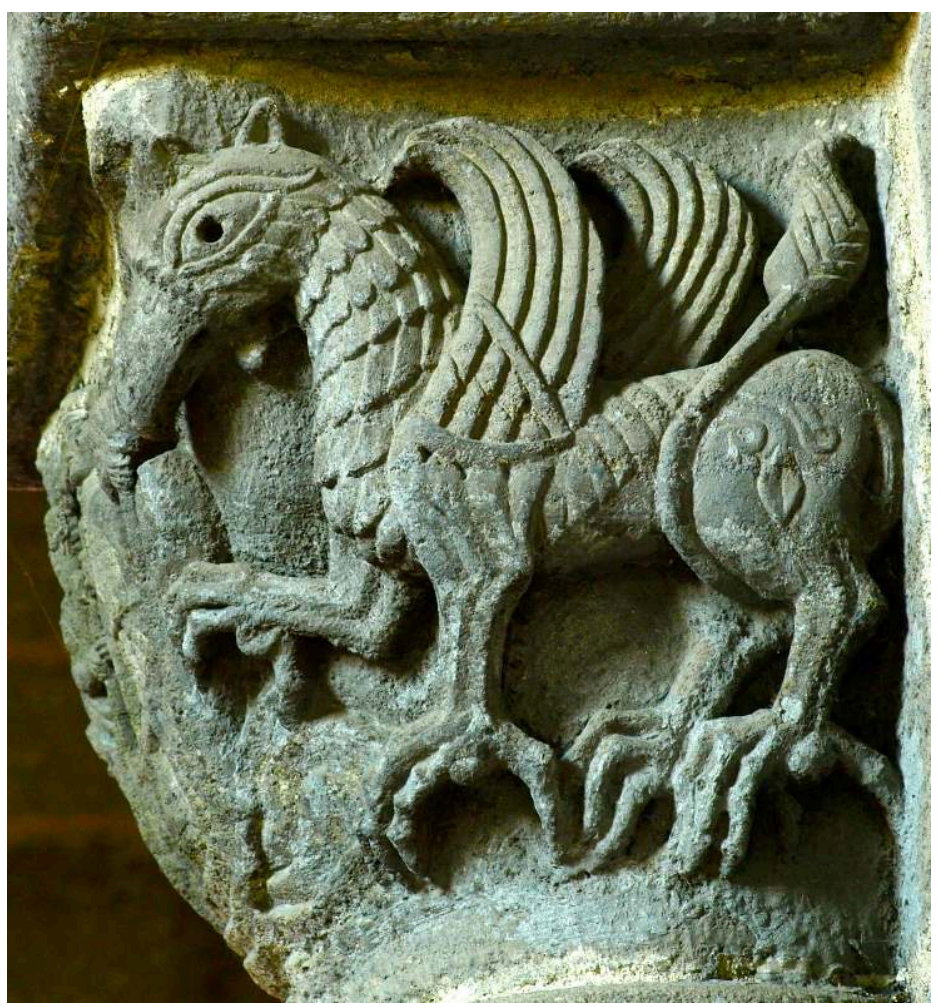

Griffon (Chanteuges)

103 Un autre point doit être précisé. Il concerne les conditions d'existence d'une hybridation dans le contexte des images romanes. Pour qu'il y ait hybridation, il faut estimer se trouver en présence d'une association de deux entités discrètes. Or, une telle appréciation est directement dépendante des catégories locales et historiques de la perception du monde créé. Prenons un exemple. Un animal avec un corps de lion et une tête d'aigle est formellement un hybride, mais il n'est pas considéré comme tel au Moyen Âge, puisque cette forme correspond à une entité connue (et nommée) : le griffon (fig. 35). De même, le centaure et la sirène correspondent à des créatures dont l'existence au Moyen Âge est souvent considérée comme aussi réelle que celle de l'éléphant ${ }^{130}$. Par conséquent, nous ne traiterons pas de ces créatures dans le présent développement consacré à l'hybridation. Il serait cependant faux de conférer à ces animaux un statut équivalent à celui d'un animal comme le mouton, qui participe de la vie ordinaire des hommes du Moyen Age. A ce titre, nous les qualifierons de merveilles, en notant que celles-ci sont associées à l'idée d'un ailleurs, souvent oriental, où la création existe sous des formes inconnues dans le monde proche, et où les rapports de continuité et de discontinuité entre les espèces sont distribués différemment. Intégrer ces créatures dans les églises permet au décor d'embrasser l'ensemble de la création, jusque dans ses limites extrêmes et donc incertaines.

On le conçoit : derrière la nécessité théorique d'une typologie, la diversité des images d'hybrides engage souvent des réalités complexes qu'il est difficile de considérer sans les rabattre sur des conceptions normatives du monde créé au Moyen Age. Si l'investigation mérite d'être menée, c'est qu'elle implique une importante question d'ordre anthropologique. Il s'agit en quelque sorte de cerner comment une société dont les classes dominantes pensent l'organisation en termes d'ordines, une société obsédée 
par les principes de classification et de hiérarchie, pense ce qui lui échappe. A un niveau plus général, et pour reprendre les catégories de Philippe Descola, il s'agit de se demander comment une société analogique, caractérisée par la séparation des existants, pense par le biais des images leur mise en relation par d'autres moyens que les correspondances et les similitudes. Cette question en implique une seconde. Face à ces images hautement problématiques, il est nécessaire de déterminer dans quelle mesure elles reflètent les seules conceptions que l'Église se fait de l'ordre et du désordre dans la création et de se demander si elles ne renvoient pas aussi à des conceptions du monde, et surtout des forces ambiguës qui y sont en jeu, largement partagées au XI ${ }^{\mathrm{e}}$ siècle et dont les clercs se verraient obligés de tenir compte.

\section{Une ornementalisation végétale de l'animal}

Fig. 36
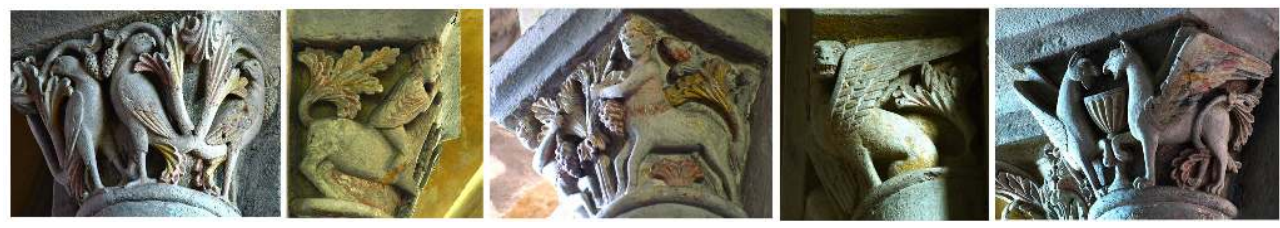

Animaux végétalisés (Mozat)

Deux édifices font un usage particulièrement intensif de l'hybridation : Saint-Pierre de Mozat et Saint-Marcellin de Chanteuges. Dans l'abbatiale de Mozat, les hybridations entre les différentes formes animales et le végétal abondent: elles concernent les griffons, les boucs, les dragons, les centaures et les oiseaux qui, tous, voient leurs formes s'altérer (fig. 36) ${ }^{131}$. Signe évident de l'importance de ces figures, tous ces chapiteaux présentent des paires et parfois même des quaternités d'animaux, et il arrive que certains de ces chapiteaux forment des paires entre eux ${ }^{132}$. On mesure en regardant ces images toute la distance qui les sépare des textes analysés auparavant. Alors que saint Bernard n'évoque que des hybridations en lien avec l'animalité (animal-animal ou animal-humain), aucune créature de ce type n'apparaît à Mozat, où l'on rencontre en revanche une série de créatures bien identifiées (des entités), dont une des extrémités s'hybride vers le végétal. Et il est tout à fait impossible de qualifier de monstruosités la plupart de ces figures, qui incarnent au contraire des valeurs tout à fait positives au sein de la création: c'est notamment le cas des oiseaux qui, on l'a vu, participent, comme le végétal, à l'ornementation de l'édifice; c'est le cas aussi des griffons qui, placés de part et d'autre d'un calice, s'intègrent dans une composition à caractère clairement eucharistique. Le processus d'hybridation traverse tout le monde animé, depuis ses manifestations les plus positives (l'oiseau) jusqu'aux plus négatives (le dragon), n'évitant que l'humain, pourtant très fortement associé au végétal dans cet édifice. On notera parallèlement le traitement singulier du centaure. Plutôt que d'en faire l'image d'une sexualité débridée, le sculpteur de Mozat met l'accent sur sa dimension positive ${ }^{133}$ : par la végétalisation de sa queue, cette figure témoigne d'une hyper-hybridation permettant d'associer positivement le végétal (dont la valeur d'ornatus est soutenue à travers toute l'église), l'animal (le cheval) et l'humain.

D'autres principes président à la réalisation de ces chapiteaux à figures hybridées. Tous montrent deux figures identiques, disposées de part et d'autre de l'axe de symétrie 
médian, et aucun d'entre eux n'engage le moindre discours narratif. L'inverse se vérifie également, puisque dans les scènes plus narratives ou historiées (Jonas, Samson et le lion...), la construction est dissymétrique et les animaux ne sont jamais hybridés. Que conclure de ces caractéristiques récurrentes? Ce qui se joue dans ces images, c'est fondamentalement l'articulation harmonieuse de la diversité du monde créé, et la duplication symétrique de ces êtres doit être comprise comme un phénomène d'intensification valorisante. Ici, l'hybridation, qui est toujours une végétalisation, doit se penser comme un procédé d'ornementalisation (au sens précisé plus haut). Par leurs extensions végétales, par leur mise en ordre symétrique, ces figures, avec toute leur hétérogénéité, participent également du décor de l'édifice et du milieu paradisiaque qu'elles contribuent à rendre sensible.

Bien qu'elle soit capable de ramener sur le même plan des créatures de natures très différentes, la végétalisation n'en est pas pour autant homogène. A Mozat, elle présente toute une gradation, depuis le simple épanouissement des queues (avec une variante pour les griffons, où le feuillage s'épanouit entre les pattes) jusqu'à l'importance considérable qu'elle prend dans les chapiteaux aux oiseaux. Les feuillages possèdent alors une ampleur qu'ils n'ont pas ailleurs et participent à l'association très poussée, voire à l'entrelacement, des animaux (dans l'un des chapiteaux, chacun des oiseaux tend le bec vers le fruit émanant de la queue végétalisée de son congénère).

Fig. 37

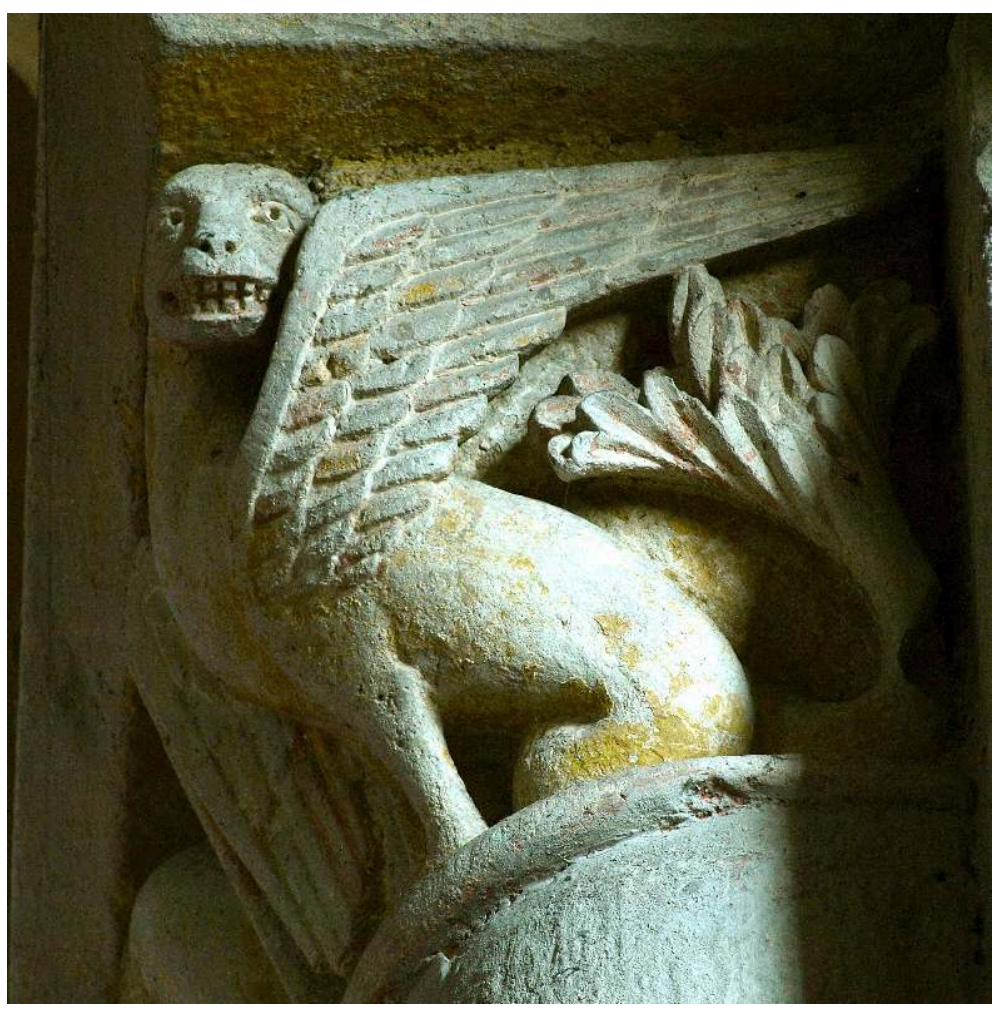

Dragons végétalisés (Mozat)

108 Se situant en dehors de toute historia, les images d'hybrides ne peuvent s'intégrer dans aucun discours moral; mieux, ce sont elles qui intègrent et harmonisent, en les soumettant à un ordre supérieur commun, des figures dont les valeurs sont normalement opposées (comme les oiseaux et les dragons). Les forces négatives ne sont 
pas ici niées, comme en témoignent ces dragons montrant agressivement leurs crocs (fig. 37); elles sont plutôt canalisées par l'ornement, comme si l'église tirait aussi sa force des tensions négatives qui la traversent. En somme, l'hybridation (associée à une disposition ordonnée, symétrisée) force la diversité des créatures - avec toutes les valeurs différencielles (voire opposées) qui s'attachent à elles - à contribuer au décor de l'édifice et à sa glorification.

Fig. 38

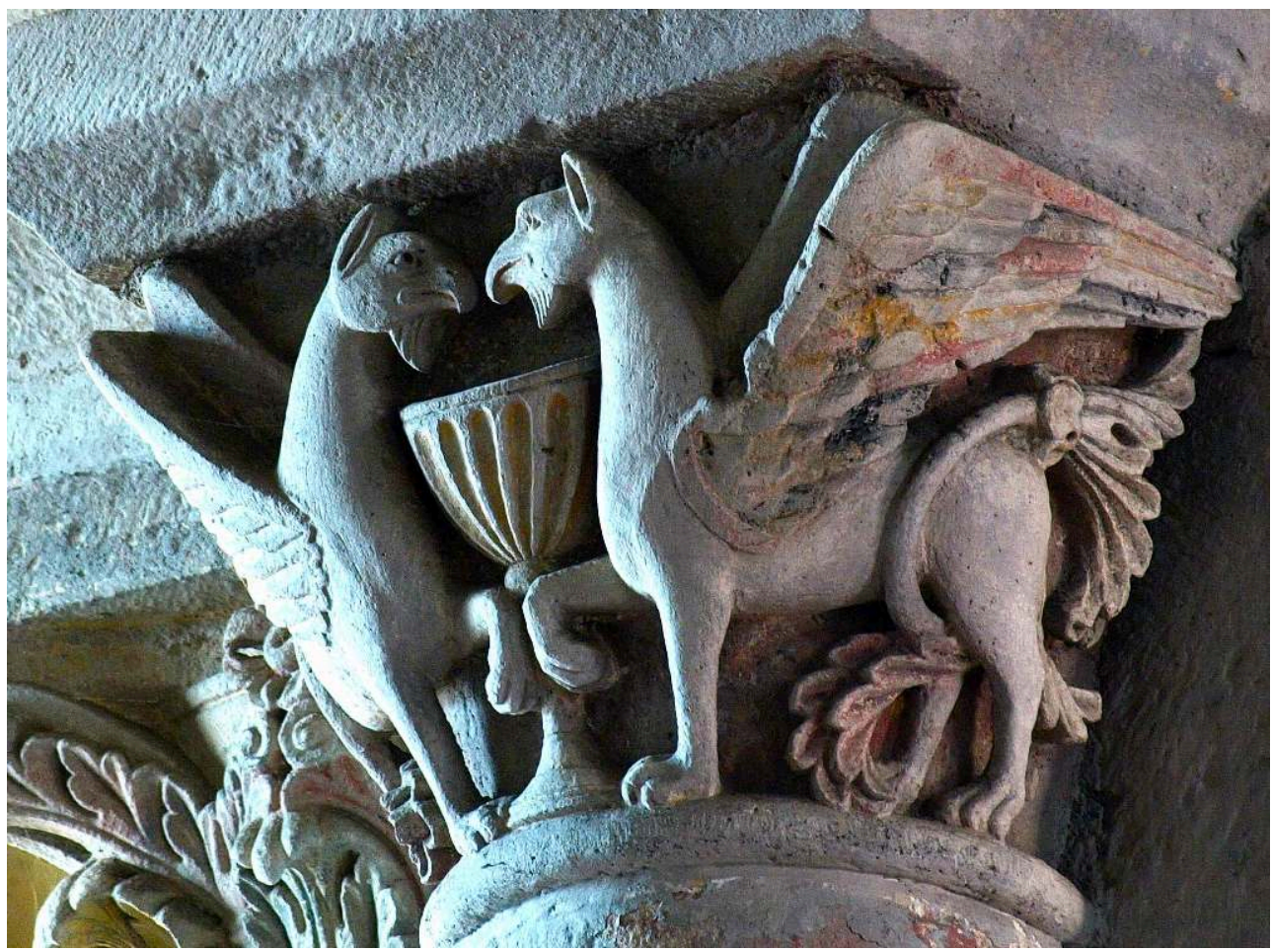

Paire de griffons végétalisés (Mozat)

L'hypothèse d'un tel processus de sublimation des forces positives autant que de canalisation et d'encadrement des forces négatives, par le biais du végétal, prend plus de consistance si l'on prête attention aux parties des corps animaux qui se végétalisent. Dans tous les exemples mozacois, c'est bien de la queue, c'est-à-dire du bas corporel, que s'élève le végétal (fig. 38). L'opposition haut/bas, si structurante pour la compréhension du monde animal, prend ici toute sa pertinence ${ }^{134}$ : ce qui est relevé, c'est avant tout ce qui pend vers le sol - la partie la plus métonymiquement animale. Si tel est bien le cas, c'est alors en tant que processus de spiritualisation (au sens fort défini au début de ce chapitre) qu'il convient de comprendre ces hybridations. Allons plus loin. Puisque, dans le cas des griffons, la gerbe végétale se déploie en lieu et place du sexe de l'animal, il semble bien que le sculpteur ait tenu à montrer que la spiritualisation de l'animalité se manifestait jusque (et même d'abord) dans son extrémité la plus corporelle.

\section{Une végétalisation spiritualisante du corps humain?}

110 L'usage très cohérent de la végétalisation à Mozat trouve son pendant dans l'église de Chanteuges, qui lui est iconographiquement très liée. De nombreux motifs présents 
dans la prestigieuse abbatiale se retrouvent ici (mêmes animaux, même intrication de l'homme et du végétal, même plasticité de la sculpture), mais leur organisation est entièrement repensée.

Fig. 39
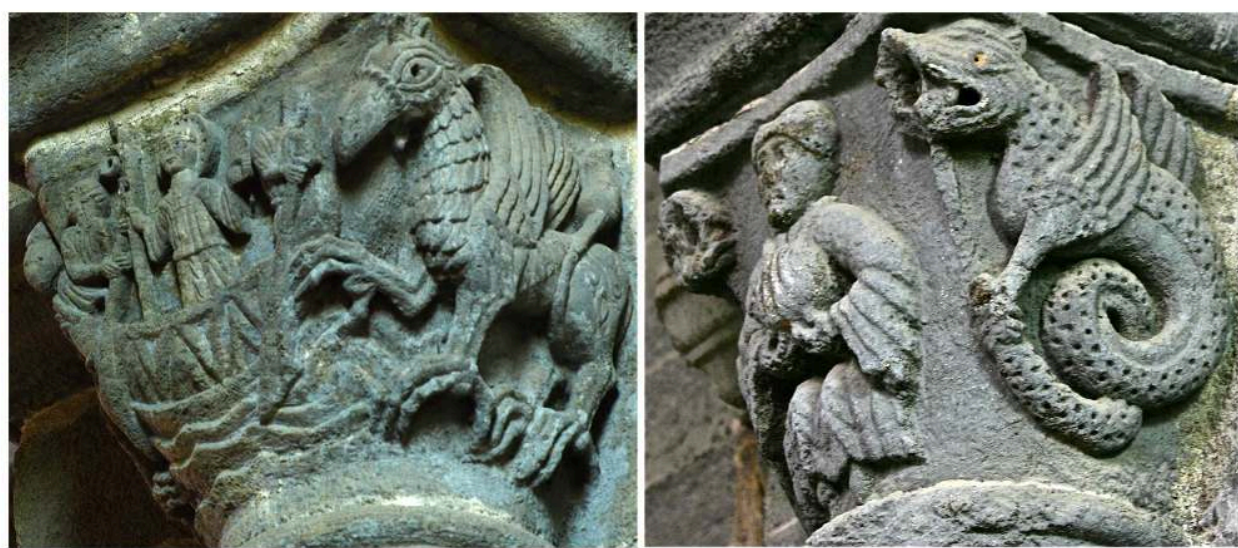

Griffons et dragons non-végétalisés dans des chapiteaux historiés (Chanteuges)

Les animaux que l'on rencontrait à Mozat dans un cadre strictement ornemental (les griffons, les lions, les dragons) conservent leur disposition symétrique, mais ils sont ici repris dans le cadre d'une historia à tendance moralisante (fig. 39). Comme pour confirmer l'incompatibilité entre hybridation ornementale et historia, ces figures ne sont pas végétalisées à Chanteuges. De fait, on assiste à un recul considérable de l'hybridation animal-végétal dans cette église.

Fig. 40

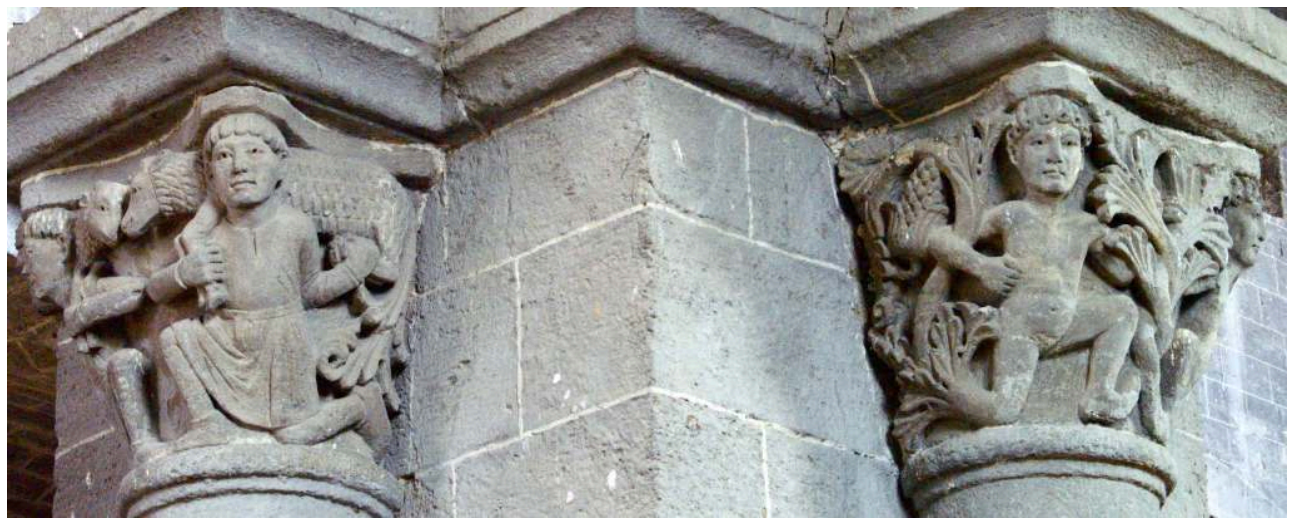

Végétalisations d'animaux et d'humains (Chanteuges)

112 Un seul animal fait l'objet d'une hybridation, du reste relativement discrète. Elle concerne la queue des animaux dans le célèbre chapiteau des "porteurs de moutons ». L'effet d'ornementalisation que provoque cette discrète végétalisation est confirmée par la symétrie axiale qui structure ce chapiteau, et par l'absence d'interaction ou de dimension narrative entre les deux groupes de figures, absolument identiques. De cette image dont on a vu qu'elle jouait un rôle articulatoire (voir chapitre V), on retiendra par ailleurs qu'elle amorce une série de chapiteaux où les relations entre les différents existants sont pensées sur un mode particulièrement intense (fig. 40). Mais alors que 
Mozat réservait l'hybridation aux animaux et préférait jouer de l'intrication pour l'humain, c'est généralement la règle inverse qui nous est ici proposée, donnant naissance à deux incroyables images d'humains végétalisés (fig. 41).

Fig. 41
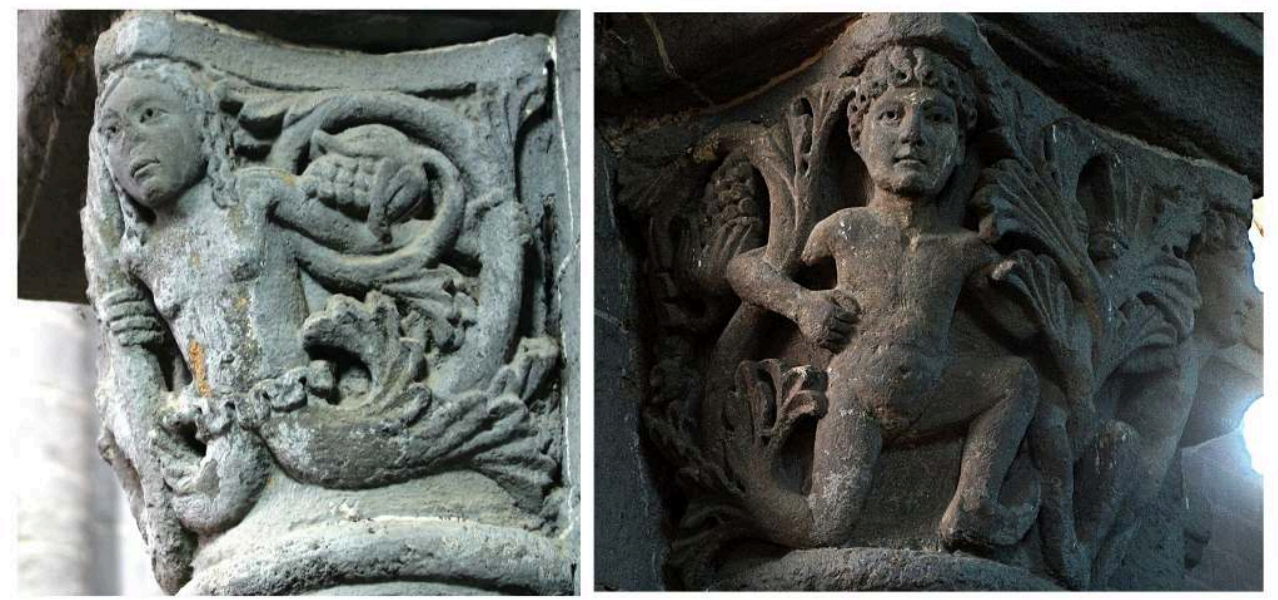

Femmes et hommes végétalisés (Chanteuges)

De ces deux figures, la version féminine est sans doute la moins troublante. De par la queue bifide, la chevelure relâchée, la poitrine dégagée, on reconnaît instantanément l'image de la sirène. Mais on aurait tort de s'arrêter à une telle identification, qui ne tient pas compte du formidable développement végétal des faces latérales. En fait, rien ne permet de déterminer le statut de cette figure, qui pourrait tout aussi bien être une femme végétalisée se trouvant ainsi intégrée à l'ornatus. En tout état de cause, la mise en évidence des caractères sexuels, secondaires et primaires, est ici patente.

Fig. 42
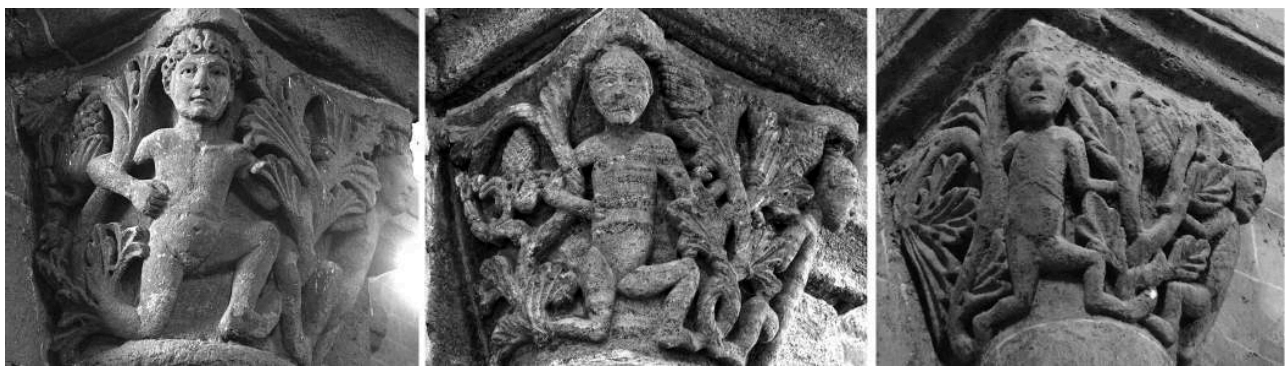

Trois versions de l'homme végétalisé (Chanteuges)

Le même procédé se retrouve dans le pendant masculin de ce chapiteau, une œuvre unique dans l'art roman, sans postérité aucune, mais suffisamment marquante pour avoir été copiée deux fois dans l'église de Chanteuges ${ }^{135}$ (fig. 42). La portée de cette figure, qui pousse la spiritualisation des corps à des niveaux inédits, s'éclaire si on la compare avec les sculptures d'édifices antérieurs, vis-à-vis desquelles elle prend position (fig. 43). 

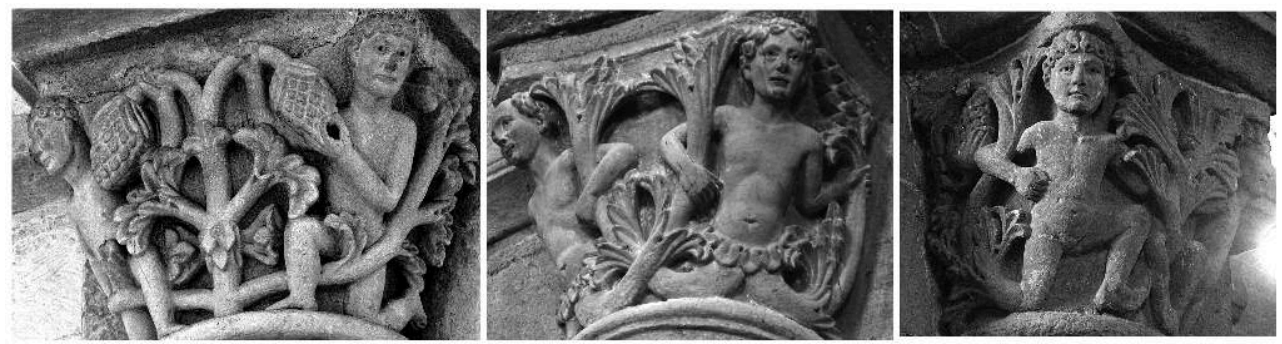

Hommes dans le végétal et hommes hybridés (Mozat, Brioude, Chanteuges)

En effet, le chapiteau de Chanteuges se pense lui-même comme une reformulation de deux chapiteaux prestigieux. Il s'agit d'abord des «tritons " à queues végétalisées de Brioude, auquel il emprunte l'enlacement du végétal par le coude, ainsi que l'hybridation dans sa partie inférieure. Mais Chanteuges introduit une différence notable : comme pour mieux marquer la différence avec le triton ou tout autre être merveilleux, l'extension végétale vient ici prolonger la cheville (voire seulement l'extrémité du pied) au lieu de se présenter comme la partie inférieure d'un être composite. L'autre chapiteau mis en jeu (peut-être plus fortement encore) est celui des hommes dans le végétal de la nef de Mozat, dont la position (un genou à terre, l'autre en avant) est reprise très littéralement, de même que la présence d'un élément végétal central. Mais, alors que dans ce dernier chapiteau, le sexe de l'homme était caché (en même temps que suggéré) par une feuille, le sculpteur de Chanteuges opte pour un déploiement sans réserve du corps masculin, dont les jambes s'ouvrent largement sur un sexe absent ${ }^{136}$.

Ces figures d'hommes et de femmes végétalisés offrent un défi de taille à l'intellection. En se fondant sur les critères formels que nous venons de dégager, sur leur ornementalisation symétrisée et végétalisée, on peut dire qu'elles contribuent à faire du corps, pris dans une continuitas avec le reste du monde créé, un élément de l'ornatus ecclésial (nous y reviendrons). A Chanteuges, l'exhibition des corps dans leur nudité et l'insistance sur les parties normalement associées à la sexualité attirent l'attention sur les forces vitales et génératives de la création. Les caractères sexuels féminins et masculins sont ici exhibés et reportés dans les extensions végétales de ces êtres, sous la forme spiritualisante d'une ornementation qui ne peut se penser sans sa dimension corporelle et matérielle. L'absence de représentation des organes sexuels ne suppose pas nécessairement une négation de la sexualité : cette physiologie rappelle plutôt certaines représentations contemporaines d'Adam et Ève avant la Chute, où leur nudité désexuée, mais néanmoins marquée par la différence des genres, évoque l'existence d'une sexualité sans tache au Paradis.

\section{Variante hyper-positive de l'hybridation : Orcival}


Fig. 44
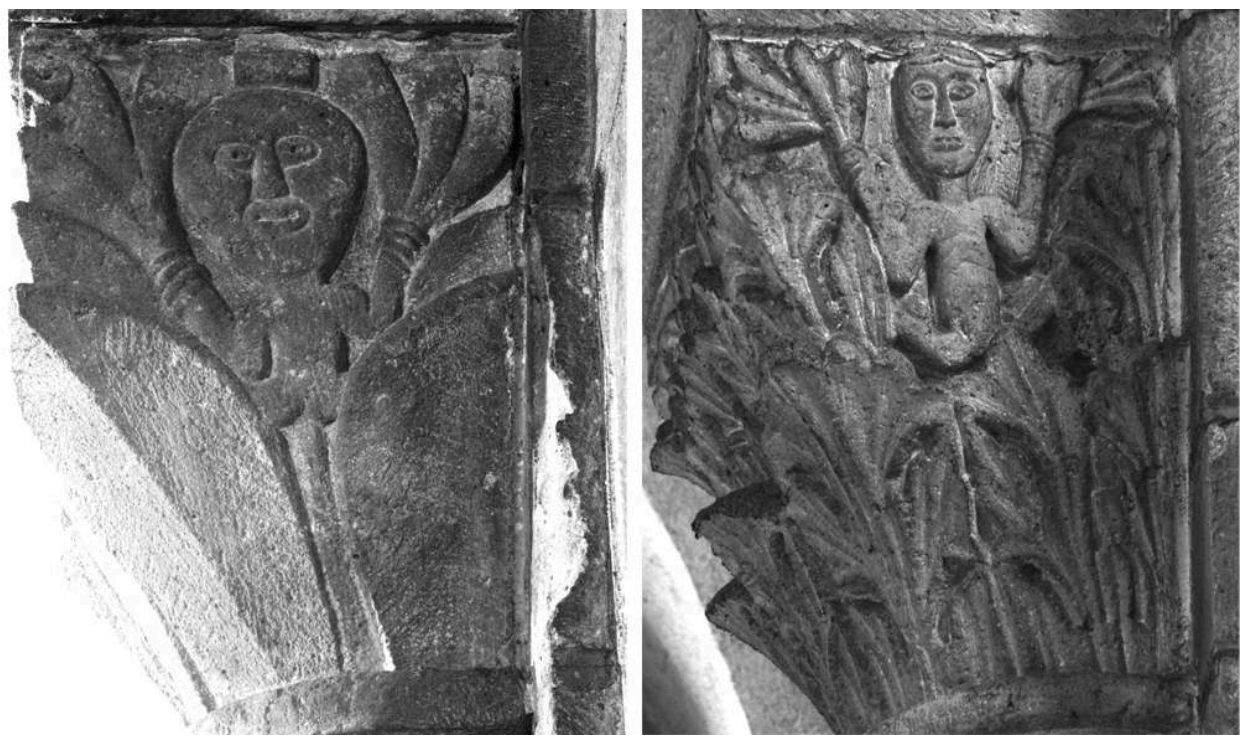

Hommes végétalisés (Orcival)

Aucun autre édifice de notre corpus ne révèle une pratique de l'hybridation aussi maitrisée et aussi sophistiquée que les deux églises que nous venons de parcourir. Cependant, dans l'intense circulation des formes qui caractérise les églises d'Auvergne, certains motifs sont cités ailleurs et adaptés aux problématiques locales. Le cas le plus frappant est sans doute celui d'Orcival, qui suit un parti-pris très singulier, conduisant notamment à évacuer tout chapiteau historié de l'hémicycle. Dans cet édifice, l'hybridation est très rare, mais particulièrement signifiante. On rencontre ainsi, aux deux extrémités de la nef et avec des proportions différentes, une figure très étrange, au beau milieu du végétal, à la tête surdimensionnée et tenant dans chacune de ses mains un bouquet de feuillages (fig. 44). Si cette figure est étrange, c'est justement parce qu'elle possède plusieurs éléments d'indiscernabilité et d'hybridation. C'est tout d'abord le cas des bras, dans la mesure où rien dans la pierre ne permet véritablement de déterminer s'ils ne sont pas aussi hybridés dans le végétal qu'ils supportent; c'est également le cas de la partie inférieure de ces corps qui se divisent en deux à la manière des sirènes bifides, mais dont le feuillage cache les extrémités ${ }^{137}$. Ces deux figures, placées respectivement dans le narthex et à la limite du transept, encadrent les chapiteaux de la nef, incarnant sur un mode désormais familier, la vitalité propre au végétal qui traverse tout cet édifice. 


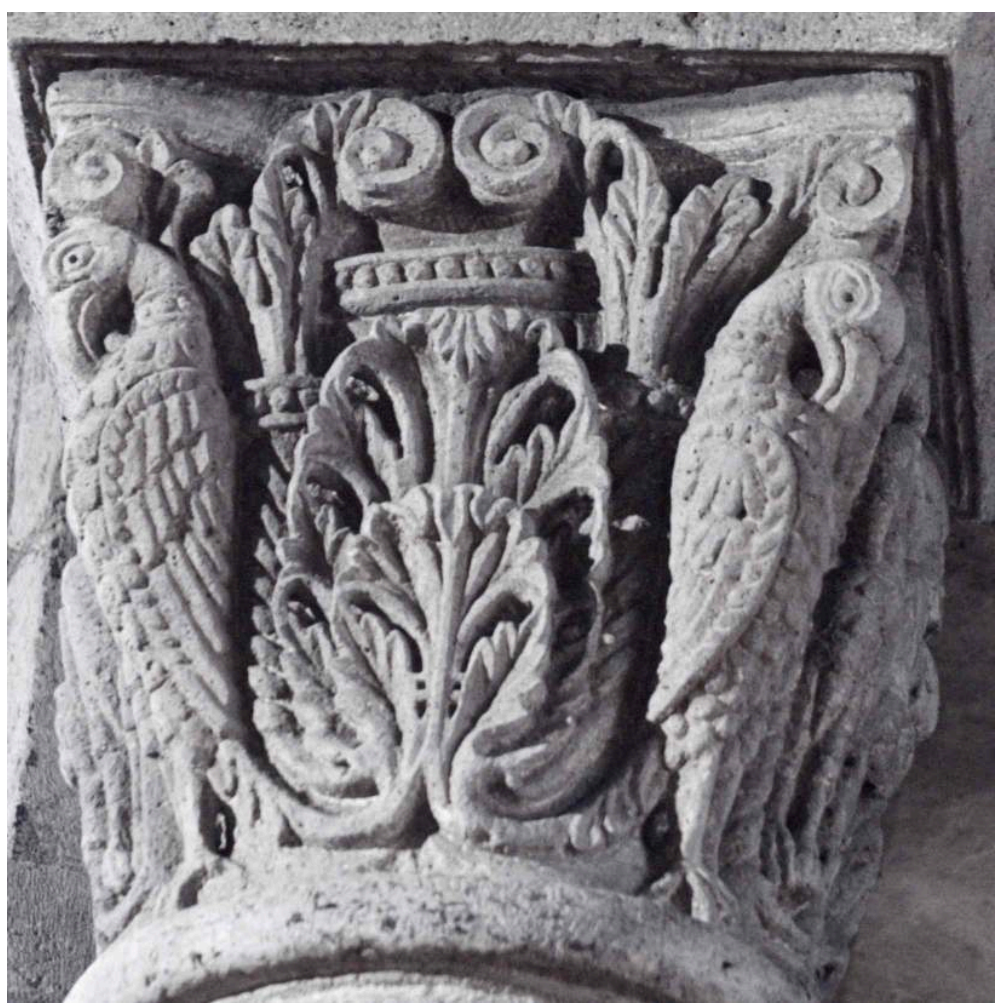

Aigles végétalisés (sanctuaire d'Orcival)

Ph. Inv. Choplain-Maston, 94.63.1873X, copyright Région Auvergne - Inventaire général, AGAGP

118 C'est dans le sanctuaire que la végétation atteint la plus haute intensité. Se déploie, sur l'ensemble des chapiteaux de l'hémicycle, une fabuleuse méditation sur le végétal, élevé ici à un niveau de dignité bien apte à célébrer le lieu le plus éminent de l'édifice. De ces huit sculptures, une seule comporte un élément animal, au plus près de l'axe de l'édifice (fig. 45). Sur chacune de ces faces, deux oiseaux sont représentés, qui tantôt s'entrelacent avec le végétal, tantôt s'hybrident avec lui dans un déploiement majestueux. Sur les faces latérales, les queues végétalisées des aigles s'accouplent en une double feuille superposée qu'encadrent deux caulicoles se terminant en crosse et que couronne une ceinture orfévrée dont la convexité dessine la forme du calathos. Nulle part ailleurs en Auvergne, l'accointance ornementale entre les habitants du ciel et le végétal ne connaît un tel développement. Si la mise en ordre et en connexion du monde créé par le biais de la symétrie et de l'hybridation fait l'objet d'une première proposition systématique dans la nef de Mozat, c'est à Orcival, dans le sanctuaire, qu'elle trouve sa formulation la plus aboutie ${ }^{138}$. 
Fig. 46

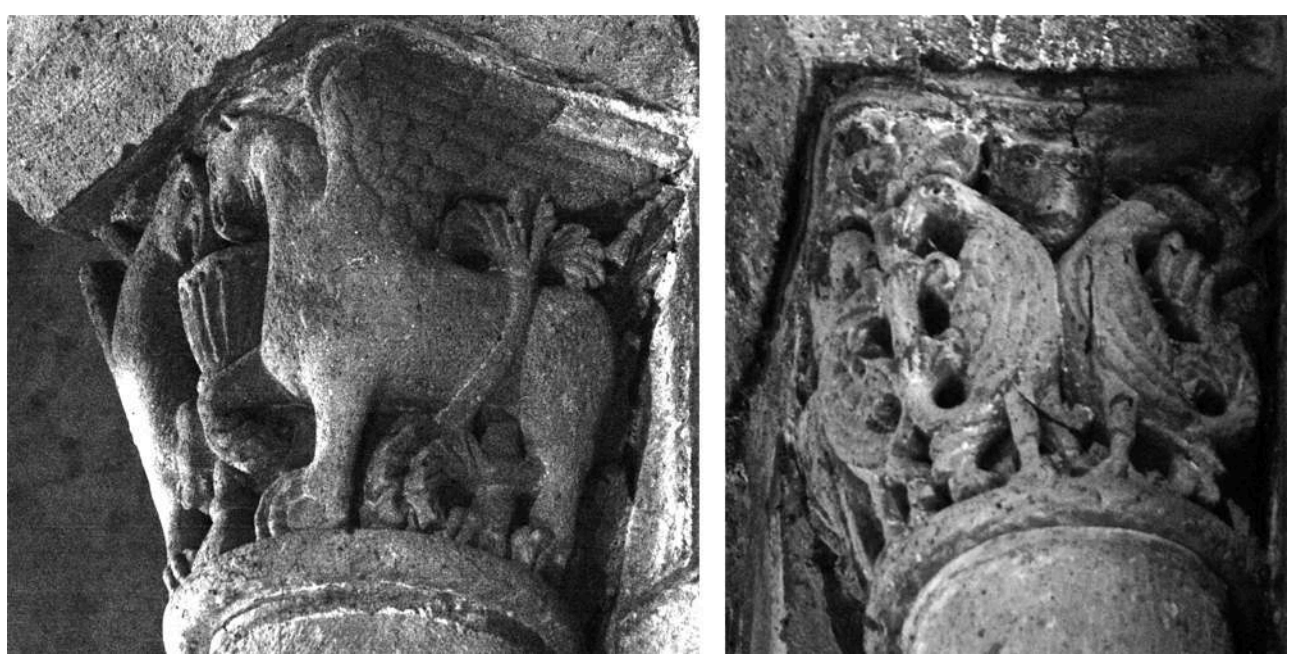

Paire de griffons et quaternité d'oiseaux végétalisés (Orcival)

Seules deux autres hybridations se rencontrent dans cette église, et s'affirment comme deux reprises explicites de Mozat (fig. 46). Il s'agit d'une part des griffons, d'une apparence physique particulièrement solide, qui viennent ici honorer la fenêtre axiale du déambulatoire. L'hybridation des queues suit en tout point celle de leur modèle et sans doute les griffons font-il écho, sur un mode mineur, aux oiseaux végétalisés du sanctuaire, qui leur font face. D'autre part, des oiseaux végétalisés apparaissent également dans le déambulatoire, sur un modeste chapiteau d'angle, plutôt rustique. En le comparant au chapiteau grandiose du sanctuaire, on mesure la différence de dignité entre les deux espaces. De plus, outre la simplification que le petit chapiteau fait subir à son modèle mozacois, on note que des têtes de bêtes se logent entre celles des volatiles; bien que leurs gueules ne soient pas ouvertes, elles sont une menace pour les oiseaux, comme il en va dans trois des autres églises de notre corpus.

\section{Positivité, ambivalence et négativité de l'hybridation : de Saint- Nectaire à Notre-Dame-du-Port}

Fig. 47
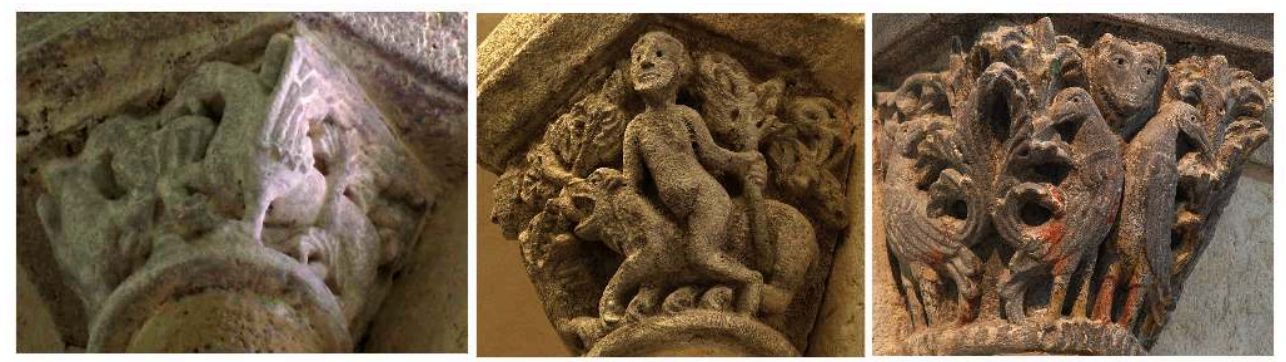

Griffons, bêtes et oiseaux végétalisés (Saint-Nectaire)

120 Le travail de reprise du vocabulaire mozacois que l'on vient de voir à l'œuvre à Chanteuges et Orcival est mené d'une manière très proche à Saint-Nectaire. On y rencontre - traitées avec moins d'ampleur - certaines des hybridations déjà observées : c'est le cas des lions, des griffons et des oiseaux, dont les queues sont ici aussi 
végétalisées et que l'on retrouve disposés symétriquement, comme à Mozat (fig. 47). Mais la création apparaît, cette fois, sous un jour sensiblement plus inquiétant, puisque des animaux comme le dragon ou le bouc, qui étaient ornementalisés à Mozat, sont traités d'une façon tout à fait nouvelle: le dragon est intégré dans une historia (le combat avec l'ange) où, logiquement, il n'est pas végétalisé, tandis que l'homme sur le bouc est désormais associé à l'animal à la lyre, ce qui lui confère un caractère clairement négatif. Dans les deux cas, ces animaux sont dévégétalisés et acquièrent la connotation morale négative qu'ils possèdent généralement dans l'art roman ${ }^{139}$.

Fig. 48

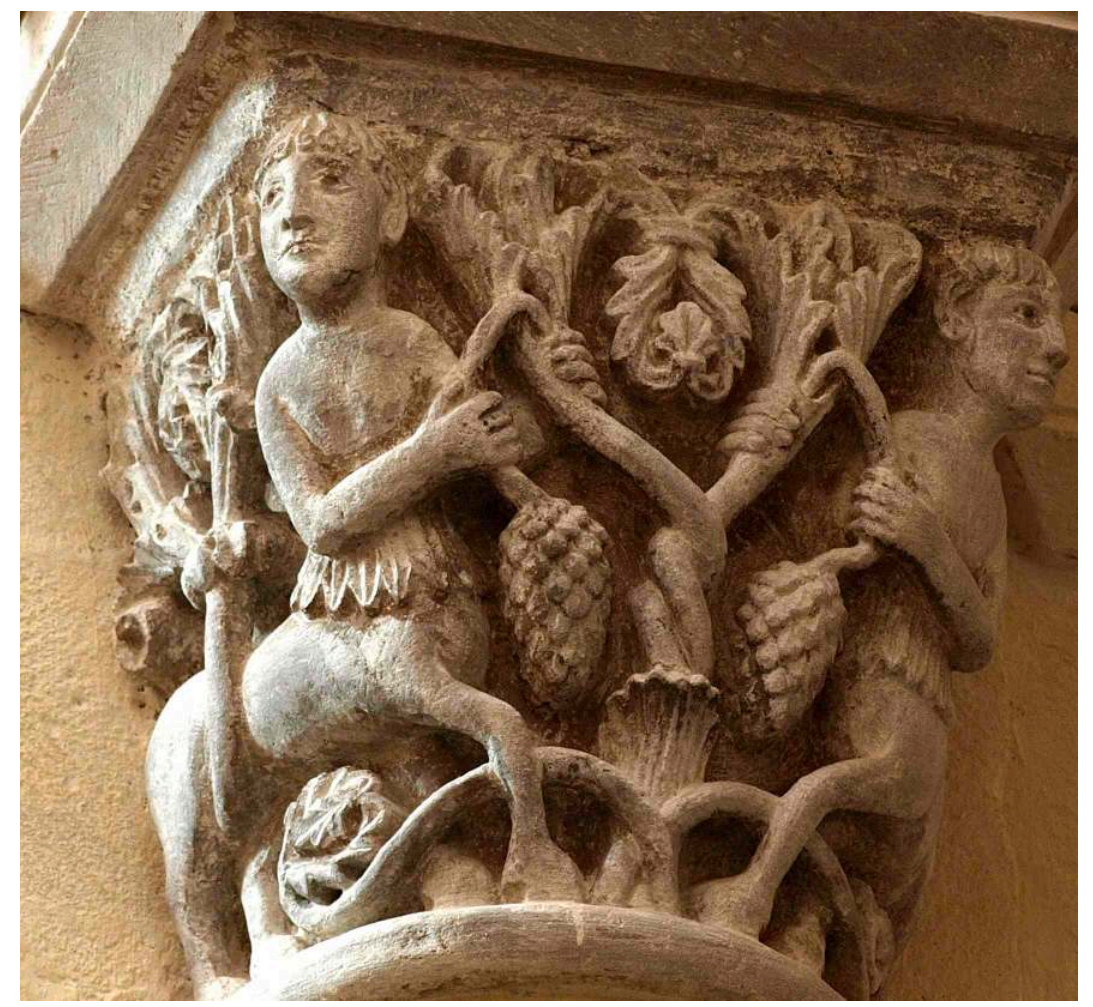

Centaures végétalisés (Notre-Dame-du-Port)

Les sculptures de Notre-Dame-du-Port reprennent certains des principes d'hybridation en vigueur à Mozat. La référence est particulièrement explicite dans l'image toute positive d'un couple de centaures dont la végétalisation a été traitée avec le style plus maniériste, propre à l'édifice clermontois (fig. 48). 
Fig. 49
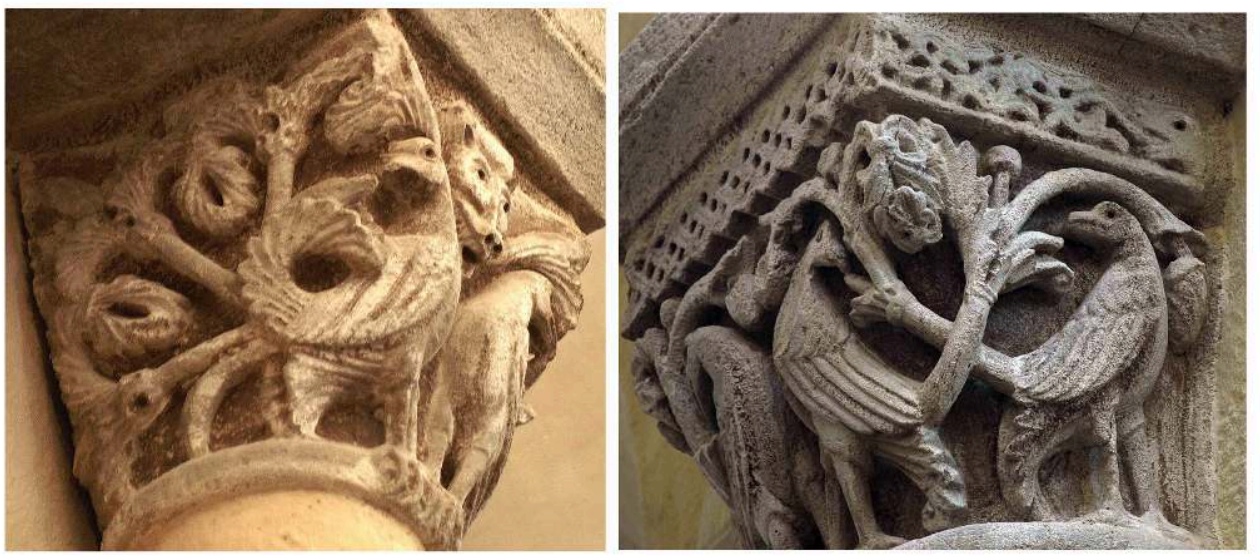

Paire et quaternité d'oiseaux dont les queues s'hybrident en caulicoles (Notre-Dame-du-Port)

Entre les deux édifices, la différence n'est pas seulement stylistique, mais aussi plus fondamentale. A Notre-Dame-du-Port, l'hybridation joue en effet un rôle nouveau et participe d'un couplage serré, liant le végétal et l'architecture. C'est ainsi qu'à deux reprises (comme on l'a vu en détail dans le chapitre IV), les oiseaux se végétalisent selon une modalité très singulière, puisque leurs queues prennent la forme de caulicoles - au sens où ce terme a été défini -, les tiges et leurs collerettes végétales suggérant de minuscules colonnes surmontées de chapiteaux végétaux (fig. 49). Un tel jeu de mise en abyme du chapiteau, qui s'opère ici par l'entremise de la vie animale, est un élément fort d'association entre l'ornement animé et son support matériel : nous aurons l'occasion d'y revenir.

Fig. 50
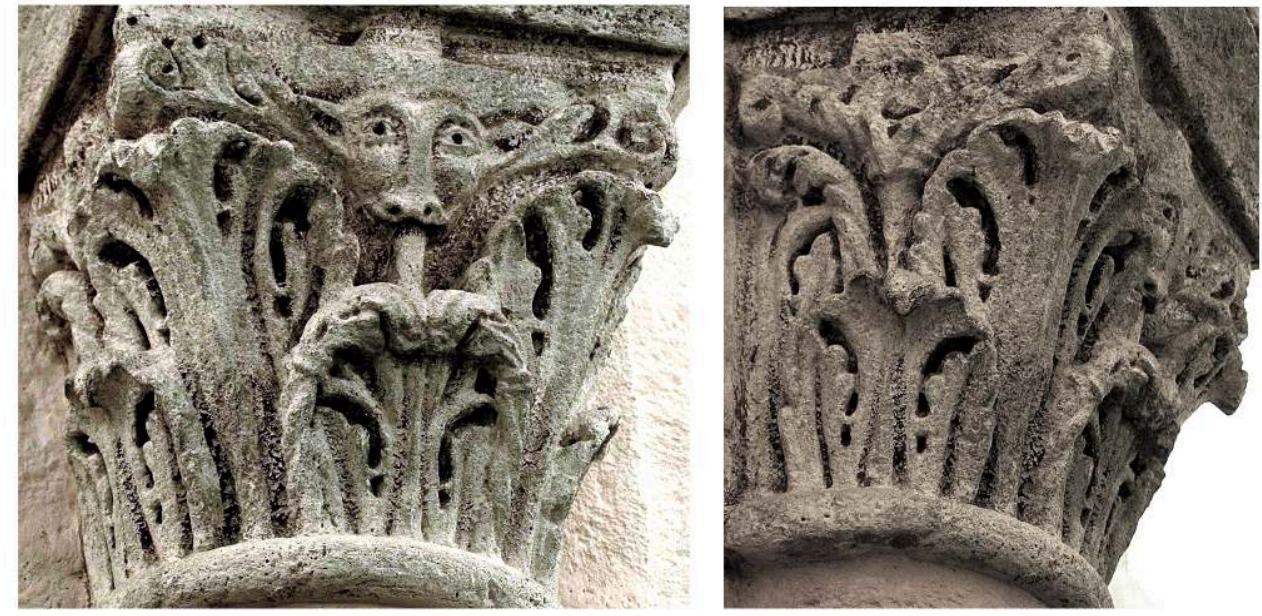

Bête aux ramures s'hybridant en volutes (Notre-Dame-du-Port)

Ce lien entre les différentes manifestations du monde créé fait l'objet d'une remarquable invention de sculpteur sur un chapiteau représentant une tête de bovidé prise dans le végétal (fig. 50). Cet animal étrange, qui engoule une tige, est littéralement traversé par la végétalité, puisque ses oreilles se prolongent en ramures feuillues dont les extrémités se confondent avec des volutes d'angle, tout en en 
inversant le sens d'enroulement (voir chapitre IV). Cette étonnante trouvaille témoigne de la façon dont l'hybridation permet d'associer l'animal avec ses ramures, le végétal avec ses rameaux et avec la structure qu'on dira « architectonique » du chapiteau, dans la mesure où ses volutes expriment, formellement au moins, une fonction portante.

Fig. 51
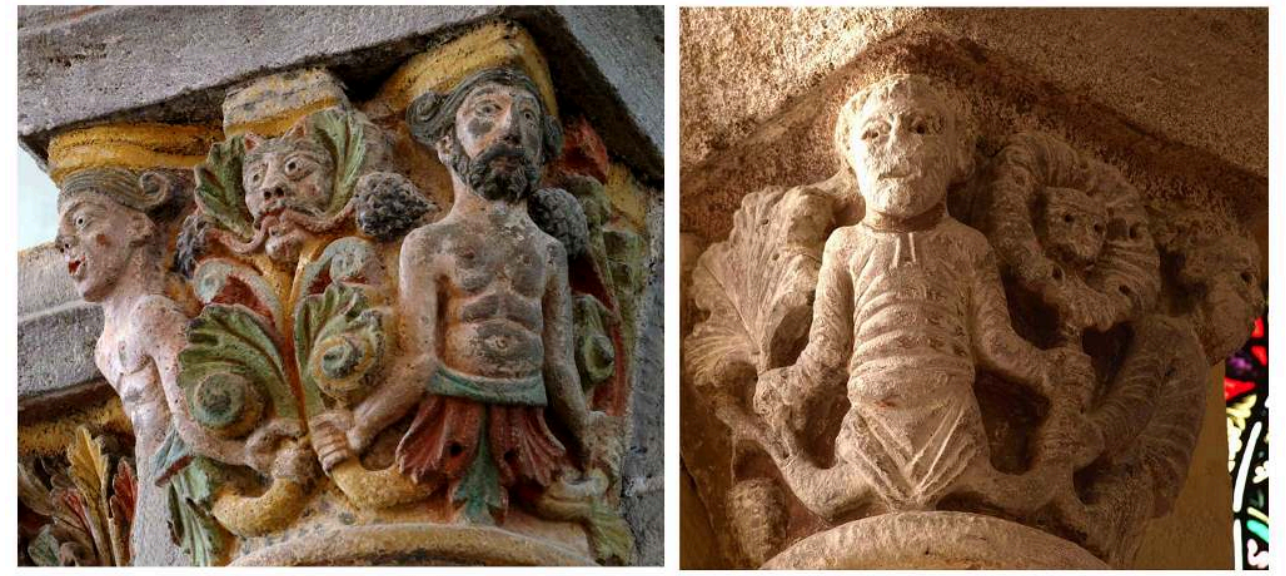

Hommes végétalisés et masque (Saint-Nectaire, Notre-Dame-du-Port)

Enfin, il faut rappeler le caractère particulièrement ambivalent de l'association entre l'humain et le végétal, telle qu'elle s'exprime à Saint-Nectaire et à Notre-Dame-du-Port. On retrouve ainsi, sur l'un des chapiteaux les plus exceptionnels du premier édifice, des hommes végétaux tout à fait proches de ceux de Brioude ${ }^{140}$. Leur nudité, le déploiement fertile de leurs extensions végétales et la manière dont leurs corps supportent l'édifice font de ces créatures l'expression la plus positive des forces vitales de la création à Saint-Nectaire. Cependant, la belle croissance végétale est comme tempérée par la présence d'un masque inquiétant entre les deux hommes. Plus encore, dans la reprise de ce même thème à Notre-Dame-du-Port, les corps ne sont plus nus, mais vêtus, et s'hybrident entre eux au centre, leur union se prolongeant en une créature totalement hybride, dotée d'une tête que l'on a pu qualifier de bestiale. A l'autre extrémité de leurs corps, leurs mollets donnent naissance à une végétation associable à celle de la Chute, sur le chapiteau voisin de l'hémicycle. On mesure ici l'ampleur de l'écart séparant ces figures inquiétantes de celles, paisibles, des premières images de notre série. Non seulement il ne peut plus être question ici de spiritualisation du corps humain, donné dans sa nudité idéale, mais c'est une vision singulièrement plus ambigüe de la continuité au sein de la création qui est ici avancée.

Fig. 52
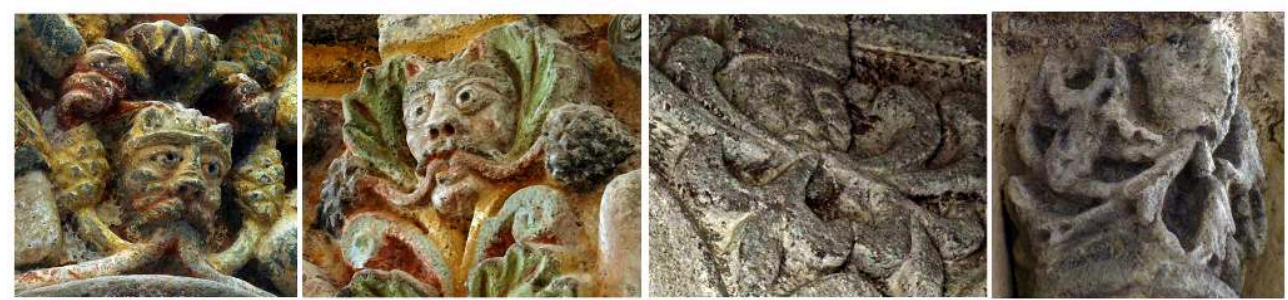

Masques végétalisés (Saint-Nectaire) 
Fig. 53
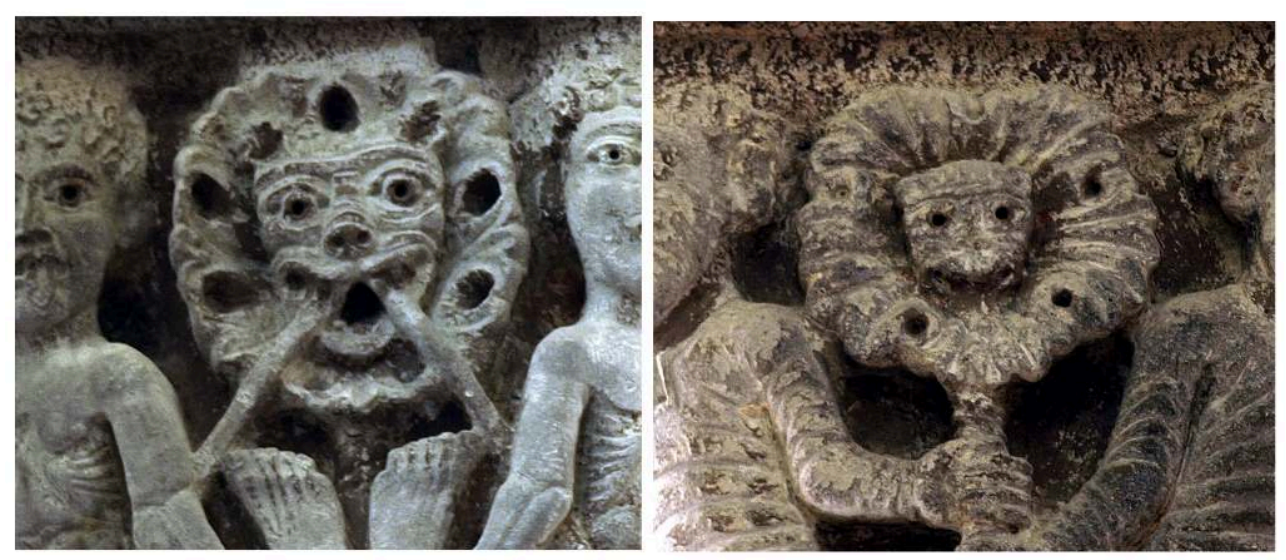

Masques végétalisés (Notre-Dame-du-Port)

Que signifient ces masques qui, dans ces deux édifices apparaissent au beau milieu des formes végétalisées ${ }^{141}$ ? Étonnante énigme que celle de ces figures traversées par le végétal, qui peuvent aussi bien en sortir que le cracher, et qui peuvent procéder autant de l'humain, de l'animal que du diabolique. Présents à quatre reprises à Saint-Nectaire (fig. 52) et deux fois à Notre-Dame-du-Port (fig. 53), ces masques sont à même d'exprimer toute une gamme de postures vis-à-vis des forces de la création, depuis l'évocation heureuse de la vitalité jusqu'à l'expression plus angoissée de forces non contrôlées. Ils ne peuvent se comprendre seuls et ne prennent sens que si on les replace au sein d'un ensemble de chapiteaux et dans le lieu de l'édifice qu'ils viennent connoter. Néanmoins, on tâchera de ne pas oublier que ces inventions formelles, dépourvues de toute référence textuelle, réagissent avec vigueur les unes par rapport aux autres, proposent des solutions plastiques contrastées et prennent des positions fermes, pensant à leur manière - expressive - le monde dans lequel elles s'inscrivent.

\section{L'image-hybride : les corps de l'architecture}

126 Une dernière réflexion nous invite à considérer l'hybridation sous un angle plus complexe, non seulement en tant qu'images d'êtres hybrides (qui restent malgré tout des représentations), mais en tant qu'images-hybrides, refusant autant qu'il est possible leur autonomie pour mieux s'inscrire et se fondre dans l'architecture. Nous avons déjà observé comment le monde animal pouvait évoquer des éléments relevant de l'architectural, et parfois s'hybrider avec eux : c'est le cas des oiseaux dont la queue se fait caulicole, à l'image d'une colonne couronnée d'un chapiteau ; c'est aussi le cas de la tête de bête dont la ramure modifie et affecte la structure qu'on a dite " architectonique» des volutes du chapiteau. Outre ces exemples animaux, on est frappé par la multiplicité des jeux sémantiques et plastiques qui tendent à faire du corps humain un élément architectonique. 
Fig. 54

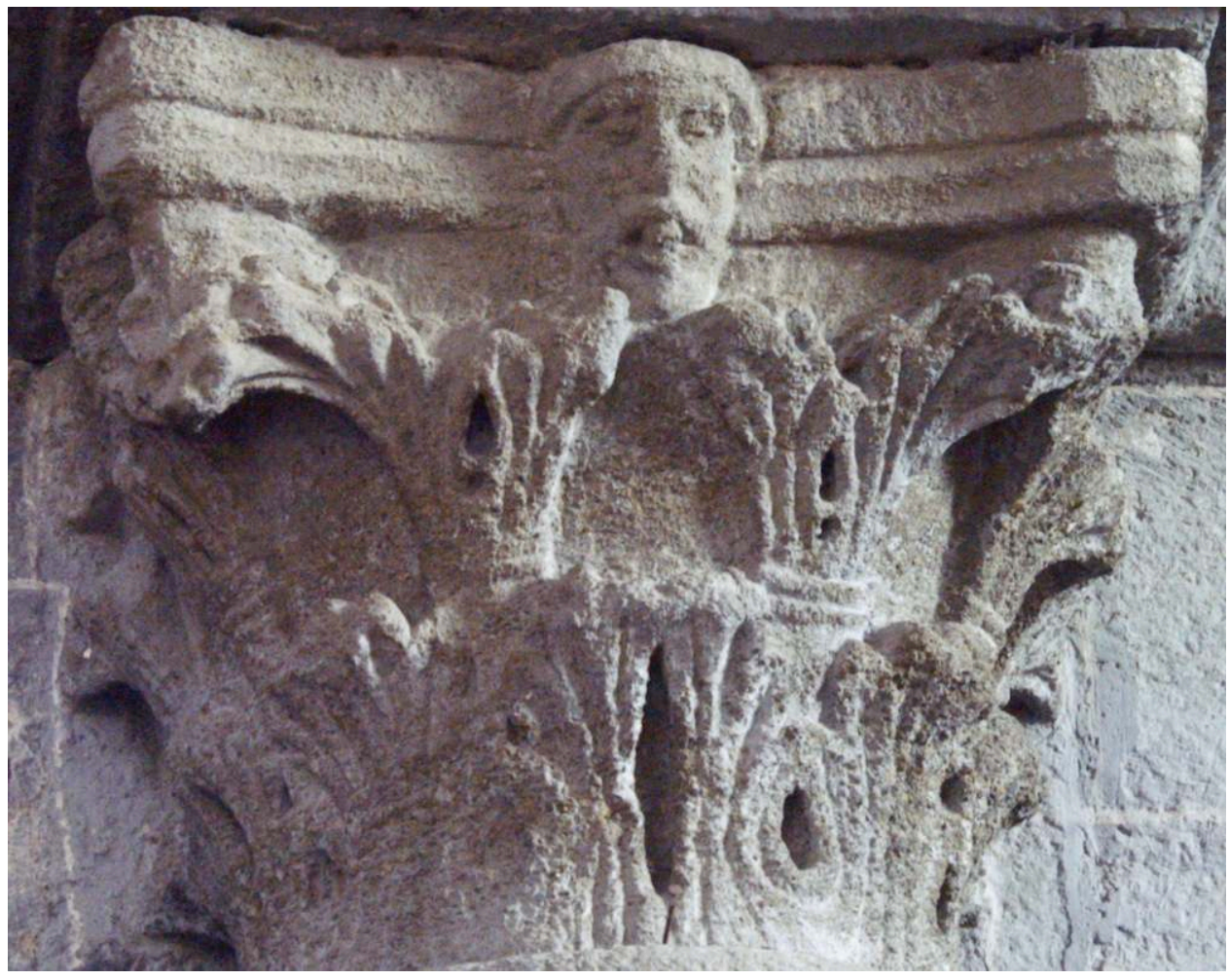

Masque anthropoïde sur l'abaque d'un chapiteau (Chanteuges)

Fidèle à la logique analogique de cette époque, fidèle notamment aux idées de correspondance entre microcosme et macrocosme qu'elle suppose, l'architecture déborde de jeux de similitude entre le corps humain et les éléments architecturés. Outre la comparaison fréquente entre l'église elle-même et le corps humain, on se rappelle qu'Isidore de Séville expliquait le terme de capitellum (chapiteau) par le fait que ce dernier constituait la tête des colonnes (" capita columnarum »; Etimologiae, XV, $8,13)$. A cet égard, les nombreuses têtes qui apparaissent de manière isolée dans les chapiteaux pourraient bien valoir comme jeu sur le signifiant, comme les affectionne tant le Moyen Age : des capita dans les capitella. De façon plus précise, l'une de ces têtes, incluse dans un chapiteau de Chanteuges (fig. 54) en lieu et place du « dé ", semble se fondre dans la pierre (ou en émerger?). L'abaque, pour l'occasion dédoublée, vient comme ceindre d'un bandeau le front de la tête barbue et suggérer une étonnante continuité entre l'humain et le minéral. Une telle intimité entre l'humain et l'architecture - notamment dans le cas de ces corps qui n'agissent pas et ne s'inscrivent dans aucune historia - est sans doute la manifestation la plus littérale du caractère vivant et animé des pierres de l'église. Certaines figures, plus complexes, dialoguent plus précisément encore avec l'aspect architectonique du chapiteau. 
Fig. 55

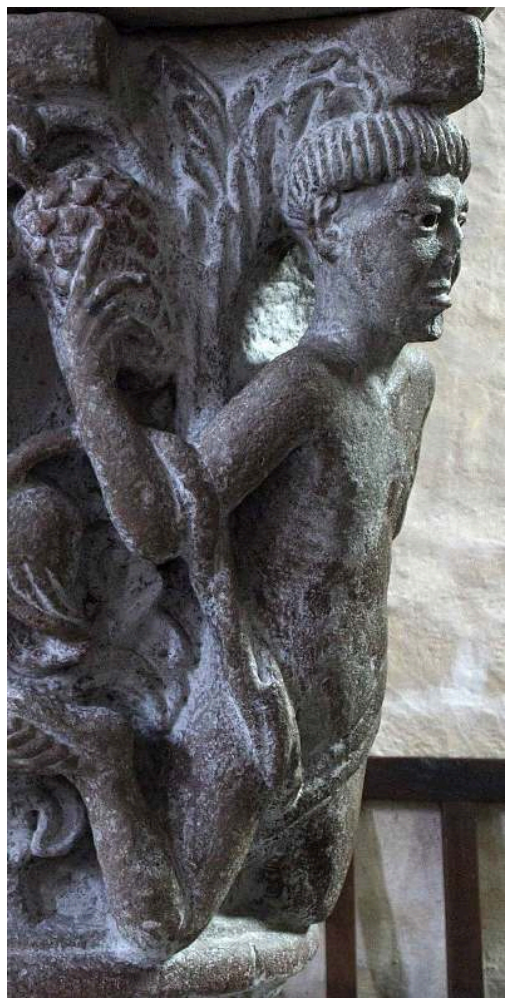

Homme colonne (Mozat)

Fig. 56

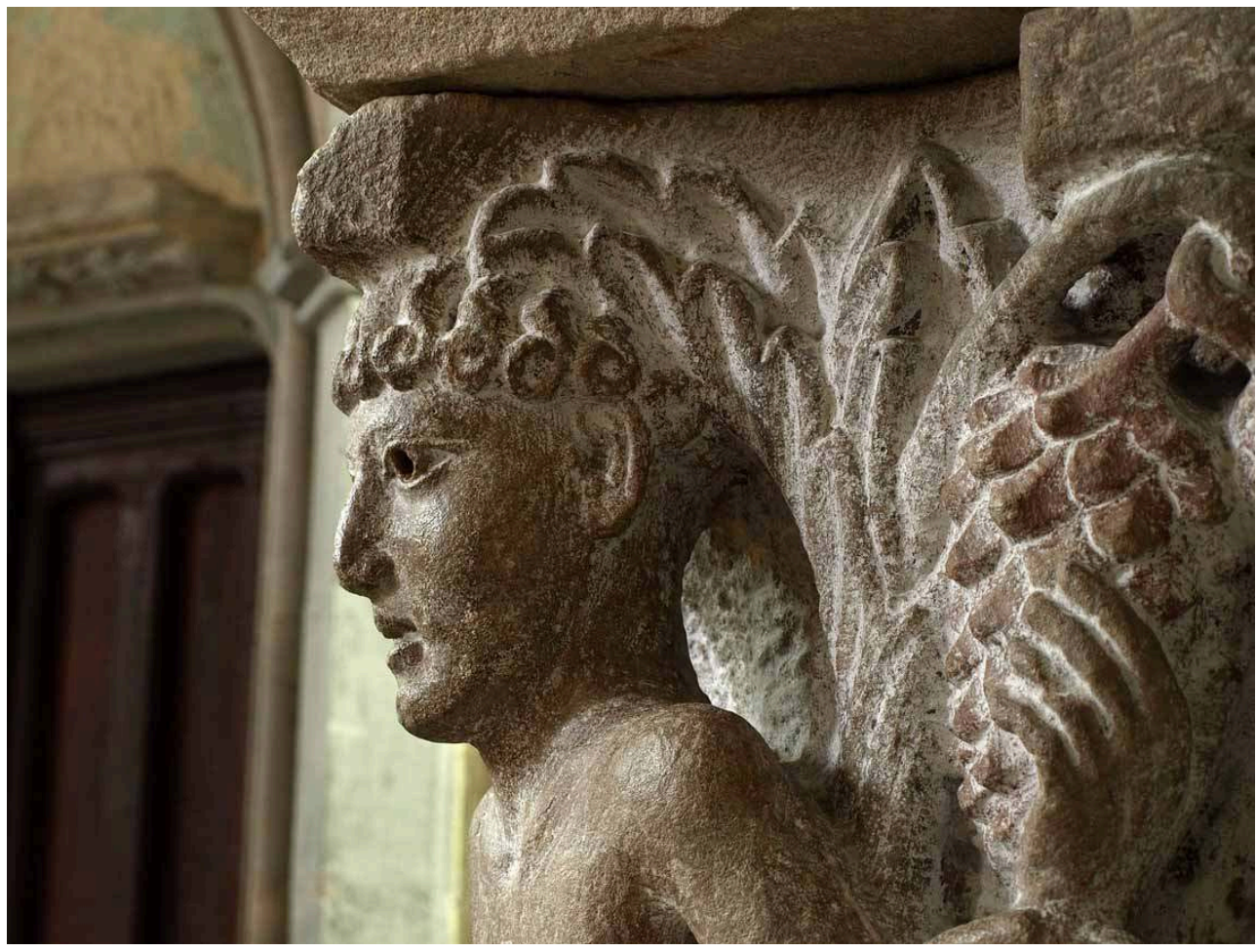

Tête soutenant l'abaque (Mozat) 
C'est singulièrement le cas d'une série de personnages que la tradition a peut-être trop rapidement qualifiés d'atlantes (fig. 55). Ce terme ne leur convient guère, dans la mesure où ils ne font pas explicitement le geste de porter un élément d'architecture; de fait, l'assignation de ces figures à ce référent antique est problématique et potentiellement source d'erreurs. Mais pour fautive qu'elle soit, cette terminologie n'en est pas moins suggestive ${ }^{142}$. Ces figures évoquent en effet une dimension architectonique et constituent en cela - on va le voir - des médiations expressives des forces jouant sur le chapiteau. Toutefois, à la différence des images antiques d'Atlas et des atlantes, nulle pesanteur n'est sensible dans ces figures gracieuses et légères; aucun geste de soutien laborieux n'est perceptible et c'est uniquement la disposition soignée des corps qui leur fait exprimer de façon privilégiée l'équilibre des forces présentes dans l'édifice. Pour le saisir, il est indispensable de considérer l'épannelage très particulier du chapiteau exemplaire de Mozat : l'abaque est extraordinairement creusée au centre de chaque face, en sorte que les figures humaines placées sur les angles du bloc sont particulièrement mises en valeur. Leur posture est d'ailleurs très singulière : la position pliée des jambes, genoux à terre, permet aux bustes de s'épanouir sur presque toute la hauteur de la corbeille. Du bas vers le haut, les corps s'autonomisent progressivement $\mathrm{du}$ fond de taille, jusqu'aux têtes qui sont quasiment traitées en ronde-bosse (fig. 56) ; l'abaque repose directement sur elles, comme le ferait un tailloir sur un chapiteau. Un rameau végétal se superpose au point précis de cette conjonction des forces, venant le consacrer par son ornementalité.

Ces images représentent des hommes nus et suggèrent des colonnes et des chapiteaux. Ce sont des figures qui, par leur corps et leur posture, non seulement personnifient et fictionnent la fonction de support de ce morceau d'architecture, mais aussi la subliment en lui donnant un corps. Ces sculptures exceptionnelles travaillent avec une remarquable intensité le lien entre l'image et son support: leur traitement manifeste qu'elles ne sont pas de pures représentations, mais qu'elles font corps avec le chapiteau dont elles exaltent le volume ; dans le même temps, ce dispositif n'a pas sa fin en lui même ${ }^{143}$. Il prend tout son sens si on se rappelle qu'il fonctionne dans cet édifice en tant qu'aboutissement d'un travail de l'image qui vise à spiritualiser l'ensemble du monde créé, par le biais de son ornementalisation. Situées dans le lieu de la plus haute densité sacrale, ces presque statues-colonnes qui entrelacent amoureusement l'humain et le végétal, qui les mettent en harmonie sous la forme hautement symbolique de la quaternité, transcendent le monde qu'elles donnent à sentir. 
Fig. 57
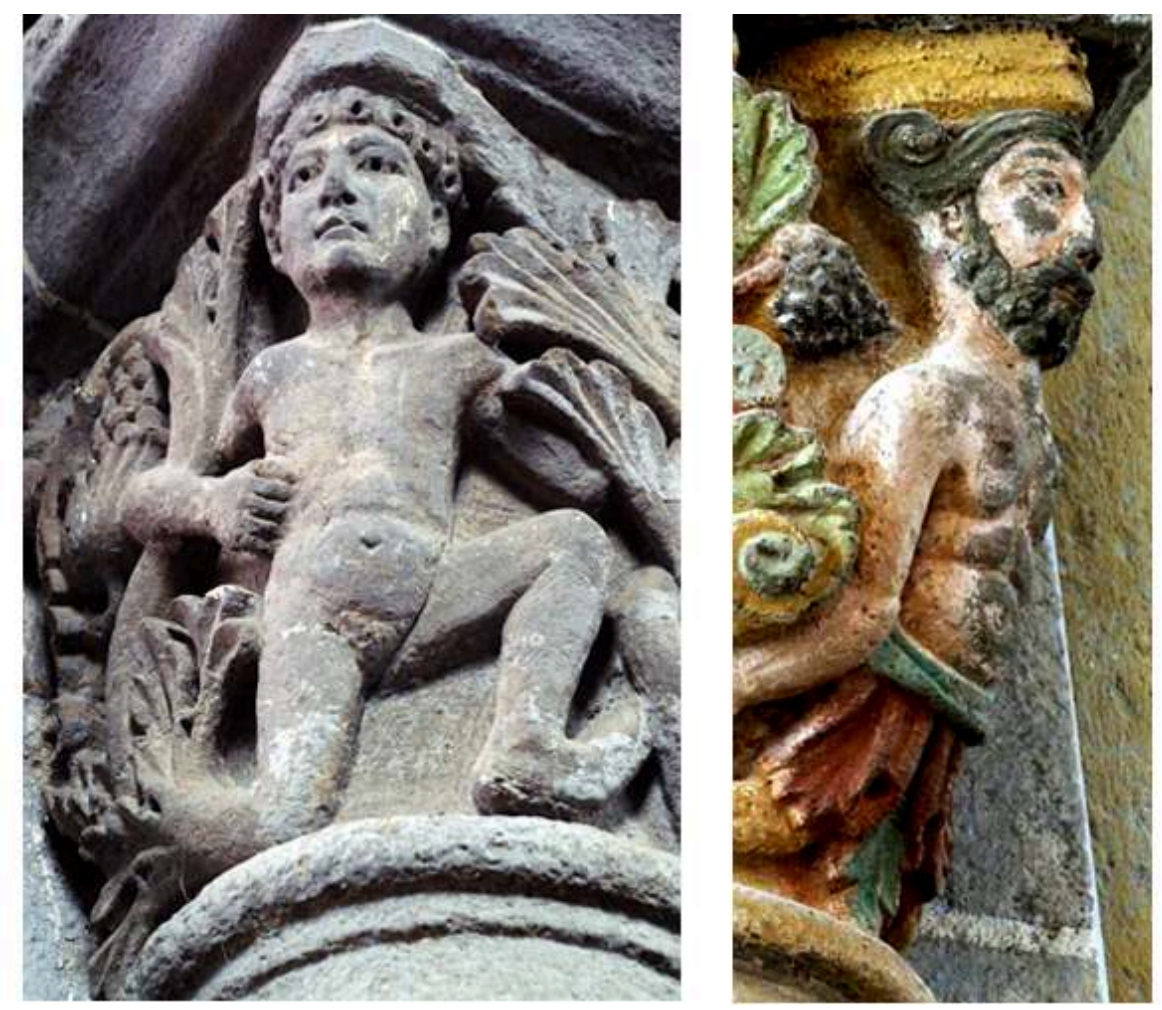

Figures d'angle avec abaque concave (Chanteuges, Saint-Nectaire)

Les caractéristiques que nous venons de dégager se reconnaissent dans d'autres édifices, notamment à Chanteuges. Dans cette église, comme à Brioude aussi, le creusement de l'abaque est considéré par B. Craplet comme étant la signature de l'atelier de Mozat ${ }^{144}$. De fait, le chapiteau des humains végétalisés (et dans une moindre mesure celui des "sirènes ») est à rapprocher de la quaternitas mozacoise : en sus de l'hybridation avec le végétal, observée précédemment, il tire parti du genou à terre, du détachement relatif de la figure vis-à-vis du support, de la tête servant d'appui à l'abaque. Ces éléments sont presque tous repris à Saint-Nectaire (fig. 57), où la coiffure des hommes végétalisés se transforme en volutes inversées pour mieux manifester une affinité avec la composition d'un chapiteau végétal ${ }^{145}$. 
Fig. 58
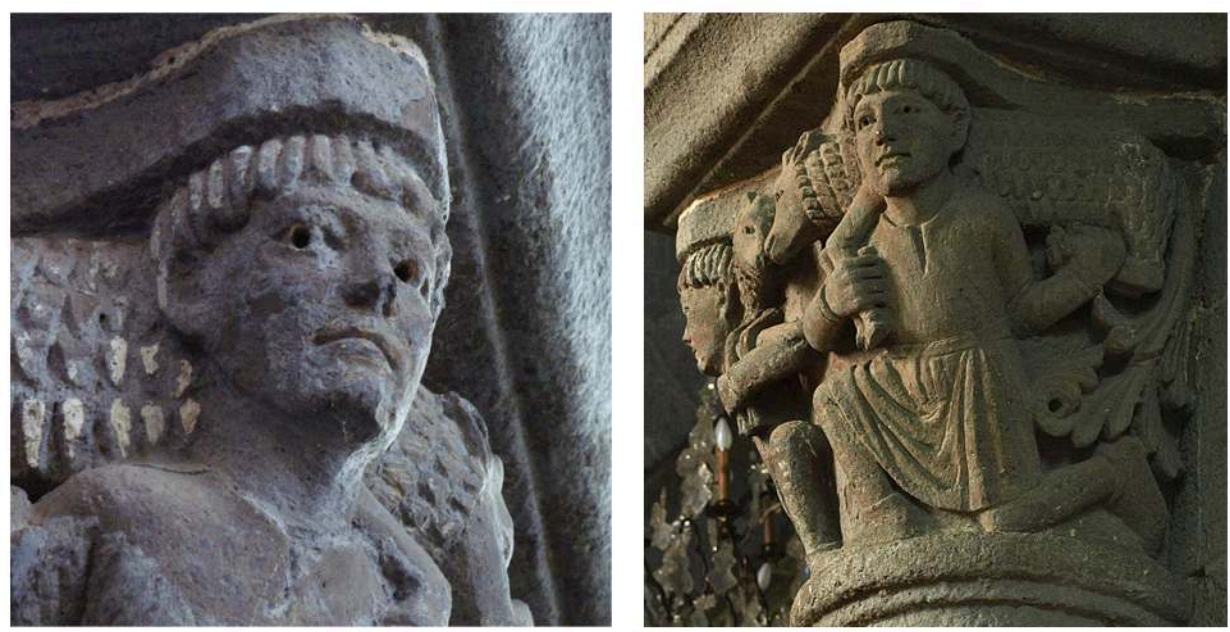

Porteurs de moutons supportant l'abaque (Chanteuges)

Les diverses manières de conjoindre des natures différentes se retrouvent dans le chapiteau des porteurs de moutons, dont la fonction est précisément d'être des «porteurs » (fig. 58). Cette image réunit tous les éléments observés dans ce chapitre : sa construction est purement symétrique, elle ne renvoie à aucune historia, l'animal s'hybride en végétal et les hommes, genoux à terre et têtes en guise de crochets de chapiteau, sont représentés en tant que soutiens matériels de l'édifice. On ne saurait exprimer de façon plus synthétique comment les différentes natures du monde créé s'associent pour participer à l'ornementation de l'édifice, à l'animation de la pierre et de la matière et recevoir en retour l'assurance de s'inscrire dans le processus de spiritualisation du vital dont ils sont les signes et les acteurs.

2 De toutes les images d'hybridations que nous venons de parcourir, on retiendra qu'elles ne fonctionnent pas sur le mode ordinaire de la signification. On peut en effet soutenir qu'elles ne signifient pas une entité précise, comme dans une sémiotique classique où l'image d'un cheval renvoie à l'entité «cheval ». Comme ces figures exceptionnelles ne renvoient à rien qui soit nommé, elles n'existent pas en tant qu'entités dans la société qui les a produites (pas même si on tient compte des éléments de ce monde que nous jugerions aujourd'hui imaginaires ou surnaturels). Pour autant, elles ne sont pas de pures abstractions : nous dirons plutôt qu'elles prennent le monde et ses entités comme un matériau, et partant, qu'elles en composent des figures hybrides auxquelles ne correspondent aucune entité connue. Ces images ne représentent pas, mais expriment et performent - au moins dans l'esprit de ceux qui adhéraient à ces images - des forces invisibles, incorporelles, si l'on veut. En d'autres termes, de l'hybridation végétale, on dira qu'elle rend sensible une qualité non visible de l'étant hybridé.

On peut, à partir de cette analyse, distinguer des tendances qui correspondent peutêtre à une évolution historique. Un premier groupe est constitué par Mozat et Chanteuges, deux édifices qui ne sont opposés qu'en apparence, puisque l'hybridation vers le végétal s'y pense toujours sous un jour extrêmement puissant, capable de spiritualiser, d'ornementaliser jusqu'aux éléments les plus problématiques de la création, comme le dragon ou, dans un autre registre, le corps humain dans sa nudité. Cette intégration du monde au décor est marquée, on l'a vu, par une mise en ordre formelle (la symétrie), un refus de l'historia et de toute caractérisation moralisante. 
Cette proposition initiale est par la suite reprise et commentée à Saint-Nectaire et à Notre-Dame-du-Port, qui infléchissent négativement ces images, tout en insistant davantage sur les forces génératives, exprimées dans toute leur ambivalence par les masques anthropoïdes ou bestialisés.

Comment comprendre la présence de telles figures au sein de l'édifice ecclésial ? Deux niveaux de lecture sont possibles (et compatibles entre eux). Le premier considère que les différentes créatures partagent cette qualité ornementale, ce continuisme vital, uniquement dans le cadre spécifique du lieu-église, dont la fonction est précisément de produire un transitus, un dispositif à même de transcender les catégories séculières. Cette qualité vitale, qui se transmet au bâtiment et vient l'animer, s'impose comme une manière de mettre en jeu sensiblement le processus de spiritualisation à l'œuvre dans l'édifice. On peut alors faire l'hypothèse d'un processus réciproque où l'église se donne comme le lieu capable de spiritualiser le monde créé et où la présence ornementalisée de ce dernier contribue en retour à vitaliser et à animer la matière même de l'édifice.

Le deuxième niveau de lecture invite à penser que ces images font référence à une conception continuiste du vivant, traversant la société qui a produit ces images et existant en dehors du contexte particulier du lieu-église. Faut-il y voir la traduction en images d'entités naturelles jouant un rôle dans la culture folklorique? Une telle hypothèse aurait le mérite d'expliquer la connotation toujours plus négative de ces figures, que l'on semble repérer de chantier en chantier, et qui s'accentue encore par la suite (dans les sculptures tardives de Brioude notamment). On serait alors confrontés à l'expression, puis à la critique, d'une croyance extra-cléricale en un continuisme entre les créatures, en écart avec le cadre analogique dominant, fondé sur la séparation hiérarchisée des espèces. Mais comment penser que l'institution ait cherché à exprimer - et avec quel talent, quelle intelligence ! - des conceptions qu'elle considérait comme des superstitions contredisant sa conception du monde ${ }^{146}$ ?

Peut-être vaut-il mieux penser que l'existence d'une dimension continuiste, présente dans la culture folklorique, pouvait s'avérer au moins en partie compatible avec les conceptions analogiques dominantes. C'est sans doute possible dans le cas de l'hybridation végétale, qui peut être lue comme la manifestation de ce que toutes les créatures vivantes partagent : une anima vegetabilis présente au sein de l'ensemble du monde vivant (voir supra). Dans la mesure où le végétal peut être tenu pour un marqueur privilégié d'une idée de croissance et de vitalité, on peut comprendre que la végétalisation ait été une manière de souligner cette qualité vitale que partagent tous les êtres animés ${ }^{147}$. Et c'est probablement sur cette communauté vitale que la spiritualisation du lieu rituel entendait s'appuyer ${ }^{148}$. Rien n'empêche dès lors de penser que les belles figures de Mozat et Chanteuges constituent un compromis acceptable entre deux types de continuismes, le premier étant intégré à l'analogisme dominant, le second, plus radical, étant peut être lié à des conceptions d'une sacralité non ecclésiale. La moralisation puis la disparition relative de ces figures seraient alors les signes d'une modification des termes de ce compromis à la fin du $\mathrm{XI}^{\mathrm{e}}$ siècle, lorsque certaines expressions des forces vitales naturelles qui pouvaient auparavant trouver leur place dans l'église sont peu à peu rejetées hors du système ecclésial et présentées sous un jour plus inquiétant. 


\section{D'un iter à l'autre : comparaisons sérielles}

137 Aux réflexions précédentes relatives à la végétalité et à l'animalité, il nous faut maintenant associer les registres du monde qui retiennent plus couramment l'attention : l'humain, les créatures spirituelles, sans compter la divinité elle-même. A ce stade, l'analyse des modes d'association de ces différentes «natures » (créées et incréées) se confondra avec celle de l'agencement du décor au sein du lieu rituel. Il n'existe en la matière aucun modèle fixe et les églises étudiées présentent une extrême diversité de solutions. Une approche comparative s'avère alors nécessaire, afin de mesurer l'amplitude de la gamme de possibilités révélée par les différents édifices, sans pour autant négliger les phénomènes de récurrence. L'approche comparative a une autre justification encore, dès lors que les œuvres se pensent les unes les autres, dans un rapport mêlé de déférence, d'appropriation et de reformulation. Si la concurrence et la surenchère entre les institutions ecclésiastiques sont bien souvent l'un des ressorts de l'inventivité architecturale et iconographique, la référence à des modèles prestigieux invite, parfois en même temps, à la citation légitimante, non sans engager cette source d'autorité dans un travail d'adaptation visant à lui conférer plus de pertinence et d'efficacité encore. Dans le cas qui nous occupe (et sur la base des hypothèses de datation adoptées ici), il faut repartir de Saint-Pierre de Mozat, dont le décor sculpté constituait une création si novatrice qu'elle a obligé les concepteurs/réalisateurs des édifices postérieurs à les penser comme une manière de prendre position par rapport à elle.

L'approche comparative que l'on propose maintenant suppose une familiarité avec les analyses menées pour chaque édifice, au fil des chapitres précédents; nous y renvoyons donc une fois pour toutes, pour plus de détails. Il paraîtra peut-être quelque peu abstrait de comparer ces édifices sans disposer à nouveau des vues des chapiteaux euxmêmes, mais il nous a semblé nécessaire, à ce stade du travail, de nous situer à un niveau de synthèse qui est précisément celui que nos cartographies aident à saisir ${ }^{149}$. Il est d'ailleurs remarquable que celles-ci nous permettent d'éprouver la cohérence de l'agencement du décor, y compris dans un cas comme Saint-Pierre de Mozat, où il ne peut être restitué que partiellement, du fait de la conservation incomplète de l'édifice roman. De manière générale, les cartographies sur lesquelles nous nous appuyons dans les pages suivantes s'avèrent particulièrement utiles pour soutenir la démarche comparative que l'on entend engager ici. 
Fig. 59

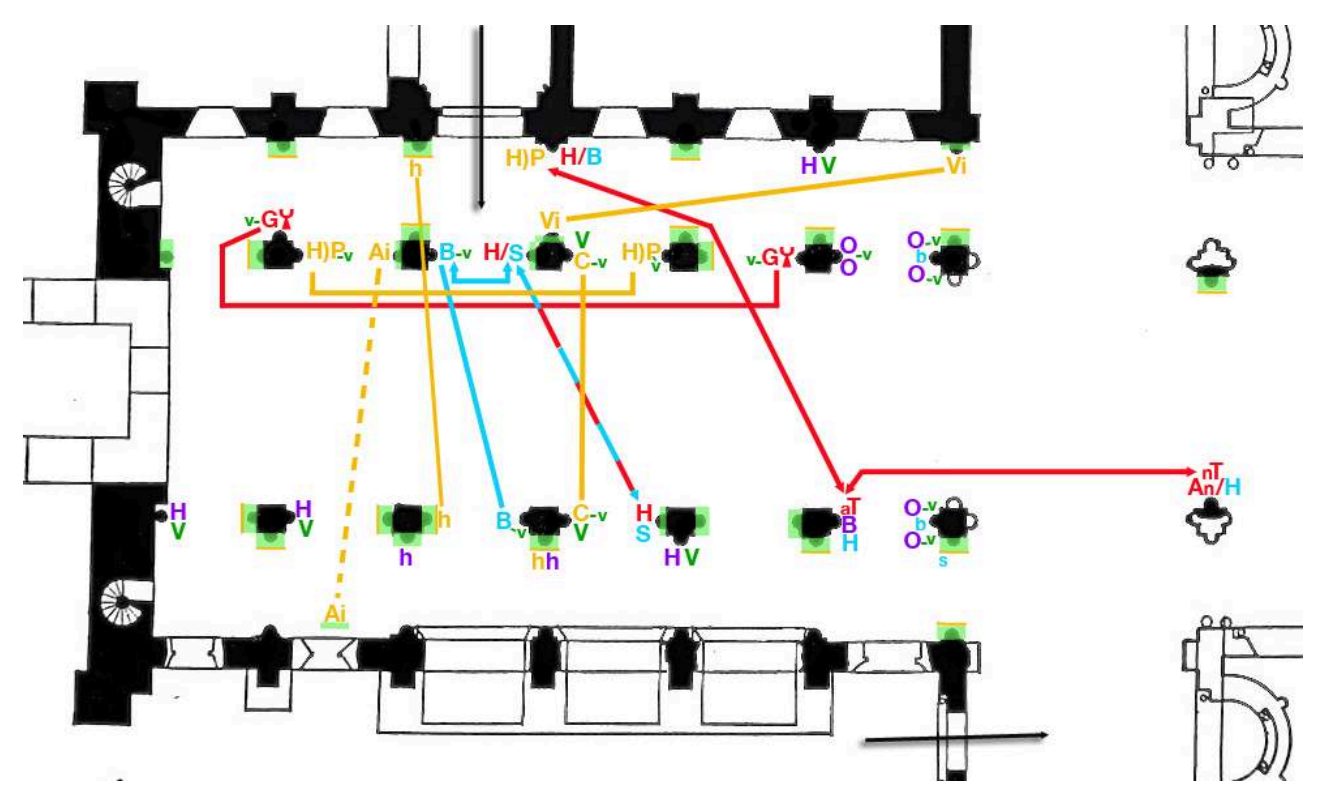

Saint-Pierre de Mozat : la porte nord comme pôle constructif du décor

\section{Mozat, référent incontournable}

Ce qui frappe d'abord, à Saint-Pierre de Mozat, c'est l'ample déploiement, dans l'ensemble de la nef, des chapiteaux à figures. L'analyse cartographique permet de repérer deux grands ensembles nettement distincts. L'un d'eux s'ordonne à partir de la porte nord, dont l'importance est ainsi mise en évidence (fig. 59). Il est essentiellement constitué par des paires, les unes disposées en symétrie longitudinale (par rapport à l'axe de la porte nord) et emboîtées, les autres en symétrie axiale ou en position légèrement diagonale, de part et d'autre de la nef centrale (avec toujours un ancrage sur l'une des piles entourant la travée d'accès par la porte nord). L'accès nord apparaît ainsi comme un pôle constructif, à partir duquel s'agence une part notable du décor sculpté. Il importe tout particulièrement de souligner qu'un ensemble structuré par des paires possède un caractère assez statique, presque clos sur lui-même. C'est du reste cet effet de clôture qu'accentue l'emboîtement des paires longitudinales sur le flanc nord de la nef, puisqu'il s'agit d'encadrer la positivité associée au prestige de la romanité par l'amorce d'une sacralité chrétienne (les griffons au calice) ${ }^{150}$. Et il est tout à fait remarquable que les chapiteaux relevant le plus nettement du registre de la romanité soient concentrés dans cette partie de l'édifice. Ainsi confèrent-ils leur tonalité aux travées auxquelles on accède depuis le porche nord; mais au lieu d'être pris dans une dynamique, ces chapiteaux sont comme circonscrits dans un ensemble local qui tend à se refermer sur lui-même.

Il y a, à cela, une exception : les chapiteaux des Victoires forment également une paire, ancrée dans la travée d'accès nord, mais qui autorise une échappée jusqu'à l'entrée du transept (fig. 59). Celle-ci reste toutefois limitée, par contraste avec le « fil rouge » qui s'amorce également à la porte nord et qui est doté d'un caractère bien plus dynamique, impossible à produire avec des paires. De fait, il s'agit d'un chaînage, fondé sur une homologie forte (tous les thèmes relèvent du paradigme de la délivrance), en même temps que sur une progression très marquée : à la porte nord, l'ambiguïté domine et 
l'on ne saurait décider si l'on est dans le registre des récits païens ou dans le domaine scripturaire (Tobie-Arion; Samson-David-Hercule); dans la travée orientale de la nef, on passe au premier chapiteau historié, à caractère indubitablement vétérotestamentaire (Jonas); puis, dans la travée droite du sanctuaire, la même thématique monte encore en dignité, en s'inscrivant dans le registre néotestamentaire (Délivrance de Pierre). Ce chaînage dynamique, qui se prolonge jusque dans l'hémicycle (avec la Résurrection du Christ), fait clairement contraste avec l'ensemble local précédemment décrit, qui reste fixé autour de la porte nord.

Fig. 60

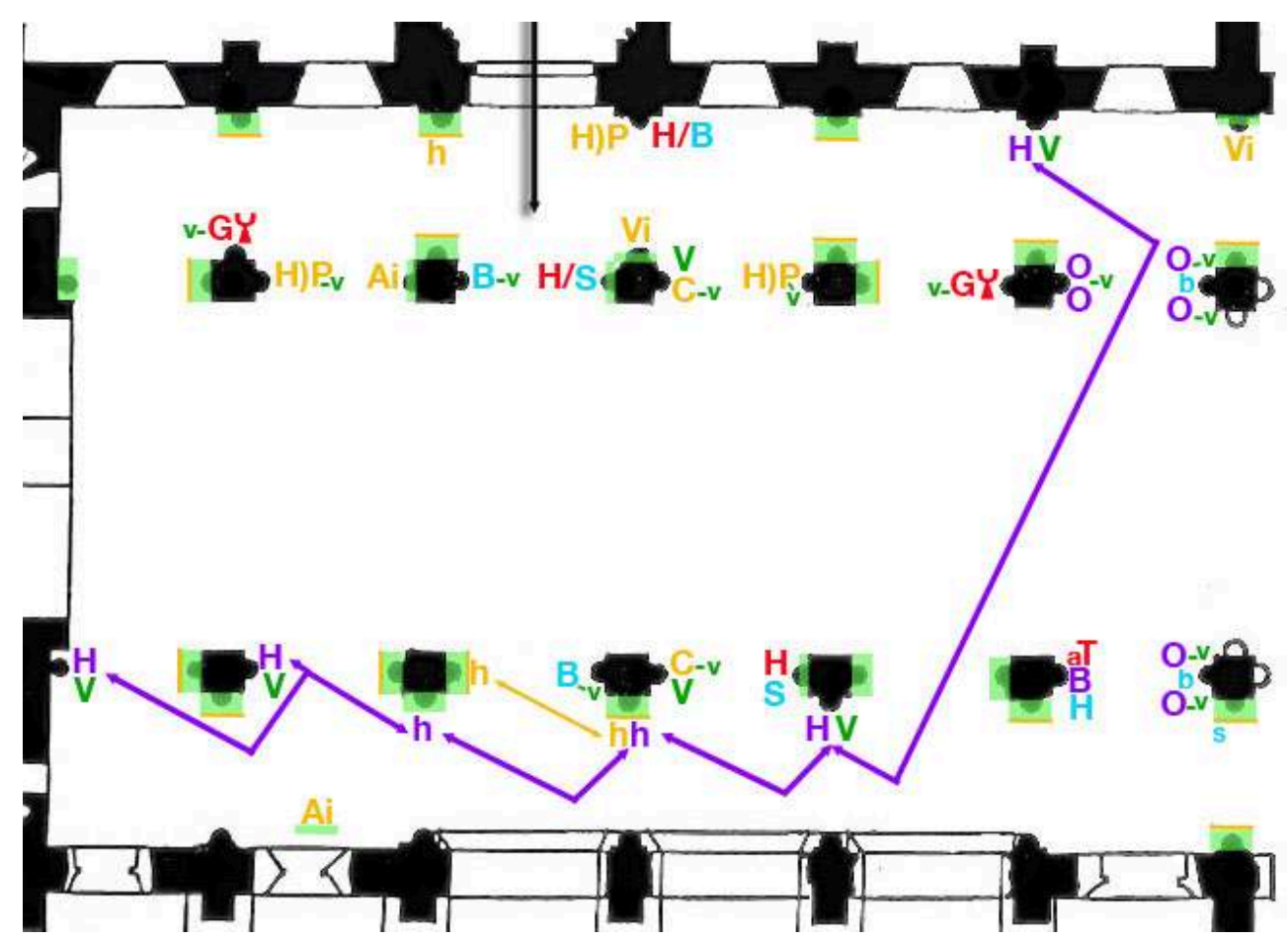

Saint-Pierre de Mozat : la séquence homme/végétal

Dans la nef (fig. 60), un second ensemble compose une longue séquence associant l'homme au végétal et faisant l'objet de variations impressionnantes, dont on ne reprend pas ici la description détaillée. Cet ensemble est construit de manière radicalement distincte du précédent. Il se déploie de façon linéaire, en partant du revers de façade et en parcourant le bas-côté sud, avant de trouver un point d'accroche sur le mur gouttereau nord, dans la dernière travée de la nef (par ailleurs, trois quaternités d'oiseaux aux queues végétalisées confèrent à cette travée, où apparaît aussi le chapiteau de Jonas, une tonalité éminemment spirituelle, sans doute liée à l'implantation du chœur liturgique). A la différence de l'ensemble lié à la porte nord, on n'observe ici aucune paire. S'affirme au contraire une volonté de différenciation maximale de chaque chapiteau, dans le souci de composer une séquence transformationnelle dynamique. Certains chapiteaux semblent même combiner et englober les caractéristiques de plusieurs de ceux qui les précèdent, non sans annoncer ce qui suit, comme dans le cas du chapiteau des hommes nus du mur gouttereau nord, qui anticipe des traits notables des quaternités de l'hémicycle. 
Au total, il est tout à fait frappant que l'on ait eu recours de manière systématique à des paires pour construire l'ensemble de la porte nord et jamais lorsqu'il s'est agi d'élaborer la séquence homme/végétal du bas-côté sud. La réalisation des chapiteaux par paires ne peut donc être tenue pour un simple procédé de production, qui serait appliqué mécaniquement. Bien plutôt, on produit des paires lorsqu'on cherche à constituer des ensembles locaux dotés d'une qualité de relative clôture (ou pour en rehausser l'éminence par le recours à diverses modalités de symétrie), tandis que, lorsqu'il s'agit de déployer des séquences dynamiques, plus directement indexées sur l'iter ecclésial, on évite le recours aux paires et on privilégie la réalisation de séries transformationnelles ${ }^{151}$.

Fig. 61

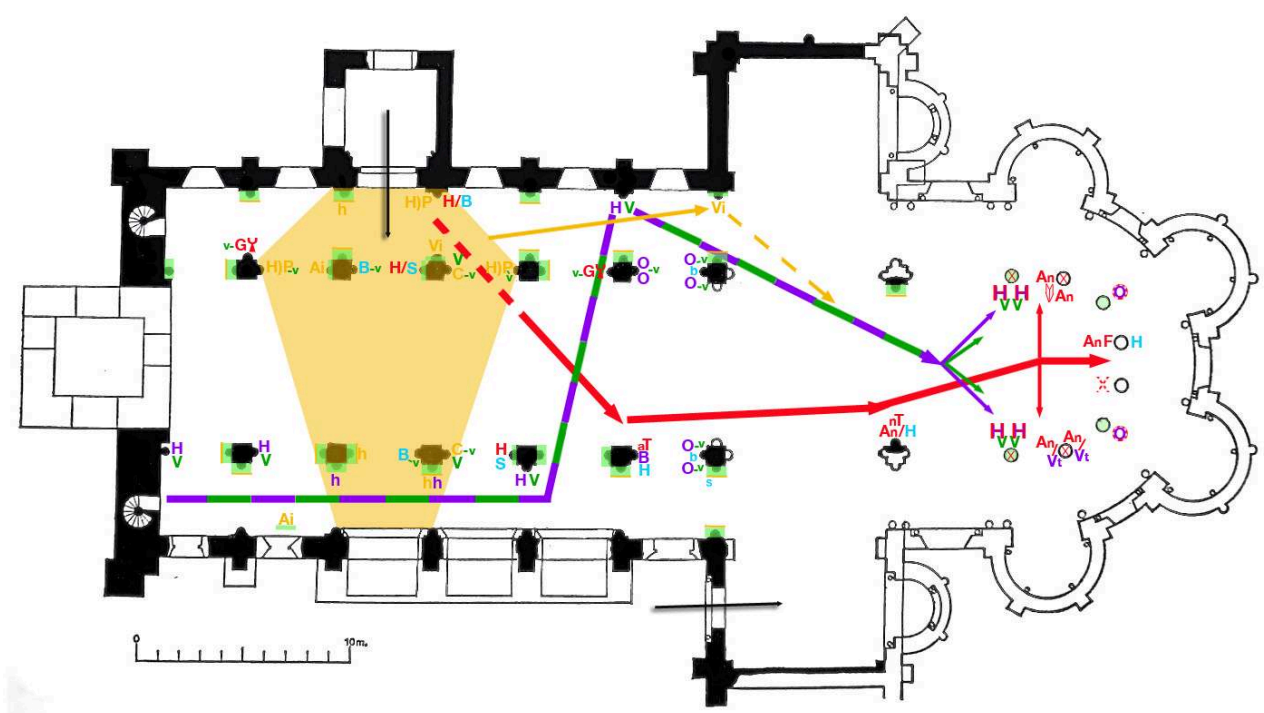

Saint-Pierre de Mozat : dynamiques confluant dans I'hémicycle

Nous ignorons tout du décor du déambulatoire de Mozat et ne connaissons, à ce jour, que cinq des huit chapiteaux qui ornaient l'hémicycle. Certaines relations que le décor devait nouer nous échappent donc, mais la manière dont les fils, qui courent dans la nef, viennent se fondre dans l'hémicycle est déjà particulièrement remarquable (fig. 61). C'est le cas de la séquence relevant du paradigme de la délivrance, qui culmine avec la Résurrection du Christ (associée sans aucun doute à au moins un autre chapiteau christologique). Plus étonnant est le prolongement de la séquence homme/végétal qui, loin de n'être reprise dans l'hémicycle que sur un mode mineur, s'y trouve au contraire amplifiée, sous la forme des quaternités d'hommes nus dans le végétal. La sublimation s'opère ici par la conjonction d'une mise en valeur extraordinairement poussée de la corporéité, de son association avec la composition rythmique des lignes végétales, de la valeur qui s'attache à la quaternité et, enfin, par le recours à une paire que l'on ne saurait imaginer autrement qu'en symétrie axiale. Par rapport à la séquence dont ils forment l'aboutissement, ces deux chapiteaux opèrent un saut de registre : en s'ordonnant au sein d'une quaternité, la conjonction de l'humain et du végétal prend une valeur cosmologique. Il est tout à fait remarquable qu'une telle transcription sensible de l'harmonie musicale de la création trouve ainsi place dans le sanctuaire. Certes, cette double quaternité est associée à deux autres quaternités, angéliques cette fois. Le cosmos tout entier est donc évoqué, avec ses quatre axes; mais, cette fois, sous 
l'espèce des créatures les plus spirituelles (les anges), qui font montre de leur maitrise sur les forces du monde créé (les vents), afin de laisser place à la puissance la plus éminence qui soit, celle de la Parole divine diffusée par les Évangiles.

Ajoutons que notre cartographie figure une troisième flèche jaune. C'est par précaution qu'elle suggère, par de discrets pointillés, que quelque chose de la romanité pourrait pointer jusque dans le chevet, d'une part parce qu'on pourrait être tenté d'associer la corporéité des hommes dans le végétal à une esthétique romanisante et, d'autre part, par souci de tenir compte d'éventuels éléments manquants, notamment dans le déambulatoire. Pourtant, en l'état actuel de nos connaissances, rien ne permet de donner plus de consistance à cette poussée de la romanité. Il nous faut donc admettre que celle-ci reste pour l'essentiel circonscrite à l'ensemble lié à la porte nord. Une atmosphère romanisante enveloppe une partie de la nef, mais celle-ci fait l'objet d'une relève par le sacré chrétien, lequel s'avère également capable d'englober une expression cosmologisée de l'harmonie musicale du monde créé.

\section{La singularité de Chanteuges}

Fig. 62

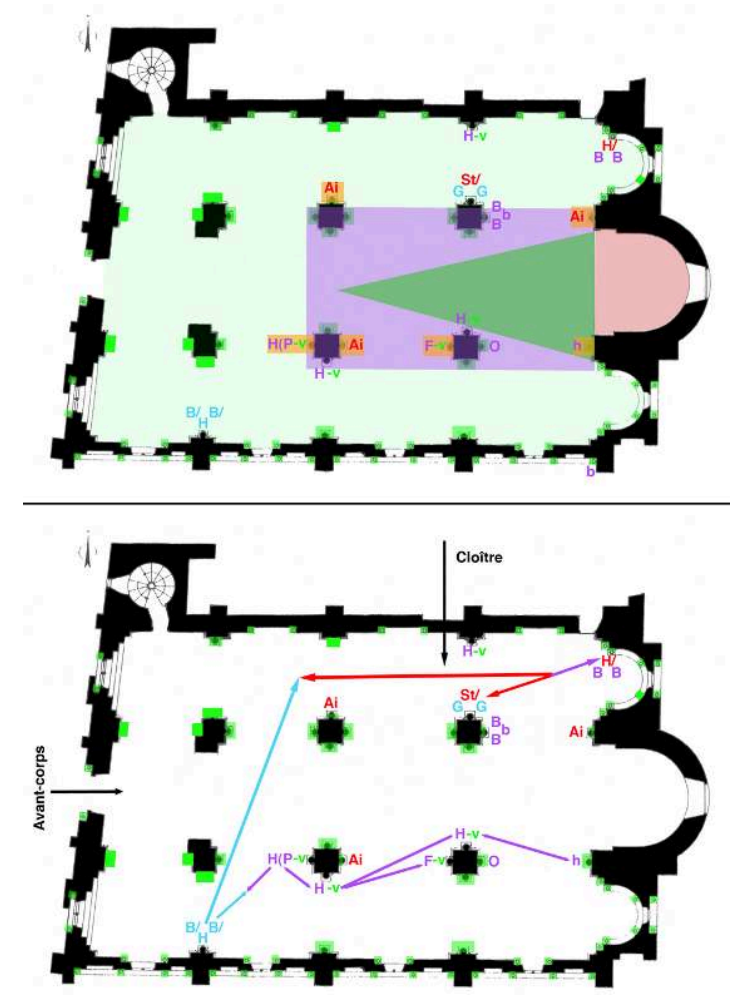

Saint-Marcellin de Chanteuges : a) chapiteaux à figures romanisants (jaune/saumon); b) principales relations

L'importance de la romanité invite à rapprocher Saint-Marcellin de Chanteuges de Mozat. Mais si les sculptures des deux édifices partagent de nombreuses qualités plastiques et pourraient être en partie le fait d'un même atelier, force est de reconnaître que les citations antiques se répartissent selon une logique tout à fait différente dans les deux églises. Alors qu'elles étaient associées à la porte d'entrée nord à Mozat, c'est au contraire autour d'une zone qu'on a identifiée comme étant 
l'emplacement du chœur liturgique, qu'on les retrouve à Chanteuges (fig. 62). Le plan basilical de cet édifice, qui est unique dans notre corpus, oblige à penser les relations entre les chapiteaux et le lieu rituel de manière tout à fait différente. En l'absence d'un transept, d'un rond-point à colonnes et d'un déambulatoire, l'agencement des chapiteaux répond nécessairement à des logiques différentes. De plus, le faible nombre de piles ponctuant une nef relativement courte et à travées amples, ainsi que l'absence de décor sculpté dans le sanctuaire, rendent difficile le déploiement d'un véritable iter, tel qu'on l'observe à Mozat. Ici, c'est davantage une opposition entre centre et périphérie qui semble à l'œuvre (à trois exceptions près, tous les chapiteaux à figures ou historiés ornent les piles centrales de l'édifice). En même temps, un autre élément structurant tient à l'opposition entre les deux portes, celle de la façade occidentale et celle permettant un accès depuis le cloître. La première est clairement associée au seul chapiteau entièrement négatif de l'église (l'avare entre les dragons), alors que les moines passant par la seconde sont accueillis par l'image d'un saint triomphant des griffons. Une flèche d'opposition (rouge/bleue) manifeste ce puissant contraste entre les deux zones d'entrée. Les chapiteaux qui ornent la limite entre le bas-côté sud et la nef se tiennent à l'écart de cette opposition morale, et c'est l'intrication des figures humaines et du végétal que l'on a vu se déployer à Mozat qui se retrouve ici, mais traitée par le procédé de l'hybridation qui était absent de l'église modèle. Tout en manifestant une fidélité iconographique explicite envers Mozat (et Brioude), la cartographie de Saint-Marcellin de Chanteuges invite surtout à analyser une situation plutôt atypique dans la mise en œuvre de l'agencement du décor sculpté. Tel n'est pas le cas de Saint-Nectaire et de Notre-Dame-du-Port dont les structures, architecturales d'abord, se rapprochent bien davantage de Mozat.

Fig. 63

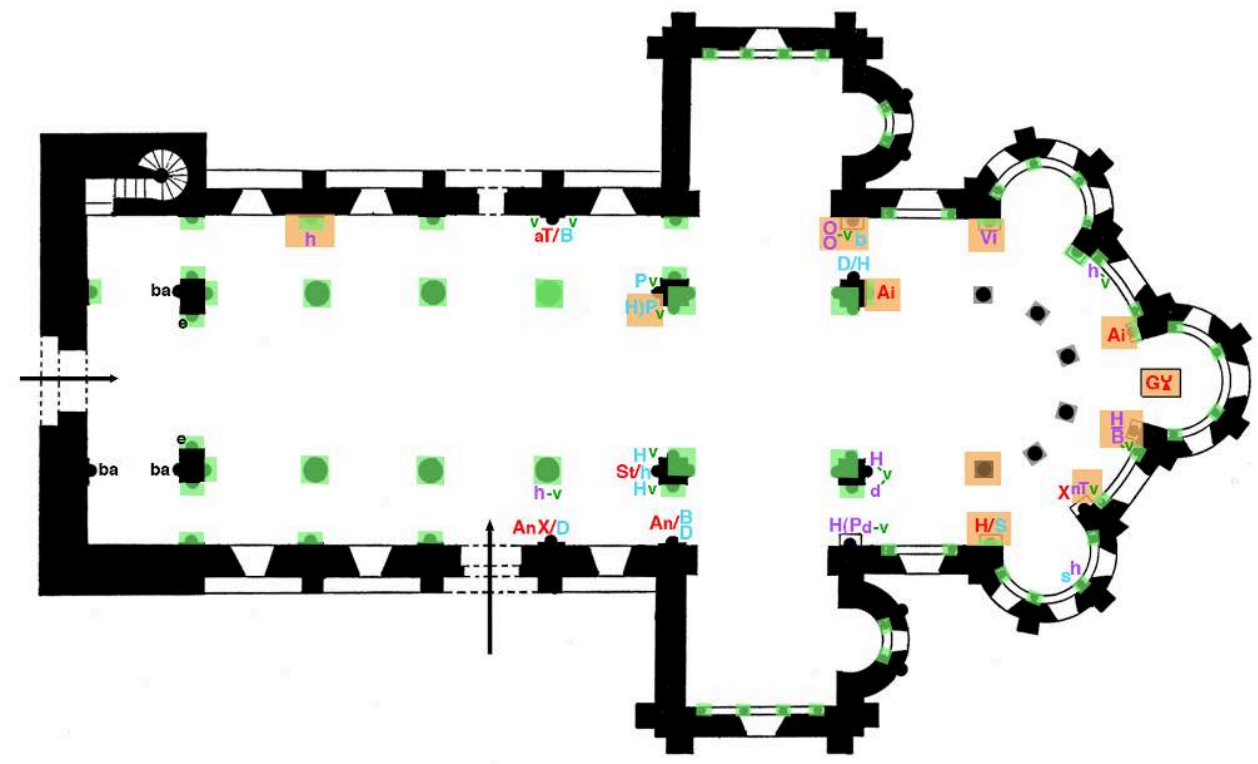

Saint-Nectaire : citations des chapiteaux de Mozat (indiquées par des rectangles colorés surimposés aux codages lettres-couleurs) 


\section{De Mozat à Saint-Nectaire}

Pour se convaincre de l'intensité du rapport sériel entre Mozat et Saint-Nectaire, il suffit de relever le nombre de citations des chapiteaux mozacois dans le second édifice (indiquées par la figure 63) ${ }^{152}$. Mais alors qu'à Mozat tous ces chapiteaux se trouvaient dans la nef, ils ont été, à Saint-Nectaire, déplacés et concentrés principalement dans le déambulatoire. Deux cas seulement font exception : le chapiteau aux trois masques qui, sur le mur nord de la nef, conserve une place presque identique à celle qu'il occupait à Mozat, et l'homme chevauchant un bouc qui, associé cette fois à un quadrupède à la lyre, prend un sens nouveau, nettement péjoratif. Ainsi, trois phénomènes se conjoignent : une reprise massive et assez littérale du répertoire mozacois; son déplacement presque complet vers une partie distincte de l'édifice, ce qui suffit à en changer assez radicalement le statut; enfin, la réinterprétation (limitée) de quelques chapiteaux spécifiques. Il s'agit là d'un ensemble d'opérations assez exemplaires de ce que peut signifier la sérialité des images médiévales.

Fig. 64

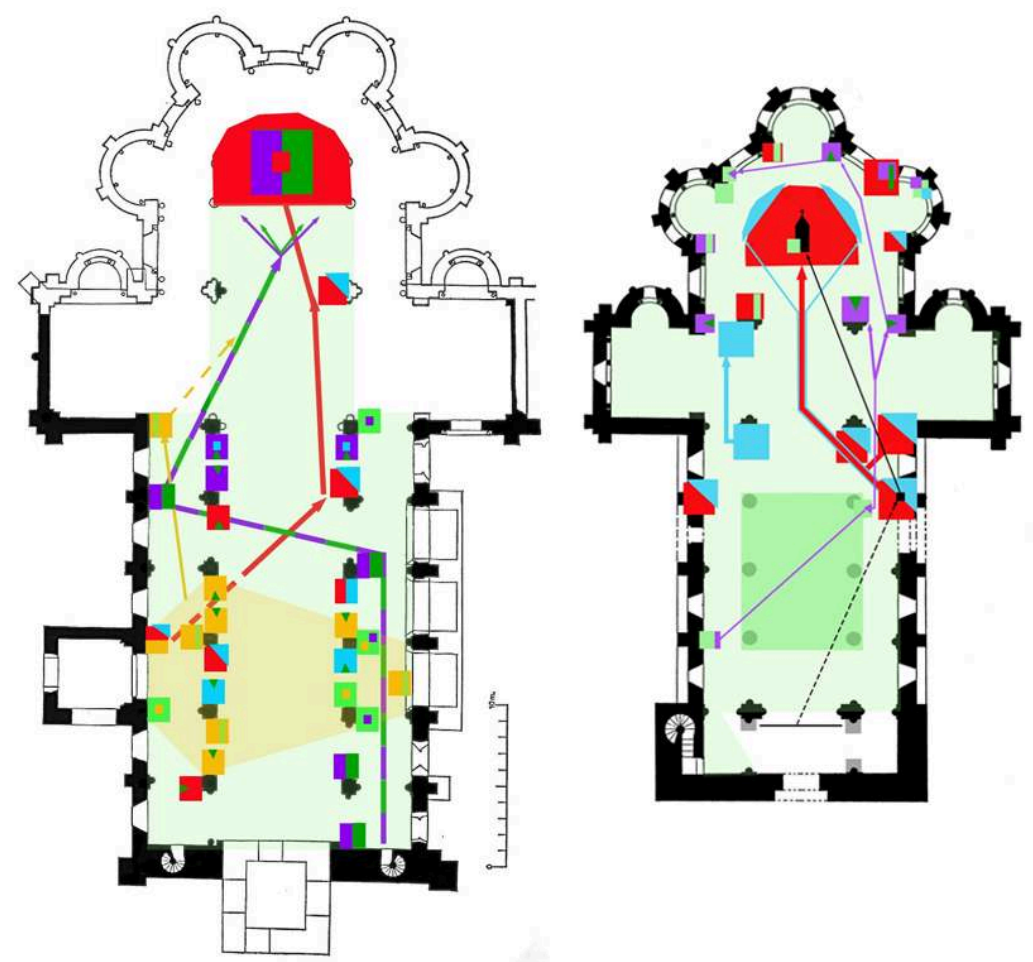

Cartographies synthétiques de Saint-Pierre de Mozat et Saint-Nectaire

Comparer Mozat et Saint-Nectaire, ce n'est donc pas confronter deux options parallèles. C'est analyser comment on s'est efforcé, dans le second édifice, de reformuler et de repenser le décor sculpté de Saint-Pierre de Mozat. Avant de parvenir à une analyse d'ensemble de cette relation sérielle, on procèdera à une comparaison par parties, en avançant d'ouest en est (fig. 64). Une première différence tient à l'absence de narthex à Mozat, alors que cet ensemble se distingue, à Saint-Nectaire, par une singularité remarquable de son décor : la présence des chapiteaux-bases ${ }^{153}$. Dans la partie occidentale de la nef, l'un des points les plus frappants est le contraste entre 
l'abondance de chapiteaux à figures, à Mozat, et la prédominance presque absolue du décor végétal, à Saint-Nectaire. C'est là la conséquence du déplacement du répertoire mozacois vers le déambulatoire. Ne reste que le chapiteau aux masques, qui fait figure de mince "relique» du décor mozacois, tout en amorçant un discret fil homme/ végétal, relayé à la porte sud par la tête humaine crachant du feuillage, avant de s'étoffer dans le déambulatoire. Dans la nef de Saint-Nectaire, on a donc, pour l'essentiel, écarté les thématiques déployées dans le même espace à Mozat, tant en ce qui concerne la romanité que l'association homme/végétal. Et on a opté pour un décor dont la végétalité omniprésente permet de créer un contraste plus manifeste avec les autres parties de l'édifice.

On pourrait être tenté, en ce qui concerne le rôle des portes latérales (au nord à Mozat, au sud à Saint-Nectaire), d'établir un rapprochement entre les deux édifices. Celles-ci jouent en effet, dans les deux cas, un rôle important dans l'agencement du décor. Il faut pourtant souligner d'importantes différences : alors que le porche nord de Mozat est l'axe de symétrie et le pôle à partir duquel se déploie d'une ample portion du décor de la nef (y compris vers l'ouest), la porte sud de Saint-Nectaire joue plutôt comme une ligne de césure entre la partie végétalisée de la nef et celle où apparaissent les chapiteaux historiés (vers l'est). Plus profondément, les deux ensembles se distinguent par leurs tonalités respectives : à Mozat, le registre de la romanité domine ${ }^{154}$; à SaintNectaire, le décor proche de la porte sud projette l'entrant au cœur d'une guerre de très haute intensité entre le Bien et le Mal (le rouge et le bleu y sont donc aussi dominants qu'ils sont discrets, dans la partie correspondante de l'édifice, à Mozat). Et tandis que la travée orientale de la nef de Saint-Nectaire multiplie les figurations de la lutte frontale entre les forces du Bien et du Mal (consacrant un chapiteau entier à des évocations animalisées des vices), celle de Mozat se colore d'un violet qui tire nettement vers le positif : les quaternités d'oiseaux végétalisés, dont deux forment une paire disposée en symétrie axiale, peuvent être vues comme une annonce (certes, menacée encore par les crocs des bestiae) de la perfection qui, sur les piles rondes de l'hémicycle, se déploie sous la forme des quaternités cosmologiques.

Dans l'impossibilité de comparer les déambulatoires des deux édifices, on en vient aux hémicycles. Les cartographies permettent d'observer une différence majeure (fig. 64): alors que le vert et le violet, dont l'association traduit toute la positivité de l'harmonie cosmique, prennent place dans l'hémicycle de Mozat et s'y entrelacent au rouge, ces deux couleurs ont totalement disparu de celui de Saint-Nectaire. Dans cet édifice, le violet est entièrement dévié vers le déambulatoire. C'est du reste à cette nécessité que semble répondre le déambulatoire : il permet en quelque sorte de décanter l'hémicycle, au bénéfice d'une positivité entièrement inscrite dans le registre de la narration christo-hagiographique. Le dispositif sanctuaire/déambulatoire peut ainsi jouer d'un contraste maximal. Couronne extérieure ceignant le lieu le plus intérieur, le déambulatoire déploie une tonalité dominante violette qui renvoie (cette fois) au statut ambigu ou indéterminé du monde créé et qui, par différence, rehausse davantage encore l'éminence sacrale du sanctuaire.

De même, le végétal n'a plus aucune place dans l'hémicycle de Saint-Nectaire, hormis sous la forme, hautement significative, de cette pierre végétalisée qu'est le chapiteau offert par Ranulfo. Un nouvel ordre, fortement architecturé, s'impose. Celui-ci n'est pas totalement absent à Mozat, où figure déjà le sépulcre du Christ sous l'espèce d'un édifice roman, du reste littéralement cité à Saint-Nectaire, mais la thématique 
architecturale connaît cette fois un déploiement tout à fait extraordinaire (tentes de la Transfiguration devenues chapelles de pierres; sépulcre du Christ; sarcophage maçonné de Bradulus, colonne offerte par Ranulfo; figuration de l'église de Saint-Nectaire). Et cette thématique traverse tout la nef, depuis les chapiteaux-bases du narthex qui en constituent comme le premier jalon, en passant par la pierre taillée de la Tentation, jusqu'à l'auto-glorification de l'édifice ecclésial, lequel est, dans le sanctuaire, si intimement associé aux figures christologiques et hagiographiques qu'il semble concentrer en lui les potentialités d'accès au salut. C'est dans cette perspective que l'on peut comprendre le caractère presque entièrement végétal des premières travées de la nef, dont les six piles rondes à chapiteaux végétaux produisent, avec les six piles rondes entièrement historiées du sanctuaire, un contraste maximal. Ainsi, l'iter ecclésial se construit à Saint-Nectaire comme un chemin entre deux ensembles quasiment inverses : on passe de chapiteaux presque entièrement végétaux (avec une amorce de référence architecturale et une infime présence de l'humain) à un décor d'hémicycle marqué par l'association des figures humaines et de l'inscription architecturée du sacré (avec une trace minime du végétal, sous l'espèce d'une végétalisation de l'architecture). Cela ne contredit en rien l'idée que le végétal participe pleinement à l'ornement du locus rituel et l'honore par sa beauté. Simplement, il contribue aussi, par contraste, à activer une dynamique qui exalte l'architecturation du sacré.

A Saint-Nectaire, le contraste entre les moments extrêmes de l'iter ecclésial est aussi accentué que possible, alors qu'à Mozat, on procède de manière non moins dynamique mais en même temps bien plus intégrative. De Mozat à Saint-Nectaire, la conception de la plus haute positivité que met en jeu le décor sculpté du sanctuaire se transforme. On passe d'une positivité qui assume l'association de l'humain et du végétal en tant que manifestation de l'harmonie musicale de l'œuvre divine à une positivité qui vise avant tout à glorifier l'inscription des forces célestes et saintes dans le lieu sacré architecturé.

\section{Saint-Nectaire et Notre-Dame-du-Port : deux relectures de Mozat}

Fig. 65
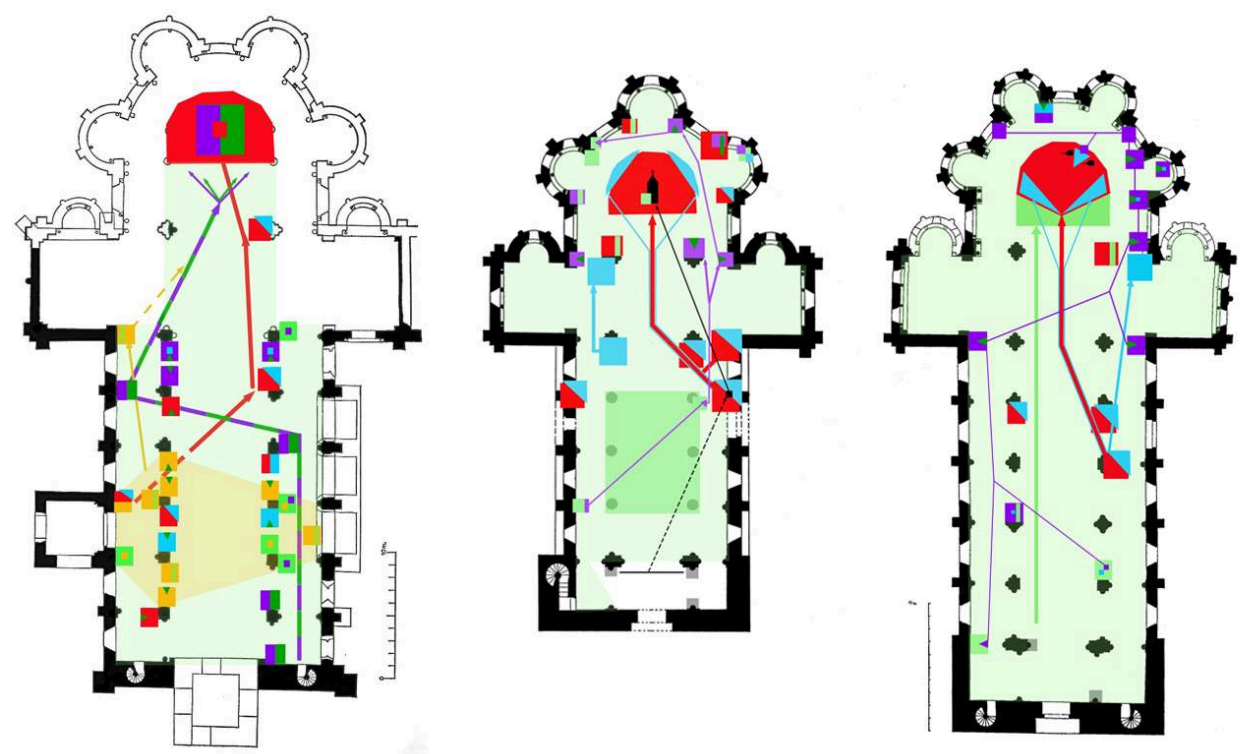

Cartographies synthétiques de Saint-Pierre de Mozat, Saint-Nectaire et Notre-Dame-du-Port 
Intégrer Notre-Dame-du-Port à la série invite à analyser comment cet édifice prend position par rapport à Mozat, tout en comparant cette prise de position à celle qui s'affiche à Saint-Nectaire. Autrement dit, plutôt que de confronter Notre-Dame-du-Port aux deux autres édifices, il s'agira de comparer deux rapports : Saint-Nectaire/Mozat et Notre-Dame-du-Port/Mozat (sans oublier, si du moins nos hypothèses chronologiques sont correctes, que Notre-Dame-du-Port peut aussi, même si ce point ne revêt pas une importance aussi décisive, avoir eu à prendre position sur la prise de position de SaintNectaire) ${ }^{155}$.

En ce qui concerne la nef, ce que l'on a dit en comparant Saint-Nectaire à Mozat pourrait être répété presque terme à terme. Pour éviter les redondances, et sans perdre de vue la perspective définie à l'instant, il sera plus aisé de mettre en relief les fortes similitudes entre Notre-Dame-du-Port et Saint-Nectaire, évidentes dès que l'on en juxtapose les cartographies synthétiques (fig. 65). Il s'agit de deux édifices à narthex, dont le décor présente la même particularité (que l'on retrouve aussi à Orcival) : la présence de chapiteaux-bases. Celle-ci est un peu plus insistante à Saint-Nectaire (trois chapiteaux, dont deux en symétrie axiale) qu'à Notre-Dame-du-Port (deux, en disposition diagonale). C'est là un type de décor extrêmement singulier et fort rare, dont les occurrences sont clairement associées à cet espace spécifique qu'est le narthex. On peut alors suggérer que les chapiteaux-bases sont liés à un "espace d'accueil », qui prélude à l'accès à la nef proprement dit, comme s'il s'agissait de poser le premier jalon - et comme "la première pierre » - d'une séquence, en soulignant la matérialité de l'église dont la végétalisation des chapiteaux va ensuite constituer une sublimation vivifiante.

Dans les deux édifices, les travées occidentales de la nef sont presque entièrement ornées de chapiteaux végétaux (à l'exception d'un chapiteau à têtes humaines à SaintNectaire et de trois chapiteaux à Notre-Dame-du-Port, deux à têtes animales et/ou humaines et une figuration des Victoires). Puis, dans les deux cas, la porte sud marque une césure forte. Les chapiteaux historiés font surgir des figures très éminentes (divines, angéliques et saintes) et place l'entrant au cœur d'une guerre frontale du Bien et du Mal : au vert des travées précédentes, se substitue la confrontation du rouge et du bleu. Dans les deux édifices, la même association de la Tentation du Christ et du Combat des anges contre les forces maléfiques forme le noyau de cet ensemble, qui est un peu plus développé à Saint-Nectaire (trois autres chapiteaux, l'un d'eux hagiographique et un autre peut-être vétérotestamentaire, le complètent) qu'à Notre-Dame-du-Port (s'y ajoute seulement le singe cordé qui, bien que relevant d'un registre fort différent, joue d'une homologie forte avec la Tentation du Christ). Par ailleurs, la disposition de ces deux ensembles est légèrement différente : centré sur la porte sud à Notre-Dame-duPort, il est, à Saint-Nectaire, déporté à droite de celle-ci (une solution qu'exige la présence de piles rondes, sans décor historié, entre la nef centrale et les bas-côtés ${ }^{156}$ ). Mais l'essentiel est que, dans les deux cas, les chapiteaux associés à la porte latérale constituent une amorce de l'ample présence du Christ et des forces célestes qui s'affiche dans l'hémicycle, d'où une forte flèche rouge (cernée de bleu) allant de l'une à l'autre. Les cartographies aident du reste à percevoir un rapprochement entre ces deux édifices et Mozat, où une flèche rouge court également depuis la dernière travée de la nef jusqu'au sanctuaire. Il est vrai que, dans ce cas, le point d'embrayage est uniquement vétérotestamentaire (Jonas) et relève du paradigme de la délivrance plutôt que du combat entre le Bien et le Mal. Mais cette similitude n'est pas indifférente et il 
n'est pas interdit de penser que l'on a, à Saint-Nectaire comme à Notre-Dame-du-Port, amplifié un élément discrètement présent à Mozat, en lui donnant un tour plus éminent et plus agonistique.

Il y a toutefois une différence notable entre Saint-Nectaire et Notre-Dame-du-Port, en partie autorisée par le plus grand allongement de la nef de cette dernière église. Tandis qu'à Saint-Nectaire l'ensemble associé à la porte sud occupe la travée orientale de la nef, c'est dans l'avant-dernière qu'il prend place à Notre-Dame-du-Port. La travée orientale s'y trouve, quant à elle, caractérisée par une barre violette, sans équivalent à Saint-Nectaire (voir plus loin, fig. 67). Certes discrète, elle ne concerne que deux chapiteaux (centaures et oiseaux à queues végétalisées), mais ceux-ci ont en commun non seulement leur haute teneur en animalité, mais surtout le fait de constituer des citations précises de Mozat ${ }^{157}$. Ils sont de surcroît fermement noués par leur disposition en symétrie axiale, sur les murs gouttereaux nord et sud. Aussi ténue soit-elle, la présence de cette barre violette n'en est pas moins hautement significative : elle contraste avec l'option adoptée à Saint-Nectaire où la nef s'achève dans une confrontation franche du rouge et $d u b b^{158}$. Et elle évoque, quoique sur un mode atténué, l'ensemble violet qui, à Mozat, prend possession de la travée orientale de la nef. Dans celle-ci, dominent du reste les oiseaux à queues végétalisées que l'on retrouve à Notre-Dame-du-Port, à un emplacement si comparable que cette similitude ne saurait être prise que comme une référence explicite au dispositif mozacois.

Fig. 66

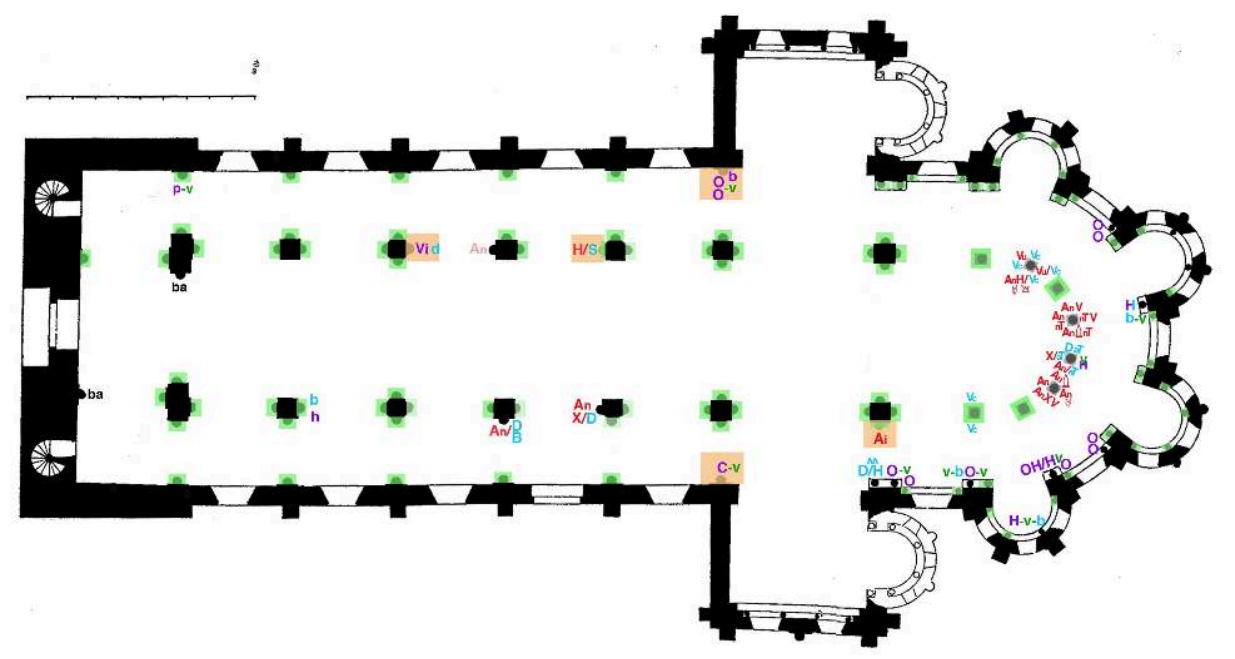

Notre-Dame-du-Port : citations des chapiteaux de Mozat (indiquées par des rectangles colorés surimposés au codage lettres-couleurs)

Au total, même si cette bande violette vise aussi à établir une jonction entre la nef et le déambulatoire où domine la même tonalité, il faut surtout souligner que le répertoire de la nef de Mozat, qui, à Saint-Nectaire, est presque entièrement déplacé vers le déambulatoire, conserve davantage droit de cité dans la nef de Notre-Dame-du-Port (fig. 66). En effet, si aux centaures et aux oiseaux à queues végétalisées, on ajoute les 
Victoires et le singe cordé, ce sont (au moins) quatre marqueurs du répertoire mozacois qui demeurent dans cette partie de l'édifice (sur un total de cinq) ${ }^{159}$. C'est un point de différenciation non négligeable et cette combinaison du violet et du rouge/bleu dans la partie orientale de la nef de Notre-Dame-du-Port n'est peut-être pas sans rapport avec le mode d'articulation du déambulatoire et de l'hémicycle dont il sera question plus loin.

Concernant les déambulatoires, une similitude majeure tient à la dominante violette, observable dans les deux cas (fig. 65 et 67). Cela n'empêche pas de souligner quelques différences. Ainsi, l'ample présence des chapiteaux végétaux dans le déambulatoire de Notre-Dame-du-Port contraste avec leur rareté dans celui de Saint-Nectaire (un seul grand chapiteau végétal) ${ }^{160}$. Par ailleurs, comme on l'a dit, le répertoire mozacois est cité de façon massive à Saint-Nectaire, alors qu'à Notre-Dame-du-Port, on est proche de ses thématiques caractéristiques (avec notamment une forte présence des oiseaux), sans qu'on puisse toutefois mentionner, dans cette partie de l'église, d'autre citation littérale que celle des aigles (fig. 66). Enfin, si le violet du déambulatoire de SaintNectaire se combine de manière assez équilibrée avec le rouge (lié notamment à la présence d'un chapiteau christologique), à Notre-Dame-du-Port, le violet fait l'objet d'une disposition plus continue (en association surtout avec le vert), bien qu'il soit aussi inquiété par la possibilité d'un basculement vers le mal (présence du bleu). Par différence, le violet de Saint-Nectaire est comme apaisé par la forte présence du rouge et peut se déployer avec toute sa force propre : ainsi, les hommes végétalisés, parfois qualifiés de tritons, offrent une évocation particulièrement intense, et non négative, des forces vitales de la création (voir plus haut). Cela est d'autant plus remarquable que ce chapiteau s'ancre sur la pile de la travée droite, dans la continuité de ceux du déambulatoire, mais aussi en bordure du sanctuaire.

Notons pour finir un enchaînement nef/déambulatoire très similaire à Saint-Nectaire et à Notre-Dame-du-Port (marqué par la flèche bleue, sur chaque cartographie; fig. 65). Dans le premier cas, ce lien prend appui sur le chapiteau entièrement négatif de la dernière pile nord de la nef (quadrupède à la lyre et homme sur un bouc), dans le second sur la présence des diables dans la Tentation et le Combat angélique (c'est là un élément de différenciation, qui justifie une flèche plus épaisse à Saint-Nectaire). Quant au point d'accroche, à l'entrée de la travée droite du déambulatoire, il est identique : il s'agit dans les deux cas de la damnation d'un pécheur. A chaque fois, cette scène voisine avec - ou fait face à - un chapiteau aux aigles, contrepoint céleste de cette évocation de la destinée infernale. Il est remarquable que l'association de ces deux chapiteaux se répète dans les deux édifices, alors que leurs emplacements diffèrent (ils apparaissent côté nord à Saint-Nectaire, côté sud à Notre-Dame-du-Port). C'est bien le signe qu'il s'agit d'un couplage thématique pertinent et cela invite à remarquer que l'efficacité d'un agencement n'interdit pas de le soumettre à de notables variations positionnelles. Celles-ci permettent toutefois de faire intervenir des corrélations spécifiques : ainsi, l'aigle de Saint-Nectaire est tourné vers le sanctuaire, car il doit en même temps faire pièce au chapiteau symétrique des hommes végétalisés, tandis qu’à Notre-Dame-du-Port, ces deux emplacements sont occupés par des chapiteaux végétaux en paire symétrique, en nette correspondance avec ceux de l'hémicycle, en sorte que l'aigle peut se concentrer, si l'on peut dire, sur son face-à-face avec le monde infernal et marquer de sa positivité l'entrée du déambulatoire. En tout état de cause, il est remarquable que la damnation prenne place, dans les deux cas, au seuil du 
déambulatoire, dont pourtant elle n'exprime nullement la tonalité dominante. Peutêtre s'agissait-il, par ce rappel des polarités morales, de situer à leur juste place le déploiement, dans cet espace, des ambivalences non moralisées propres au monde créé.

Fig. 67
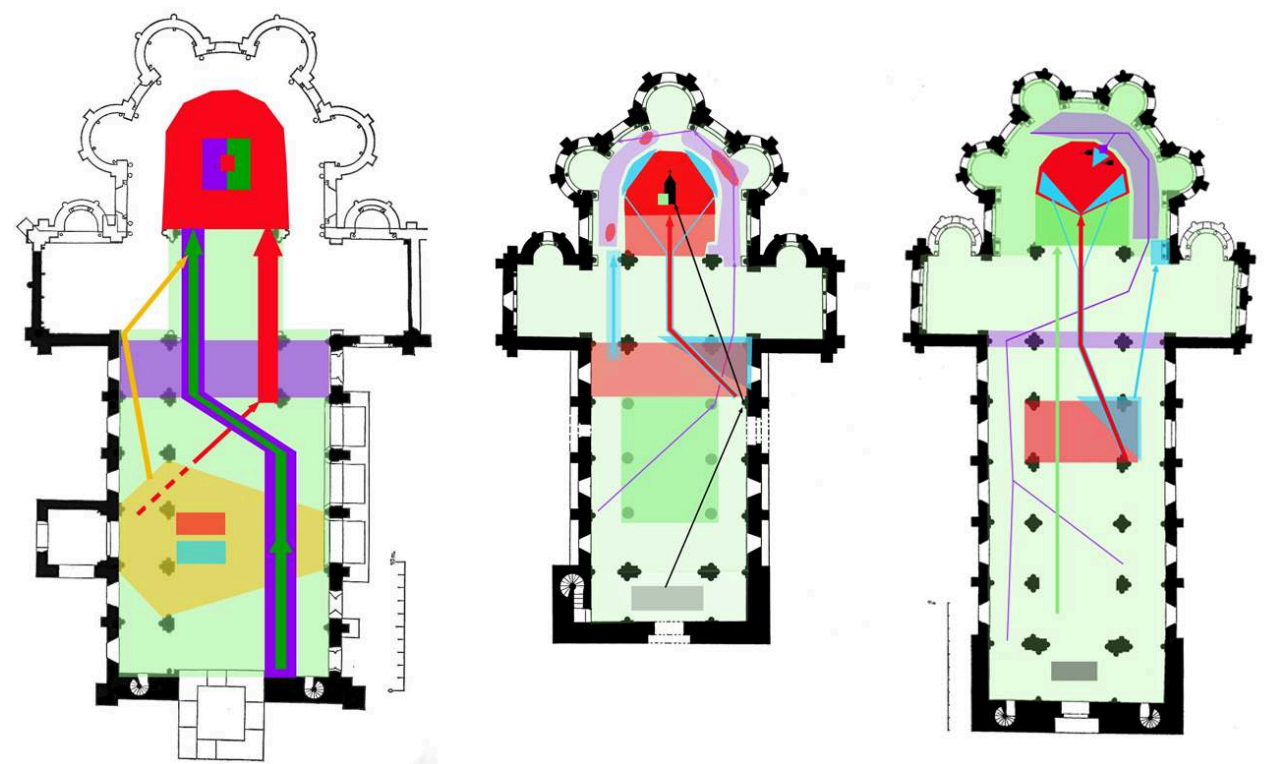

Cartographies synthétiques de Saint-Pierre de Mozat, Saint-Nectaire et Notre-Dame-du-Port

Considérons enfin les hémicycles (fig. 67). A l'évidence, le rouge domine dans les trois cas; mais c'est plutôt sur les différences qu'il convient d'insister. La première tient à la place du négatif (bleu). La cartographie de Saint-Nectaire indique qu'il est comme refoulé vers la bordure externe de l'hémicycle, alors qu'il est nettement plus présent, au cœur même du sanctuaire de Notre-Dame-du-Port. En effet, à Saint-Nectaire, les figures maléfiques ou négatives sont peu nombreuses et presque toujours reléguées sur les faces tournées vers le déambulatoire (diables menaçant Ranulfo, tentant Nectaire ou s'opposant à la descente du Christ aux enfers; cavalier de l'Apocalypse). Toutefois, il ne faudrait pas minorer exagérément le rôle du négatif, surtout si l'on tient compte de la présence du Jugement dernier, un thème dont la localisation dans le sanctuaire est plus qu'exceptionnelle avant le XIVe siècle et qui, de surcroît, est très rarement traité sur les chapiteaux ${ }^{161}$. Ce qui prend place en ce lieu, avec la figuration du Jugement dernier, c'est la dissociation ultime du Bien et du Mal; c'est la révélation d'un univers clivé, où la béatitude parfaite de l'Ecclesia triumphans a pour contrepartie l'éternel enfermement des mauvais. Il s'agit bien de signifier que le Mal est écarté, soustrait à la perfection ecclésiale; mais cela implique aussi de montrer le Christ non point comme pôle de ralliement de l'unité communautaire, mais en tant qu'il est engagé dans l'opération judiciaire visant à diviser radicalement l'humanité. Reste que, malgré l'importance de cette figuration du Jugement, le Mal est nettement plus présent encore à Notre-Damedu-Port, avec la figuration du Péché originel, celle des Vices (comme Ira, qui occupe une face entière), ou encore des scènes de discorde, qui apparaissent sans autre contrepoint positif que leur environnement végétal. A Notre-Dame-du-Port, la guerre $\mathrm{du}$ Bien et du Mal garde toute son intensité jusqu'au sein même du sanctuaire, que son décor est par conséquent bien loin de qualifier comme un lieu de paix paradisiaque. 
Autre différence, la glorification de l'architecturation du sacré est moins poussée à Notre-Dame-du-Port qu'à Saint-Nectaire. On retrouve certes, dans l'édifice clermontois, le donateur laïque apportant sa contribution à l'édification matérielle de l'église, sous l'espèce d'un chapiteau amplement végétalisé. La valeur salvifique de ce geste y est peut-être même affichée avec plus d'insistance encore qu'à Saint-Nectaire, puisque Stefanus écrase le vice sous ses pieds et touche le livre tenu par l'ange, qui renvoie au Livre de vie figuré sur le chapiteau de l'Assomption de Marie. Par ailleurs, le Templeéglise terrestre où officie Zacharie et l'église céleste à laquelle la Vierge ouvre l'accès jouent un rôle décisif, puisqu'ils produisent, grâce à leurs similitudes formelles et à leur disposition symétrique, un puissant dispositif venant encadrer les forces vitales de la Création. Ces deux architectures jouent un rôle stratégique majeur dans l'opération de relève que met en séquence le décor sculpté : c'est par le biais de l'architecturation de l'Ecclesia que peut s'accomplir le passage de la vitalité du monde créé (voulue par Dieu et dotée d'une positivité certaine) à la Vie céleste (dotée d'une perfection bien plus complète). En même temps, le réseau d'images associées à l'architecturation du sacré se déploie à Saint-Nectaire avec une ampleur plus considérable encore. Cette problématique massive est amorcée par la ligne noire qui, sur la cartographie synthétique (fig. 67), court à travers la nef et qui ne figure pas sur celle de Notre-Damedu-Port (on y retrouve certes les chapiteaux-bases du narthex, mais il n'y a pas d'élément relais dans la nef). Soulignons à nouveau, au regard de la question de l'animation vitale de l'édifice de pierres, la force stupéfiante d'un chaînage qui place, dans le narthex, le rappel de cette matérialité strictement minérale que le décor vient vivifier et sublimer, puis, à la porte sud, une scène évoquant (pour l'exorciser) la possibilité d'une transmutation maléfique de la pierre, avant d'afficher, dans le sanctuaire, l'ordre des transformations légitimes. A Saint-Nectaire, il s'agit manifestement de construire un dispositif tout entier orienté vers l'auto-glorification du bâtiment même où figure le décor (et où repose le corps du saint), alors que la question de l'architecturation du sacré semble posée, à Notre-Dame-du-Port, sur un plan plus général.

161 Une différence plus nette encore tient au fait que le végétal est totalement écarté de l'hémicycle à Saint-Nectaire, et presque entièrement de son déambulatoire, alors qu'il bénéficie, à Notre-Dame-du-Port, d'une présence non seulement quantitativement ample ${ }^{162}$ mais aussi qualitativement renforcée. Un iter végétalisé, rendu cartographiquement par une flèche verte allant de la nef au chevet, s'y construit comme progression, à la fois vers une plus grande unitas des types végétaux (au sein de laquelle ne cesse de se manifester une certaine varietas), et du fait de la mise en évidence de plus en plus insistante d'un marqueur spécifique (le caulicole) ${ }^{163}$. Ce dernier, que l'on propose de saisir comme une forme d'architecturation verticale de la végétalité, est bien à même de pousser à sa plus haute intensité la sublimation/ spiritualisation de l'église par l'ornatus végétal. En tout cas, alors qu'à Saint-Nectaire, la végétalité, dotée par ailleurs d'un rôle éminemment positif, doit néanmoins s'effacer des parties les plus sacrées de l'église, elle participe activement à la dynamique de l'iter mis en place par le décor sculpté de Notre-Dame-du-Port. Enfin, une ultime différence tient à l'apparition d'un enclave violette dans l'hémicycle de Notre-Dame-du-Port, alors que cette couleur en est exclue à Saint-Nectaire ${ }^{164}$. Il s'agit certes d'une présence restreinte, mais elle se concentre dans une figure dotée d'une force énigmatique peu commune, la personnification des forces vitales de la création. Eu égard à l'ample déploiement du violet dans le déambulatoire, il s'agit là d'un point d'accroche décisif, 
qui permet l'encadrement des forces vitales de la création par l'architecturation du sacré et sa relève au profit d'une Vie céleste qui ne semble accessible que par le détour du bâtiment-église.

\section{L'iter en travail}

162 Au total, Saint-Nectaire et Notre-Dame-du-Port proposent deux manières de répondre au défi que constitue le décor de Saint-Pierre de Mozat. Ces deux réponses sont très proches l'une de l'autre, tout en se distinguant par des accents spécifiques. Le retravail effectué à Notre-Dame-du-Port semble présenter, par rapport à celui accompli à SaintNectaire, deux traits apparemment contradictoires. D'un côté, on assume une part du puissant végétalisme de Mozat, ce qui conduit à lui faire une large place dans l'hémicycle, alors qu'il en est exclu à Saint-Nectaire. De l'autre, si une manifestation des forces vitales du monde créé trouve dans l'hémicycle une formulation ambivalente (et donc loin d'être unilatéralement négative), d'autres font l'objet d'une réinterprétation franchement péjorative : les hommes nus dans le végétal, expression d'harmonie cosmique à Mozat, prennent ici une valeur inverse, à l'image de leurs pieds retournés et de l'entité végétalo-bestiale sous l'emprise de laquelle ils apparaissent (voir plus haut). Ces figures ont également été interprétées comme une négativisation des hommes végétalisés de Saint-Nectaire qui, eux, ne présentaient pas de caractère clairement inquiétant.

En fait, le travail accompli à Notre-Dame-du-Port est assez cohérent et on peut y voir la conjonction de trois processus visant à reformuler les particularités mozacoises. Ces trois processus tiennent à l'intégration d'un végétal de plus en plus sublimant, à la négativisation franche de certaines figures exprimant la vitalité du monde créé et, enfin, à l'intégration/encadrement par le sacré architecturé d'une figure aussi singulière que la personnification des forces vitales. Il y a là une palette de stratégies dont la combinaison permet de reprendre quelque chose du fil violet-vert de Mozat, tout en l'intégrant dans une vision beaucoup plus clairement moralisée. Par contraste, l'option adoptée à Saint-Nectaire est d'une bien plus grande simplicité : elle consiste à écarter entièrement le violet et le vert de l'hémicycle, au profit d'un positif entièrement anthropomorphique et architecturé. Alors même qu'on constate l'abondance des citations littérales de Mozat, nettement plus nombreuses qu'à NotreDame-du-Port, Saint-Nectaire fait le choix de s'opposer de manière très frontale aux propositions mozacoises. Pour sa part, Notre-Dame-du-Port adopte une stratégie plus complexe, plus subtile, dont le résultat peut sembler sur certains points plus proche de l'esprit de Mozat, quoiqu'en même temps la relecture moralisante et la négativisation des entités exprimant la vitalité inhérente au monde créé soient poussées plus loin qu'à Saint-Nectaire.

Pour jouer d'une opposition plus diamétrale, la solution adoptée à Saint-Nectaire n'en présente pas moins quelques traits particulièrement remarquables. Sans doute parce que le déploiement d'un discours d'auto-glorification du lieu sacré architecturé lui fait face avec une solidité éprouvée, on peut y accorder place, jusque sur la bordure interne du sanctuaire, à une figuration remarquable et non négative des forces vitales de la création (les hommes végétalisés). Parallèlement, alors qu'à Notre-Dame-du-Port, la quaternité des hommes dans le végétal de Mozat est réinterprétée très négativement (les hommes aux pieds retournés), à Saint-Nectaire, la seule citation de la séquence 
mozacoise associant l'humain et le végétal (l'homme à califourchon sur une branche) fait l'objet, avec Zachée dans son arbre, d'une relève positive, par englobement dans la narration néotestamentaire. Cette dernière opération est, du point de vue de la transformation sérielle, d'une efficacité qui n'a d'égale que son ambivalence. Si le végétal trouve ici sa place et semble même être le moyen qui permet au pécheur d'entrer en communication avec le Christ, le sens de la scène, que ses mobilisations en rapport avec la liturgie de la consécration intensifient, suggère plutôt un appel à s'arracher au végétal (mozacois) pour pénétrer avec le Christ dans l'édifice dont il fait sa demeure (en l'occurrence, Saint-Nectaire). Mais Notre-Dame-du-Port n'est pas en reste dans la subtilité, car la personnification des forces vitales de la création développe une position qui se situe, en quelque sorte, entre la formule vitalement positive de Mozat et celle, liturgiquement relevée, de Saint-Nectaire (et qui les tire toutes les deux dans le sens de leur ambivalence potentielle). Dans les deux édifices (sous des formes bien distinctes, mais non contradictoires), c'est sans doute la puissance avec laquelle se déploie le discours sur l'architecturation du sacré, et la confiance dans les vertus de l'édification ecclésiale qui en découle, qui autorisent à faire place à des figurations des forces vitales de la création qui conservent, tout en en permettant la relève, quelque chose de l'esprit de Mozat.

Il convient, pour finir, de s'interroger sur la signification de l'écart constaté entre Mozat et les autres édifices traités ici. Pour Jean Wirth, ce qui les sépare s'explique aisément : d'un côté, «l'art sensuel et idyllique » de Mozat et son «indulgence envers la chair » témoignent de conceptions de la vie monastique quelques peu relâchées, qui justifient la reprise en main par Cluny, en 1095; de l'autre, le décor sculpté de SaintNectaire et de Notre-Dame-du-Port témoigne d'une "réaction moraliste", caractéristique de l'adhésion à la réforme grégorienne ${ }^{165}$. En somme, il s'agirait d'une opposition radicale entre les édifices liés à un contexte grégorien et ceux qui auraient été conçus en dehors de celui-ci. Pourtant, cette conception semble trop tranchée et elle repose sur une interprétation de la réforme grégorienne comme dualisme radical que l'on s'est efforcé, au début de ce chapitre, de récuser.

Entre Mozat d'une part, Saint-Nectaire et Notre-Dame-du-Port de l'autre, l'écart que nos comparaisons se sont employées à mettre en évidence doit être conçu comme un retravail visant à produire des transformations majeures, mais non point pourtant une opposition diamétrale. Outre que le décor de Mozat ne présuppose pas une exaltation du paganisme ou du plaisir sensuel, on ne peut pas dire non plus qu'il imprègne l'abbatiale d'une atmosphère idyllique (et peu christianisée). La présence du Mal y est certes particulièrement faible, mais, pour autant, toute moralisation n'en est pas absente. On ne peut négliger le fait que l'entrant est accueilli par deux images de la domination sur les forces bestiales (Samson-David-Hercule et le singe cordé). L'épanouissement de la corporéité, amplement observable dans l'église, est au prix de cette maîtrise, d'emblée affichée, du charnel/bestial. De plus, la prise en compte de la dynamique de l'iter modifie profondément la compréhension du décor, dans la mesure où il implique un cheminement vers une sacralité clairement inscrite dans le message scripturaire.

Quant à Saint-Nectaire et Notre-Dame-du-Port, s'il est évident qu'ils témoignent d'une accentuation du moralisme grégorien, on ne saurait y voir l'expression d'un dualisme absolu qui, du reste, ne correspond pas aux orientations dominantes du clergé réformateur. En l'occurrence, on est loin d'un radical mépris du monde, comme en 
témoigne le fait que, dans chaque édifice, au moins une figure associée aux forces vitales de la création préserve son ambivalence (leur personnification associée à un arbre de vie à Notre-Dame-du-Port, les hommes végétalisés à Saint-Nectaire). Et on est loin aussi d'observer un phénomène systématique de réinterprétation caricaturale des chapiteaux de Mozat. Beaucoup d'entre eux sont repris littéralement et conservent une plastique qui n'est pas si éloignée du référent mozacois. Les formes du monde créé gardent une part de cette beauté qui contribue à honorer le lieu rituel.

Saint-Pierre de Mozat ne livre donc pas une vision idyllique du monde créé, ni SaintNectaire et Notre-Dame-du-Port une image diabolisée de celui-ci. Dans tous les cas, il s'agit de traverser les ambivalences du monde créé pour s'approcher de la perfection céleste. Et tandis que Mozat exprime une conception plus immanente du rapport entre le Créateur et sa création, qui permet de s'appuyer sur les harmoniques du monde pour engager l'iter menant au divin, les édifices postérieurs évoqués ici donnent à l'iter une dimension plus tensive et plus agonistique. Il est indéniable que les combats propres à la réforme grégorienne s'intensifient. Mais sans doute faut-il également tenir compte du statut des édifices : Notre-Dame-du-Port est une priorale-cure et Saint-Nectaire un sanctuaire de pèlerinage. Les interactions avec le monde laïque y sont sans doute plus directes et plus constantes que dans une abbaye comme Mozat (ou Chanteuges), et peut-être cela conduit-il à faire place à d'autres types de rapport au monde créé. Le décor de l'abbatiale Saint-Pierre de Mozat a d'abord été conçu pour la communauté monastique elle-même. Sûre de son caractère spirituel, celle-ci semble avoir opté pour un décor qui, sans nier la place du Mal, témoigne de sa propre participation, en pleine confiance, à l'harmonie musicale de l'univers. Le décor emblématiserait alors la projection de la vie spirituelle des moines dans un ordre liturgico-cosmologique en prise directe avec le divin. Par différence, les autres édifices témoigneraient d'un engagement plus immédiat dans les conflits du monde terrestre et leur décor se montrerait soucieux d'opposer aux risques d'une sacralité diffuse la glorification d'une concentration du sacré dans des lieux architecturés qui sont à la fois les symboles de la puissance cléricale et les instruments d'une conformation de la société à ses buts spirituels.

\section{Ouvertures}

Prenons maintenant le point de vue de Sirius. Imaginons qu'entre dans ces églises romanes d'Auvergne un homme qui aurait échappé à cinq siècles d'histoire de l'art vasarienne fondée sur la domination de l'historia sur l'ornement, qui aurait échappé aussi à trois siècles de construction du naturalisme, qui ignorerait tout de l'opposition Nature-Culture, qui n'aurait pas lu Descartes, et qui par conséquent ne saurait imaginer que seuls les hommes possèdent une âme et que les animaux ne sont que purs corps. Cet homme là, s'il regardait attentivement les chapiteaux de ces édifices, serait bien en peine de deviner les fondements religieux de leurs images (la Trinité, l'Incarnation, la Passion du Christ...). S'il cherchait à comprendre le culte rendu dans ces temples, sans doute en viendrait-il à imaginer une dévotion particulière à la vie végétale, d'étranges pratiques impliquant des relations tantôt affectueuses, tantôt violentes, entre les hommes et les bêtes et quelques anecdotes incompréhensibles impliquant des humains.

Un tel exercice d'estrangement, tel que l'ont proposé les formalistes russes et plus récemment Carlo Ginzburgi66, ne peut être que le fruit d'un travail spécifique : il va de 
soi qu'aucun regard "naï ", aucun estranger ne saurait exister en soi. Une telle déprise des catégories ordinaires de la perception ne peut être que construite et provoquée, que ce soit à travers une démarche artistique (comme c'est le cas chez Chlosky) ou par le biais d'une recherche exigeante.

Comment "décoloniser» notre regard de ces habitudes par lesquelles nous avons appris à voir le Moyen Age et ses images? Comment réunir ce qui avait été abstraitement séparé, réévaluer ce qui avait été dévalorisé par l'histoire récente? Comment retrouver les associations, les catégories pertinentes $\mathrm{du} \mathrm{XI}^{\mathrm{e}}$ siècle ? Le moyen le moins incertain consistait à prendre en compte l'intégralité du décor sculpté, sans présupposer des rapports de hiérarchie entre ces images, à tout considérer avec un égal sérieux : les chapiteaux végétaux perdus dans l'obscurité d'un narthex, peu éclairés, jamais publiés ni analysés; les images animales qui ne renvoient à aucune mention scripturaire; les étranges compositions d'êtres hybrides; les prestigieuses scènes de l'Apocalypse comme les éléments d'hagiographie locale. Toutes ces images, tous ces chapiteaux ont été re-photographiés systématiquement et analysés face par face.

Toutefois, si une telle exhaustivité est la condition nécessaire pour engager l'enquête, elle ne saurait être suffisante. C'est sans doute aussi parce que les catégories contemporaines relatives à l'«environnement» ont largement évolué depuis une trentaine d'années que nous sommes aujourd'hui en mesure de porter un regard neuf sur ces images. Les travaux de Bruno Latour puis ceux de Philippe Descola ${ }^{167}$ ont pris acte de la mise en crise systématique des critères qui fondaient traditionnellement l'opposition entre Nature et Culture dans la tradition occidentale. Ce binôme constitutif, qui confère à l'homme un privilège et une extériorité certaine vis-à-vis du monde matériel, apparaît désormais comme une spécificité locale propre à l'Occident des trois derniers siècles. Comme le montre P. Descola, la majorité des cultures, dans l'espace et dans le temps, ne possède pas l'équivalent de nos catégories exclusives de " Nature », ou même celle d'" Animal » construite par opposition avec l'humain. Tel est le cas du Moyen Age, qu'il est aujourd'hui urgent de considérer comme antérieur à ce "grand partage" naturaliste occidental, qui a conduit à chasser les animaux des églises, à exclure les abattoirs des centres-villes, à créer des parcs et des réserves naturelles : bref à séparer ce que l'on appelle aujourd'hui la Nature et la Culture. Loin de connaitre un tel clivage, le monde des XIe et XIIe siècles et ses images fonctionnent davantage sur un mode analogique impliquant des liens permanents, intenses et de natures très variées entre les différentes créatures, humains compris.

Prendre acte de cette différence ontologique est la première façon de répondre à la question qui s'est imposée d'une manière récurrente à cette étude : que viennent faire tant d'images du monde créé dans l'édifice rituel d'une religion à la fois anthropocentrique et théocentrique, qui exclut les créatures non-humaines de ses pratiques ordinaires? Une image comme celle d'un homme dominant un lion, présente à Mozat et à Orcival, ne renvoie pas aux seules références textuelles qu'elle évoque, qu'elles soient bibliques (David ou Samson) ou antiques (Hercule et le lion de Némée). Elle rappelle aussi à celui qui la regarde la violence des bêtes sauvages, qui est une caractéristique du monde d'après la Chute, et la possibilité pour des hommes exceptionnels de canaliser cette violence. Dans le même temps, cette image évoque aussi un impératif de domination tout intérieur, celui des bonnes pensées (raisonnables) sur les mauvaises (bestiales). Elle fonctionne comme un nœud où viennent se lier un ensemble de relations traversant ce qu'un «moderne» aurait 
appelé la Nature et la Culture; un nœud où l'humain, l'animal et les mouvements de l'âme se répondent et se croisent dans les vertiges de l'analogie.

Dans une telle ontologie, les différentes images du monde créé, qu'elles soient animales ou végétales, n'existent jamais per se, mais sont toujours susceptibles, notamment par le biais de la correspondance entre le microcosme et le macrocosme, de tenir un discours sur l'homme. Même les sociétés les plus analogiques sont anthropocentrées, ne seraitce qu'en raison du fait que des humains sont les producteurs de ces discours ${ }^{168}$, mais c'est tout particulièrement le cas du christianisme médiéval qui confère à l'homme un statut d'exception au sein des différentes créatures, en raison à la fois du rapport de ressemblance qui le lie au Créateur, et de l'Incarnation (d'un Dieu qui se fait homme). Cet analogisme anthropocentré, qui trouve de nombreux échos tant dans la littérature morale que dans les écrits de médecine, n'est ni bon ni mauvais en soi. Il est le principe d'intelligibilité qui permet de penser le mécanisme par lequel l'homme est relié au reste de la création, avec toute l'ambivalence que celle-ci possède à la suite de la Chute. Les représentations de créatures sur les chapiteaux, présentes en nombre notamment dans les nefs et les déambulatoires des édifices auvergnats assument largement cette fonction articulatoire : elles relient l'homme et le lieu ecclésial au reste du monde et donnent une ampleur cosmique aux discours moraux ; dans le même temps, ces images donnent une intelligibilité au monde créé, l'associant intimement à la créature humaine qui en constitue le centre et la finalité.

La place tout à fait centrale qu'occupent les procédés analogiques dans la société qui créé ces édifices, est un premier élément pour expliquer la multiplication des images de non-humains au sein des églises, mais elle est loin d'être suffisante. En effet, le processus que nous venons de décrire ne fonctionne que dans un cadre symbolique au sens large. C'est à partir d'entités reconnaissables constituant de véritables catégories culturelles que la machine analogique tisse le monde : des créatures qui possèdent un nom, une forme relativement standardisée, et auxquelles une production textuelle est attachée. Mais que faire alors de la majorité des chapiteaux des églises romanes qui ne représentent rien, de ces motifs végétaux ou abstraits qui ne peuvent être identifiés à aucune espèce réelle ou imaginaire, à aucun nom, aucun texte? Que faire de tous ces hapax, de ces images-limites ne s'inscrivant dans aucune catégorie culturelle précise? Notre hypothèse est que ces chapiteaux constituent une manière de penser ce qui échappe à la stricte lecture analogique du monde. Cette dernière, qui fonctionne sur la mise en relation d'un monde fragmenté en multiplicité d'entités discrètes est, de fait, confrontée à un problème de continuité : dès lors, l'évocation de la vie, qui traverse et anime l'ensemble des créatures, devient une question particulièrement cruciale. Tout ce passe comme si, dans ces édifices, la représentation d'un système symbolique mettant en ordre le monde créé, était secondée par la mise en image du principe vital qui les animait. Ce que nous avons appelé continuitas exprime ce caractère transversal de la vie, qui est la positivité a-morale de la création. 
Fig. 68

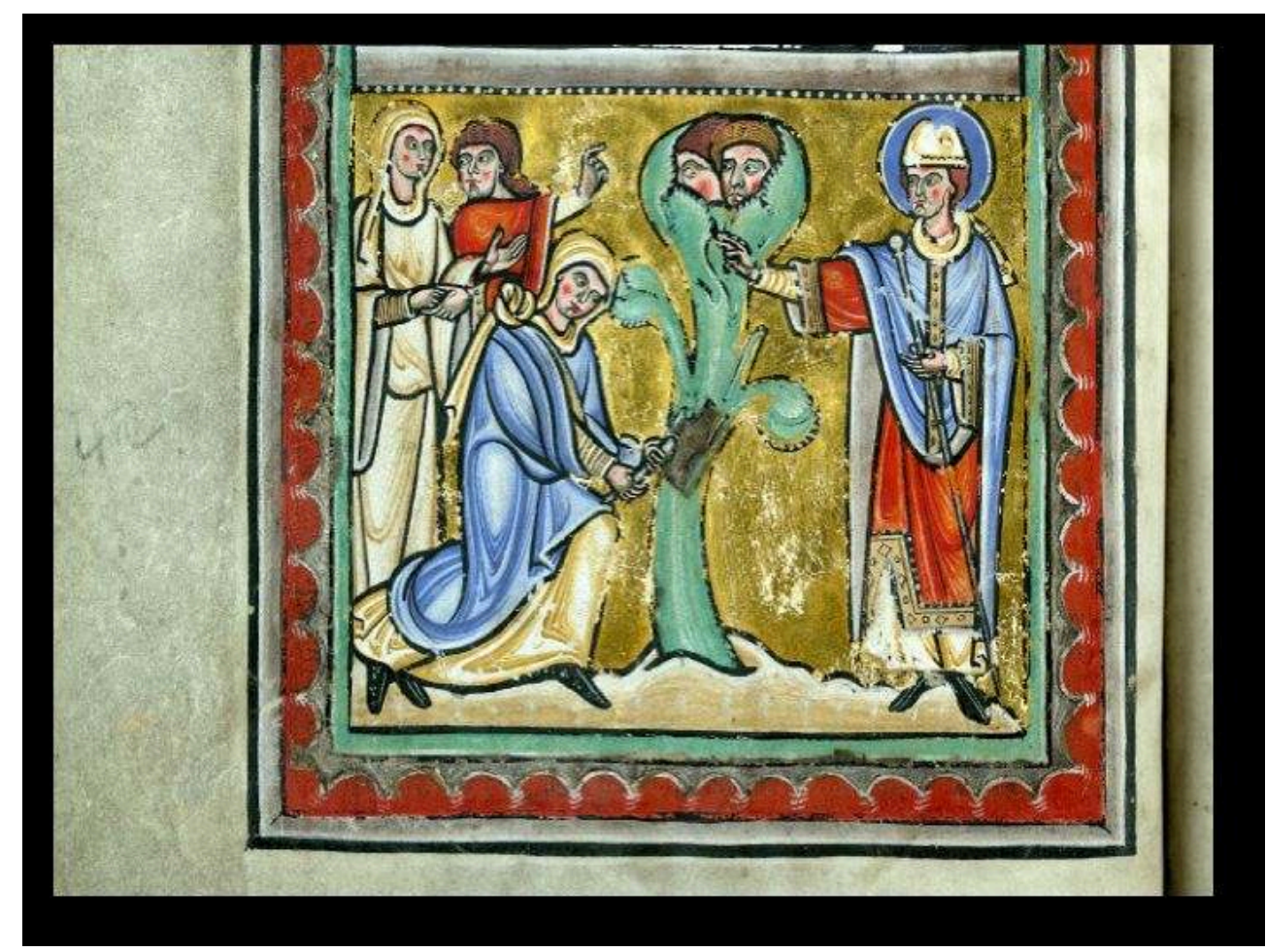

Saint Amand ordonnant d'abattre un arbre sacré (Vie de saint Amand; Valenciennes, Bibl. Mun., ms. 500 , f. 66 v., vers 1175)

Ce domaine est sans doute l'un des plus délicats, celui où les références manquent particulièrement et où les questions restent les plus ouvertes. Nous pourrions les poser de la façon suivante : si la représentation est à même de représenter des créatures, comment peut-elle évoquer visuellement ce qui les anime, et est incorporel ${ }^{169}$ ? Et, si elle s'y risque comment peut-elle suggérer la vie inhérente aux différentes créatures non-humaines, sans risquer de tenir un discours panthéiste ou simplement idolâtre? Les représentations médiévales de l'Arbre de vie du jardin d'Eden témoignent de cette difficulté. Nous avons vu que ce végétal exceptionnel, capable de donner l'immortalité, pouvait être représenté comme une création hybride, abritant des têtes humaines dans son feuillage (fig. 15). Dans les mêmes années, une représentation très proche servait à identifier les arbres magiques de la forêt auxquels les païens du temps de saint Amand s'obstinaient à rendre un culte ${ }^{170}$ (fig. 68). Une iconographie très proche est donc utilisée pour évoquer deux types de vitalité, dont l'une est légitime, paradisiaque, et l'autre illégitime, païenne, voire diabolique. Au-delà de la différence entre les deux manuscrits concernés, un tel rapprochement rend compte de l'ambivalence des représentations des forces de la création dans ce contexte historique.

Cette ambivalence aurait pu constituer un frein ; elle fut plutôt un terreau fertile où, en l'absence de toute norme unifiée, chaque édifice chercha comment accorder les conceptions cléricales du monde et les croyances folkloriques relatives à la création. Il est pratiquement impossible de connaître en quoi ces dernières consistaient dans l'Auvergne du XI $\mathrm{XI}^{\mathrm{e}}$ siècle, mais à un certain niveau de généralité, et compte tenu de croyances repérées dans les régions avoisinantes, en amont et en aval de notre période, il est plus que probable que cette société ait connu des pratiques magiques associées aux éléments naturels, prêtant à ces derniers si ce n'est une intériorité, au moins une 
forme d'agentivité171. Il suffit de penser aux questions que Burchard de Worms, dans son célèbre pénitentiel (rédigé quelques générations avant la construction de Mozat), recommande de poser au fidèle venant se confesser pour entrevoir, de façon certes déformée par le regard clérical, cet autre rapport à l'environnement qui existait à l'époque $^{172}$ :

Q.65 As-tu cueilli des herbes médicinales en récitant des enchantements impies et non en chantant le symbole et l'oraison dominicale, à savoir le Credo et le Pater? [...]

Q. 66 As-tu prié ailleurs qu'à l'église ou à un autre lieu sacré [locum religiosum] que ton évêque ou ton prêtre a désigné, c'est-à-dire aux sources, aux pierres, aux arbres ou aux croisées des chemins, et as-tu allumé un cierge ou une torche pour vénérer le lieu, ou as-tu apporté du pain ou toute autre offrande, ou mangé ou recherché quelque chose pour le salut de ton corps ou de ton âme?

[...]

Q. 92 As-tu honoré des herbes, de l'ambre ou le jeudi en l'honneur de Jupiter ?173

Ces interrogations supposent que des fidèles puissent investir les choses en question, et notamment les plantes, d'une certaine sacralité en dehors du cadre ecclésial, et les utilisent comme support de leurs pratiques. La prise en compte de ce monde folklorique et son éventuelle intégration dans les lieux rituels chrétiens ont malheureusement été à l'origine d'une histoire de l'art des plus confuses, cherchant, le plus souvent au prix d'anachronismes brutaux, des images «celtiques » ou " païennes » au sein des églises romanes. A juste titre, l'anthropologie historique s'est largement construite en critiquant des études qui s'obstinaient à penser ces images en tant que survivances d'une "culture populaire» ou d'une "religion populaire», depuis l'Antiquité jusqu'au XVI siècle $^{174}$. La critique de ces notions et de l'historiographie folkloriste traditionnelle a, depuis, permis une approche plus critique et plus historique des "superstitions " ${ }^{175}$. Grâce à ce travail de clarification et aux travaux issus de l'anthropologie de la nature et de celle des images, il est possible de ré-ouvrir aujourd'hui ce dossier, et de considérer ces images et leurs sources à nouveaux frais. Dans ce chantier immense, l'analyse des édifices romans d'Auvergne permet d'avancer quelques hypothèses de travail.

Dans leur critique des superstitions, les prédicateurs condamnent fermement les usages magiques non-cléricaux des végétaux et des animaux, tous les actes qui postulent ou confèrent un pouvoir à des éléments du monde matériel. Mais pour virulentes qu'elles soient, ces critiques ne doivent pas se comprendre comme l'expression d'un rejet du monde créé ou comme le fruit d'une séparation absolue entre le matériel et le spirituel. Ce que reprochent les prédicateurs, c'est avant tout que cette matérialité n'ait pas été inscrite dans une sacralité légitime, ecclésiale. L'Église est loin de rejeter le monde créé dans son ensemble (le décor des édifices en témoigne); elle l'instrumentalise plutôt, le spiritualise, l'intègre dans son cadre propre (peut-être en tirant un bénéfice du prestige et des forces que des pratiques réalisées en dehors du cadre ecclésial confèrent au monde matériel). La question mérite d'être posée dans le cas des édifices romans d'Auvergne, non seulement parce que les références visuelles à la culture antique sont particulièrement fréquentes, mais surtout parce que certains chapiteaux ne peuvent s'expliquer à partir de la seule culture cléricale. Comme il est impossible d'imaginer la tolérance d'un quelconque culte païen au sein du temple chrétien, on peut faire l'hypothèse que ces images seraient des formations de compromis, comme disent les psychanalystes, cherchant à concilier, de manière acceptable, des modes de rapport au monde différents, qui coexistent au sein de la même société. 
180 Pour faire face à cet enjeu, plusieurs procédés iconographiques ont été élaborés et combinés. Tout d'abord, si la végétalité constitue le point de départ des évocations de la Vie, avec les valeurs de croissance qui lui sont associées, sa présence sur les chapiteaux passe presque toujours par le filtre de l'ornement. Les artistes romans accentuent le caractère inorganique de leurs créations, mélangent les feuillages et les ornements abstraits, tordent les branches en entrelacs et en improbables contorsions pour mieux témoigner du caractère artificiel de cette évocation. Ce travail sur la matière laisse entendre que les créations naturelles ne sont pas dignes d'éloge en elles-mêmes, mais seulement en ce qu'elles sont transformées par leur présence dans le lieu ecclésial. Aucun chapiteau végétal ne saurait passer pour l'évocation d'une plante particulière qui posséderait telle ou telle vertu magique. C'est parce que les essences ne sont pas reconnaissables, parce que le végétal est spiritualisé par son ornementalisation, par le travail artisanal et sa présence dans le lieu rituel, qu'il peut servir de moyen expressif pour évoquer la vitalité de la création, sans courir le risque de l'idolâtrie ${ }^{176}$.

Le caractère artificiel de ces images, qui marque l'écart entre le lieu-église et le monde des apparences ordinaires, ne se limite pas aux chapiteaux strictement végétaux ou abstraits. Différents procédés d'hybridation permettent d'embrasser et de réunir l'ensemble du monde créé, et de le connecter à l'église : un corps humain, qui semble supporter sans effort le tailloir et la voûte de l'édifice, se prolonge en fleurs et en fruits; la queue d'un oiseau donne naissance à de minuscules colonnes dotées de chapiteaux; les cheveux d'un homme ou la ramure d'une bête voient leurs extrémités s'enrouler pour mieux imiter les volutes des chapiteaux corinthiens. Toutes ces hybridations permettent au décor de l'église de réunir les multiples formes du monde créé, dans une même continuité, qui est celle de la vie. 
Fig. 69

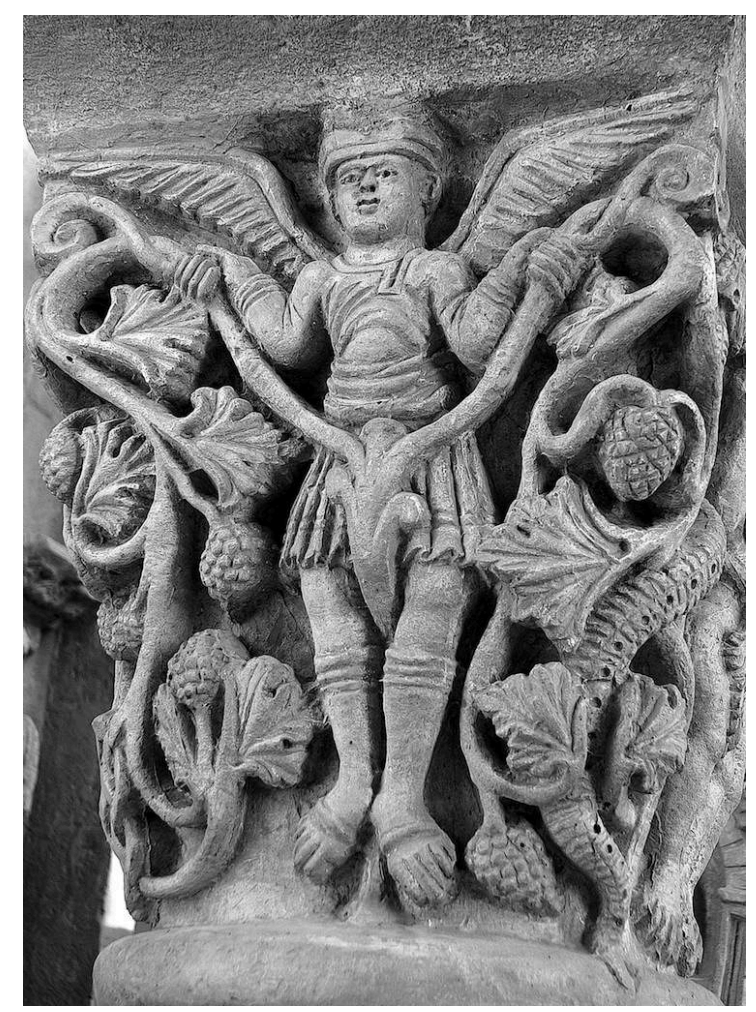

Notre-Dame-du-Port : personnification ailée des forces vitales (mais ambivalentes) de la création après la Chute, allégorisées par l'arbre dont elle tient des branches opposées

Ces différents procédés prennent soin d'utiliser le potentiel ornemental de la création en évitant toute personnalisation, toute inflexion formelle qui risquerait de prêter une quelconque intentionnalité à des éléments naturels et pourrait s'exposer à l'accusation d'idolâtrie. Une figure, toutefois, une seule sur l'ensemble de notre corpus, rompt avec ces précautions. On l'a rencontrée sur l'un des chapiteaux du rond-point de NotreDame-du-Port (fig. 69). Rappelons brièvement le sens que nous avons donné à cette figure ailée, dépourvue de nimbe, vêtue court à la mode antique, qui laisse s'ériger entre ses jambes une verge tout à fait phallique s'épanouissant en feuilles et en fruits ${ }^{177}$. Si l'on a eu maintes fois l'occasion de revenir sur le lien associant le végétal aux facultés de fertilité et de génération des forces naturelles, aucune image ne l'exprime de façon aussi littérale que celle-ci, où se combine deux conceptions d'une vitalité forcément sexualisée après la Chute : la branche tenue par la main gauche du génie renvoie tout d'abord au Mal, puisque la tige s'hybride ou plus exactement entre en tangence avec l'Arbre de la connaissance. Mais on ne saurait assimiler cette image à la seule critique de la luxure et de l'amour charnel, dans la mesure où la branche tenue dans la main droite est chargée de feuilles et de fruits et s'ornementalise en un entrelacs qui conduit, sans discontinuer, à une autre branche tenue par un ange. La création marquée par la Chute, d'un côté, est donc reprise en main par l'ordre divin, de l'autre. Elle est en mesure de signifier sa nature bénéfique et de la faire participer au décor du monde (créé) et à l'ornatus de la maison de Dieu. Cette figure ailée ne doit donc pas être comprise comme celle d'un génie de la Nature - «génie» dont l'existence est incompatible avec le christianisme, «Nature » dont la notion serait ici anachronique mais comme une manière de rendre sensible sous la forme d'une personnification (en 
manière d'Eros quelque peu ambigu, mais solidement encadré par des images sanctifiées de la Vierge), l'ambivalence des forces vitales et génératives de la création, qui sont tout à la fois favorables ou défavorables, fécondes mais tentatrices et mortelles pour l'homme ici-bas. Le chrétien doit rendre grâce au Créateur de leur aspect bénéfique pour sa vie, en écarter toute forme de concupiscence et en accepter les aspects négatifs comme une expiation de la Chute (évoquée sur une face voisine du chapiteau).

On le voit : même si les images du monde créé doivent être pensées en rapport avec toute la hiérarchie de l'univers (ce que suggère particulièrement bien les diverses quaternités humaines, cosmiques, angéliques de l'hémicycle de Mozat), la place très singulière qu'elles peuvent être amenées à prendre dans les églises (comme dans le cas de la figure ailée de Notre-Dame-du-Port) ne peut se comprendre indépendamment des manières dont les hommes en ressentent les forces dans leur corps (comme le montrent les humains végétalisés de Chanteuges), dans les êtres débordant des limites (comme les centaures), dans leur existence (comme celle à laquelle les bergers prêtent un visage à la fois familier et inquiétant). L'Église n'aura pu alors les ignorer et aura donc tenté d'en donner une image qui lui permette de les fixer à la fois pour incarner leur incorporalité trouble et troublante et s'assurer de leur maitrise sous la protection d'un ange qui en conjure la face diabolique et grimaçante (sur un chapiteau reculé d'une absidiole).

Pour autant, on ne peut considérer tous ces êtres comme autant de reflets fidèles et imagés des conceptions de leur époque, ni établir à partir de ce corpus des conclusions ayant une valeur générale pour la société du $\mathrm{XI}^{\mathrm{e}}$ siècle. Aucun dogme, aucune bible des illettrés ne se donne à lire ici. Pas plus qu'il n'existe une conception unique de la création à l'époque médiévale, dans tous les groupes sociaux et tous les contextes locaux, il n'existe un discours strictement unifié tenu par l'ensemble de ces images c'est au contraire leur diversité, voire leurs divergences qui nous sont apparues jusque et même surtout dans les reprises d'une église à l'autre. Et bien que, à l'intérieur d'une église, ils représentent des points d'intensité iconographique particulièrement denses au regard des autres représentations (notamment les peintures murales), ces chapiteaux ne se suffisent quasiment jamais à eux-mêmes et n'existent qu'au sein d'un réseau d'images où leur propos est relayé, tempéré ou infléchi, par d'autres images, qui leur répondent à distance. Dans les édifices que nous avons choisis, l'homogénéité formelle entre les différentes sculptures, les jeux de renvois et de citations invitent à considérer le décor sculpté d'une église comme l'expression d'un même ensemble sériel, d'un lieu d'images possédant - ou plutôt produisant en la "bricolant » - sa logique propre qu'un autre édifice viendra renouveler ou compromettre.

C'est à cette échelle, celle du réseau de chapiteaux au sein de chaque édifice, que l'on peut dégager de véritables prises de position. Ce que nous avons appelé agencement désigne cette mise en relation des différents chapiteaux au sein d'un édifice, qui se pense en fonction des valeurs, liturgiques et symboliques, que l'on accorde aux différentes parties de l'édifice. Chaque édifice propose un iter singulier, un chemin de transformation spirituelle en images, dont les modalités et les étapes sont à chaque fois différentes. La comparaison cartographique des différents réseaux montre (d'une façon particulièrement colorée!) avec quelle liberté chaque église s'est réappropriée le problème qui lui était posé, proposant à partir d'un matériau en partie commun, des agencements nouveaux, et par là sa propre vision du monde. Ces ensembles de 
sculptures doivent alors se penser comme des micro-événements, comme les fruits singuliers de rapports de forces contextuels où interviennent notamment des injonctions cléricales et des croyances locales, ainsi que la prégnance de propositions formelles dans les édifices proches, déjà consacrés ou en chantier.

Les édifices que nous avons pris en compte ont été réalisés au cours d'une période très courte, sans doute moins d'une cinquantaine d'années. Des milliers d'images d'une qualité exceptionnelle ont été créées dans ce bref laps de temps, qui constitue un observatoire de premier choix pour saisir le processus de création au Moyen Age. Les références explicites d'un édifice à l'autre montrent l'existence d'une culture visuelle partagée dans une vaste zone géographique, où l'invention formelle passe largement par un travail de reprise, de réinterpréation, de ré-agencement et de transformation d'images pré-existantes. Les églises d'Auvergne nous obligent alors à penser une création artistique et une évolution des formes qui est loin de suivre une confortable progression linéaire vers un art toujours plus accompli. C'est une histoire plus chaotique qui nous est apparue, faites de géniales apparitions et de bricolages incertains, où une proposition artistique et théorique majeure, incarnée ici par l'abbatiale de Mozat, définit un nouveau cadre de pensée (et de débat ?) pour les artistes et les commanditaires contemporains.

\section{NOTES}

1. Le mot "nature» existe bien au Moyen Age avec le sens de création. Ainsi Honorius Augustodunensis parle-t-il d'une «natura creata non creans » (cf. Clavis physico, BnF, ms. lat. 6734, fol. 3v.). Sur l'apparition de la notion de Nature au sens moderne du terme, on renvoie à Philippe DESCOLA, Par-delà nature et culture, Paris, Gallimard, 2005. C'est à la configuration ouverte par l'apparition de cette notion que l'auteur réserve le concept de "naturalisme», tandis que le mode d'identification caractéristique de l'Europe occidentale avant le XVII ${ }^{\mathrm{e}}$ siècle relève de ce qu'il dénomme « analogisme ».

2. On trouvera une discussion plus complète des questions évoquées ici dans J. BASCHET, La civilisation féodale, op. cit., partie 2, ch. 4 et « L'humain (et l'institution) comme paradoxe. Corporel et spirituel dans l'Occident médiéval ", dans Patrick HENRIET (éd.), Corps en société. Perception et usages du corps au Moyen Age, Rennes, PUR, sous presse.

3. J. WIRTH, L'image à l'époque romane, op. cit., partie III, ch. III, p. 257sq. On évoque ici une discussion engagée dans Jérôme BASCHET, «Jean Wirth, la Vierge aux longues nattes et l'ange au sourire. A propos de L'image à l'époque gothique (et de L'image à l'époque romane) », publication en ligne, octobre 2008, http://www.editionspapiers.org/node/26

4. Ibid., p. 259-261.

5. Voir Patrick HENRIET, La parole et la prière au Moyen Age. Le Verbe efficace dans l'hagiographie monastique des $\mathrm{XI}^{e}$ et $\mathrm{XII}^{e}$ siècles, Bruxelles, De Boeck, 2000, p. 146-159 et 360-362, qui souligne combien l'érémitisme ascétique d'un Pierre Damien doit être compris dans le cadre d'une vision ecclésiologique plus ample, qui combine fuite du monde et désir de le sauver.

6. "Nam sicut corpus vivificatur anima et regitur, ita donis Sancti Spiritus etiam corporalia aecclesiae sanctificantur... Ut enim anima in hac vita sine corpore non regitur, ita sancta aecclesia sine corporalibus 
donis, spiritualibus in praesenti non utitur ", PLACIDE DE NONANTOLA, Liber de honore Ecclesiae, éd. L. DE HEINEMANN et E. SACKUR, MGH, Libelli de lite, II, Hanovre, 1892, p. 605, cité par Patrick HENRIET, « En quoi peut-on parler d'une spiritualité de la Réforme grégorienne? ", Revue d'Histoire de l'Église de France, 96, 2010, p. 71-91 et "Corporalia et spiritualia, ou l'Église et le corps en contexte "grégorien ». A propos d'une formule de Placide de Nonantola " (sous presse), où il souligne «à quel point les réformateurs 'grégoriens' les plus intransigeants se situaient dans une logique d'acceptation et d'investissement du monde matériel, lequel était subordonné au spirituel sans jamais être condamné ».

7. "Corporalia et spiritualia », ibid.

8. Voir Herbert KESSLER, Spiritual Seeing. Picturing God's Invisibility in Medieval Art, Philadelphia, Pennsylvania UP, 2000, ainsi que "A Gregorian Reform Theory of Art », dans Serena ROMANo et Julia ENCKELL JULLIARD (éd.), Roma e la Riforma gregoriana. Tradizioni e innovazioni artistiche (XI-XII secolo), Rome, Viella, 2007, p. 25-48 (où il est notamment question des conceptions de Pierre Damien, qui admet que les images peuvent aider à s'élever de la vision corporelle à la contemplation spirituelle, soit une perspective fort peu dualiste). Sur la conversion de l'Occident à une iconicité de plus en plus assumée et en particulier aux images tri-dimensionnelles, voir Jean-Claude sснмітт, Le corps des images. Essais sur la culture visuelle au Moyen Age, Paris, Gallimard, 2002.

9. On reviendra sur l'anagogie sugérienne, qui pousse particulièrement loin cette dynamique.

10. Notons qu'Anselme amplifie aussi considérablement le discours sur les béatitudes propres aux corps spirituels des élus ressuscités, lesquels constituent l'un des modèles par excellence de la spiritualisation du corporel (Proslogion, ch. 25, éd. Michel CORBIN, Paris, Cerf, 1986, p. 118-120).

11. "Summus namque opifex universitatem quasi magnam citharam condidit, in qua veluti chordas ad multiplices sonos reddendos posuit : dum universum suum opus in duo, vel duo sibi contraria distinxit. Spiritus enim et corpus quasi virilis et puerilis chorus gravem et acutum sonum reddunt, dum in natura dissentiunt, in essentia boni conveniunt (...) Reciprocum sonum reddunt spiritus et corpus, angelus et diabolus, caelum et infernus, ignis et aqua, aer et terra, dulce et amarum, molle et durum, et sic caetera in hunc modum ", Liber XII quaestionum, PL, 172, c. 1179. Voir Marie-Dominique CHENU, La théologie au douzième siècle, Paris, Vrin, 1976, p. 19-51, T. LESIEUR, Devenir fou pour être sage, op. cit. et Marta CRISTIANI, Cecilia PANTI et Graziano PERILLO (éd.), Harmonia mundi. Musica mondana e musica celeste fra Antichità e Medioevo, Florence, SISMEL, 2007.

12. P. HENRIET («Corporalia et spiritualia», op. cit.) cite notamment Humbert de Moyenmoutier qui explique que les dons des fidèles à l'Église font l'objet d'une sanctification qui «élève les patrimoines terrestres au rang de trésors célestes ». L'un des enjeux majeurs de la réforme grégorienne tient effectivement à la justification des possessions matérielles de l'Église, dès lors que celle-ci prétend aussi accentuer son caractère spirituel et se dégager de l'emprise des laïcs.

13. Pour plus de précision sur ces questions, voir Jérôme BASCHET, « Âme et corps dans l'Occident médiéval : une dualité dynamique, entre pluralité et dualisme ", dans Archives de Sciences Sociales des Religions, 2000 (oct.-déc.), 112, p. 5-30.

14. La formule de Pierre Damien relative aux corps glorieux («caro facta spiritalis») doit impérativement être comprise comme «la chair devenue spirituelle», et non comme «la chair devenue esprit »; cf. Hymnus de gloria paradisi, PL, 145, c. 86.)

15. Sur les clercs comme "homines spirituales", voir Yves CONGAR, "Homo spiritualis ", repris dans Études d'ecclesiologie générale, Londres, Variorum Reprints, 1983. La définition des spiritualia englobant l'église et toutes " les choses par lesquelles s'accomplissent les sacrements spirituels ", ainsi que les charges ou redevances propres « aux personnes spirituelles » (les clercs), figure dans la Summa decretorum de Rufin, vers 1157-59, citée par P. HENRIET, «Corporalia et spiritualia », op. cit. 16. Sur ce retournement, voir D. IOGNA-PRAT, La Maison Dieu, op. cit., et M. LAUWERS, Naissance du cimetière, op. cit. 
17. Pour tout ce qui concerne la consécration, voir D. IOGNA-PRAT, ibid. ch. 5 et D. MÉHU (éd.), Mises en scène et mémoires de la consécration, op. cit.

18. Didier мÉHU, «Locus, transitus, peregrinatio. Remarques sur la spatialité des rapports sociaux dans l'Occident médiéval (XI ${ }^{\mathrm{e}}$-XIII ${ }^{\mathrm{e}}$ siècle) ", dans Construction de l'espace au Moyen Age : pratiques et représentations, Paris, Publications de la Sorbonne, 2007, p. 275-293 (citation p. 286).

19. D. Iogna-Prat a attiré l'attention sur ce texte, dans lequel il voit « un tournant majeur dans l'histoire de l'élaboration d'une doctrine du lieu de culte en Occident » (ibid., p. 415-416).

20. Voir Bénédicte PALAzzo-BERTHOLON et Éric PALAzzo, «Archéologie et liturgie. L'exemple de la dédicace de l'église et de la consécration de l'autel », Bulletin monumental, 159-IV, 2001, p. 305-316. Sur la relecture de l'adresse du Christ à Pierre dans le sens d'une légitimation de l'édification des églises, voir les chartes provençales commentées par M. LAUWERS, «Consécration d'églises, réforme et ecclésiologie monastique. Recherches sur les chartes de consécration provençales du $\mathrm{XI}^{\mathrm{e}}$ siècle ", dans D. MÉHU (éd.), Mises en scène et mémoires de la consécration, op. cit., p. 118 et 138-141. Notons que la valorisation de la pierre de taille, dont la technique se diffuse à partir des $\mathrm{X}^{\mathrm{e}}-\mathrm{XI}^{\mathrm{e}}$ siècles, prend aussi appui sur ces versets bibliques (voir les textes cités par D. MOREL, Tailleurs de pierre, op. cit., I, p. 527-531).

21. "...alia [ecclesia] est corporalis in qua videlicet divina officia celebrantur, alia spiritualis que est fidelium collectio, sive populus per ministros convocatus et in unum congregatus ab eo... Ecclesia autem materialis spiritualem designat ", GUILLAUME DURAND, Rationale divinorum officium, I, I, 1-2, éd. A. DAVRIL et T.-M. THIBODEAU (CC, CM, 140), Brepols, Turnoult, 1995, p. 11.

22. "Est etiam tota ex fortissimis lapidibus uiuis brunis scilicet et durissimis ut marmor facta, et deintus diuersis speciebus depicta, et deforis teolis et plumbo obtime cooperta », The Pilgrim's Guide: A Critical Edition, éd. Pamela GERSON et al., Londres, Harvey Miller, 1998, II, p. 76-78; cité par Didier MÉHU, "Les figures de l'édifice ecclésial d'après le 'Guide du pèlerin de Saint-Jacques de Compostelle' ", dans Michel LAuwers (éd.), Lieux sacrés et espace ecclésial (IXe-XVe siècle), Cahiers de Fanjeaux, 46, 2011, p. 98 et 113.

23. Tandis que la tête d'un singe est associée à une inscription évoquant les tromperies du diable, le lion est entouré par cette formule : «orior exanimis, vitam dat sp(iritus) oris » (je nais sans vie, le souffle de la bouche me donne la vie). Il s'agit bien sûr d'une référence à la lecture christologique de la destinée du lionceau, mort-né puis ressuscité par sa mère. Mais en faisant parler le lion, qui a ainsi accédé à la vie, l'inscription semble aussi prêter sa voix à celui qui entre dans l'église, en quête de vie spirituelle.

24. Si nous disons, comme ici dans le titre, végétalité (et plus loin ornementalité), plutôt que "végétation » et " ornementation », c'est pour signifier que nous visons des fonctions et non des motifs.

25. Ces chapiteaux ne sont qu'un exemple, particulièrement manifeste, de la prolifération du végétal dans l'art roman. $C f$. Jean-Claude BONNE, "Le végétalisme de l'art roman. Nature et sacralité ", dans Agostino PARAVICINI BAGLIANI (dir.), Le monde végétal. Médecine, botanique, symbolique, Micrologus' Library 30, Florence, Sismel-Edizioni del Galluzo, 2009, p. 95-120.

26. THEOPHILUS, De diversis artibus, éd. et trad. angl. C. R. DODWELL, Oxford, Oxford University Press, 1986, p. 61 [1ère éd. 1961]. L'expression « paradysi speciem » revient quelques lignes plus loin.

27. Ibid., p. 63.

28. SUGER, Scriptum consecrationis, 15 (Euvres, tome I, éd. Françoise GASPARI, Paris, Les Belles Lettres, 1996, p. 52). Suger ayant commencé ce passage, qui est la grande prière terminale de son mémoire, par la formule « Bénie soit la gloire du Seigneur en sa demeure (de loco suo) », il est clair que «l'église présente» inclut la domus materialis (cf. Jean-Claude BONNE, "Pensée de l'art et pensée théologique dans les écrits de Suger", dans Christian DESCAMPs (dir.), Artistes et philosophes : éducateurs?, Paris, Éditions du Centre Pompidou, 1994, p. 20-23). 
29. Sur la triple valeur « cognitive, logique et ontologique » de species, cf. Giorgio STABILE, « Teoria della visione come teoria della conoscenza ", La visione e lo sguardo nel Medioevo, t. I, Micrologus' Library 5, Florence, Sismel-Edizioni del Galluzo, 1997, p. 230-231.

30. Bien que les textes de Théophile et de Suger soient postérieurs de plusieurs décennies à nos églises d'Auvergne, ils expriment d'une façon particulièrement claire la conception de l'ornatus qui prévalait à l'époque romane.

31. Idéalement seulement, car les clercs eux-mêmes se déchirent à ce sujet, comme en témoigne l'opposition entre Suger et saint Bernard.

32. Cf. chapitre I, note 56 .

33. Decor et decus ayant le même accusatif, decorem doit être entendu au double sens dans la formule de Théophile : Domine dilexi decorem domus tuce.

34. Sur la " gloire », $c f$. supra note 28 et la citation de Pierre de Roissy dans le chapitre I, note 15.

35. Suger, De administratione, op. cit., p. 134. L'anagogie sugérienne est une rationalisation (allégorique et savante) des ornements somptueux de son église, mais aussi une description du sentiment (intuitif) de changer de monde que leur contemplation suscite - quelque chose que le fidèle devait éprouver à sa manière quand il passait de son environnement quotidien à l'intérieur d'une église. (Dans le passage cité, Suger déclare: «la beauté multicolore des gemmes me fait revenir de mes soucis extérieurs »). Une phrase célèbre du Liber Jacobus l'évoque ainsi: « Celui qui parcourt les nefs du palais [les tribunes] dans les hauteurs, s'il y est monté triste, il est rendu heureux et consolé [letus et gavisus efficitur], après avoir contemplé la beauté parfaite de cette église », (The Pilgrim's Guide, op. cit., p. 92, trad. modifiée). Sur le langage utilisé dans ce texte pour décrire l'église, cf. D. MÉHU, « Les figures de l'édifice ecclésial », op. cit.

36. THÉOPHILE, De diversis artibus, op. cit., p. 63. La suite du texte décrit l'intensité de ce que le fidèle ressent devant la varietas des ornementa ornementaux. Il évoque ensuite l'effet que doit avoir sur celui-ci les sujets historiés (Passion du Christ et des martyrs, Jugement dernier...).

37. Ibidem, p. 64 (le terme ordo, que nous retrouverons sous la plume de Théophile a au Moyen Age un spectre sémantique très large dont les contextes demandent qu'on spécifie les traductions possibles).

38. Parce qu'elle est destinée à célébrer la puissance du Seigneur (ou des seigneurs), cette esthétique se plaît aux qualités sensibles des matériaux (richesse, éclat multicolore, accumulation, préciosité...), telles qu'elles sont mises en œuvre, par exemple, dans l'orfèvrerie ou le vitrail ; elle n'est pas à comprendre en termes modernistes de beauté ou de plastique purement formelles (même si elle joue aussi de ces qualités, comme on le voit à Mozat).

39. Mais le problème se posera d'une « sacralité » propre à la création d'après la Chute, en un sens du mot « sacralité » qui demandera à être justifié.

40. Michel LAUWERS, "Le cimetière dans le Moyen Age latin. Lieu sacré, saint et religieux", Annales. HSS, 54, 1999, p. 1047-1072; Jean-Claude SCHMITT, « La notion de sacré et son application à l'histoire du christianisme médiéval ", repris dans Le corps, les rites, les rêves, le temps. Essais d'anthropologie médiévale, Paris, Gallimard, 2001, p. 42-52 et Dominique IOGNA-PRAT, « De l'usage du sacré en histoire médiévale », 2010, Collections Menestrel, http://www.menestrel.fr/spip.php? rubrique1367.

41. HUGUES DE SAINT-VICTOR, De sacramentis, cité par D. IOGNA-PRAT, La Maison Dieu, op. cit., p. 475, note 2 (texte daté vers 1131).

42. Éric PALAzzo, «Le végétal et le sacré : l'hysope dans le rite de la dédicace de l'église ", dans Kathleen G. CUSHING et Richard F. GYUG (éd.), Ritual, Text and Law. Studies in Medieval Canon Law and Liturgy Presented to Rogers E. Reynolds, Burlington (USA), Ashgate, 2004, p. 41-49 (notamment p. 48 : l'hysope est particulièrement propre à l'aspersion des murs car ses racines pénètrent entre les pierres et que ses vertus thérapeutiques contre les affections respiratoires l'associent au souffle et, de là, au domaine spirituel). 
43. Sermo LXXII, éd. G. LUCCHESI, Petri Damiani Sermones, CC, CM, 57, Turnhout, Brepols, 1983, p. 421-430.

44. Leo MARSICANUS, Narratio de consecratione ecclesiae Casinensis, éd. Tommaso LECCISOTTI, " Il racconto della dedicazione della basilica desideriana nel codice Cassinese 47 ", dans Angelo PANTONI, Le vicende della basilica di Montecassino attraverso la documentazione archeologica, Montecassino, 1973 (Miscellanea Cassinense, 36), p. 213-225. Nous devons à Didier Méhu les références de cette note et de la précédente.

45. Sur cette œuvre, nous renvoyons au travail en cours de Didier Méhu, à la présentation qu'il en a donné lors d'un séminaire à l'EHESS en 2008 et à ses travaux déjà cités sur la consécration.

46. On songe au mouvement d'élévation compris dans l'anagogie sugérienne.

47. L'identification possible des trois personnages est discutée par Denis GRIVOT et George ZARNECKI, Gislebertus, sculpteur d'Autun, s.l., Éditions Trianon, 1960, p. 70.

48. À Notre-Dame d'Orcival, où le végétal occupe une position privilégiée, des colonnes engagées à l'extérieur des deux absidioles orientales comportent exceptionnellement de grands chapiteaux végétaux.

49. Seules les églises de Chanteuges, Notre-Dame-du-Port et Orcival ont conservé l'essentiel de leurs chapiteaux extérieurs d'origine. A Mozat, un tout petit nombre de chapiteaux extérieurs ont été remontés. Seule des quatre églises, Orcival a conservé sa tour d'origine, quoique qu'elle soit un peu plus tardive que le reste de l'édifice et que sa flèche ait été refaite au XIX ${ }^{\mathrm{e}}$ siècle.

50. Nous ne prenons en compte à l'extérieur (et seulement d'une façon très globale) que les seuls chapiteaux, sans traiter de la hiérarchisation ornementale de l'architecture par l'articulation marquée des volumes, les parements colorés, les bandeaux de motifs courants, les jeux d'appareils et d'arcatures... Pour en rester aux chapiteaux, les deux absidioles orientales du chevet de l'église d'Orcival sont scandées par deux colonnes engagées couronnées d'importants chapiteaux végétaux qui marquent à l'extérieur l'éminence de cette partie de l'église et du rôle qu'y joue le végétal.

51. Les piédroits du portail sud de la façade occidentale de la basilique de Saint-Denis offrent un exemple remarquable d'élévation : ils mettent en scène, à côté des médaillons des travaux des mois, enlacés dans des rinceaux végétaux et exprimant le transitus du temps cyclique de la création, une allégorie de l'ascension humaine, sous la forme d'un personnage debout sur la pointe des pieds et les bras tendus vers une colonnette qui le surmonte et dont le fût ornée d'une spirale végétale habitée est surmonté d'un chapiteau corinthien ( $c f$. J.-C. BONNE, «Le végétalisme de l'art roman », op. cit., p. 95-99).

52. Rappelons que nous entendons par caulicole la combinaison d'une tige ou gaine (souvent torsadée), d'une collerette et du feuillage qui en émerge, $c f$. chapitre IV (Notre-Dame-du-Port).

53. Sur les oiseaux comme catégorie générique et positive qui n'appelle pas d'identification spécifique, $c f$. la section suivante sur l'animalité.

54. Analyse plus développée de ce chapiteau dans J.-C. BONNE, «Le végétalisme de l'art roman », op. cit., p. 105-107.

55. Il en a été question dans le chapitre IV, consacré à Notre-Dame-du-Port.

56. On trouve un chapiteau quasiment identique dans le déambulatoire d'Orcival (voir corpus topo-photographique).

57. Jean WIRTH, «La flore sculptée du XIIIe siècle en France » dans Le monde végétal, op. cit., p. 121-136.

58. Honorius AUGUSTODUNENSIS, Elucidarium, I, 67, (notre traduction), pour le texte latin cf. l'édition d'Yves LEFÈVRE, L'Elucidarium et les lucidaires, Paris, E. De Boccard, 1954, p. 373. L'ouvrage, rédigé au début $\mathrm{du}$ XII ${ }^{\mathrm{e}}$ siècle, connut un grand succès comme manuel élémentaire de théologie dogmatique. Le végétal peut naturellement être pensé au Moyen Age sous bien d'autres 
catégories que celles d'Honorius (botanique, cuisine, magie et usage populaire, alchimie, poésie, modèle allégorique d'arborescence, cosmologie...).

59. Et le sculpteur n'hésite pas à trancher brutalement dans une composition quand elle rencontre le mur d'applique du chapiteau d'une colonne engagée : le développement virtuel du principe formel de l'ordo l'emporte sur son actualisation parfaite ou complète.

60. Pour rendre l'idée particulière d'une vie qui préserve des maladies, des atteintes de l'âge et de la mort, des têtes humaines ont été placées dans les feuilles de «l'Arbre de vie » (fig. 15).

61. Gn 2, 9 et Ap 22, 2-5. Voir Chiara CRISCIANI, "Il lignum vitce e i suoi frutti» dans Le monde végétal, op. cit, p. 176 et note 5, qui cite les principales formes significatives sous lesquelles la végétation apparaît dans les Écritures, et donne une bibliographie d'orientation sur «l'efflorescence du monde végétal » dans la littérature pastorale, théologique et allégorique. On peut consulter aussi, au sein d'une abondante bibliographie, la synthèse d'Eleanor sIMMONS GREENHILL, "The Child in the Tree. A Study of the Cosmological Tree in Christian Tradition ", Traditio, 10, 1954, p. 323-371.

62. HUGUES DE SAINT-VICTOR, In Salomonis Ecclesiasten, hom. 2, PL, 175, c. 137a.

63. Honorius AUGUSTODUNENSIS, De anima et de Deo (vers 1115-1120), édité par Marie-Odile GARRIGUES dans Études Augustiniennes, 12, 1977, p. 212-278 (citation p. 250; il est précisé ensuite que l'homme partage les sens avec les animaux).

64. La notion en est déjà présente chez Honorius et devient courante au XIII ${ }^{\mathrm{e}}$ siècle.

65. GUILLAUME DE CONCHES, Glosae super Boetium, III, éd. L. NAUTA, CC, CM, 158, Turnhout, Brepols, 1999, p. 172. C'est une affirmation commune au Moyen Age que l'homme partage le vivere cum herbis et arboribus.

66. Munich, Bayerische Staatsbibliothek, $\mathrm{Clm}$ 13002, fol. 7 v., vers 1165. Sur les conceptions de l'homme-microcosme, voir notamment Marie-Thérèse D'ALVERNY, « L'homme comme symbole : le microcosme ", dans Simboli e simbologia nell'alto medioevo (Settimana di Spoleto, 23), Spolète, CISAM, 1976, p. 123-183.

67. HONORIUS AUGUSTODUNENSIS, Elucidiarum, I, 59, op. cit., p. 371. Sur la façon dont les scolastiques traitent de la faculté végétative en l'homme au XIII ${ }^{\mathrm{e}}$ siècle, voir Paola BERNARDINI, "Corpus humanis est vegetabile, sensibile et rationale. L'âme végétative dans les commentaires au De Anima au XIII ${ }^{\mathrm{e}}$ siècle» dans Le monde végétal, op. cit., p. 137- 155 (« On tient d'Avicenne la dénomination 'anima vegetabilis' ", ibid., p. 143, note 16).

68. Cf. J.-C. BONNE, « Le végétalisme dans l'art roman », op. cit., p. 110-111.

69. On doit à Victoria Sweet une importante étude sur la viriditas chez Hildegarde : Rooted in the Earth, Rooted in the Sky. Hildegard of Bingen and Premodern Medecine, New York et Londres, Routledge, 2006, chap. 5, "The Green Humor » et "Conclusion» p. 125-165. L'auteur recentre radicalement la viriditas d'Hildegarde sur sa nature d'humeur végétale et sa valeur médicinale.

70. Selon une expression de Cassiodore, dans Variarium libri duodecim, lib. IX, epist. 2, citée par Victoria Sweet (ibid., n. 98, p. 251), dans les pages consacrées à la viriditas chez les Pères de l'Église (ibid., p. 141-144).

71. Ibid., p. 141.

72. Ibid., p. 144-150.

73. C'est l'objet de la démonstration de Victoria Sweet que nous suivons ici.

74. V. SWEET, Rooted in the Earth, op. cit., p. 165.

75. Ibid., p. 154.

76. « Herbarum namque atque arborum vita viriditas vocatur », Grégoire le Grand, Moralia in Job, lib. 6, \$16, cité ibid., p. 238, n. 1.

77. « aquosum vero aliis [i-e les autres cercles célestes] viriditatem humectatione sua immittit ", Hildegarde de Bingen, Liber divinorum operum simplicis hominis, A. DEROLEZ et P. DRONKE (éd.), CC, CM 92, Turnhout, Brepols, 1996, Pars I, visio 2, cap. 10, linea 1. 
78. «Divinitas [...] in opere suo velut rota integra est » ou " sicut circulus [...] comprehendit », dans ibidem, Pars 1, visio 2, cap. 2 et « Deus enim ignis occultus est ", dans Id., Orationes, meditationes, visiones et alia (Epistularium), L. VAN ACKER et M. KLAES-HACHMÖLLER (éd.), CC,CM, 91B, Turnhout, Brepols, 2001, classis 8 , textus 381, p. 140 , linea 40 , parmi bien d'autres références. On ne peut pas suivre Victoria Sweet quand elle rejette l'interprétation théologico-cosmologique traditionnelle de la viriditas d'Hildegarde comme une énergie vitale et générative animée par Dieu et qu'elle soutient qu'elle est seulement d'essence terrestre (earth-essence). Il est vrai qu'Hildegarde l'a d'abord conçue comme une qualité et/ou une substance médicinale purement végétale, comme il ressort de ses premiers écrits dans les années 1150 (comme le De causce et curce et la Physica, op. cit., p. 132-134); mais, dans la cosmogénèse plus tardive du Liber divinorum operum (1163-1173), où la notion se fait plus fréquente, la viriditas tient manifestement sa virtus diffusive de l'énergie (vis ou potentia) de Dieu « qui produit toute vie ». La position de Victoria Sweet postule implicitement un dualisme entre le spirituel et le matériel qu'Hildegarde nous semble chercher à tout prix à dépasser (c'est aussi pourquoi elle nous intéresse ici).

79. «Deus quoque igneam rationalitatem animce, quee spiraculum vitce est, homini [...] immisit. [...] Ipsa namque anima toti corpori se infundit [...]. Sic etiam rationalis anima in corpore cum humido spiramine, qucecumque vult, dictat », ", HILDEGARDE DE BINGEN, Orationes, meditationes, op. cit., classis 8 , textus 381 , pag. 140, linea 21. Cela suppose la conjonction entre trois entités : l'anima rationalis, l'animasouffle (spiramentum) et le corps (corpus).

80. Rappelons que nous nommons conventionnellement "chapiteau-base " un chapiteau qui présente le profil amplifié d'une base retournée (il se trouve en plusieurs exemplaires dans les narthex de Saint-Nectaire, Notre-Dame-du-Port et Orcival; voir chapitre III).

81. Sur la figure 17 , la base de la colonne de droite est un remploi antique.

82. Ce chapitre reprend une partie de la matière avancée dans Pierre-Olivier DITTMAR, Naissance de la bestialité. Une anthropologie du rapport homme-animal dans les années 1300, thèse de doctorat sous la direction de Jean-Claude Schmitt, Paris, EHESS, 2010. Par ailleurs, on consultera avec profit: Jacques VOISENET, Bestiaire chrétien. L'imagerie animale des auteurs du Haut Moyen Age, Toulouse, Presses Universitaires du Mirail, 1994 et Bêtes et hommes dans le monde médiéval. Le bestiaire des clercs $d u V^{e}$ au XII ${ }^{e}$ siècle, Turnhout, Brepols, 2000 ; Michael CAMILLE, «Mouths and meanings : towards an anti-iconography of medieval art », dans Brendan CASSIDY (éd.), Iconography at the crossroads, Princeton, Princeton UP, 1993, p. 43-54; W. DÉONNA, « Salva me de ore leonis, à propos de quelques chapiteaux romans de la cathédrale de Saint-Pierre à Genève ", Revue Belge de philologie et d'histoire, 28, 1950, p. 479-511; Raphaël GUÉSURAGA, Le thème de la dévoration dans la sculpture romane de France et d'Espagne. Étude iconographique, enjeux politiques, aspects eschatologiques, thèse de doctorat sous la direction de Michel Pastoureau, Paris, EPHE, 2001; Gaston DUCHET-SUCHAUx et Michel PASTOUREAU, Le bestiaire médiéval. Dictionnaire historique et bibliographique, Paris, Le léopard d'or, 2002 ; IDEM, Bestiaires du Moyen-Âge, Paris, Seuil, 2011 ; Rémy CORDONNIER et Christian HECK, Le bestiaire médiéval, Paris, Citadelles, 2011 ; Ron BAXTER, Bestiaries and their Users in the Middle Ages, Bridgend, Sutton Publishing, 1998.

83. Les conséquences d'un tel constat ont également été tirées dans Meyer SCHAPIRO, Romanesque Architectural Sculpture. The Charles Eliot Norton lecture, Chicago, University of Chicago Press, 2006, p. 185-209 (chapitre « Animal imagery in romanesque sculpture »).

84. Émile MÂLE, L'art religieux au XIII 'e siècle en France, Paris, A. Colin, 1958 [1898], p. 103 ; Y. LEFÈVRE, L'Elucidarium et les lucidaires, op. cit.

85. Gn 1, 28: "Crescite et multiplicamini, et replete terram, et subjicite eam, et dominamini piscibus maris, et volatilibus caeli, et universis animantibus, quce moventur super terram ».

86. Dans le premier récit : «Dieu dit : "Je vous donne toutes les herbes portant semence, qui sont sur la surface de la terre, et tous les arbres qui ont des fruits portant semence : ce sera votre nourriture. A toutes les bêtes sauvages, à tous les oiseaux du ciel, à tout ce qui rampe et qui est 
animé de vie, je donne pour nourriture toute la verdure des plantes" et il en fut ainsi. » (Gn 1, 2930). Cette précision alimentaire se retrouve dans le second récit $(G n 2,16)$.

87. "Yahvé Dieu dit : "Il n'est pas bon que l'homme soit seul. Il faut que je lui fasse une aide qui lui soit assortie" " (Dixit quoque Dominus Deus: Non est bonum esse hominem solum: faciamus ei adjutorium simile sibi); Gn 2, 18 .

88. Sur la réception médiévale de ce passage, voir « Le seigneur des animaux », op. cit.

89. On se fera une idée des usages politique du modèle paradisiaque en lisant Philippe BUC, L'ambiguité du Livre. Prince, pouvoir, et peuple dans les commentaire de la bible au Moyen Âge, Paris, Beauchesne, 1994, p. 71-122 («Politique dans le jardin d'Eden »).

90. «Nous appelons pecus tout ce qui est privé de l'apparence et du langage humain, mais l'usage est de nommer précisément pecora (bestiaux) les animaux propres à l'alimentation, comme les ovins ou les porcs, ou appropriés au service de l'homme, comme les chevaux et les bovins (Pecus dicimus omne quod humana lingua et effigie caret. Proprie autem pecorum nomen his animalibus adcommodari solet quae sunt aut ad vescendum apta, ut oves et sues; aut in usu hominum commoda, ut equi et boves) ", ISIDORE DE SÉVILLE, Étymologies. Livre XII. Des animaux, éd. et trad. J. ANDRÉ, Paris, Belles-lettres, 1986, p. 38-39 (XII, I, 5). Cette distinction entre les différents types de créatures existe avant la Chute (le terme de iumenta est alors préféré à celui de pecus), mais les bêtes sont alors soumises à la domination de l'homme. Leur présence au Paradis est généralement justifiée dans l'exégèse comme une prescience de la part du Créateur de la Chute à venir de l'homme.

91. Voici le texte tel qu'il est cité en ouverture du livre XIX du Speculum Naturale (les variations par rapport au texte original des Étymologies sont minimes) : «le terme de «bêtes » convient proprement aux lions, pards, tigres, loups, renards, chiens, singes, etc. dont la bouche et les ongles sont cruels, mais non aux reptiles. "Bêtes» vient de la force (vi) de leur cruauté (saeuinunt). On les appelle fauves (ferae) parce qu'elles jouissent d'une liberté naturelle et sont emportées (ferantur) par leur désirs. Elles donnent libre cours à leurs impulsions, errent ça et là et sont emportées où leur humeur les entraîne (Isidor. Bestiarum uocabulum proprie conuenit leonibus, pardis, tigribus, lupis et vulpibus canibus ac simiis ac ceteris, quae uel ore uel unguibus saeuinunt, exceptis serpentibus. Bestiae dictae a ui qua saeuinunt. Ferae appellatae eo quod naturali utantur libertate et desiderio suo ferantur. Sunt enim liberae eorum voluntates, et huc arque illuc uagantur et quo animus duxerit, eo feruntur ", VINCENT DE BEAUVAIS, Speculum quadruplex sive Speculum majus. Vol. 1. Speculum Naturale, Douai 1624, fac-similé, Graz, Akademische Druck, 1964, col. 1383.

92. P.-O. DITTMAR, Naissance de la bestialité... op. cit.

93. "Animalia noxia vivos homines aut poenaliter laedunt, aut salubriter exercent, aut utiliter probant, aut ignoranter docent ", AUGUSTIN, De Genesi ad litteram, III, 17, 26, éd. P. Agaësse et A. Solignac, Paris, Institut d'Etudes Augustiniennes, 2000, p. 252-254.

94. Honorius AUGUSTODUNENSIS, Elucidarium, I, 67, voir supra.

95. J. VOISENET, Bêtes et hommes, op. cit., p. 119 et suiv.

96. Michel zink, Nature et poésie au Moyen Age, Paris, Fayard, 2006, p. 156.

97. Henri PLATELLE, Les exemples du livre des abeilles, Turnhout, Brepols, 1997, p. 86; Astrik I. GABRIEL, Student Life in Ave Maria College. Mediaeval Paris. History and Chartulary of the College, (Medieval Studies, 14) Notre Dame, Indiana, 1955, p. 171.

98. L'aigle est une figure ambivalente dans la tradition chrétienne et possède aussi un versant négatif. Cependant, dans le Physiologos, l'aigle est présenté comme une figure du Christ ressuscité, sur la base du Psaume «Ta jeunesse sera renouvelé comme celle de l'aigle » et l'éditeur rappelle que chez Aristote déjà, il est « le seul oiseau auquel les hommes donnent l'épithète de divin »; voir Physiologos. Le bestiaire des bestiaires, éd. et trad. A. zUCKER, Grenoble, Jérôme Millon, 2005, p. 78-82.

99. Z. SWIECHOWSKI, La sculpture romane d'Auvergne, op. cit., p. 325. 
100. Pour les oiseaux, un chapiteau de Notre-Dame-du-Port fait exception et montre une relation entre un homme et un échassier (voir chapitre IV). Les griffons sont quand à eux utilisés dans un registre négatif à Chanteuges, en tant que forces menaçant un saint.

101. On notera par exemple qu'il existe deux standards dans la représentation des aigles. Le premier, présent à Mozat, Saint-Nectaire et Notre-Dame-du-Port, est composé de trois aigles juchés sur une large corbeille végétale, l'aigle central étant frontalisé. Dans le second type, présent à Brioude et Chanteuges, l'aigle central tourne la tête vers la droite, et repose sur une corbeille végétale bien plus modeste.

102. Orcival est la seule église de notre corpus où une sirène apparaît sans être végétalisée. Nous exposons notre définition de la «merveille » un peu plus loin, dans la partie consacrée à l'hybridation.

103. Une caractéristique bien relevée par Z. SWIECHOWSKI, La sculpture romane d'Auvergne, op. cit, p. 255.

104. En poussant la logique d'identification le plus possible, nous obtenons : poisson, monstre marin, dauphin, sirène, lion, singe, dragon, bouc, centaure, aigle, griffon, oiseau, bête (3 types), âne ?, bovidé ?, cheval, serpent, échassier, mouton.

105. Dans le cas de ce chapiteau, il est possible d'interpréter le végétal tenu par l'homme comme une verge permettant de le guider (la domination de l'homme est aussi marquée par la main gauche tenant les cornes). On gardera alors à l'esprit que cet outil se donne à voir comme étant «naturel», n'ayant pas fait l'objet d'un transformation par l'homme. Pour une analyse plus précise des chapiteaux mentionnés ici, voir notamment le chapitre II, consacré à Mozat.

106. Pour les différentes hypothèses relatives aux porteurs de moutons, voir le chapitre $V$, consacré à Chanteuges.

107. Z. Swiechowski note avec pertinence que la radicalisation morale de cette image dans l'église de Droiturier donne à voir un singe au sexe proéminent accompagné d'un diable; un livre ouvert sépare ce groupe de l'homme (La sculpture romane d'Auvergne op. cit., p. 195). Voir également à ce propos l'exemple du chapiteau de Brioude, traité infra.

108. Le caractère sexué du singe, qui était vraisemblablement explicite ici, est suggéré dans les autres édifices par de généreuses feuilles poussant entre ses jambes.

109. Gil bartholeyns, Pierre-Olivier ditTmar et Vincent Jolivet, «Des raisons de détruire une image », Images Re-vues [En ligne], 2 | 2006, document 1, mis en ligne le 01 janvier 2006, consulté le 28 octobre 2011. URL : http://imagesrevues.revues.org/248.

110. Cette scène n'a, semble-t-il, jamais été identifiée. L'hypothèse que nous proposons n'a été possible que grâce à une mise en série avec les autres versions de ce thème (et à de multiples agrandissements de l'image). On a ainsi pu reconnaître les jambes écartées autour des feuillages et, entre les deux figures, une corde torsadée tout à fait semblable à celle qui figure sur l'autre chapiteau aux singes d'Orcival.

111. Une gueule animale apparaît également dans le chapiteau des Vents. Nous avons fait l'hypothèse qu'il s'agissait d'identifier la figure qui lui est associée comme le Vent de la mer.

112. R. GUÉSURAGA, Le thème de la dévoration dans la sculpture romane, op. cit.

113. Leurs actes ne sont d'ailleurs pas strictement négatifs, dans la mesure où le châtiment des pécheurs participe de la justice divine.

114. Notons que l'opposition entre l'homme et le singe est présente à deux reprises, et que l'opposition Bien/Mal est par ailleurs suggérée par la baleine de Jonas, par la présence des têtes de bêtes au milieu des oiseaux et par la présence des soldats endormis au pied du sépulcre du Christ.

115. La végétalité peut même devenir parfois dominante, comme à Orcival : dans ce cas, elle se trouve combinée avec des oiseaux qui contribuent à son animation et accentuent encore la dimension très positive de ces chapiteaux. 
116. Ce qu'avait bien remarqué Françoise Saunier dans son analyse de la répartition des thèmes animaliers dans les églises de Haute-Auvergne: "Répartition des thèmes animaliers dans l'édifice roman de Haute-Auvergne », Cahiers de Saint-Michel de Cuxa, 24, 1993, p. 135-145.

117. Rappelons toutefois la présence de quelques animaux utilisés par les hommes (pecus) : les poissons de la Multiplication des pains, le cheval de l'Apocalypse (à Saint-Nectaire).

118. Le terme "Neutre » est à entendre ici en un sens fort. Sans entrer dans la discussion qu'elle peut appeler, on rappellera la définition que Roland Barthes en propose : «J'appelle Neutre tout ce qui déjoue le paradigme [c'est-à-dire] l'opposition de deux termes virtuels [...] le Neutre ne renvoie pas à des "impressions » de grisaille, de «neutralité ", d'indifférence. Le Neutre - mon Neutre - peut renvoyer à des états intenses, forts, inouïs. 'Déjouer le paradigme' est une activité ardente, brulante "; "Le neutre est le champ des intensités non-paradigmatiques [...] et nous demandons en conséquence que le neutre ne soit pas conçu, connoté comme un aplatissement des intensités, mais au contraire comme un émoustillement », Roland BARTHES, Le Neutre. Cours au Collège de France (1977-1978), éd. Th. Clerc, Paris, Le Seuil, 2002, p. 31-32 et 246.

119. A l'inverse, le monde animal ne suggère pratiquement jamais la croissance. A l'exception des lionceaux de Chanteuges, les animaux représentés ici sont sans âge, comme insensibles au passage du temps.

120. On pourrait déplacer la proposition et admettre que la valeur ornementale de ces créatures vient en amont du sens moral. Voir Meyer Schapiro : « Keep in mind, then, that the interpretation of animal imagery are not religious symbolism or pure decoration, but rather decoration which has religious meaning, decoration which has an expressive value and quality, which has a poetic character through its relation to human feelings, impulses, the embodiment of instinct and passions - not necessarily in terms of theological polarities of good and evil ", Romanesque Architectural Sculpture, op. cit., p. 191. Nous reviendrons sur cette question à propos de l'hybridation.

121. Augustin, Confessions, XII, 35.

122. "Habent enim omnia, quamdiu sunt, mensuras, numeros, ordines suos: quae cuncta merito considerata laudantur ne sine occulta pro suo genere moderatione pulchritudinis temporalis etiam ex alio in aliud, transeundo mutantur » AUGUSTIN, La Genèse au sens littéral, op. cit., III, XVI, 25, p. 252-253.

123. A ce titre, il est important de garder à l'esprit l'éventuelle fonction apotropaïque de ces images, qui peuvent aussi protéger. La fonction de protection, qui fait la plupart du temps appel à des images d'animaux violents, peut être considérée comme faisant partie de l'« ornementation » au sens médiéval. Voir Herbert L. KESSLER, "Evil Eye(ing). Romanesque Art as a Shield of Faith », dans Colum houricane (éd.), Romanesque Art and Thought in the Twelfth Century. Essays in honor of Walter Cahn, Princeton, 2008, p. 107-136 ; Alessia TRIVELLONE, « Têtes, lions et attributs sexuels : survivances et évolutions de l'usage apotropaïque des images de l'Antiquité au Moyen Âge ", Cahiers de Saint-Michel de Cuxa, 34, 2008, p. 208-221.

124. Conrad RUDOLF, The "Things of Greater Importance": Bernard of Clairvaux's "Apologia" and the Medieval Attitude Toward Art, Philadelphia, University of Pennsylvania Press, 1990. Voir le point bibliographique dans Thomas DALE, "The monstrous ", dans Conrad RUdolf (éd.), A companion to Medieval Art, Romanesque and Gothic in Northern Europe, Oxford, Blackwell, 2006, p. 253-273.

125. Pictor in Carmine : ein Handbuch der Typologie aus der Zeit um 1200 : nach Ms 300 des Corpus Christi College in Cambridge, K. A WIRTH (éd.), Berlin, G. Mann, 2006 ; Jean WIRTH, L'image à l'époque gothique (1140-1280), Paris, Cerf, 2008, p. 88.

126. Ces aspects sont développés dans Pierre-Olivier DITTMAR «Les corps sans fins. Extensions animales et végétales dans les marges de la représentation (XIII ${ }^{\mathrm{e}}-\mathrm{XIV}^{\mathrm{e}}$ siècle) », Micrologus, 20, 2012, p. 25-42; voir aussi du même auteur «Le seigneur des animaux entre pecus et bestia. Les animalités paradisiaques des années 1300 ", à paraître dans Micrologus Library.

127. «Etre saint, c'est distinguer soigneusement les différentes catégories de la création, c'est élaborer des définitions justes, c'est être capable de discrimination et d'ordre [...] Etre saint, c'est 
être entier, c'est être un; la sainteté, c'est l'unité, l'intégrité, la perfection de l'individu et de ses semblables ", Mary douglas, De la souillure, Essai sur les notions de pollution et de tabou, Paris, La Découverte-Syros, 2001, p. 73.

128. Rappelons que nous nous référons à l'analogisme en tant que mode d'identification, tel qu'il a été défini par P. DESCOLA (Par-delà nature et culture, op. cit.).

129. Par exemple chez Thomas de Cantimpré : "Ibrida animal quadruped est bigenerum, id est ex diversis natum, ut dicit Ysidorus. Sicut ex equo et asinos mulus nascitur, ita ybrida nascitur ex apris silverstris et porcis domestricis », Prologue du De natura rerum, livres III et XIX, éd. par J.B. FRIEDMAN, La science de la nature : théories et pratiques, Cahiers d'études médiévales, 2, Paris/Montréal, 1974, p. 138.

130. Michel PASTOUREAU et Claudia RABEL, «Histoire des images, des symboles et de l'imaginaire ", dans Jean-Claude SCHMITT et Otto Gerhard OEXLE (éd.), Les tendances récentes de l'histoire médiévale en France et Allemagne, Paris, Publications de la Sorbonne, 2002, p. 607 ainsi que Patricia GRAVESTOCK, " Did imaginary animals exist?", dans Debra HAssig (dir.), The Mark of the Beast. The Medieval Bestiary in Art, Life and Literature, New-York-Londres, Routledge, 2000, p. 119-140. La croyance dans l'existence effective de telle ou telle créature n'était pas homogène - de nombreux auteurs, à commencer par Augustin et Isidore, remettant en cause leur existence. Voir à ce propos Jacqueline LECLERCQ-MARX, La sirène dans la pensée et dans l'art de l'Antiquité et du Moyen Âge. Du mythe païen au symbole chrétien, Bruxelles, Académie royale de Belgique, 1997.

131. Trois autres chapiteaux peuvent être associés à ce corpus. Il s'agit du masque crachant du végétal dans la crypte, de la sirène retrouvée dans la salle capitulaire et du chapiteau des hommes chevauchant des lions conservé au Musée lapidaire, ce dernier pouvant à nos yeux provenir des parties détruites de l'abbatiale (voir chapitre II).

132. Mozat comporte même une triade (avec deux formules de disposition des oiseaux végétalisés).

133. Jacqueline LECLERCQ-MARX, « Le centaure dans l'art préroman et roman. Sources d'inspiration et modes de transmission ", Cahiers de Saint-Michel de Cuxa, 37, 2006, p. 33-42.

134. Un des critères les plus fréquents de distinction entre l'homme et l'animal est l'orientation du premier vers le haut (par la bipédie) et la proximité des animaux avec le sol qu'ils regardent (par exemple, Augustin, Cité de Dieu, XXII, 24).

135. Pour l'analyse de cette série, voir le chapitre V consacré à Chanteuges. On notera que l'épanalage de l'abaque est moins marqué dans les copies que dans «l'original ", ce qui on le verra, n'est pas anodin.

136. L'analyse in situ de cette image et de ses copies permet d'affirmer que nous ne sommes pas dans le cas d'une figure dont le sexe aurait été mutilé.

137. On notera qu'une des feuilles tenues par l'homme dans le chapiteau du narthex se termine par une volute d'angle, s'inscrivant ainsi dans la structure générale du chapiteau (les " doigts » des mains de cette figure pourraient être vus aussi comme des collerettes annelées). Le caractère très fruste de ce chapiteau pourrait laisser penser qu'il est antérieur aux autres; il serait alors plus significatif encore qu'on en ait repris les motifs, un peu plus tard, dans le chapiteau proche du transept.

138. Sur ce chapiteau, voir supra « Végétalité ».

139. Le bouc garde une minuscule barbichette végétale, comme une relique de son ornementalisation à Mozat. Enfin, il faut relever que les porteurs de moutons sont ici traités sur un mode à la fois plus dynamique (par la position déséquilibrée) et plus négatif (l'un deux tire la langue) : les animaux portés par les bergers ne possèdent plus la queue végétale qu'ils avaient à Chanteuges.

140. Le chapiteau de Saint-Nectaire reprend certains partis-pris en place à Brioude, avec une insistance sur la différence d'âge entre les deux personnages et l'épannelage très vif de l'abaque. 
141. Il existe aussi un masque de ce type dans la crypte de Mozat.

142. Il convient de noter que l'Auvergne possède une série de chapiteaux, proches formellement de ceux dont nous parlons ici, et qui représentent de véritables atlantes, les mains soutenant le tailloir (cf. Z. SWIECHOWSKI, La sculpture romane d'Auvergne, op. cit., p. 260-285).

143. Nous suivons ici Jean Wirth: «Si l'on ajoute que la grande majorité des figures occupe l'angle, leur tête servant de crochet au chapiteau, on peut considérer qu'elles sont consubstantielles au monument et qu'elles ne participent pas d'un type de représentation qui permette de faire abstraction du support », J. WIRTH, L'image à l'époque romane, op. cit., p. 169.

144. B. CRAPLET, Auvergne romane, op. cit., p. 295.

145. Le chapiteau de Saint-Nectaire représentant les hommes végétalisés insiste peut-être moins sur la dimension de support de ces figures, dans la mesure où leur partie inférieure ne repose pas directement sur l'astragale. En revanche, il est capital de relever que ce chapiteau est le seul exemplaire historié de Saint-Nectaire à posséder une abaque creusée, du type de Mozat/ Chanteuges. Un détail qui confirme à la fois le statut d'exception de cette image dans l'iconographie de Saint-Nectaire, et le lien entre ce dispositif et la mise en valeur du corps humain.

146. Cette hypothèse est reprise dans les « Ouvertures ", voir infra.

147. Notons au passage que, dans le cadre plus moral des hybridations homme-animal, c'est également une qualité non visible de l'être qui est exprimée : en l'occurrence, sa bestialité latente dans le monde d'après la chute.

148. Insistons sur le fait que ces conclusions ne valent que pour l'hybridation végétale. L'hybridation animale possède un statut tout à fait différent, puisque dans ce domaine l'impératif de classification est renforcé par la nomination des animaux par Adam. Logiquement, les hybridations animales sont presque toujours négatives.

149. Le lecteur peut, s'il le souhaite, afficher à l'écran les différents chapitres, pour retrouver les vues des chapiteaux concernés.

150. Rappelons que la romanité est codée par la couleur jaune, le Bien par le rouge, le Mal par le bleu et les motifs qui ne se laissent pas associer de manière univoque au Bien ou au Mal par le violet. Pour une explicitation plus précise des catégories qui sous-tendent ce codage, on renvoie au chapitre I. Indiquons seulement que le violet couvre une large gamme de cas, allant de figurations qui peuvent être inquiétantes à d'autres qui sont manifestement positives (sans que ni les unes ni les autres ne puissent être explicitement qualifiées en termes moraux), en passant par celles qui témoignent du statut mêlé, ou non encore déterminé, du monde créé.

151. Un cas intermédiaire est celui des chapiteaux formant une paire, mais dont les variantes produisent une nette gradation : ainsi, la version des Victoires située à la limite du transept souligne leur envol (et donc leur dimension spirituelle) bien plus nettement que la version placée en face de la porte nord. Toutefois, la dimension dynamique susceptible d'être mise en jeu par une paire reste nécessairement limitée.

152. Sept chapiteaux du déambulatoire sont des citations, complètes ou partielles, de ceux de Mozat. S'y ajoutent le chapiteau des griffons au calice (fenêtre haute du sanctuaire), celui des saintes femmes au sépulcre, dans l'hémicycle, ainsi que deux chapiteaux de la nef, soit au total 11 citations de Mozat. Il se peut qu'il y en ait eu d'autres encore, qui se référaient aux chapiteaux désormais perdus du déambulatoire ou du mur gouttereau sud de l'abbatiale de Mozat.

153. Voir chapitre III, pour l'analyse de ces chapiteaux-bases.

154. Cette notion, adoptée comme une hypothèse de lecture propre au cas de Mozat (voir chapitre II), englobe des chapiteaux qui, dans leur majorité, relèveraient ailleurs d'un codage violet.

155. Rappelons que nous adoptons la datation haute qui situe l'achèvement du chantier de l'abbatiale de Mozat vers 1080 (voir chapitre II). Saint-Nectaire et Notre-Dame-du-Port peuvent être situées peu après, entre 1080 et 1100 . Plusieurs arguments nous font estimer que Saint- 
Nectaire présente plus de proximité avec Mozat que Notre-Dame-du-Port, ce qui pourrait être l'indice d'une légère antériorité. De plus, le retravail sériel accompli à Notre-Dame-du-Port semble impliquer la prise en compte de certains chapiteaux de Saint-Nectaire. Mais on admettra volontiers que ces indices laissent une ample marge d'incertitude.

156. Cette différence de disposition pourrait être plus importante qu'il n'y paraît. Si l'on adopte la restitution liturgique proposée pour Saint-Nectaire (chœur limité à la croisée du transept), la dernière travée de la nef était occupée par l'autel de la croix (et peut-être aussi par le tombeau d'Auditeur). Dans ce cas, il conviendrait de mettre en rapport les singularités du décor de cette travée avec son éminence liturgique, au moins autant qu'avec la porte sud. A Notre-Dame-duPort, le chœur liturgique devait occuper plusieurs travées de la nef et était par conséquent caractérisé par des tonalités variées (vert/violet, rouge/bleu, violet). Dans ce cas, l'ensemble évoquant la guerre du Bien contre le Mal devait être, plus nettement qu'à Saint-Nectaire, associé à la porte latérale.

157. L'évaluation des références de Notre-Dame-du-Port à Mozat est ici compliquée par le fait que l'authenticité de certains chapiteaux des deux dernières travées orientales de la nef est discutée. Faute d'éléments absolument décisifs, nous avons pris le parti de la plus grande prudence en choisissant de ne pas les inclure dans notre étude (voir chapitre IV). Ce n'est pas une raison, malgré tout, pour les ignorer. En fait, seul celui qui présente trois têtes au-dessus d'une couronne d'acanthes serait susceptible d'affecter notre analyse. Dans l'hypothèse où ce chapiteau serait authentique, il viendrait, d'une part, faire écho aux deux chapiteaux occidentaux à têtes animale ou anthropomorphe, et d'autre part, renforcer l'importance de la zone violette de la dernière travée de la nef, dont il vient d'être question. Il nous suffira ici de signaler ce point et de garder en mémoire sa possibilité, voire même sa haute probabilité, pour lui redonner la place qui pourrait être la sienne dans l'ensemble, sans qu'il soit besoin de surcharger la comparaison par l'ajout d'une nouvelle cartographie. On pourra ajouter mentalement - à titre d'hypothèse forte - ce chapiteau aux cartographies suivantes comme aux développements qui les accompagnent, sans qu'on ait besoin de revenir sur ce point.

158. Rappelons cependant la présence, en face de la porte sud de Saint-Nectaire, de la tête crachant des feuillages, qui sert de relais au très mince fil violet qui traverse la nef. Il s'agit d'un appui beaucoup plus discret que celui qui est produit par la barre violette de Notre-Dame-du-Port et qui, surtout, ne semble pas faire référence au répertoire mozacois.

159. Il faut tenir compte à la fois de la différence de localisation du répertoire mozacois et de sa présence nettement moins marquée à Notre-Dame-du-Port (5 citations) qu'à Saint-Nectaire (11 citations, complètes ou partielles). L'écart serait un peu moins marqué si l'on tenait compte du chapiteau des anges-évangélistes de la nef de Notre-Dame-du-Port, postérieur à l'époque romane, mais qui pourrait avoir repris une iconographie d'origine, ainsi que du chapiteau aux trois têtes, d'authenticité discutée (voir note 158). Dans les deux cas, il s'agit de chapiteaux placés dans la nef, de sorte que la concentration du registre mozacois dans cette partie de l'édifice pourrait s'en trouver accentuée.

160. Neuf grands chapiteaux végétaux sur la couronne du déambulatoire à Notre-Dame-du-Port, sur un total de 14 (nombre il est vrai nettement supérieur à celui de Saint-Nectaire, où la couronne du déambulatoire ne comporte que huit grands chapiteaux).

161. Sur les questions relatives à la localisation du Jugement dernier dans l'église, voir Jérôme BASCHET, «L'enfer en son lieu : rôle fonctionnel des fresques et dynamisation de l'espace cultuel », dans Sofia BOESCH GAJANO et Lucetta SCARAFFIA (éd.), Luoghi sacri e spazi dela santità, Turin, Rosenberg \& Sellier, 1990, p. 551-563, ainsi que L'iconographie médiévale, op. cit., p. 83-85.

162. Rappelons qu'il y a quatre chapiteaux végétaux dans le sanctuaire (dont un comportant des figures en son sein) et neuf grands chapiteaux végétaux dans la couronne du déambulatoire (sur un total de 14).

163. Pour une analyse précise de l'iter végétalisé de Notre-Dame-du-Port, voir chapitre IV. 
164. A Saint-Nectaire, l'intense violet du chapiteau des hommes végétalisés prend place sur la bordure interne du sanctuaire, mais reste associé à la séquence du déambulatoire. Il ne s'intègre pas à la partie la plus éminente du décor que composent les piles rondes de l'hémicycle.

165. J. WIRTH, L'image, op. cit., p. 166-167, 298-300 et 321-327.

166. Carlo GinzBurg, A distance. Neuf essais sur le point de vue en histoire, Paris, Gallimard, 2001, p. 15-36 (« L'estrangement. Préhistoire d'un procédé littéraire »).

167. Bruno LATOUR, Nous n'avons jamais été modernes, Paris, La Découverte, 1993 ; P. DESCoLA, Pardelà nature et culture, op. cit.

168. "L'obsession des correspondances entre l'homme et le cosmos permet en effet de fixer dans une créature de privilège un foyer plus dense limitant et la prolifération des signes à son échelle, et leur capacité illimité de réverbération dans un monde clos, garantie qu'une connaissance ordonnée et une pratique réparatrice sont possibles, qu'une table d'orientation existe afin de se repérer dans le parcours inlassable des similitudes ", P. DEsCoLA, Par-delà nature et culture, op. cit., p. 287.

169. Pour la notion d'incorporel, on renvoie à Anne COQUELIN, Fréquenter les incorporels. Contribution à une théorie de l'art contemporain, Paris, PUF, 2006 et B. PRÉVOST, «Direction dimension : Ninfa et putti ", Colloque A. Warburg, à paraître.

170. Vita Amandi, Valenciennes, Bibl. Mun., ms. 500, f. 66 v., vers 1175.

171. Le terme d'agentivité est ici utilisé en référence à l'agency, telle qu'elle est théorisée dans Alfred GELL, L'art et ses agents. Une théorie anthropologique, Dijon, Les Presses du réel, 2009.

172. Le pénitentiel a été rédigé dans les premières années $d u \mathrm{XI}^{\mathrm{e}}$ siècle, mais s'est ensuite largement diffusé pendant tous les $\mathrm{XI}^{\mathrm{e}}$ et $\mathrm{XII}^{\mathrm{e}}$ siècles jusqu'en Italie.

173. Il convient bien entendu de tenir compte des difficultés de lecture et d'interprétation de ce texte. Sur Burchard de Worms, on lira en dernier lieu François GAGNON, Le corrector sive medicus de Burchard de Worms (1000-1025). Présentation, traduction et commentaire ethno-historique. Mémoire de Master sous la direction de P. Boglioni, Montréal, 2010.

174. Mikhail BAKHTINE, L'œuvre de François Rabelais et la culture populaire du Moyen Âge et sous la Renaissance, Paris, Gallimard, 1970 ; Claude GAIGNEBET et Jean-Dominique LAJOUX, Art profane et religion populaire au Moyen Age, Paris, PUF, 1985.

175. Jean-Claude schmitT, «Superstitions », dans Jacques LE GOFF et René RÉMOND (dir.), Histoire de la France religieuse, Paris, Seuil, 1988, vol. I, p. 416-551; Michel LAUWERS, «'Religion populaire', culture folklorique et mentalités. Notes pour une anthropologie culturelle du Moyen Age ", Revue d'Histoire Ecclésiastique, 82, 1987, p. 221-258 ; Jean WIRTH, Sainte Anne est une sorcière et autres essais, Genève, Droz, 2003.

176. Cette conception des images végétales change clairement à l'époque gothique, l'identification d'espèces précises devenant alors possible (J. WIRTH, « La flore », op. cit.).

177. Pour une analyse détaillée de cette image et de ses relations avec les autres faces du chapiteau comme avec les chapiteaux environnants, voir le chapitre IV (Notre-Dame-du-Port). 


\section{INDEX}

Keywords : romanesque art, capitals, Auvergne, Anthropology, iconography, Saint-Pierre de Mozat, Mozac, Saint-Nectaire, Notre-Dame-du-Port, Clermont-Ferrand, Saint-Marcellin de Chanteuges, Notre-Dame d'Orcival, animal, hybrid, plant

Mots-clés : art roman, chapiteaux, auvergne, Moyen Age, Anthropologie, Iconographie, SaintPierre de Mozat, Mozac, Saint-Nectaire, Notre-Dame-du-Port, Clermont-Ferrand, Saint-Marcellin de Chanteuges, Notre-Dame d'Orcival, animal, végétal, hybride 